The development of an evaluation method to support circular building design

\author{
PIETER BEURSIKENS
}
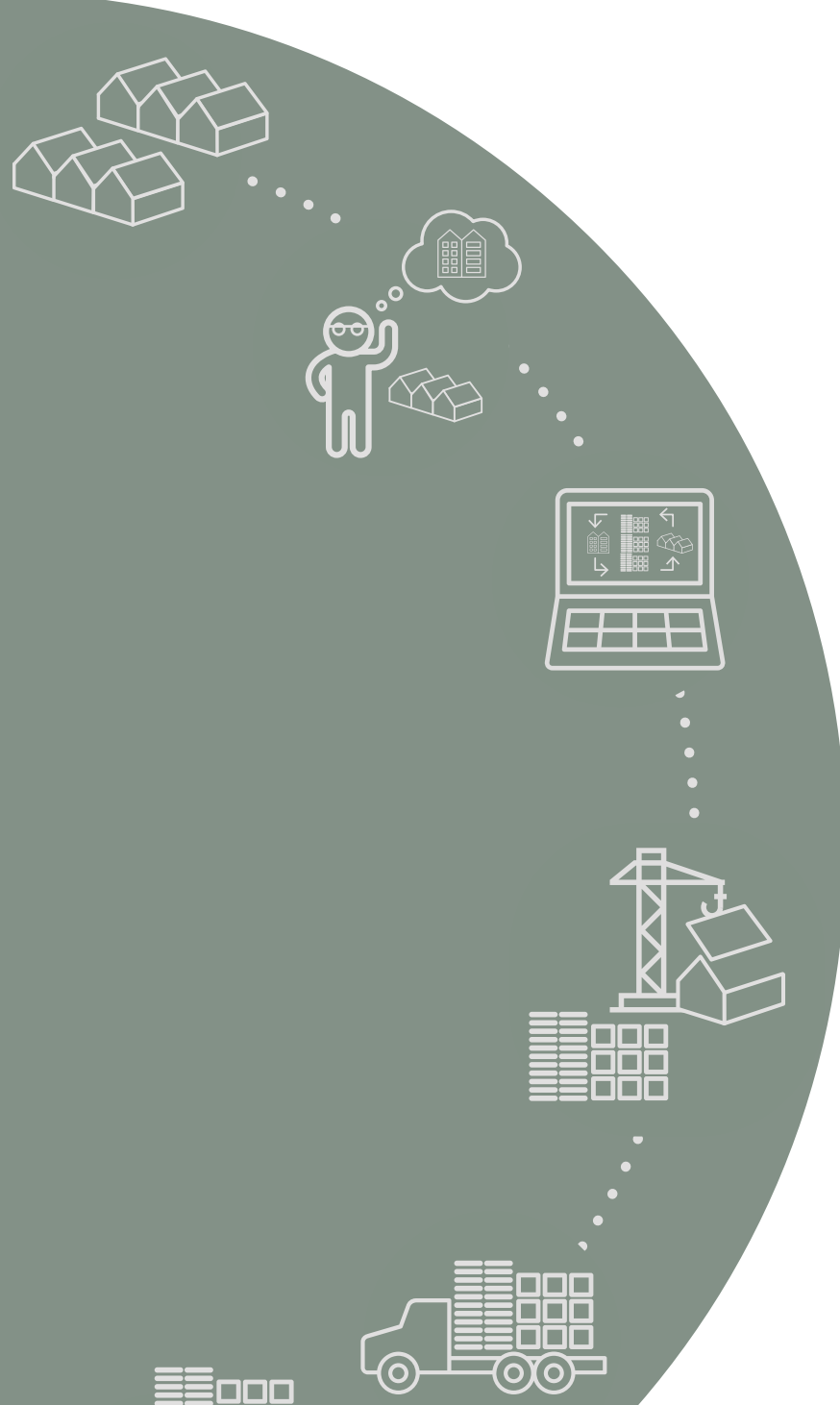

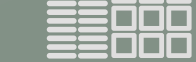





\section{THE DEVELOPMENT OF AN EVALUATION METHOD TO SUPPORT CIRCULAR BUILDING DESIGN}

Pieter Beurskens 



\title{
THE DEVELOPMENT OF AN EVALUATION METHOD TO SUPPORT CIRCULAR BUILDING DESIGN
}

\author{
DISSERTATION
}

to obtain

the degree of doctor at the University of Twente, on the authority of the rector magnificus, prof. dr. ir. A. Veldkamp, on account of the decision of the Doctorate Board, to be publicly defended

on Thursday, the 9th of September 2021 at 14.45 hours

by

Pieter Robert Beurskens

born on $27^{\text {th }}$ of July, 1992

in Lelystad, The Netherlands 
This dissertation has been approved by:

Supervisors:

Prof. dr ir. L.A.M. van Dongen

Prof. dr. ir. J.I.M. Halman

Co-supervisor:

Dr. E. Durmisevic

PhD Thesis, University of Twente, Enschede, The Netherlands

\section{UNIVERSITY OF TWENTE. I}

This research was supported by the European Union's Horizon 20/20 research and innovation programme under grant agreement No 642384 and was carried out as part of the Buildings As Material Banks project.

Cover design: Ana-Maria Magdalinoiu

Printed by: Ipskamp printing

Lay-out: Pieter Beurskens

ISBN: 978-90-365-5204-2

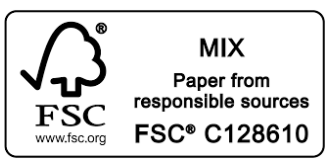

DOI: $10.3990 / 1.9789036552042$

(c) Pieter Beurskens, 2021. If one refers to the author, title and year of publication, every part of this thesis may be used for non-commercial purposes, free of charge and free of copyrights without the written permission from the author. For commercial purposes written permission from the author is required. 


\section{Graduation committee}

Chair and secretary

Prof. dr. ir. H.F.J.M. Koopman University of Twente

Supervisors

Prof. dr ir. L.A.M. van Dongen University of Twente

Prof. dr. ir. J.I.M. Halman University of Twente

Co-supervisor

Dr. E. Durmisevic University of Twente

Members:

Dr. J.T. Voordijk University of Twente

Prof. dr. ir. A.M. Adriaanse University of Twente

Prof. dr. ir. T. Klein Delft University of Technology

Prof. dr. ir. J.J.N. Lichtenberg Eindhoven University of Technology

Prof. dr. ir. arch. N. de Temmerman Vrije Universiteit Brussel 


\section{Summary}

The conventional way of construction has become a burden to the dynamic society of the 21st century. Buildings are not designed to be easily transformed to meet changing requirements, instead they are designed as static rigid entities that cannot be modified without demolition. Buildings are commonly designed with a disregard to the end-of-first-life, leading to the loss of almost all applied energy and labour and materials at the end-of-life, contributing greatly to the generation of waste.

In this thesis the enormous amounts of construction and demolition waste is considered the physical evidence of an industry that contains a fundamental error in its design and its sequential resource utilisation. To transform the construction industry into a sustainable and resilient industry that is resource responsible, buildings should be seen as temporary depositories of valuable building products that maintain their value after first, second and further use. Thereby, creating a circular model of material use instead of a linear model of material consumption. Therefore, the design of buildings, building systems and building products with a high potential to be reused is considered a necessity to move towards a construction industry that, (1) creates building products with increased resource productivity; (2) is less dependent on virgin resources and; (3) contributes to the elimination of the concept of waste.

The aim of this research is to support the transition from the current linear 'take-make-dispose' pattern to a so-called circular construction industry, an industry that is based on the principles of a cirular economy. To achieve this goal it is considered essential to understand how the reuse potential of buildings can be increased. Therefore, the goals of this research is the development of an assessment method to evaluate the reuse potential of buildings and building products. The aim of this method is to supports designers in making informed design-decisions to increase the reuse potential of buildings and building products. Furthermore, the establishment of such a reuse potential assessment method enables decision makers to set reuse potential targets to enhance the transition towards a circular construction industry. The research aim and research approach are further defined in chapter one.

In chapter two, the background and scope of the research are defined. Key contribution of this chapter are the building product reuse design typology and -framework. The reuse design typology provides a better understanding of reuse design methods and categorises different reuse strategies. The reuse design typology is based on two important design characteristics, 'design intent', and 'type of configuration', where reversible building design is classified as indeterminate configurations that enable deliberate reuse. Based on the reuse design typology the building product reuse design framework has been developed, identifying six routes of how reuse applications can transform its potential to be reused in the future.

In chapter three the enablers, opportunities and barriers for deconstruction and reuse have been studied from an environmental, social, organisational, compliance and legislation, technical and economical 
perspective. This comprehensive literature analysis provided a better understanding of the factors that impact the reuse potential of buildings and buildings products and concludes with a conceptual reuse potential framework that defines five main variables that either directly or indirectly influence the reuse potential of building products, namely: 1) impact of 'additional processes'; 2) impact of 'avoided processes'; 3. impact of 'reuse on the embodied value'; 4. impact of 'reuse on the operational value' 5. impact of 'external influences'. Based on the conceptual reuse potential framework a general strategy has been derived to support designers in the design of buildings and building products with a high reuse potential: "design buildings, systems and products: with high embodied value to allow for the impact of 'additional processes'; that maintain most of their embodied value during reuse processes, and; to allow the impact of 'reuse on the operational value' to be reduced to a minimum through upgrading the parts that impact the operational value". In addition to the literature study, in chapter four, the key design for disassembly and reuse strategies have been synthesized to provide an overview of the key strategies to support reuse of building products, which together with the assessment method from Durmisevic (2006) form a base for the development of the reuse potential evaluation method.

The development of the reuse potential evaluation method is described in chapter five. The key contribution of this chapter is the development of the reuse potential evaluation method, that allows an automated assessment based on the input of the composition of the building structure. The reuse potential assessment method builds upon the assessment method of Durmesevic (2006). Key contributions of the reuse potential assessment method are:

1. The division in key indicators such as; 1. embodied value, 2. re-claim effort and 3. re-conditioning effort, each composed of one or more criteria and sub-criteria;

2. The assessment method, which provides insights on multiple levels (building-, system-, product score) and reuse types (building-, system-, product reuse) to satisfy multiple goals: e.g. provide guidance to designers to increase the reuse potential or allow clients to set strategic reuse goals per function and evaluate their goals;

3. The automated assessment based on the input of the composition of the building structure, to enable a systematic and objective evaluation of the reuse potential.

Finally, in chapter six, the reuse potential evaluation method has been tested and verified using a critical retrospective case study approach. The first case study object is 'Villa Zebra - Red House' building, which is a successful reuse example. The second case study object called '4th Gymnasium' is a non-successful reuse example, which despite its effort of being designed with the intention to be easily reused and relocated was mainly demolished with merely the reuse of a few easily accessible parts. Both case studies have been thoroughly analysed using quantitative and qualitative methods to demonstrate and validate the reuse potential evaluation method. The application of the reuse potential evaluation method on two case study buildings has shown to provide valuable insights in how the reuse potential could be evaluated and improved upon. To further improve the validity of the reuse potential evaluation method it is recommended to apply the reuse potential method in additional case studies. 


\section{Samenvatting}

De conventionele manier van bouwen is een probleem geworden voor de dynamische samenleving van de 21ste eeuw. Dit komt voornamelijk doordat gebouwen veelal worden ontworpen als statische rigide entiteiten waarbij geen rekening is gehouden met toekomstige aanpasbaarheid en hergebruik van onderdelen. Hierdoor gaan ingrepen in de gebouwde omgeving altijd gepaard met de creatie van grote hoeveelheden bouw- en sloopafval, resulterend in de vernietiging van bijna alle toegepaste energie, arbeid en materialen na de eerste gebruiksfase.

In dit proefschrift wordt de enorme hoeveelheid bouw- en sloopafval beschouwd als het fysieke bewijs van een industrie die een fundamentele fout maakt in zowel het ontwerp als de daarop volgende omgang met de materialen aan het einde van de levensduur. Om de bouwsector te transformeren in een duurzame industrie die verantwoord omgaat met grondstoffen, zullen gebouwen niet meer moeten worden gezien als eindproducten, maar als tijdelijke opslagplaatsen van waardevolle bouwproducten. Hierbij is het van belang dat er een circulair model van materiaalgebruik gecreëerd wordt, waarin bouwproducten hun waarde behouden na het eerste, tweede en verdere gebruik in plaats van een lineair model van materiaalverbruik dat eindigt met afval. Het ontwerpen van gebouwen, bouwsystemen en bouwproducten met een hoge hergebruik potentie wordt dan ook als noodzakelijk beschouwd om de bouwsector te veranderen naar een industrie dat (1) bouwproducten creëert met een verhoogde grondstofproductiviteit (2) minder afhankelijk is van nieuwe grondstoffen en; (3) bijdraagt aan het uitbannen van het begrip afval.

Het doel van dit onderzoek is het versnellen van de transitie van het huidige lineaire 'take-make-dispose'principe naar een bouwsector die functioneert volgens de principes van de circulaire economie. $\mathrm{Om}$ dit doel te bereiken wordt het als essentieel gezien om inzicht te krijgen in de hergebruikpotentie van gebouwen en bouwproducten. Daarom is het doel van dit proefschrift het ontwikkelen van een methode om de hergebruik potentie van gebouwen en bouwproducten meetbaar te maken. Deze methode zal ontwerpers ondersteunen in het ontwikkelen van gebouwen met een hoge hergebruik potentie. Daarnaast verschaft toepassing van de methode inzicht in de mogelijkheden tot het verhogen van de hergebruik potentie. Het onderzoeksdoel en de onderzoeksaanpak zijn gedefinieerd in hoofdstuk 1.

In hoofdstuk 2 wordt het onderzoekskader gedefinieerd. De belangrijkste bijdrage van dit hoofdstuk is de hergebruikstypologie en het hergebruiks-raamwerk. De hergebruikstypologie biedt inzicht hoe verschillende ontwerpmethodes op basis van hergebruik potentie kunnen worden onderscheiden en categoriseert verschillende hergebruik strategieën. De hergebruikstypologie onderscheidt de ontwerpmethode op twee kenmerken: 'ontwerpintentie' en 'type configuratie'. Hierbij wordt een omkeerbaar gebouwontwerp (reversible building design) geclassificeerd als een onbepaalde configuratie die bewust ontworpen is om in meerdere samenstellingen ingezet te kunnen worden. Op basis van de hergebruikstypologie is een raamwerk gedefinieerd waarin zes routes zijn geïdentificeerd die inzicht bieden in de impact van een (hergebruik) toepassing op de potentie om het product in de toekomst te kunnen hergebruiken. 
In hoofdstuk 3 zijn de enablers, kansen en barrières voor demontage en hergebruik onderzocht vanuit ecologisch, sociaal, organisatorisch, wetgeving, technisch en economisch perspectief. Deze uitgebreide literatuuranalyse geeft inzicht in de factoren die van invloed zijn op de hergebruik potentie van gebouwen en gebouwproducten en resulteert in een conceptueel hergebruik potentie raamwerk waarin de vijf belangrijkste variabelen zijn gedefinieerd: 1) impact van 'aanvullende processen'; 2) impact van 'vermeden processen'; 3. impact van 'hergebruik op de ingebedde waarde'; 4. impact van 'hergebruik op de operationele waarde' 5 . impact van 'externe invloeden'.

Gebaseerd op het hergebruik potentie raamwerk is een strategie afgeleid om ontwerpers te ondersteunen bij het ontwerpen van gebouwen en bouwproducten met een hoge hergebruik potentie: "ontwerp gebouwen, systemen en producten: met een hoge ingebedde waarde om de impact van 'aanvullende processen mogelijk te maken '; welke zoveel mogelijk hun ingebedde waarde behouden tijdens hergebruikprocessen, en; welke de impact van' hergebruik op de operationele waarde tot een minimum te beperken door de onderdelen die de operationele impact beïnvloeden te upgraden". Naast de literatuurstudie zijn in hoofdstuk 4 de belangrijkste ontwerpstrategieën voor demontageen hergebruik gesynthetiseerd. Dit overzicht vormt samen met de beoordelingsmethode van Durmisevic (2006) het vertrekpunt voor de ontwikkeling van de beoordelingsmethode van de hergebruikpotentie van gebouwen en bouwproducten.

De ontwikkeling van de beoordelingsmethode wordt beschreven in hoofdstuk 5. De belangrijkste bijdrage van dit hoofdstuk is de methode om de hergebruik potentie van gebouwen en bouwproducten te beoordelen. $0 \mathrm{~m}$ de beoordeling zo objectief mogelijk te maken is de beoordeling zoveel mogelijk geautomatiseerd op basis van de input van de samenstelling van de gebouw- en productopbouw. De beoordelingsmethode bouwt voort op de beoordelingscriteria van de beoordelingsmethode van Durmesevic (2006). De belangrijkste bijdragen van de methode om de hergebruik potentie van gebouwen en bouwproducten te beoordelen zijn:

1. De verdeling in indicatoren zoals; 1 . ingebedde warde, 2. moeilijkheid van terugwinning en 3. moeilijkheid van herstellen, die elk weer bestaan uit meerdere criteria en sub-criteria;

2. De evaluatiemethode die inzicht biedt op meerdere niveaus (middels een gebouw-, systeem-, productscore) en hergebruikstypen (gebouw-, systeem-, producthergebruik) om meerdere doelen te faciliteren: e.g. ontwerpondersteuning te bieden aan ontwerpers om de hergebruikpotentie te vergroten of opdrachtgevers strategische hergebruikdoelen per functie te laten evalueren;

3. De geautomatiseerde beoordeling op basis van de samenstelling van de gebouwstructuur en productopbouw, om tot een systematische en objectieve beoordeling van de hergebruikpotentie te komen.

Ten slotte is in hoofdstuk 6 de beoordelingsmethode van de hergebruikpotentie van gebouwen en bouwproducten getest en geverifieerd met behulp van een kritische retrospectieve case study-benadering. Het eerste case study-object is het 'Villa Zebra - Red House'-gebouw, dat meerdere malen succesvol is hergebruikt. Het tweede case study-object genaamd '4th Gymnasium' is ondanks de inspanning om het gebouw te ontwerpen met de bedoeling om dit gemakkelijk te kunnen verplaatsen en hergebruiken alsnog gesloopt. Beide vergelijkbare gebouwen zijn grondig geanalyseerd met behulp van kwantitatieve en kwalitatieve methoden om de ontwikkelde beoordelingsmethode te testen en valideren. De hergebruik potentie beoordelingsmethode geeft waardevolle inzichten in hoe de hergebruikpotentie van beide cases zou kunnen worden verbeterd. Om de methode volledig te valideren, is mijn aanbeveling om aanvullende case studies uit te voeren. 


\section{Table of contents}

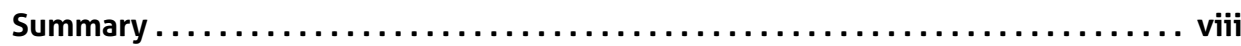

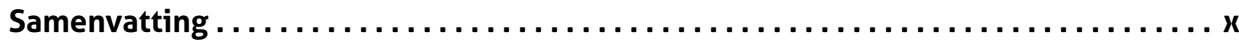

Part I - Research clarification

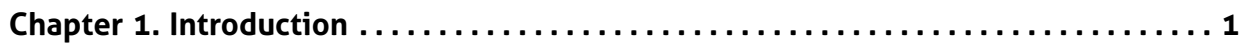

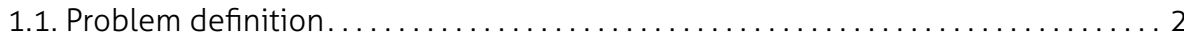

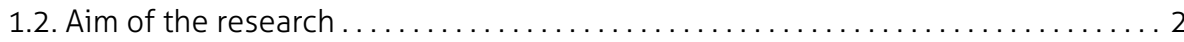

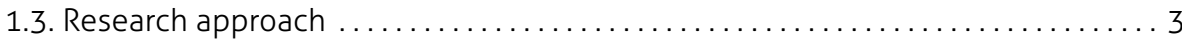

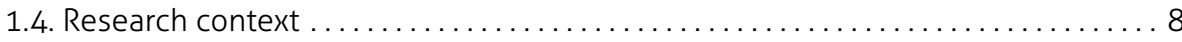

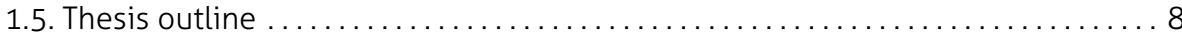

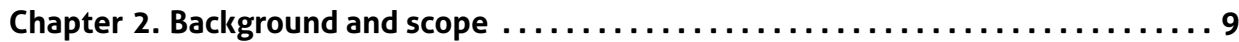

2.1. Introduction ............................................ 10

2.2. Defining the circular economy concept and principles................. 10

2.3. Types of obsolescence and theory of levels of change.................. 14

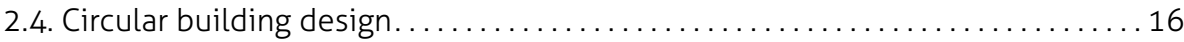

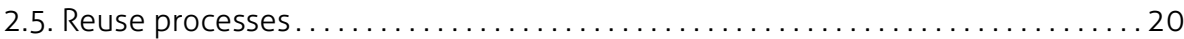

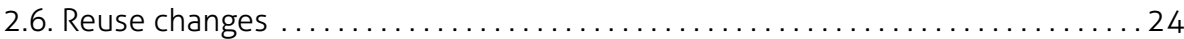

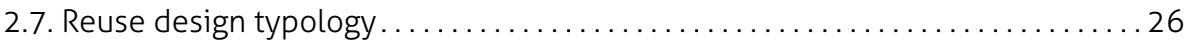

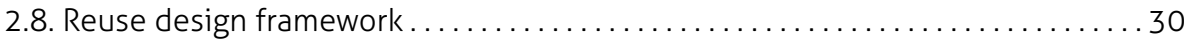

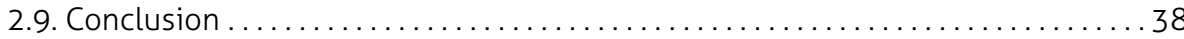

\section{Part II - Descriptive study I}

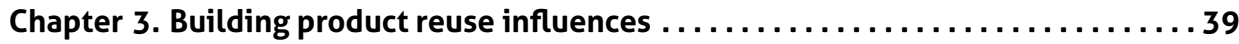

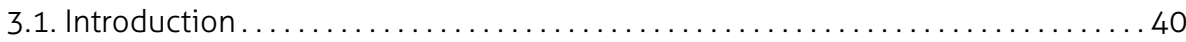

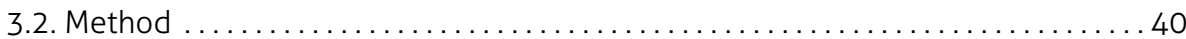

3.3. Enablers, opportunities and barriers for deconstruction and reuse ..........41

3.4. Reuse potential framework .................................. 77

3.5. Conclusion ............................................. 89

Chapter 4. Design strategies to support reuse $\ldots \ldots \ldots \ldots \ldots \ldots \ldots \ldots \ldots \ldots \ldots$

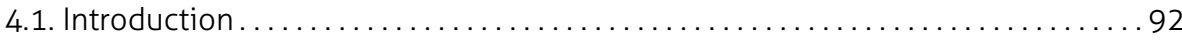

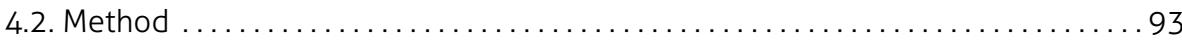

4.3. Design for disassembly guidelines and principles .................... 94

4.4. Conclusion ............................................ 106 


\section{Part III - Prescriptive study}

Chapter 5. Reuse potential evaluation method...................... 109

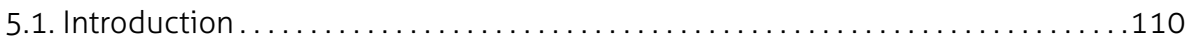

5.2. Scope of the reuse potential evaluation method $\ldots \ldots \ldots \ldots \ldots \ldots \ldots \ldots \ldots 11$

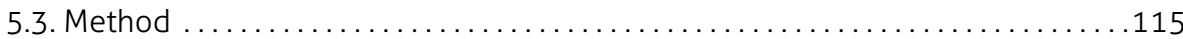

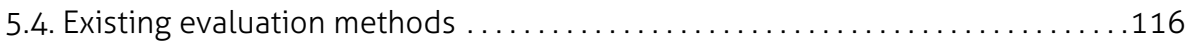

5.5. Building composition to automated assessment. ...................118

5.6. Development of the reuse potential evaluation method ................136

5.7. Conclusion .................................................

\section{Part IV - Descriptive study II}

Chapter 6. Testing the reuse potential evaluation method............... 161

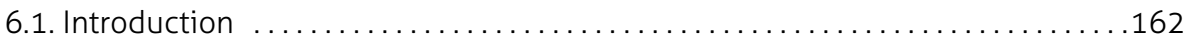

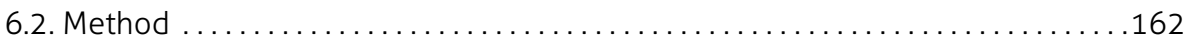

6.3. Qualitative analysis Red House.................................... 164

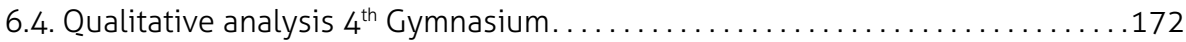

6.5. Qualitative comparison of Red House and $4^{\text {th }}$ Gymnasium . . . . . . . . . . . . 181

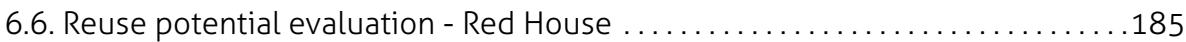

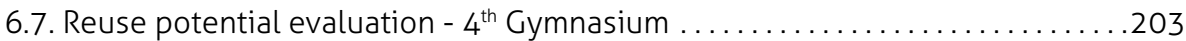

6.8. Discussion $\&$ conclusion . . . . . . . . . . . . . . . . . . . . . . . . . 220

Chapter 7. Discussion and conclusion ........................... 223

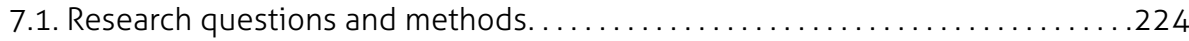

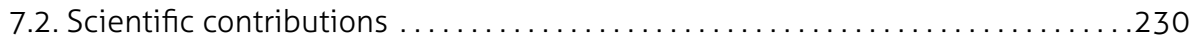

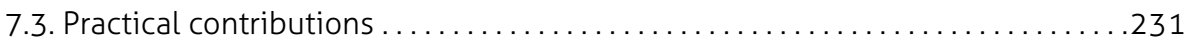

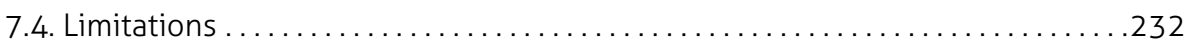

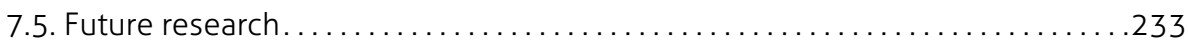

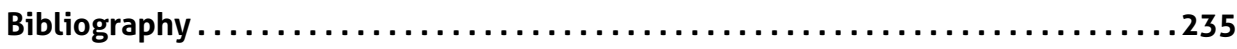

Part V-Supplements

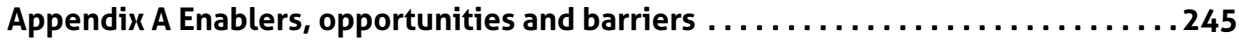

Appendix B Design for Disassembly guidelines. . . . . . . . . . . . . . . 253

Appendix C Assessment values of the reuse potential evaluation method . . . . . 267

Acknowledgements.................................... 274

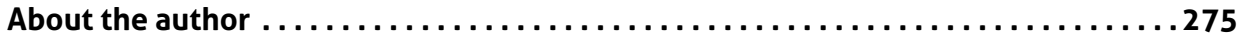




\section{Part I - Research clarification}

In this section the research clarification is presented to identify the goals that the research is expected to realise and to develop a plan for reaching them. In chapter 1, the problem definition, aim of the research and research appoach are defined. Furthermore, relevant research areas are examined to define the scope of the research in chapter 2. This stage results in a definition of circular building design and an initial understanding of the different reuse design strategies that define the scope of the research.

\section{Chapter 1 Introduction}




\section{1 | Introduction}

This thesis concerns the development of a reuse potential evaluation method, a method to support circular building design. The first chapter provides an introduction of the research presented in this thesis, including the problem definition, aim of the research, research approach, research context and the thesis outline.

\subsection{Problem definition}

The 20th century was a time of remarkable progress with steady economic growth, accompanied by an increase of resource consumption and a raising negative impact on the environment (UNEP, 2011). The dominating model in the past century can be characterized by its linear model of material use, following a 'take-make-dispose' pattern. All steps in this pattern involve resources, energy and labour, in which the last step leads to the destruction of applied energy and labour, creating enormous amounts of waste at the end of life. This also accounts for the construction industry, which relies heavily on virgin resources and generates large amounts of waste. The global extraction of construction minerals has grown by a factor 34, from 667 million tons in 1900 to 22,931 million tons in 2005 (Krausmann et al., 2009). In Europe the linear model of material use makes the construction industry is responsible for more than $50 \%$ of the total resource extraction, $42 \%$ of the total energy use and its associated emissions and $35 \%$ of the total waste generation (EU Commission, 2011; Eurostat, 2017).

The conventional way of construction has become a burden to the dynamic society of the 21st century, buildings are not designed to be transformed to meet changing requirements, instead they are designed as static rigid entities that cannot be modified without demolition. The enormous amounts of construction and demolition waste is the physical evidence of an industry that contains a fundamental error in its design and its sequential resource utilisation.

The problem definition of this research can be stated as follows:

Buildings are designed with a disregard to the end-of-first-life, leading to the loss of almost all applied energy and labour and contributing greatly to the waste generation at the end of its life.

\subsection{Aim of the research}

One way, to transform the construction industry into a sustainable and resilient industry that is resource responsible, is to consider buildings as temporary depositories of valuable building products that maintain their value after first, second and further use, creating a circular model of material use instead of a linear model of material consumption. To create a circular model of material use, buildings and building products should be designed in 
such a way to allow the extension to a second and further life and continuously create incentives for future reuse by its design.

To define the aim of this research, in line with Verschuren and Doorewaard (2015), a distinction is made between the objective of the research and the objective in the research:

The objective of this research is stated as follows:

To contribute to the transition of an industry that is based on a linear 'take-make-dispose' pattern into a circular building industry that (1) creates building products with an increasing resource productivity; (2) is less dependent on virgin resources and; (3) contributes to the elimination of the concept of waste.

The design of buildings and building products with a high potential to be reused is considered a necessity to move towards a circular construction industry. In past research Design for Disassembly has been identified as a key strategy to support the reuse of building products. This resulted in researchers identifying a plethora of design strategies to support the design of decomposable and reusable building structures and the identification of multiple enablers, opportunities and barriers that either restrict or support the reuse of building products. Although, design strategies provide generic design support, they are often limited to guidelines, principles and checklists, which are unable to quantify the resulting impact it has on the reuse potential of the building products.

To support the adoption of circular building design, a solid framework is required that supports and measures the design of building components and elements with a high reuse potential. Until now, there is no framework that measures the reuse potential of buildings and building products and supports the designer and engineers in the design of buildings with a high reuse potential.

Therefore, the objective in this research is stated as follows:

To support circular building design by the development of an evaluation method that enables an assessment of the reuse potential of buildings and building products and provides design knowledge to support designers and engineers to increase the reuse potential of their designs.

The objective in this research resulted in the following main research question:

M-RQ. How can the reuse potential of buildings and building products be evaluated and provide design knowledge to support circular building design?

\subsection{Research approach}

\subsubsection{Introduction}

The Design Research Methodology (DRM) proposed by Blessing and Chakrabarti (2009), can be considered as a suitable research approach to answer the main research question and realize the research objectives as formulated in section 1.2. In 'design research' the main 
objective is the development of understanding, and the development of support, with the overall aim to make design more effective and efficient to enable design practice to develop more successful products (Blessing and Chakrabarti, 2009, p. 5). In addition, Van Aken (2004, p. 225) states that the ultimate objective of 'design science' is to develop valid and reliable design knowledge, i.e. knowledge that can be used in designing solutions to problems in the field in question. The development of DRM was based on an extensive review of design research and describes various methods that aim at performing rigorous research by helping to plan and implement design research. Furthermore, DRM focuses on developing design support methods and provides a comprehensive research methodology. Therefore, it is suitable for the development of an evaluation method to support circular building design.

According to the DRM framework, the main phases of a comprehensive design research study include the following stages (Blessing and Chakrabarti, 2009, pp.15-16): 1. research clarification; 2 . descriptive study I; 3. prescriptive study; 4. descriptive study II.

DRM-based research can involve all of these phases, however often only some of them are covered due to limitations of time or access to critical resources. Furthermore, in each research phase a distinction is made between three study types (Blessing and Chakrabarti, 2009, p.18): 1. review-based study, research based only on the review of literature; 2. comprehensive study, research that includes a literature review as well as a study in which the results are produced by the researcher; 3. initial study, research that closes a project and involves the first few steps of a particular stage to show the consequences of the results and prepare the results for use by others.

In the DRM framework seven main types of design research are specified, as shown in Table 1.01, which will likely result in useful research results. The research presented in this thesis can be classified as design research type 6 , which consists of a review-based research clarification, a review-based descriptive study I, a comprehensive descriptive study and a comprehensive descriptive study II. To elaborate on the research methodology of this thesis, the four main phases of this research will be specified. Furthermore, in Figure 1.01 the research approach and structure for the research in this thesis is presented.

Table 1.01: Research types of the design research methodology (Blessing and Chakrabarti, 2009, p.60)

\begin{tabular}{|c|c|c|c|c|}
\hline $\begin{array}{l}\text { Research } \\
\text { type }\end{array}$ & $\begin{array}{l}\text { Research } \\
\text { clarification }\end{array}$ & Descriptive study I & Prescriptive study & Descriptive study II \\
\hline 1 & Review-based & $\rightarrow$ Comprehensive & & \\
\hline 2 & Review-based & $\rightarrow$ Comprehensive & Initial & \\
\hline 3 & Review-based & Review-based & $\rightarrow$ Comprehensive & Initial \\
\hline 4 & Review-based & Review-based & $\rightarrow \begin{array}{c}\text { Review-based } \\
\text { initial/comprehensive }\end{array}$ & $\rightarrow$ Comprehensive \\
\hline 5 & Review-based & $\rightarrow$ Comprehensive & $\rightarrow$ Comprehensive & Initial \\
\hline 6 & Review-based & $\rightarrow$ Review-based & $\rightleftarrows$ Comprehensive & $\rightleftarrows$ Comprehensive \\
\hline \multirow[t]{2}{*}{7} & Review-based & $\rightarrow$ Comprehensive & $\rightleftarrows$ Comprehensive & $\rightleftarrows$ Comprehensive \\
\hline & & & advised step $\rightarrow$ & optional step $\rightarrow$ \\
\hline
\end{tabular}




\subsubsection{Research clarification - Define circular building design and reuse types:}

The objective of the research clarification phase is to identify the goals that the research is expected to realise and to develop a plan for reaching them (Blessing and Chakrabarti, 2009, p.30). The aim of this research is stated in section 1.2, which can defined as the development of an evaluation method that is based on design knowledge to support circular building design. In order to determine the focus and scope of the research, based on a literature study the circular economy concept and its application to the construction industry will be explored. Key concepts, such as the theory of levels of change, functional decomposition and physical building entities, reuse processes, reuse changes and reuse design concepts are examined. In order to identify the scope of the reuse potential evaluation method, the following research questions are defined:

\section{RQ1. How can circular building design be defined? (Chapter 2)}

RQ2. Which types of building reuse and building product reuse methods can generally be identified in the building practice? (Chapter 2)

This stage results in a definition of circular building design, an initial understanding of the different reuse design strategies, which will be used to define the scope of the research.

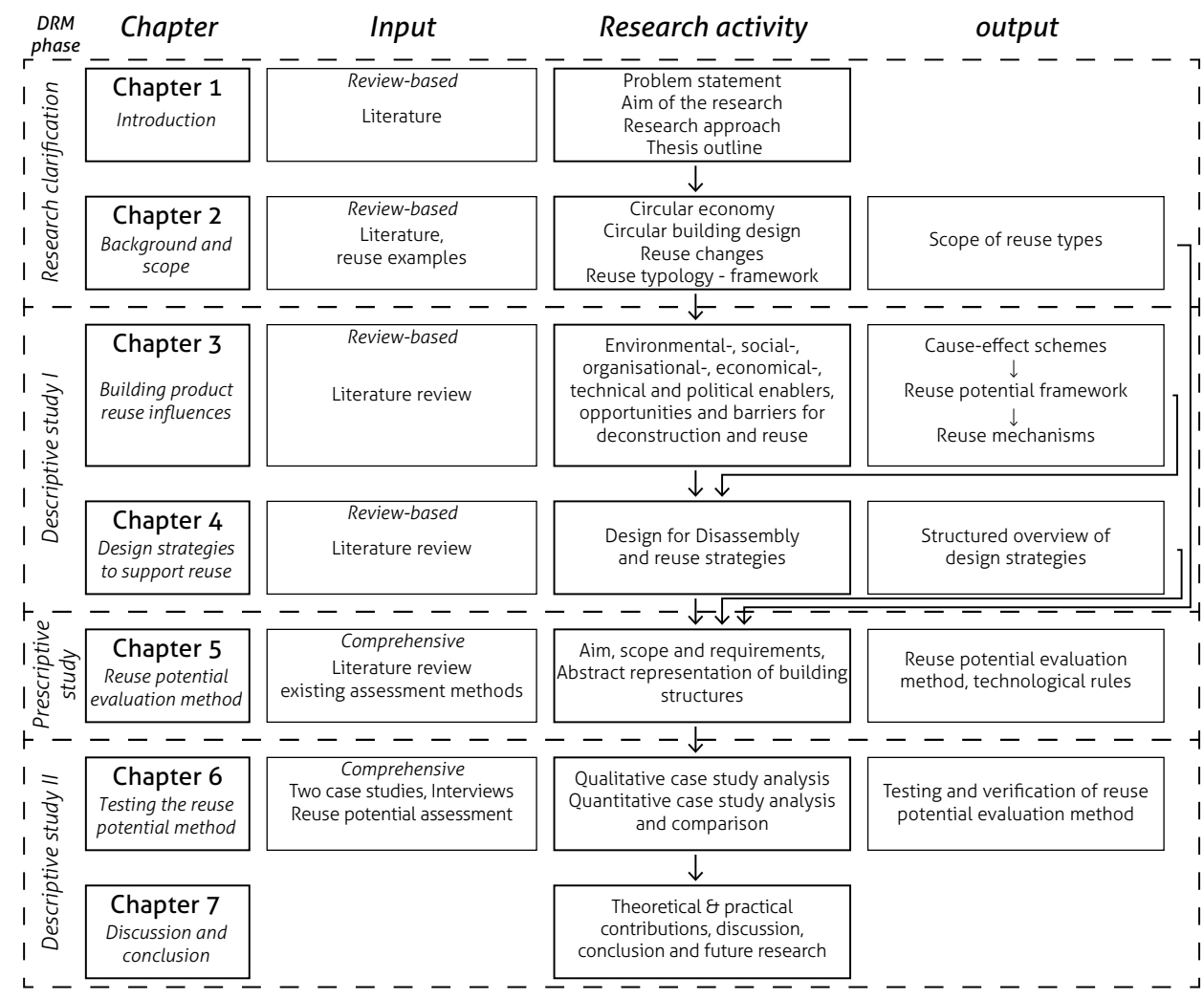

Figure 1.01: Research approach and structure of the research in this thesis, representing the main input, study types, methods, research activity, knowledge outputs and the DRM phase and chapter. 


\subsubsection{Descriptive study I - Understanding building product reuse mechanisms and design for disassembly and reuse guidelines:}

The objective of descriptive study $I$ is to increase understanding of the design problem and identifying criteria for evaluating design support methods (Blessing and Chakrabarti, 2009, p. 32). Descriptive study I contains two parts: part I. aims at improving the understanding of the enablers, opportunities and barriers of building product reuse from multiple perspectives, and; part II. aims at improving the understanding of the reasoning how Design for Disassembly guidelines can improve the reuse potential of building products.

In order to increase the understanding whether or not a building product will be reused, a literature study to the common enablers, opportunities and barriers will be performed. Furthermore, a synthesis will be performed to identify the main causes and effects of the factors that enable or constrain reuse of building products. To develop a framework of indicators to evaluate the reuse potential of buildings and building products, the following research questions are defined:

RQ3. Which enablers, opportunities and barriers for deconstruction and reuse can be identified in literature? (Chapter 3)

RQ4. What are the main causes and effects of the enablers, opportunities and barriers for deconstruction and reuse? (Chapter 3)

RQ5. How can the main factors of deconstruction and reuse be structured in a conceptual framework to evaluate the reuse potential of buildings and building products? (Chapter 3)

Descriptive study I - part I, should result in a framework that specifies the main variables that influence the reuse potential of buildings and buildings products and provides a solid basis for the reuse potential evaluation method. Furthermore, it should provide insight in reuse mechanisms and identify a main strategy how the reuse potential can be increased based on its design.

Design for Disassembly is considered a key strategy to enable building products to be re-claimed and reused. Therefore, it is essential to review existing Design for Disassembly guidelines and principles, to gain a comprehensive overview of design guidelines to support building product reuse. This overview can be taken into account during the development of the reuse potential evaluation method. In descriptive study I - part II, the following research question will be examined:

RQ6. Which 'Design for Disassembly' guidelines can be identified in literature to support reuse of buildings and building products and what is the guideline's reasoning? (Chapter 4)

Descriptive study I - part II, should result in a structured overview of the main Design for Disassembly guidelines and principles.

\subsubsection{Prescriptive study - Development of the reuse potential evaluation method:}

The objective of the prescriptive study is to develop a design support approach based on the understanding and criteria identified in descriptive study I (Blessing and Chakrabarti, 2009, p.35). In this stage, the reuse potential evaluation method will be developed, starting with the aim, scope and defining the requirements of the reuse potential evaluation method, secondly, existing evaluation methods will be studied, after which the reuse potential evaluation method will be developed. The goal of this stage is to answer the following research questions: 
RQ7. What existing methods can be identified in literature to evaluate the reuse potential of buildings and building products? (Chapter 5)

RQ8. How does an evaluation method that enables the assessment of the reuse potential of buildings and building products and provides design support to designers and engineers look like? (Chapter 5)

The aim of this research corresponds with the mission of design-science. According to Van Aken (2004, p.226), the mission in design-science is to develop scientific knowledge to support the design of interventions or artefacts by professionals and to emphasise its knowledge orientation. In addition, Van Aken (2004, p.226) stated: 'design-science is not concerned with action itself, but with knowledge to be used in designing solutions, to be followed by design-based action'.

The goal of this research is the development of an evaluation method that is based on scientific knowledge that allows for an objective assessment, and provides insights and knowledge that can be used to improve design-based actions. A method that is based on so-called technological rules would be an appropriate solution (Van Aken, 2004). A technological rule, is defined by Bunge (1967, p.132) as "an instruction to perform a finite number of acts in a given order and with a given aim". A technological rule follows the logic of "if you want to achieve $Y$ in situation $Z$, then perform action $X$ '. Therefore, this stage should result in an evaluation method that consists of a set of steps that includes an algorithm to perform an assessment that embraces the logic of technological rules, which are based on grounded scientific knowledge to improve design-based actions.

\section{Descriptive study II - Evaluation of the reuse potential assessment method:}

The objective of descriptive study /I is to evaluate the design support that has been developed in the previous stage based on its usability and applicability, to identify whether the support can be used for the task for which it is intended, and its usefulness, to identify whether the support has the expected impact (Blessing and Chakrabarti, 2009, p. 38). The goal of this stage is to answer the following research question:

RO9. How usable, applicable and useful is the evaluation method that is presented in this study if applied to case studies? (Chapter 6)

In this research, the reuse potential evaluation method will be tested using a case study method. Two critical retrospective cases will be selected conform the 'case/control' method. Both cases will be analysed using qualitative research methods, including a literature study and open interviews, and the application of the proposed evaluation method. After the application of the reuse potential evaluation method it is possible to compare the results with the qualitative analysis, to test the usability, applicability and its usefulness.

The thesis then ends with a discussion and conclusion in which the main contributions are reviewed as well as the research approach and validity of results. Furthermore, recommendations for future research are given. 


\subsection{Research context}

This research was part of a Horizon 20|20 EU research and innovation project called: Buildings as Material Banks (BAMB). Within the BAMB project, 15 partners from 7 European countries have worked together with one mission: enabling a systemic shift in the building sector by investigating and creating circular solutions (Debacker et al., 2016).

The following partners have worked together in the BAMB project: Brussels environment, BAM international, Building Research Establishment (BRE), EPEA, Drees \& Sommer, IBM, Ronneby Kommun, Sarajevo Green Design Foundation, SundaHus, Technical University of Munich, University of Twente, University of Minho, VITO, Vrije Universiteit Brussels and Zuyd University of Applied Sciences. The BAMB project started in September 2015 and progressed for 3,5 years.

The aim of the project is to develop integrating approaches, methods and tools that will enable the shift: Materials passports and Reversible Building Design - supported by the new business models, policy propositions, and management and decision-making models. Activities within the BAMB project are divided in 7 work packages:

WP1. Developing a blueprint for dynamic and circular buildings and materials upcycling

WP2. Developing materials passports and corresponding database \& platform

WP3. Developing reversible building design tools for dynamic and circular buildings

WP4. Testing BAMB results through prototyping and pilot projects

WP5. Facilitating future applications and exploitation of BAMB results

WP6. Communication \& dissemination

WP7. Project management and coordination

The research presented in this thesis contributes to work package 3, developing reversible building design tools in the form of a reuse potential evaluation method. The BAMB project provided an international audience that reinforced the relevance and need for the development of a reuse potential evaluation method.

\subsection{Thesis outline}

In Figure 1.01 the research approach and structure of the research in this thesis is presented. In chapter 1 and 2, the research clarification is presented, defining the problem statement, aim of the research and relevant research areas are examined to define the scope of the research (RO1 and RO2). In chapter 3, descriptive study I will be performed to gain a better understanding of the factors that influence the reuse potential of building products (RO 3-5). Furthermore, in chapter 4 , the reasoning of existing 'Design for Disassembly' guidelines are explored (RO6). In chapter 5, the prescriptive study is presented defining the Reuse Potential Evaluation Method to (RO7 and ROQ8). In chapter 6, the usability, applicability and usefulness of the proposed evaluation method is tested using two case in-depth case studies (RO9). Finally, in chapter 7, the findings are discussed with respect to the initial aim of the research, the practical and theoretical contributions and limitations of the research are explained and recommendations for future research are formulated. 


\section{Chapter 2 Background and scope}

"Every design decision is a decision about the future" Pieter Beurskens 


\section{2 | Background and scope}

In this chapter the scope of the research is defined. In order to answer the M-RQ, it is important to understand and define the scope of the research. Therefore, the aim of this chapter is to answer the following research questions: RO1: How can circular building design be defined? RO2: Which types of building reuse and building product reuse methods can generally be identified in the building practice? Both research questions will be answered by reviewing literature on the application of the circular economy concept in the construction industry, including key concepts, such as the theory of levels of change, functional decomposition and physical building entities, reuse processes, reuse changes and reuse design. Finally, the chapter will conclude with a reuse design framework that provides understanding of the topic and specifies the scope of the research.

\subsection{Introduction}

The 20th century was a time of remarkable progress with steady economic growth, accompanied by an increase of resource consumption and a raising negative impact on the environment (UNEP, 2011). The dominating model in the past century can be characterized by its linear model of material use, following a 'take-make-dispose' pattern. All steps in this pattern involve resources, energy and labour, in which the last step leads to the destruction of applied energy and labour, creating enormous amounts of waste at the end of life. This also accounts for the construction industry, in which the global extraction of construction mineral has grown by a factor 34, from 667 million tons in 1900 to 22,931 million tons in 2005 (Krausmann et al., 2009). In Europe the construction industry is responsible for more than $50 \%$ of the total resource extraction, $42 \%$ of the total energy use and its associated emissions and 35\% of the total waste generation (EU Commission, 2011; Eurostat, 2017). Emphasizing the need for a construction industry that is less material intensive and more resource responsible.

The transition from a linear model to a circular model of material use is considered key to transform the construction industry into a sustainable industry. After the Ellen MacArthur Foundation (EMF) released their reports in 2012, 2013 and 2014, Towards the Circular Economy, the circular economy concept started to gain momentum among practitioners and scholars (Kirchherr, Reike \& Hekkert, 2017; Blomsma \& Brennan, 2017). Although the circular economy concept is not new, it is considered essential to accomplish the main goal, sustainable development.

\subsection{Defining the circular economy concept and principles}

The circular economy concept is defined in many different ways meaning different things for different people, these various understandings are considered problematic for the 
further development of the concept (Blomsma \& Brennan, 2017). To overcome this gap, Kirchherr et al., (2017) performed a critical review of 114 circular economy definitions, gathered from peer-reviewed journal articles as well as policy papers and reports such as Ellen MacArthur Foundation (2012), from which they coded on 17 dimensions, relating to core principles, aims and enablers of the circular economy, to provide a transparent view regarding the current understanding of the circular economy concept.

Firstly, as core principles, Kirchherr et al., (2017) identified the hierarchically ranked 4R-framework (reduce, reuse, recycle and recover) as an important operationalisation principle of the circular economy and the systems perspective which addresses the different levels at which a transition needs to occur to achieve a true circular economy, namely: micro level; meso level and macro level. Secondly, the aim of the circular economy is sustainable development, whereby environmental quality, economic prosperity and social equity should be accomplished simultaneously, without neglecting the factor time. Lastly, the enablers of a circular economy, being novel business models that shifts businesses from generating profits from selling products, to generating profits from the flow of materials and products over time and the consumers perspective, addressing their responsibility and willingness to participate in a circular economy being essential in the success of novel business models.

Finally, Kirchherr, Reike \& Hekkert (2017, p.224) came up with a definition, which can be understood, as the summary of their coding framework, incorporating the core principles, aims and enablers as identified previously, namely:

"A circular economy describes an economic system that is based on business models which replace the 'end-of-life' concept with reducing, alternatively reusing, recycling and recovering materials in production/distribution and consumption processes, thus operating at the micro level (products, companies, consumers), meso level (eco-industrial parks) and macro level (city, region, nation and beyond), with the aim to accomplish sustainable development, which implies creating environmental quality, economic prosperity and social equity, to the benefit of current and future generations"

Their definition is included to provide an overview of the main concepts that are recognised to be essential in a circular economy, although it does not mean that their definition is definitive. As they argue the circular economy is understood as a construct that is developed through a multi-stakeholder discourse, which does not authorise a single group to define the circular economy.

To add on this, it should be noted that in addition to the 4 R-framework that is adopted in the definition provided above, there exists a wide variety in the number of hierarchically ranked R-frameworks. Reike, Vermeulen, and Witjes (2017) revealed in their literature review of 69 peer-reviewed articles that there exists confusion among different scholars and disciplines regarding the number of R-words, hierarchical order and the definitions. They identified that different combinations and numbers of R-words were presented, ranging from the often mentioned 3R-imperatives 'reduce, reuse and recycle' up to 10R-imperatives, while only $60 \%$ of the authors apply a clear hierarchy, of which the hierarchical order varies. Additionally, they noted that the majority of the more nuanced typologies 7Rs-10Rs are 
identified in contributions published after 2010. Finally, Reike et al. (2017) identified a synthesized 10R typology, to serve as a step towards a comprehensive and systematic understanding of circular economy among various disciplines and stakeholder groups. Their 10R typology distinguishes three types of loops: short loops, where product remains close to its user and function (RO refuse, R1 reduce, R2 resell/ re-use, R3 repair); medium loops, where products are upgraded and producers are again involved (R4 refurbish, R5 remanufacture, R6 repurpose), and; long loops, where products lose their original function ( $\mathrm{R} 7$ recycle materials, $\mathrm{R} 8$ recover (energy), R9 re-mine).

In addition to the distinction of three types of loops, another conceptualisation introduced by Bocken, de Pauw, Bakker, \& van der Grinten (2016) makes a clear distinction between three types of resource flows; minimising resource input by 'narrowing' resource flows, extending product life by 'slowing' resource flows and recycling materials to enable 'closing' resource flows. Their terminology has been built upon the work of Stahel (2010) and McDonough \& Braungart (2002). To bring this conceptualisation in line with the R-imperatives of Reike et al. (2017) a fourth resource flow has been identified, to eliminate leaking resource flows, to address resource flows that at this moment are still escaping the circular model of material use. The following four resource flows are visualised in Figure 2.02 and are defined as follows:

Narrowing resource flows: "Aimed at using fewer resources per product" (Bocken et al., 2016, p. 309)

Slowing resource flows: "Through the design of long-life products and product-life extension (i.e. service loops to extend a product's life, for instance through repair, remanufacturing), the utilization period of products is extended and/or intensified, resulting in a slowdown of the flow of resources." (Bocken et al., 2016, p. 309)

Closing resource flows: "Through recycling, the loop between post-use and production is closed, resulting in a circular flow of resources" (Bocken et al., 2016, p. 309)

Leaking resource flows: Aimed at the elimination of energy recovery based on useful materials, elimination of contamination of useful material streams with hazardous substances and the elimination of useful materials from landfills.

Narrowing resource flows focusses on providing material services with less material production and processing, which can be achieved e.g. through optimisation of the manufacturing stage or smart product design, so fewer resources are used per product. Narrowing resource flows have the potential to reduce the amount of resources being consumed and can thus have a great effect on the number of resources flowing through the entire system.

While narrowing resource flows and leaking resource flows is no specific strategy that support a circular model material use, the identification of leaking resource flows puts emphasis on the existence of a flow that should not be overlooked and requires attention to strive for full elimination of useful resources being incinerated, contaminated and 
Table 2.02: 10R typology related to four distinctive resource flows

\begin{tabular}{|c|c|c|c|}
\hline Resource flows & Loop type & R-imperatives & Description \\
\hline \multirow[t]{2}{*}{ Narrowing } & \multirow{4}{*}{$\begin{array}{l}\text { Shortest } \\
\text { loops }\end{array}$} & Ro Refuse & $\begin{array}{l}\text { Make product redundant by abandoning its function on } \\
\text { by offering the same function with a radically different } \\
\text { product }\end{array}$ \\
\hline & & R1 Reduce & $\begin{array}{l}\text { Increase efficiency in product manufacture or use by } \\
\text { consuming fewer natural resources and materials }\end{array}$ \\
\hline \multirow{5}{*}{ Slowing } & & R2 Resell/ Reuse & $\begin{array}{l}\text { Reuse by another consumer of discarded product } \\
\text { which is still in good condition and fulfills its original } \\
\text { function }\end{array}$ \\
\hline & & R3 Repair & $\begin{array}{l}\text { Repair and maintenance of defective product so it can } \\
\text { be used with its original function }\end{array}$ \\
\hline & \multirow{3}{*}{$\begin{array}{l}\text { Medium } \\
\text { long loops }\end{array}$} & R4 Refurbish & Restore an old product and bring it up to date \\
\hline & & R5 Remanufacture & $\begin{array}{l}\text { Use parts of discarded product in a new product with } \\
\text { the same function }\end{array}$ \\
\hline & & R6 Repurpose & $\begin{array}{l}\text { Use discarded product of its parts in a new product } \\
\text { with a different function }\end{array}$ \\
\hline Closing & \multirow{3}{*}{$\begin{array}{l}\text { Long } \\
\text { loops }\end{array}$} & R7 Re-cycle & $\begin{array}{l}\text { Process materials to obtain the same (high grade) or } \\
\text { lower (low grade) quality }\end{array}$ \\
\hline \multirow{2}{*}{ Leaking } & & R8 Recover & Incineration of material with energy recovery \\
\hline & & R9 Re-mine & The retrieval of materials after the landfilling phase \\
\hline
\end{tabular}

Note: considering the lack of clear descriptions regarding the R-imperative in the publication of Reike et al. (2017) the provided descriptions are therefore based adopted from Potting et al. (2016), which seem to convey the same meaning as Reike et al. (2017), except R9 Re-mine was missing in Potting et al. (2016) and is based on Reike et al. (2017).

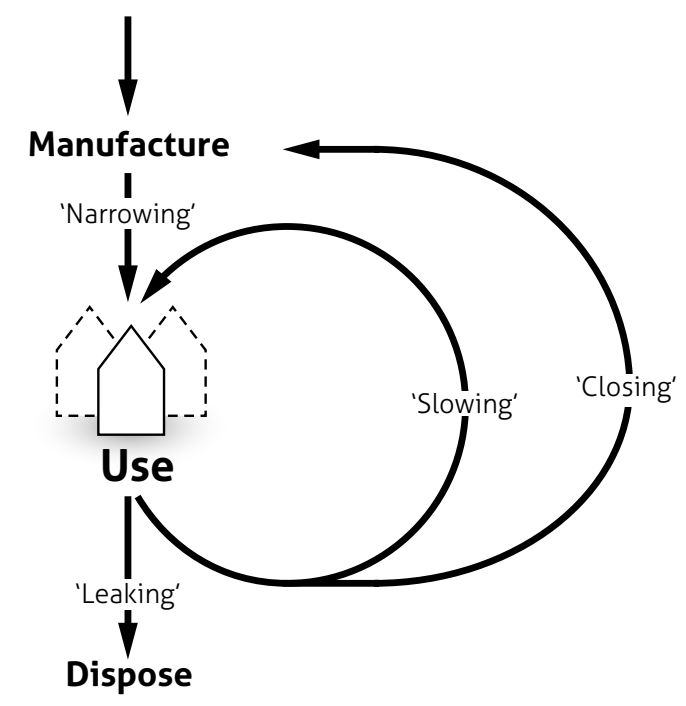

Figure 2.02: Conceptual model of four distinct resource flows that should be addressed in a circular economy 
landfilled. Narrowing resource flows focusses on providing material services with less material production and processing, which can be achieved e.g. through optimisation of the manufacturing stage or smart product design, so fewer resources are used per product. Narrowing resource flows has the potential to reduce the amount of resources being used and can thus have a great effect on the number of resources flowing through the system. As Bocken et al., noted, "the end result of "slowing" and "narrowing" could be the same. However, "slowing" invokes a different relationship with time, whereas "narrowing" accepts the speed of resource flows" (2016, p.310). Therefore, the factor time is of major importance, otherwise resource efficiency can easily lead to opposite effects, resulting in little to no savings.

To clarify the focus of the four resource flows, they have been brought in relation with the 10R typology of Reike et al. (2017), as shown in Table 2.02. This table provides a clear overview of the scope of this research, which is focused on enhancing the reuse potential of building products, in which reuse is used as a general term that encompasses all forms of subsequent use of an object or material after its first and further life to prolong and extend its useful life, especially aiming at high quality product reuse. In the context of the four resource flows that have been identified, the aim of this research is slowing resource flows in the construction industry.

\subsection{Types of obsolescence and theory of levels of change}

To provide guidance on how to design buildings within a circular economy it is important to understand the causes why building (products) are falling into disuse, and how the theory of levels of change can respond to these causes.

\subsubsection{Types of obsolescence}

To be able to design buildings in line with the circular economy concept, it is important to understand the causes why buildings or rather building products become obsolete and result in building products being replaced prematurely or even the demolition of entire buildings. The understanding of the types of obsolescence (causes) makes it possible to react to these reasons. The reaction to types of obsolescence often requires a physical reaction (effect), to accommodate the shift and prevent the building and its components from premature obsolescence.

Numerous researchers have identified the premature replacement of building products as a mismatch between the technical service life - the period over which a building product can technically fulfil its function, and the functional service life - the period over which a certain product can fulfil its expectations (Durmisevic, 2006; Nordby, 2008; Nunen, 2003; Paduart, 2012; Sassi, 2009). The causes for this mismatch are also known as reasons for obsolescence, which can be defined as the resulting condition of the inability to accommodate change (Kohler et al., 2010). In general the reasons for obsolescence can be traced down to two reasons: 1) due to deterioration e.g. aging or natural decay, which is related to the technical service life and in principle cannot be avoided, or 2) due to its functional service life: (Langston et al., 2008; Ashby, 2013; Kohler et al., 2010; Rudbeck, 1999): 
Functional obsolescence; refers to the change in ownership objectives and user demands that lead to possibly function change from the purpose for which the building was originally designed (e.g. residential buildings built in the 1950s with very small apartments, or office buildings with deep plans or low ceiling heights);

Physical obsolescence; refers to poor maintenance, which accelerates the state of a building to deteriorate to such an extent that its repair is no longer worthwhile (All buildings experience deterioration due to natural decay, which can be delayed with proper maintenance and is therefore not considered an attribute of obsolescence but rather of age);

Technical obsolescence; refers to the advances that technology makes, which renders the existing building product obsolete, because it is no longer technologically superior to its alternatives (e.g. window frames or solar panels are replaced with an improved model because of its expected lower operating costs or greater efficiency).

Legal obsolescence; refers to the inability of the building or building products to meet new regulations (e.g. the increasing requirements for thermal and sound insulation, new requirements for disabled access or building products that are contaminated with asbestos);

Economic obsolescence; refers to the period of time over which ownership or use of a particular building is considered to be the least cost alternative for meeting a business objective regarding investor interest (e.g. the replacement or upgrade of the façade when retrofitting a building is very expensive and therefore cheaper to demolish and construct a new building, or the increase in land value can drive the decision to demolish and built more units on the same area of land to maximise land value);

Social obsolescence; refers to taste, fashion, aesthetic preference that changed and lead to the need of a building to be updated (e.g. the external appearance of a building). The mismatch between technical- and functional service life offers enormous opportunities for reuse, by utilizing the remaining technical service life and unlocking their full potential.

\subsubsection{Theory of levels of change}

The acknowledgement of a building being a composition of building functions that change at different rates to react to the different types of obsolescence has already been recognized by Professor Habraken in the 1960's, when he introduced three levels of decision making: urban fabric, support and infill (Habraken, 1961) and formed the foundation of the theory of levels of change.

The theory of levels of change is essential in circular building design. This theory acknowledges that a building is a composition of different layers or building functions that change at different rates, the more the layers are connected and interrelated, the greater the difficulty and cost to accommodate change (Brand, 1994; Schmidt, 2014). As Brand states, "An adaptive building has to allow slippage between the differently-paced systems of site, structure, skin, services, space plan and stuff. Otherwise the slow systems block the flow of the quick ones, and the quick ones tear up the slow ones with their constant change" (1994, p. 
20). Whereby, in the effect of quick changing functional layers can be identified as the most problematic ones, because they provoke the demolition of slower changing levels. This makes it essential to design buildings with reduced connectedness and interrelatedness between different functional layers, to ease change and support reuse by non-destructive disassembly methods to slow material flows.

After Habraken introduced the three levels of decision making, Duffy (1990) increased the numbers of layers to shell, service, scenery and set, and in 1994, Steward Brand defined the six shearing layers of change, site, structure, skin, services, space plan, stuff. Most recently, Schmidt (2014) expanded the interpretation of the layer concept by the addition of the layers social (humans in and around the building, e.g. users, owners, neighbourhood community) and surroundings (larger physical context in which the building sits, e.g. neighbouring buildings, public space), which are considered crucial when considering the building in time. Schmidt (2014, p.359) argues "that buildings (and their constituting parts) cannot be thought of in isolation to their surrounding context and that users along with their social perceptions and agendas 'shear' against the building layers". Additionally, he removed explicit labelling of the lifespan of each layer, because this may vary depending on use typologies, solutions and contextual conditions, as shown in Figure 2.03, in which the faster and slower changing layers are depicted through the proximity of the arrows of each layer.

\subsection{Circular building design}

In a circular economy, the notion of a building as a whole object, that is conceived, designed and constructed as a complete entity does not exist. In a circular economy, each part has its own functionality and lifespan, whereby the application in one building might represent only a short part of the product's entire life cycle and, demolition and waste are considered a design error (Debacker et al., 2016). Therefore, a circular building should be envisioned

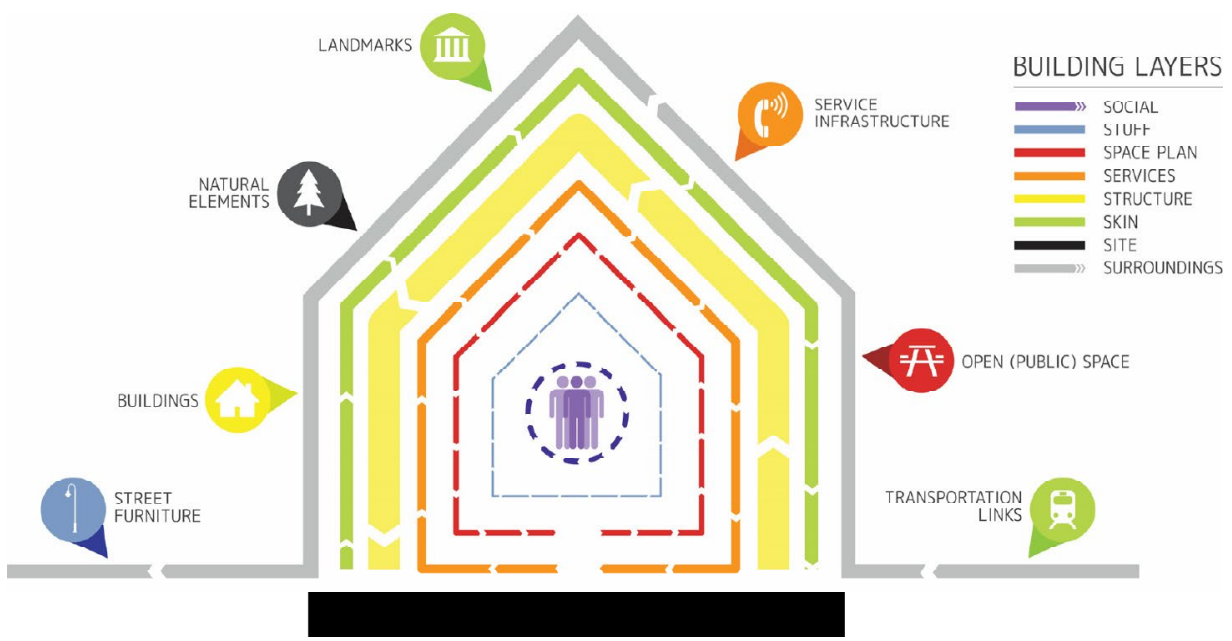

Figure 2.03: Revised building layers model, adopted from Schmidt (2014, p.358). 
as a collection of parts, that have the capacity to accommodate changing demands through an open assembly of parts that can form an indefinite number of configurations and can be assembled, disassembled, replaced and reused without alteration or destruction of any element, keeping their value as high as possible. Circular building design is often used interchangeably with reversible building design, in this research circular building design is adopted.

In this research, circular building design is defined as: A design approach to create buildings that have the capacity to accommodate changing demands by taking into account all life cycle stages, to minimise resource input by narrowing resource flows, retain a high embodied value through design for disassembly, reparation and refurbishment and extend product life by slowing resource flows, utilise recyclable materials to enable closing resource flows, and eliminate leaking resource flows by continuously forming an incentive for future reuse.

Building upon the theory of levels of change, Durmisevic (2006, p.105) noted that the building layers that represent the physical parts are multidimensional and do not have consistent lifespans and changing rates for all parts within this functional layer. This is also reflected in the revised building layer model of Schmidt (2014), who removed explicit labelling of lifespans, because this may vary depending the product function and contextual conditions. To address the multidimensionality of each layer, Durmisevic (2006) introduced the term functional decomposition - the allocation of functions to separate building parts to respond to changing conditions. Taking into account functional dependencies, functional decomposition is considered essential for circular building design. Depending on the desire to effectively accommodate change and reuse, more functions may be identified that should be designed with a minimum dependencies and connectedness between the different functions.

To provide clear guidance in respect to the functional decomposition of a building, the following main building functions and sub-functions have been identified, based on Durmisevic (2006), as shown in Figure 2.04: load-bearing: foundation, structure, floors; enclosure: facade open, facade closed, roof; finishing: (raised) floor, (lowered) ceiling, partitioning, stairs, and; servicing: water, electrical, heating, ventilation. Building upon the research of Durmisevic (2006) and Deniz \& Dogan (2014), each building sub-function can be sub-divided into four basic element functions, which should in turn be designed as independent layers to accommodate change:

Support: refers to parts whose main function is to transfer and resist loads, of all structural forms imposed by the internal and external environments, often also identified as the carrier for control, finishing and integration parts;

Control: refers to parts whose main function is to manage, regulate and/or moderate factors (such as air, moisture, heat, etc.);

Finish: refers to parts whose main function is to contribute to the visual and aesthetic appearance of the building's sub-function, and;

Integration: refers to the parts whose main function is to connect, lock or hold parts in place. 


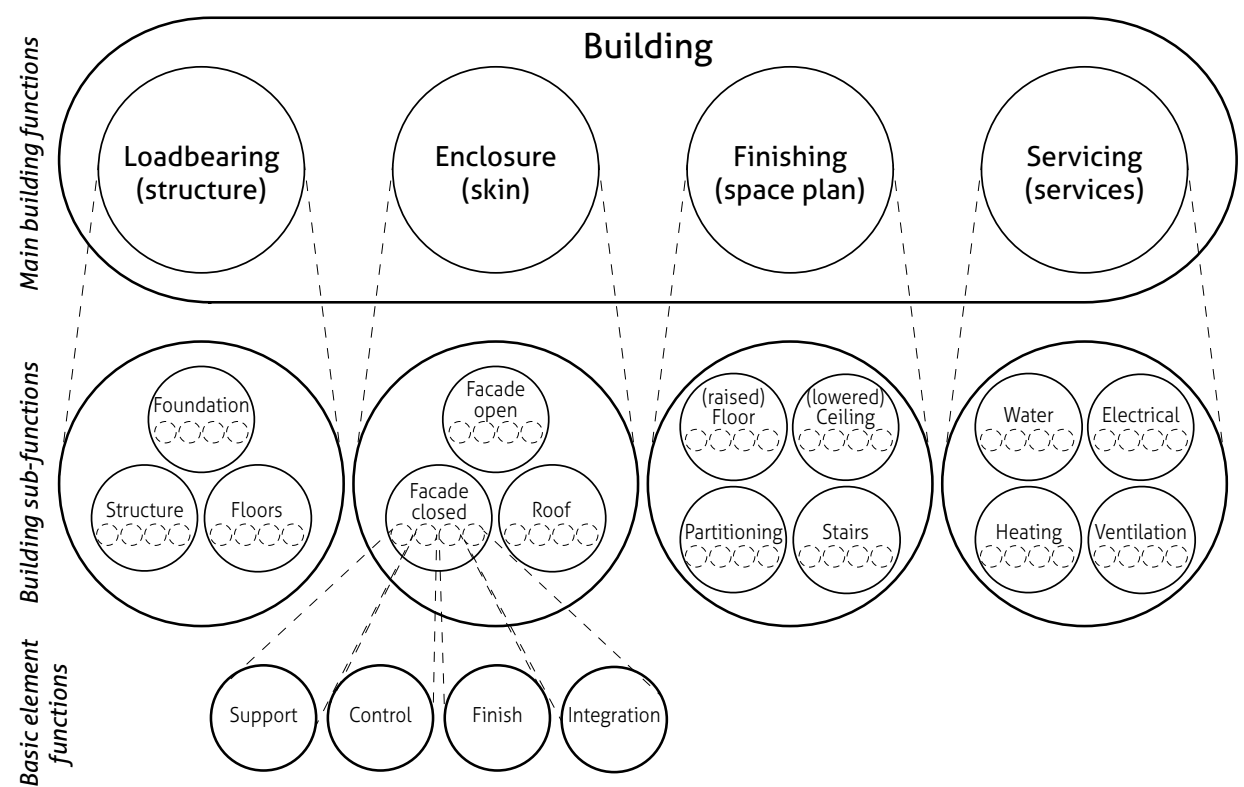

Figure 2.04: Functional decomposition of a building (based on Durmisevic, 2006, and Deniz \& Dogan, 2014)

In addition to the functional decomposition, the relation between functional decomposition and the physical decomposition - the integrity of the building products and their interfaces are essential, because they will determine the effort that is required to perform the changes and the potential to reuse the parts that will become available for reuse.

Building upon Durmisevic (2006), who noted that change does not only rely on the functionality of an assembly and its use life cycle, but also on the technical life cycle of physical elements, thus identifying functional levels and physical levels of buildings. Durmisevic (2006) states that "each physical level within a building deals first with its own life cycle duality, and secondly with the fact that surrounding components may have different changing rates" (p.107). To be able to identify these physical levels, the technical composition of the building should be identified, which can be seen as the systematisation of all building parts according to their functionality and physical product levels. With the aim to define physical product levels entities that can be assembled and disassembled as one part, that correspond to one building sub-function and within the sub-function to one basic element function, to reduce the connectedness and interrelatedness between the different functions. Thereby reducing the effort required to accommodate the different technical and functional rates of change.

To provide guidance how functional levels correspond to physical entities, it is important to define the different type of products that can be distinguished as physical entities that can be disassembled and relocated at once and can reduce the complexity and connectedness of building products. Therefore, the hierarchy of physical building entities has been introduced, based on work of previous researchers (Bakx, Beurskens, Ritzen, Durmisevic, \& Lichtenberg, 2016; Durmisevic, 2006; Eekhout, 2016; Vibaek, 2011), and are defined as follows (Figure 2.05): 


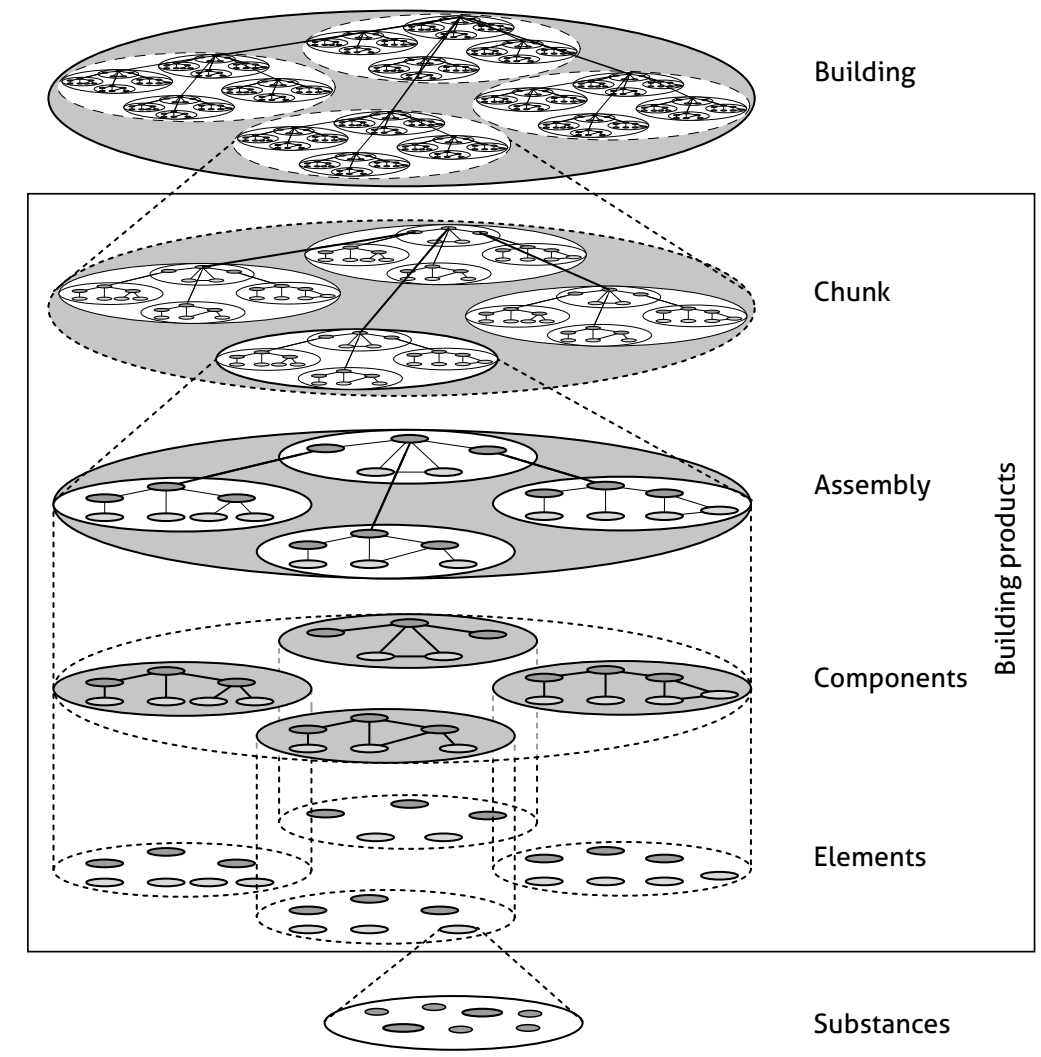

Figure 2.05: Hierarchy of physical building entities (based on Bakx, Beurskens, Ritzen, Durmisevic, \& Lichtenberg, 2016; Durmisevic, 2006; Eekhout, 2016; Vibaek, 2011)

Substance: is a raw material or particle in unprocessed state, which are often processed to create homogeneous or composite elements, e.g. sand, cement, clay, iron ore;

Element: is the smallest building product, which cannot be divided into smaller units without destructive disassembly methods, representing one basic element function;

Component: is a configuration of at least two elements that form an entity that can be assembled and disassembled at once, representing only one building sub-function and one or more basic element functions, e.g. a window frame, door frame or wall panels;

Assembly: is a configuration of at least two elements and form an entity that can be assembled and disassembled at once, representing at least two building sub-functions of the same main building function, e.g. a façade frame configuration of closed and open façade components.

Chunk: is a configuration of assemblies, components and elements that form an entity that can be assembled and disassembled at once, representing at least two main building functions, e.g. a volumetric module consisting of a structural frame component, a façade frame assembly and a partitioning wall assembly. 


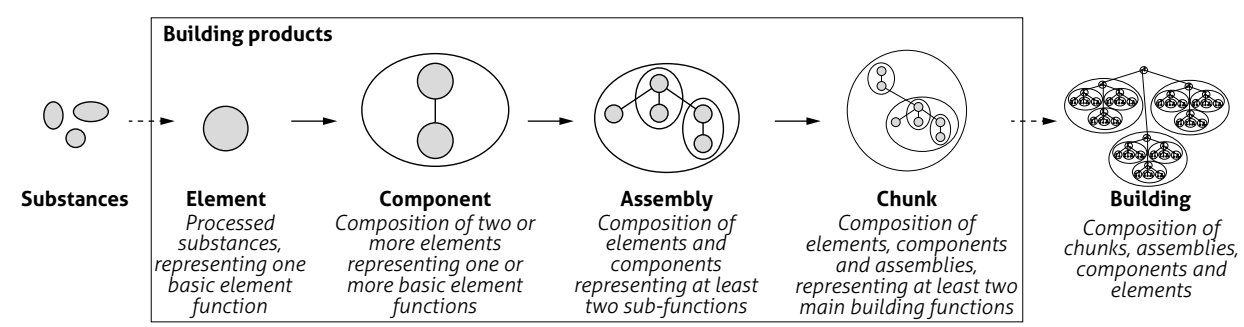

Figure 2.06: Hierarchy of physical building entities and their relation to the functional decomposition.

Building: represents the collection of all elements and/ or components, assemblies and chunks, which in most cases cannot be relocated without prior disassembly of its constituting products.

The hierarchy of physical building entities are defined as inclusive levels, whereby the higher level incorporates the lower levels. To further clarify the hierarchy of physical building entities, Figure 2.06 is added, whereby the schematic representation shows the minimum requirements for each level and their relation to the functional decomposition.

The lowest physical entities are substances and the highest physical entities are buildings, which have been separated from the building products that are defined in between, to indicate a difference in the characteristics of these levels e.g. substances are often not present in the building because of the transformation process in which the resultant is an element that often merges several substances and elements into one solid element, such as an in-situ concrete floor. Furthermore, the building as entity separates itself from the other entities by the (in general) inability to relocate the entire collection of products at once. When the term 'building product' is used, this refers to elements, components, assemblies and chunks.

\subsection{Reuse processes}

In the design realm of circular buildings two design methods can be distinguished: 1) the design of buildings that incorporate reclaimed building products, and 2) the design of buildings of which the products are designed to enable future reuse. For both methods it is important to understand the processes that are involved to enable the reuse of building products, which ultimately define whether or not a building product will be reused. Therefore, seven processes have been identified that characterise all resource flow strategies. Additionally, all seven processes have been related to typical process steps that may be required to enable each strategy, which are defined in Table 2.03 and visualised in Figure 2.07. Regarding the scope of this research emphasis is put on the processes related to slowing material flows.

To study the reuse potential of building products to enable slowing resource flows, four key processes have been identified that ultimately determine the effort that is required to perform reuse activities that affect the decision whether or not a building product will be reused:

Acquisition: Represents the process that is required to identify, inspect and select existing building products that could be used in 'new' building design. The timing of this process may vary broadly, as shown in Figure 2.07, it may depend on the context e.g. from before 
reclamation to after reclamation or after re-conditioning and is not limited to these three options;

Re-claim: Represents the non-destructive and careful disassembly, collection, separation and possibly sorting of unused building products with the aim to minimise the need for re-conditioning before re-application. In the case of closing resource flows, the reclamation process might as well comprise destructive disassembly, separation and sorting methods;

Re-condition: Represents all processes that may be required to bring the product to the demanded state for its new use or before re-application;

Re-apply: Represents the processes that are required to bring the product back in use, such as: performance tests, certification, market access, delivery, modification and re-assembly, to extend its product life.

In contrast to the current design practice, which Van Hinte, Jongert \& Peeren (2007) categorise as a goal-oriented design approach - whereby the architect designs a building according to a set programme for a certain location and relies on the abundant availability of materials, designers should move towards a means-oriented design approach - where the design starts from the means available - the available reclaimed building products, and tries to approach the less strictly defined goal. To move towards such a design approach, the first step, acquisition is key in order to identify unused (building) products that can be used to form new buildings. Gorgolewski (2017) identified eleven potential sources or methods that can be used to identify (building) products for reuse in the buildings, namely: database of reclaimed materials, buildings being demolished nearby, materials on the site, demolition contractors, salvage yards, exchange and sales websites, specialist brokers, industrial waste streams, infrastructure waste, clients' other buildings, reconditioned goods direct from supplier. Whether a building is designed to enable future reuse or to design buildings with reclaimed building products, eventually, in both scenarios designers need to embrace a means-oriented design approach and utilise those eleven potential sources in their design processes to enable circular material flows.

Table 2.03: Material flows related to strategies and coherent process steps

\begin{tabular}{|c|c|c|}
\hline Resource flows & Process & Typical process steps ${ }^{2}$ \\
\hline Narrowing ${ }^{1}$ & Optimise & $\begin{array}{l}\text { Extraction, harvest, manufacturing, market access, sale/ lease, } \\
\text { distribution, delivery, modification, assembly }\end{array}$ \\
\hline \multirow[t]{4}{*}{ Slowing ${ }^{1}$} & Acquisition & Identification, inspection and selection \\
\hline & Re-claim & Disassembly, collection, separation, sorting \\
\hline & Re-condition & $\begin{array}{l}\text { Maintenance, cleaning, (direct) reuse/ no change, reconfiguration, } \\
\text { repair, refurbish, redistribution, remanufacture and cascaded use }\end{array}$ \\
\hline & Re-apply & $\begin{array}{l}\text { Testing, certification, storage, stock-holding, market access, resale/ } \\
\text { lease, redistribution, delivery, modification and re-assembly }\end{array}$ \\
\hline Closing $^{1}$ & Re-process & Down-cycling, functional recycling, upcycling, biodegradation, cascade \\
\hline Leaking & Eliminate & $\begin{array}{l}\text { New process technologies, adapted product design, policies that } \\
\text { minimise and eventually eliminate leaking resource flows }\end{array}$ \\
\hline
\end{tabular}

${ }^{1}$ Narrowing, slowing and closing resources flows are adopted from Bocken et al. (2016, p. 309): ${ }^{2}$ the defined typical process steps for eacht material flow have been identified based on: Gorgolewski (2017); Allwood et al. (2011), Cooper \& Gutowski (2015). 
The second step re-claim identifies the effort that is required to retrieve the building products, which is mainly determined by the technical ability to disassemble the parts without damaging them, with the aim to minimise the need for re-conditioning before re-application. The incorporation of design for disassembly strategies can facilitate in effective building deconstruction at the end-of-its service life, to ease the reclamation of building products and enable direct reuse of building products.

The third step re-condition identifies the effort that is required to bring the product to the demanded state for its new use, with the aim to keep the re-conditioning effort to a minimum. As a guiding principle in circular design, Walter Stahel (2010) introduced the inertia principle: "Do not repair what is not broken, do not remanufacture something that can be repaired, do not recycle a product that can be remanufactured. Replace or treat only the smallest possible part in order to maintain the existing economic value of the technical system"(p.195). Den Hollander et al. (2017) noted that in order to conform to this principle the product integrity - "the extent to which a product remains identical to its original (e.g., as manufactured) state, over time [...] or in a state as close as possible to their original product, for as long as possible"(p. 519), is essential to minimise or even eliminate environmental impact when performing re-conditioning actions to preserve or restore the product's added economic a value over time. In the context of the physical building product levels it would be best to keep the product integrity of each level as high as possible when reusing a building product, to reduce the environmental impact to a minimum and maintain their value as much as possible.

The fourth step represents the effort that is required adjust, modify and assemble the product in its new context, including the effort to bring the product in compliance with regulation and warranty standards, which might be required to allow re-application.

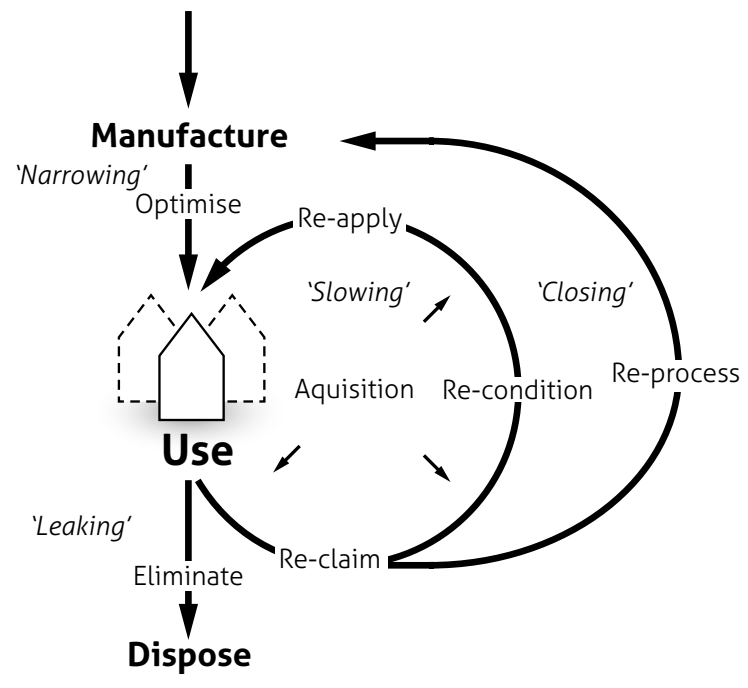

Figure 2.07: Resource flow model with specified approaches per resource flow, defining the four essential steps to support slowing resource flows 
The design approach that is used to design buildings using reclaimed building products can have a detrimental effect on the product integrity of the products and their re-conditioning effort that is required to apply the reclaimed products, which ultimately impacts the environmental benefit of reuse. Although, building design is never entirely means-oriented or goal-oriented, but rather a bit of both, the emphasis on means-oriented design is important (Van Hinte et al, 2007; Gorgolewski, 2018). For example, a design that is derived upon the reclaimed building materials is more likely to take full benefit of the reclaimed building products than a design that is forced to incorporates reclaimed building products.

Based on the analysis of metal component reuse Cooper \& Allwood (2012) identified two key factors that affect the type of reuse that may occur, 1) the performance of the product (parts), being the state and efficiency with which the product (parts) completes the function (to determine the amount of re-conditioning that is required to reuse the product, e.g. superficial reconditioning or extensive reconditioning), and 2) the demand for the function it provides. When demand is high, the product is likely to be applied close to its original state and have the least environmental impact, while in the situation of low demand, the product may be transformed or cascaded into the desired functionality, with the result of an increased environmental impact.

For reuse to occur there needs to be sufficient supply and demand for reclaimed building products. Sufficient supply is necessary for the designer to select reclaimed building products whose means match the requirements of the design and keep the product integrity as high as possible. To unlock the full potential of the reclaimed building products, the designer should seek to match the product characteristics with their design requirements and avoid over-capacity and conflicting requirements to a minimum. In Figure 2.08, three scenarios are shown that describe the relationship between the product characteristics and the requirements, whereby the designer should seek to comply the product characteristics with the requirements as much as possible. To exemplify the effect when product characteristics are not properly matched with their requirements. Lazarus (2003), describes that steel beams

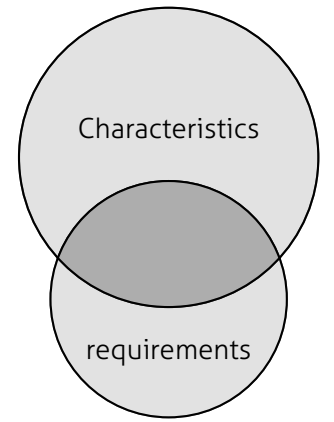

a. Product characteristics do not comply with requirements

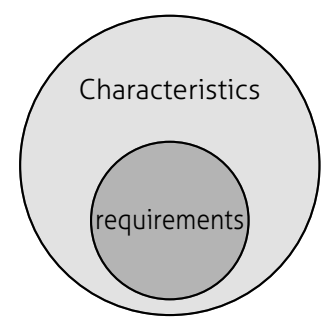

b. Product characteristics exceed the requirements

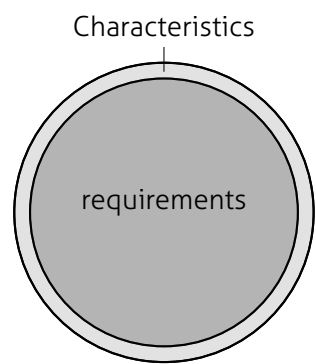

c. Product characteristics comply with requirements

Figure 2.08: Relationship between product characteristics and requirements, adopted from Meijs, \& Knaack, (2012) 
are often reused under the conservative assumption that they were made from the lowest steel grade, because of the absence of material specification. This can however require larger foundations and supporting structures to support oversized beams, amplifying the environmental impact because of exceeding product characteristics (Cooper \& Gutowski, 2017). One of the aspects that is of great importance to guarantee an environmental benefit when reusing building products, is to properly match the product characteristics of reclaimed building products with the requirements.

\subsection{Reuse changes}

In this research the term 'reuse' is used as a general term defined as: 'the subsequent use of a product or material after its first and further life', with the main focus on the reuse of building products, the constituents of which a building is composed, rather than the reuse of building materials. Since, the aim of this research is to support high quality product reuse in which all embodied values (materials, labour, energy and economic capital) are preserved, instead of destroyed by recycling or even down-cycling materials, to enable reuse for the construction of new buildings.

The 10R-imperatives are often used as an operationalisation principle of the circular economy, while the direct relation between the 10R imperatives and building product reuse is rather ambiguous. Because a building should be considered a collection of parts, which can be identified according to the physical building product levels, e.g. elements, components, assemblies and chunks, the reuse of each part might require a different or even a multitude of R-imperatives. This makes it impossible to classify the reuse of building products according to the 10R-imperatives as was introduced and also pointed out by Reike et al. (2017). Additionally, the 10R typology overlaps in their actions that are performed for each R-imperative. To give an example, Reike et al. (2017) describe the key activities of a customer for R2: resell/ Re-use to be "buy 2nd hand, or find buyer for your non-used produced/possibly some cleaning, minor repairs", while the key activities of a customer for R3: repair was described as "making the product work again by repairing or replacing deteriorated parts". With building products that performs a static function such as a structural column, makes the distinction between minor repair and repair or replacing deteriorated parts ambiguous and unclear.

To overcome this ambiguity an overview is made that clearly identifies the different types of physical changes that may be performed to support product reuse, as shown in Table 2.04. This overview expands upon the research of Allwood, Ashby, Gutowski \& Worrell (2011), who mainly focused on element level changes. The proposed table expands into component, assembly and chunk level change and three additional types of change are idenitified, namely: configurative-, substitutive- and dividing changes. While the reuse of building products may encompass a combination of reuse changes before its actual re-application, this overview provides clear distinction between the different changes that may be required before its re-application. Additionally, it is important to note that reuse changes that irreversibly change the product at element level, may eventually have a cascading effect on the product value, such as deformative, subtractive, dividing, and destructive changes. 
Table 2.04: Types of product changes to support reuse (types of change adopted from Allwood et al. (2011, p.371), are indicated with the asterisk sign).

\begin{tabular}{|c|c|c|}
\hline Element level changes & $\begin{array}{l}\text { Component, assembly and } \\
\text { chunk level changes }\end{array}$ & \\
\hline processed state & Initial state processed state & Types of product change for reuse \\
\hline & & $\begin{array}{l}\text { a) No change*: } \\
\text { The product is transferred from one } \\
\text { application to another }\end{array}$ \\
\hline & & $\begin{array}{l}\text { b) Superficial change*: } \\
\text { Changes are made to the surface of } \\
\text { the product only, e.g. cleaning of an } \\
\text { element }\end{array}$ \\
\hline & & $\begin{array}{l}\text { c) Configurative change: } \\
\text { The arrangement of existing products } \\
\text { in a way to create a new product or } \\
\text { adapted product, using demountable } \\
\text { connections that do not affect the } \\
\text { integrity of the products. }\end{array}$ \\
\hline & & $\begin{array}{l}\text { c) Deformative change*: } \\
\text { Alterations are made to the form of } \\
\text { an element without addition or } \\
\text { subtraction of material substances, } \\
\text { e.g. bending of a metal part }\end{array}$ \\
\hline & & $\begin{array}{l}\text { d) Subtractive change*: } \\
\text { Products or substances of a lower } \\
\text { physical product level are removed } \\
\text { from the original product, e.g. partial } \\
\text { disassembly of a component or } \\
\text { sanding of an element } \\
\end{array}$ \\
\hline & & $\begin{array}{l}\text { d) Substitutive change: } \\
\text { A product is replaced by a different } \\
\text { product, e.g. the replacement of a } \\
\text { defective or unrepairable part }\end{array}$ \\
\hline & & $\begin{array}{l}\text { g) Dividing change: } \\
\text { One or more elements are cut into } \\
\text { two or more parts, forming two or } \\
\text { more products, with or without } \\
\text { leftover parts }\end{array}$ \\
\hline$\underset{\text { or }}{\longrightarrow}$ & & $\begin{array}{l}\text { i) Formative or additive change*: } \\
\text { Joining or combining multiple material } \\
\text { substances that are treated in such a } \\
\text { way to change their composition in } \\
\text { order to create or repair a product, or } \\
\text { even merge elements or components } \\
\text { into a fixed product, e.g. the } \\
\text { production of a prefab concrete blocks } \\
\text { using in-situ concrete or welding } \\
\text { elements together. }\end{array}$ \\
\hline 0 & $\Omega$ & $\begin{array}{l}\text { h) Destructive change*: } \\
\text { Breaking a product down into its raw } \\
\text { material substances so it can be } \\
\text { reused as raw materials in production } \\
\text { processes or the destruction of locked } \\
\text { parts to reclaim reusable products }\end{array}$ \\
\hline
\end{tabular}




\subsection{Reuse design typology}

The situations in which reuse occurs are diverse and are often characterised based on criteria that best describes its type of reuse, such as the origin of the reused part, e.g. constructional product reuse, non-constructional product reuse (Van Hinte et al., 2007; Gorgolewski, 2018), the destination, e.g. in-situ reuse or relocated reuse (Tingley, Cooper and Cullen, 2017; Gorgolewski, 2018; Addis, 2006), the type of recovery method that was used to enable the reuse of the product, e.g. repair, refurbishment, remanufacturing, recycling (Geldermans, 2016), the type of product that is reused, e.g. primary structure, building envelope, services (Gorgolewski, 2018; Geldermans, 2016) or the type of products level, building reuse, system reuse, component reuse, or element reuse (Tingley et al., 2017; Gorgolewski, 2008). Each of these categorisations serve their own purpose, for example, the distinction between in-situ reuse and relocated reuse provides a good understanding of the different processes that have been necessary to enable its reuse. Relocated reuse is often much more costly and labour-intensive to achieve, because of the additional sourcing, design and logistical effort it requires. Although, despite the multitude of available categorisation in literature, a categorisation that provides a better understanding about the effect the selected reuse design strategies can have on the potential for future reuse lacks. Therefore, the aim of this section is to define a reuse design typology that provides an overview of different reuse design methods and their related reuse strategies, which can double as a reuse design framework to categorise reuse design solutions and reuse case studies, to provide a better understanding of the effect of their design solution on the potential for future reuse.

As already mentioned earlier, the design of circular buildings often encompasses two distinct design methods, namely the design of buildings that incorporate reclaimed building products, and the design of buildings of which the products are designed to enable future reuse. Therefore, the typology should not only address reuse of existing building products, but also incorporate the ability to enable future reuse. While there are big differences between the two design methods, e.g. the source of the materials that are used, there are also similarities, such as the potential to reclaim the (used) building products and enable future reuse, which in this case is the aim of the typology.

To provide a better understanding of reuse design methods, a reuse design typology is proposed that identifies four distinct reuse design methods, as shown in Figure 2.09. The reuse design typology is defined based on two important design characteristics, with on the $x$-axis the 'design intent' of the product and on the y-axis the 'type of configuration'.

The first design characteristic, 'design intent' is based on Shedroff (2009), who identified two types of reuse: 1) deliberate reuse, the reuse of products in a way it was intended for and expected to be used for, and 2) unintended reuse, the reuse of products in ways the designer could not have anticipated at in their initial design. This distinction is of major importance, since it allows the categorisation of reuse types in design strategies that could have been incorporated in initial design of (building) products and strategies that would not have been possible to incorporate in initial design.

To give an example, the existing building stock is often not designed to enable easy reclamation and reuse, which poses many unintended reuse opportunities to extend their functional life. It 
should be noted that unintended reuse opportunities often convey a certain level of cascading and degradation of the product integrity and their embodied product values, which often cannot be undone. While deliberate reuse strategies aim at the reuse of products as it was initially designed for. Design strategies that can facilitate deliberate reuse are: design for disassembly, design for adaptability and design for manufacture and assembly (lacovidou \& Purnell, 2016). All these strategies are aimed at supporting the designer or architect in designing the building and its parts to enable future deconstruction and reuse in either a similar configuration and functionality or even in different configurations and possibly different functionalities. In the typology matrix, deliberate reuse is termed by 'design', as it is designed for and unintended reuse by 're-design', since it requires modification of the original design intent.

The second design characteristic, 'type of configuration' is based on Schulitz (1996), who identified two types of configurations: 1) indeterminate configurations, which implies a design that is configured as an open hierarchical system of building products, which can form an indefinite number of configurations and can be replaced independently, whereby disassembly and reuse do not require alteration or destruction of any element, and; 2) determinate configurations, which implies a design whereby elements and components are combined in such a manner that they are determined for a specific location and function and form a rigid and more or less unchangeable object.

Building products that can be categorised as indeterminate configurations are products that allows for multiple life cycles and support reuse, while building products that classify as determinate configurations are designed with a disregard to the end of functional life and are designed with only one life cycle in mind, which is still the dominant design method in conventional construction. Therefore, if a building product is designed conform a determinate configuration, the design is termed 'conventional', and if a building product is designed conform an indeterminate configuration, the design is termed 'reversible'.

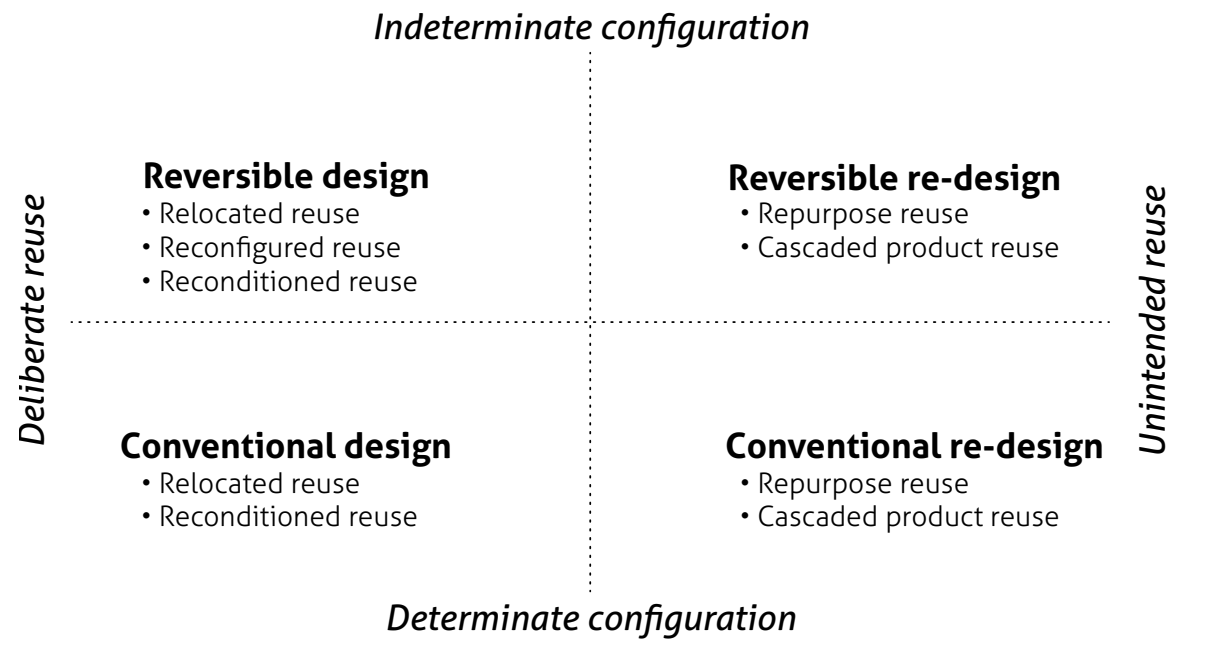

Figure 2.09: Building product reuse design typology, characterising four distinct design methods, based on design intent and type of configuration, and their related reuse strategies. 
The combination of both design characteristics resulted in four reuse design methods as shown in Figure 2.09, with a focus on building products. These design methods can be used to, either categorise new building product designs or building product designs with reused building products:

Reversible design Represents the design of building products that are configured as indeterminate structures that are intentionally designed to enable multiple applications and configurations, by utilizing non-destructive disassembly methods to preserve its product integrity and maintain their value through life, resulting in a design that supports a continuous product life extension.

Reversible re-design Represents the alteration of existing building products in such a way that their new design surpasses their initial design intent and forms an independent structures that is intentionally designed to enable multiple applications and configurations, by utilizing non-destructive disassembly methods its product integrity is preserved to maintain their value through life, resulting in a design that supports a continuous product life extension.

Conventional design Represents the design of building products that are designed for a specific functionality and integrated in a building forming a dependent structure that does not allow for reuse or reconfiguration without alteration or destruction of some of their parts, thereby always incurring some sort of cascading or reconditioning before re-application, resulting in design that ultimately limits its product life.

Conventional re-design Represents the alteration of existing building products to suit a specific location and functionality for which the product was not designed and is integrated in its new context as a dependent structure that does not allow for reuse or reconfiguration without alteration or destruction of some of their parts, thereby always incurring some sort of cascading or reconditioning before re-application, resulting in a design that ultimately limits its product life.

In addition, based on the research of Cooper \& Gutowski (2015), Gorgolewski (2018), lacovidou \& Purnell (2016), Tingley et al (2017) five reuse strategies specified for buildings have been defined and related to distinctive reuse strategies. To further clarify the scope of each strategy, they have been related to the different types of product changes that can be performed to support reuse, as shown in Table 2.05:

Relocated reuse Is a design strategy that enables the product life extension of (building) product by moving it to a different context, e.g. in its original building (in-situ) or outside the original building (ex-situ), whereby the product integrity is maintained as much as possible.

Reconfigured reuse Is a design strategy that enables the product life extension of (building) products by changing the configuration of some or all of the elements, to meet changing demands, the product integrity of the product is modified, while at element level the integrity of each product is maintained.

Reconditioned reuse Is a design strategy that enables the product life extension of (building) products by bringing the product back in a; working-, as new-, or even improved state, while maintaining the same functionality. 
Repurpose reuse Is a design strategy that enables the product life extension of (building) products for a different function than it was originally intended for, while keeping the amount of physical product changes to a minimum.

Cascaded reuse Is a design strategy that enables the product life extension of (building) products for a different function or in a different form than it was originally designed, by altering or destroying some of their parts reuse in its new form is supported.

In addition to cascaded reuse, a sub-strategy of cascaded reuse has been recognised based on recent reuse examples, such as the 'Resource rows project', as shown in Figure 2.17. The reuse strategy is aimed at supporting the reuse of so-called 'high-volume - low value' products that were initially not designed to be reused and were not considered as potential future resources due to their low value, while their high volume allows for businesses to take benefit of economies of scale. The strategy is termed post-modularisation, because the modularisation is applied as an afterthought, to increase their application range and thereby supporting the reuse at large scale and overcome the low value barrier:

Post-modularisation reuse Is a design strategy that is aimed at the reuse of 'high-volume low value' building products that were initially not designed to be reused, while by altering the product into smart modular dimensions and taking the benefit of economies of scale, versatile products can be identified, which may ultimately result in re-designed building products that allow for continuous product life extension.

Some reuse design strategies have been identified to support reversible design methods and conventional design methods. The distinction whether the building product can be considered as reversible or conventional is mainly determined whether the product can be disassembled without damaging its parts. Thus, the type of reuse strategy and its product changes that have been performed to support reuse might be the same, but the outcome for future reuse is different based on the integration of the product in its new context. Finally, to support closing material flows, reuse strategy re-process has been added in Table 2.05.

Table 2.05: Reuse strategies related to the types of product changes it may convey

\begin{tabular}{|c|c|c|c|c|c|c|c|c|c|c|}
\hline \multirow[b]{2}{*}{$\begin{array}{l}\text { Physical building } \\
\text { product levels }\end{array}$} & \multirow[b]{2}{*}{ Reuse strategies } & \multicolumn{9}{|c|}{ Types of product change for reuse } \\
\hline & & 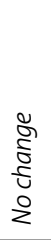 & 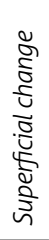 & 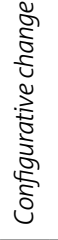 & 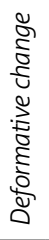 & 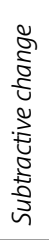 & 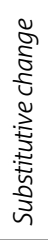 & 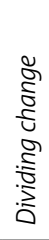 & 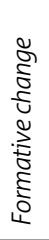 & 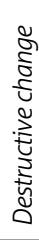 \\
\hline Products & Relocated reuse & $x$ & $x$ & & & & & & & \\
\hline Products & Reconfigured reuse & $x$ & $x$ & $x$ & & & & & & \\
\hline Products & Reconditioned reuse & & $x$ & $x$ & $x$ & $x$ & $x$ & $x$ & $x$ & \\
\hline Products & Repurpose reuse & & $x$ & $x$ & $x$ & $x$ & $x$ & $x$ & $x$ & \\
\hline Products & Cascaded product reuse & & $x$ & & $x$ & $x$ & $x$ & $x$ & $x$ & \\
\hline Substances & Re-process & & & & & & & & & $x$ \\
\hline
\end{tabular}




\subsection{Reuse design framework}

The combination of reuse strategies and their integration in its new context can have a major effects on the potential to reuse the product in the future. To give an example, a reversible design by itself does not guarantee indefinite reuse possibilities, because the product might be integrated in a building using methods that limit their reversibility and thereby lock their potential to reuse the product in the future without damaging the product. This may be considered the integration of a reversible design in a way it was not intended to be reused, which can be seen as the re-design of the product in a conventional manner, compromising the potential to reuse the product without damaging its parts in the future. Therefore, e.g. with reversible designs it is important to keep their reuse within their application range, reuse them in ways it was intended to be used, and prevent its new application and integration from compromising its potential for future reuse.

To provide an understanding of the different transformations a reused product can undergo and understand the effect of their design solution on the potential for future reuse, the product reuse design typology has been transformed into a reuse design framework by adding the possible transformations a product can undergo depending on the reuse strategies and its integration in its new context, as shown in Figure 2.10 with the arrows. This framework allows the categorisation of initial design and reuse design solutions to make the designer conscious about the effect of their reuse design solution on its potential for future reuse.

To start, every building product may be categorised as a reversible design or a conventional design. Sequentially, based on the type of reuse strategies that have been used to support reuse, its reuse design solution can be identified as one of the four design methods, which identifies the type of transformation the product has undergone. For example, for a reversible design to preserve the product integrity and keep the product as close as possible to its initial use, the reuse application should stay within its deliberate reuse options, while for a conventional design it might be worth investigating the opportunities to transform the product into a reversible re-designed product that allows future reuse options without damaging its parts. Once a conventional design is transformed into a reversible re-design by its reuse design solution, and the product will be reclaimed and reused in the future, the re-design is its starting point and thus can be defined as the reversible design. In this situation the new defined reversible design can be reused within its own deliberate reuse solutions and stay a reversible design or become again re-designed into either a conventional or reversible manner, which makes the process of reusing products a continuous process. Every time the reuse strategy and its integration in its new context defines the ability of the product to be reused without damaging its parts. The preferred reuse strategy would off course be the solution that keeps the product as close as possible to its original design solution to minimise the additional processes that are required to reuse the product, thus keeping the additional environmental impact as low as possible. 


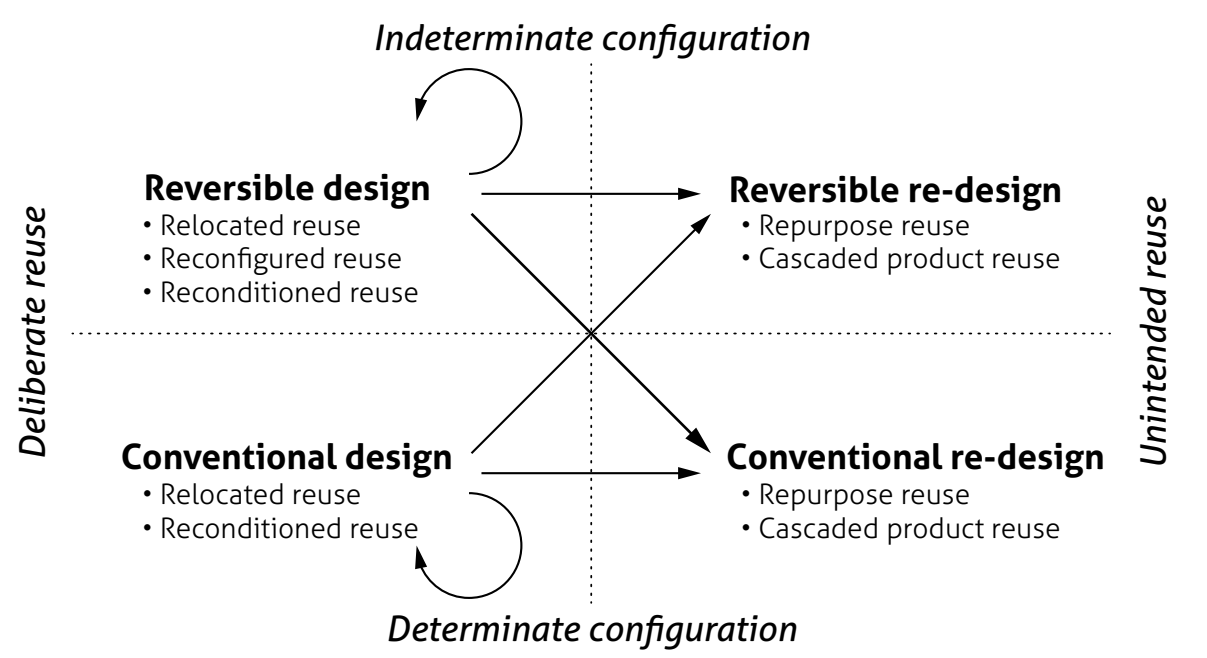

Figure 2.10: Building product reuse design framework, characterising four distinct design methods, based on design intent and type of configuration, and their related reuse strategies and identifying how their characteristics can change based on their reuse application.

To clarify the building product reuse design framework, reuse examples from practice are used to describe the six different transformations that may occur when reusing building products.

\section{Reversible design remains reversible design after reuse}

The reuse of building products in ways they were intended for to be used will keep their product integrity, maintain their product value and enable future product life extension without affecting the product's value.

An example of such a product life extension is the 'Circular module' that is designed as part of the Green Transformable Building lab in Heerlen (Figure 2.11), which is one of the pilot project of the Buildings As Material Banks project (Goens et al., 2018). The project demonstrates how building functions can be separated into independent
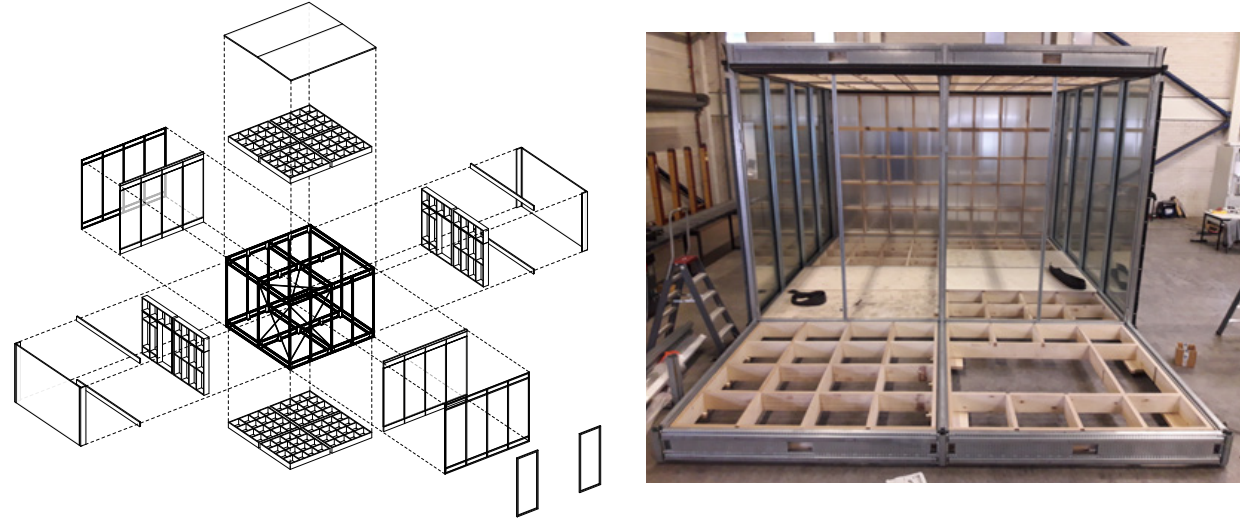

Figure 2.11: Green transformable building lab-Circular module (Capelle et al., 2019) 
and exchangeable sub-assemblies, in which demountable intermediary connections support the reuse and reconfiguration of its parts without damaging them. The module is dimensioned based on a modular grid of $2,4 \times 2,4 \mathrm{~m}$ to support exchangeability and multifunctionality of parts, e.g. the floor assembly can be used as a wall assembly. The steel structure is based universal steel profile that utilises a generic geometry to support the standardisation of demountable primary- and secondary connections. The Circular module demonstrated one successful transformation, whereby a part of the facade was disassembled and reused as floor cassette to enable the extension of the module without the creation of any waste or damage to parts. This example resembling the deliberate reuse of an indeterminate configuration, whereby a reversible design remains a reversible design after reuse.

\section{Reversible design becomes reversible re-design after reuse}

The reuse of building products in ways they were not intended to be used for, represents the re-design of a product that can be considered a reversible design into a reversible re-design. As Cooper \& Allwood (2012) determined, if there is no demand for the function a product provides, but wants to reuse the product, one may decide to transform or re-design the product into a product for which a demand exists. In this case the re-designed product is an indeterminate configuration that allows the product to be reclaimed and reused without damaging its parts.

To give an example Rotor Deconstruct, a company that facilitates in the reclamation and reuse of construction materials, reclaimed laminated timber beams from an old warehouse that was to be demolished. The laminated timber beams could easily be disassembled by detaching the nuts and bolts and support direct reuse to keep the product as close as possible to its original functionality. Instead, Rotor Deconstruct decided to divide them in similarly sized parts of 5-7m to support reuse as table tops and kitchen counters, because there is a know demand for such products (Gielen, 2018). As they stated, the direct reuse of a laminated timber beam would impose too much of a risk to their business, because it would require them to perform costly transportation of large elements, overcome structural performance and insurance issues, while not knowing if there is a demand for this dimension of laminated beams (Gielen, 2018). In this example the decision was made
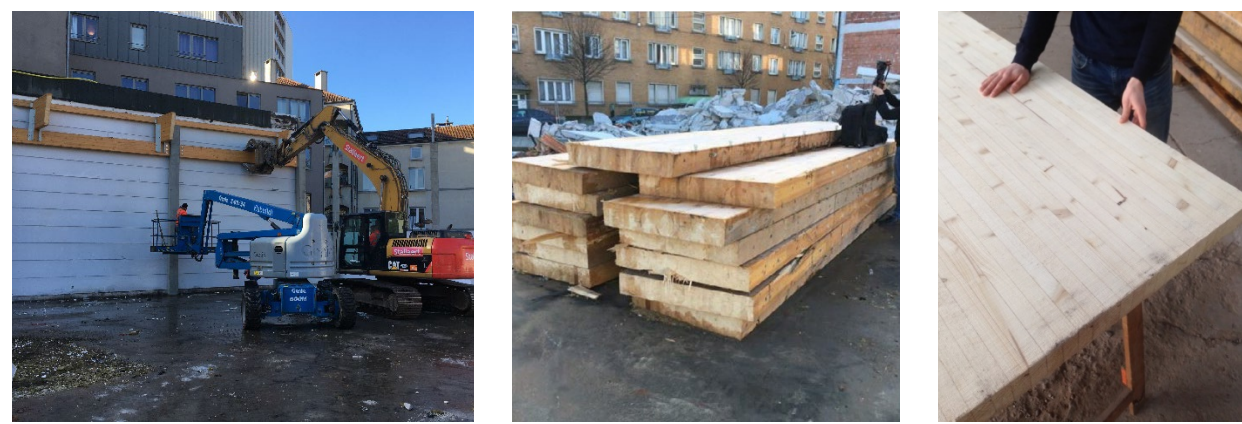

Figure 2.12: Left to right) reclamation of laminated timber beams, reclaimed beams cut in reusable parts, beams finished as table tops (RotorDC, 2018) 
to change the function of the reclaimed building product in order to increase the sales potential and overcome barriers that would prevent its reuse when seeking to reuse the reclaimed product in a similar functionality.

It should be noted that the change in functionality from structural element to interior furniture can be seen as a degradation in functionality, which cannot be undone. Although, the new functionality as a table top can be considered a reversible re-design, which will extend the product life of the timber parts. Cooper $\&$ Gutowski (2015) state, to guarantee environmental benefits of reusing products, the reused product must displace sales of new products. In this example the reuse of laminated timber panels will not displace new production of virgin materials for laminated timber beams, but the need of virgin materials for table tops and kitchen counters. It might be argued that a table top does not require structural laminated timber. Therefore, one should always be cautious in the re-design of products to support reuse and be aware of the effect it has on the demand for virgin materials. While the reuse of laminated timber beams as table tops and kitchen counters is still better than incineration for energy recovery.

\section{Reversible design becomes conventional re-design after reuse}

The reuse of building products in ways they were not intended to be used for, represents the re-design of a product that can be considered a reversible design, but in this instance into a conventional re-design, which does not allow the product to be reclaimed and reused without damaging its parts.

\section{Conventional design remains conventional design after reuse}

The reuse of building products in ways they were intended to be used for, while the initial design does not allow for reclamation without alteration or destruction of some of their parts and thus requires some degree of reconditioning before reuse, its reused design also lacks the ability to reclaim the parts without alteration or destruction of some of their parts.

To give an example, in the REBRICK project a patented technology was developed to allow bricks, with a low-to-modest cement content in the mortar, to be cleaned, separated (full bricks from broken or damaged bricks) stacked and wrapped in an automated process at a competitive price (Gamle Mursten, 2018), as shown in . This technology enables the reuse of
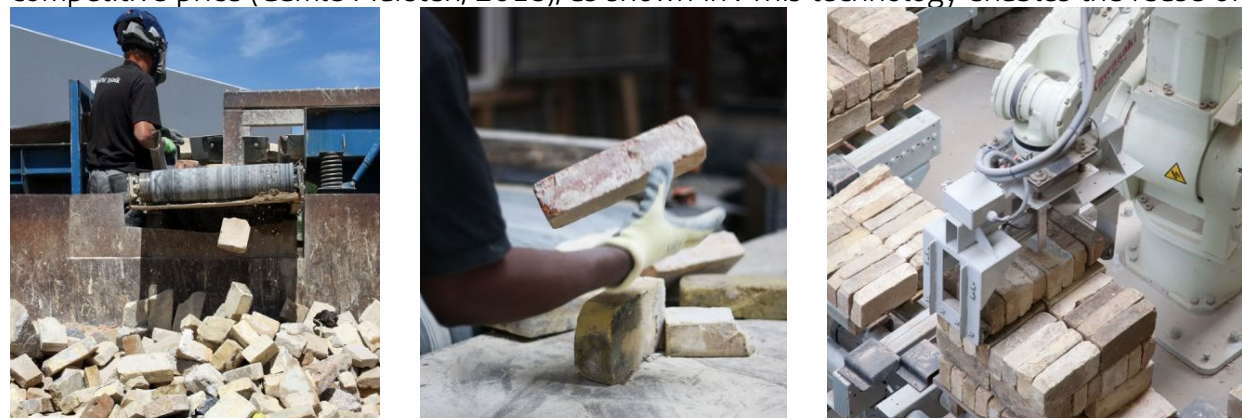

Figure 2.13: Rebrick process, (Gamle Mursten, 2018) 
bricks that would otherwise be demolished, crushed and recycled as aggregates, destroying all their embodied values. In the REBRICK project the bricks are brought back to its original state and functionality to allow reuse as if they were never used. While to ensure the reuse in the future, it is important that low-to-modest cement content in the mortar is used, otherwise it would not be possible to reuse them again. The reuse application can however still be called conventional design, because reuse application may still render certain bricks ,to become broken or damaged, unable to be reused after its second life extension.

Another example of a conventionally designed building of which the building products have been reused in a conventional manner is the adaptive reuse project of the Sala Beckett building in Barcelona, Spain by Flores \& Prats Architects. The original building was Barcelona's Old Peace $\&$ Justice Cooperative Building from the 1920s, which was left to decay and in a ruinous state. While on the inside of the building a number of decorations and architectural features were preserved in its walls, roof and floors, from its former glory (Flores \& Prats, 2018). To preserve the history and cultural value of the building, the architects started with an extensive survey to document the existing situation and inventory all building features such as doors, windows, flooring and stairs the building contained. All building features have been carefully studied and modelled to perform design studies, how all building features could best be integrated in its new design, as shown in Figure 2.15. All building features have been carefully reclaimed, restored, repaired and are reused in a 'reconfigurative' manner to serve the needs of the new theatre, while maintaining the history and cultural value. Often the elaborate process of reclaiming and restoring main building elements to bring them to an as new state to extend their functional life is economically not viable due to the high labour costs in developed economies and low prices of new building products. In this situation the embodied architectural, cultural and emotional value of those parts makes the building so unique, which are irreplaceable, which allows the additional costs to extend their product life.
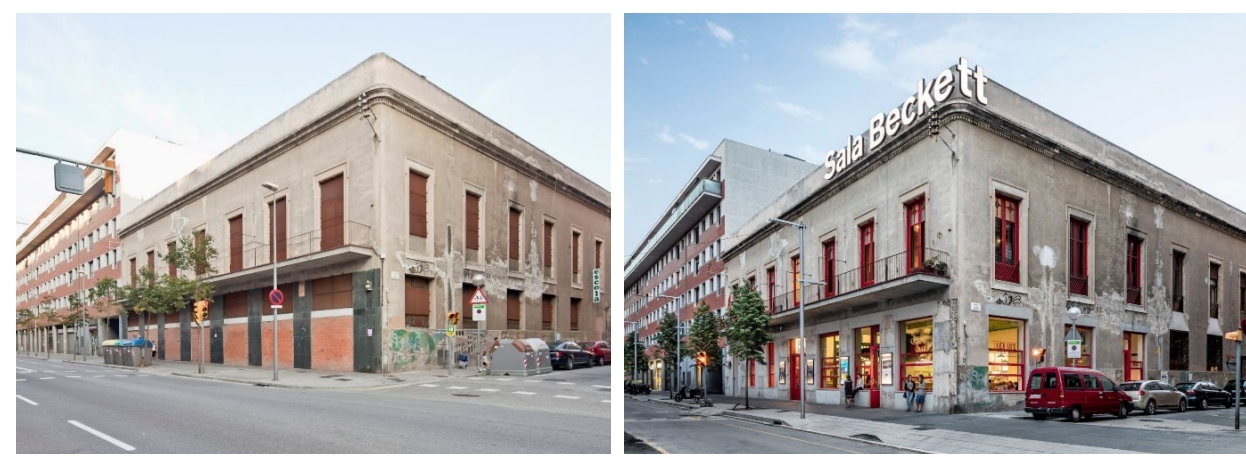

Figure 2.14: State of the Sala Beckett building before and after adaptive reuse (Flores \& Prats, 2018).
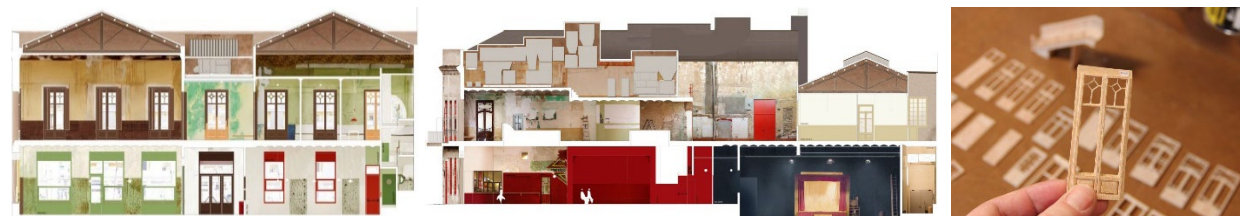

Figure 2.15: Documenting the existing situation and inventorying all building features (Flores \& Prats, 2018). 


\section{Conventional design becomes reversible re-design after reuse}

The reuse of building products in ways they were not intended to be used for, whereby a product is being re-designed that was considered to be a conventional design into a reversible design, which will allow the product to be reused and reconfigured in the future, without damaging its parts .

The reuse strategy cascaded reuse is often used to transform building products from conventional design into a reversible re-design, whereby the sub-strategy post-modularisation was recognised as a strategy to support economic reuse of low-value high volume building products. Two examples will be given to exemplify this strategy: 1) the SUPERLOCAL project in Kerkrade, The Netherlands and; 2 ) the resource rows project of the Lendager Group in Orestad, Denmark.

The SUPERLOCAL project is an experimental urban redevelopment in which three obsolete social housing blocks with over 400 dwellings are being dismantled to develop approximately 125 new dwellings on location. Their aim is to reuse as much materials of the 50 year old concrete apartment blocks as possible, to support the transition towards a circular economy (Superlocal, 2018). In this project new deconstruction methods are being explored, in which the apartment blocks are being cut into modular concrete units, which will be used to build new dwellings. Additionally, existing building products such as doors and window frames will also be reused in the new dwellings. This new approach challenges the status quo of the end-of-life treatment of monolithic in-situ concrete apartment buildings, which are usually referred to as static structures that do not contain any potential to be reused at high quality. While this alternative approach to mechanical demolition allows parts of the building to be reused at high quality and extends their
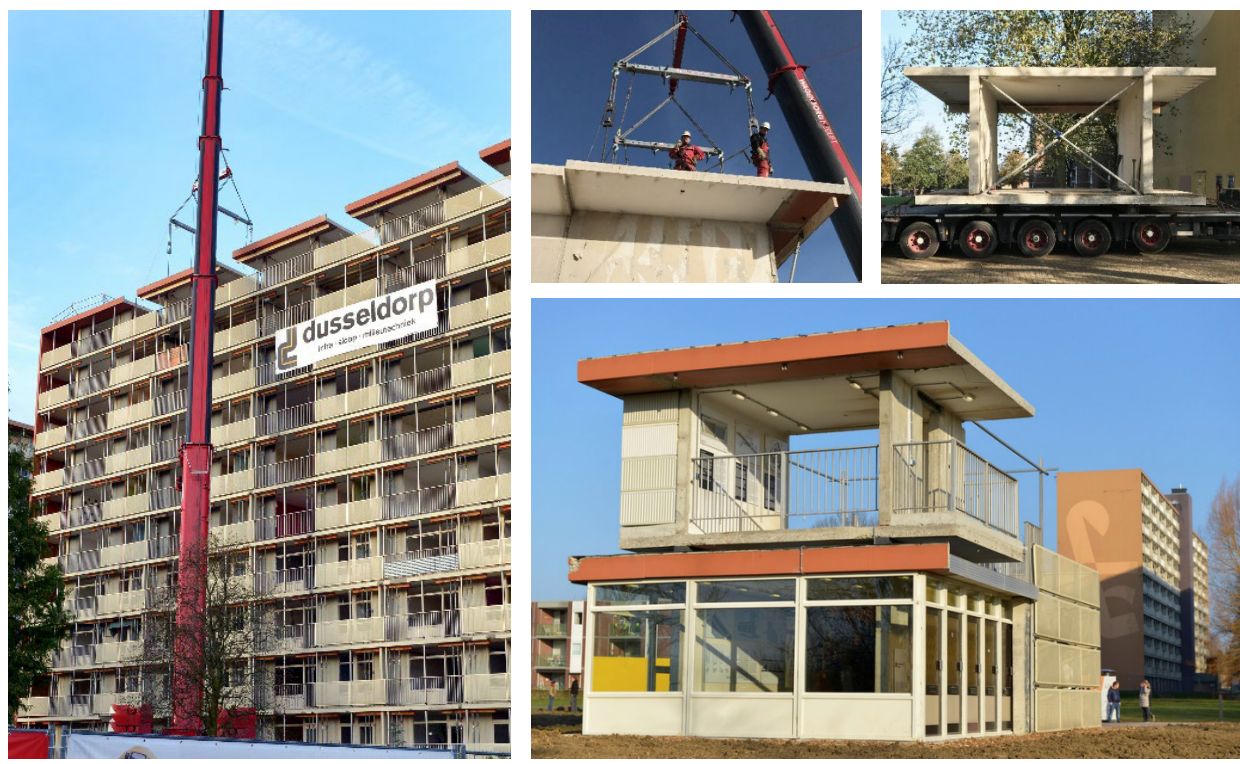

Figure 2.16: Extraction of modules from the apartment blocks, which are reused in the demonstration project, SUPERLOCAL Pavilion (Maurer United Architects, 2018) 
functional life. In this research this reuse strategy is referred to as post-modularisation, whereby the re-design of existing building products that were designed as conventional products are being transformed into modules that thereafter allow for future reuse without altering or damaging them. However, it should be noted that this is a demonstration project and the used deconstruction method, cutting the building into concrete modules, would in the current economic climate not have been an economically viable alternative (Bruijns, 2018).

Another example of post-modularisation reuse is the resource rows project of the Lendager Group in Denmark. The Lendager group focusses on resource optimisation and upcycling of products, which they describe as: "the process whereby the value of waste materials is increased through the recycling process, ideally also creating a product with a longer lifespan than the original Lendager" (Lendager group, 2018a). In their resource rows project, a unique solutions was developed to allow the reuse of brick façades of abandoned rural homes into new building design in the cities. Often it is not possible to recover the actual bricks due to high cement content in the mortar. Therefore, they came up with the idea to cut the façades into sections and form new modular facade frames based on the brick sections. This will not only reduce the carbon footprint by the reuse of existing brick walls and displacing the need of brick production based on virgin resources, but also provide character and history to the new buildings (Lendager, 2018b). Additionally, the new modular facade frames will support the continuous reuse without damaging them, transforming the conventional brick application into a reversible re-design.
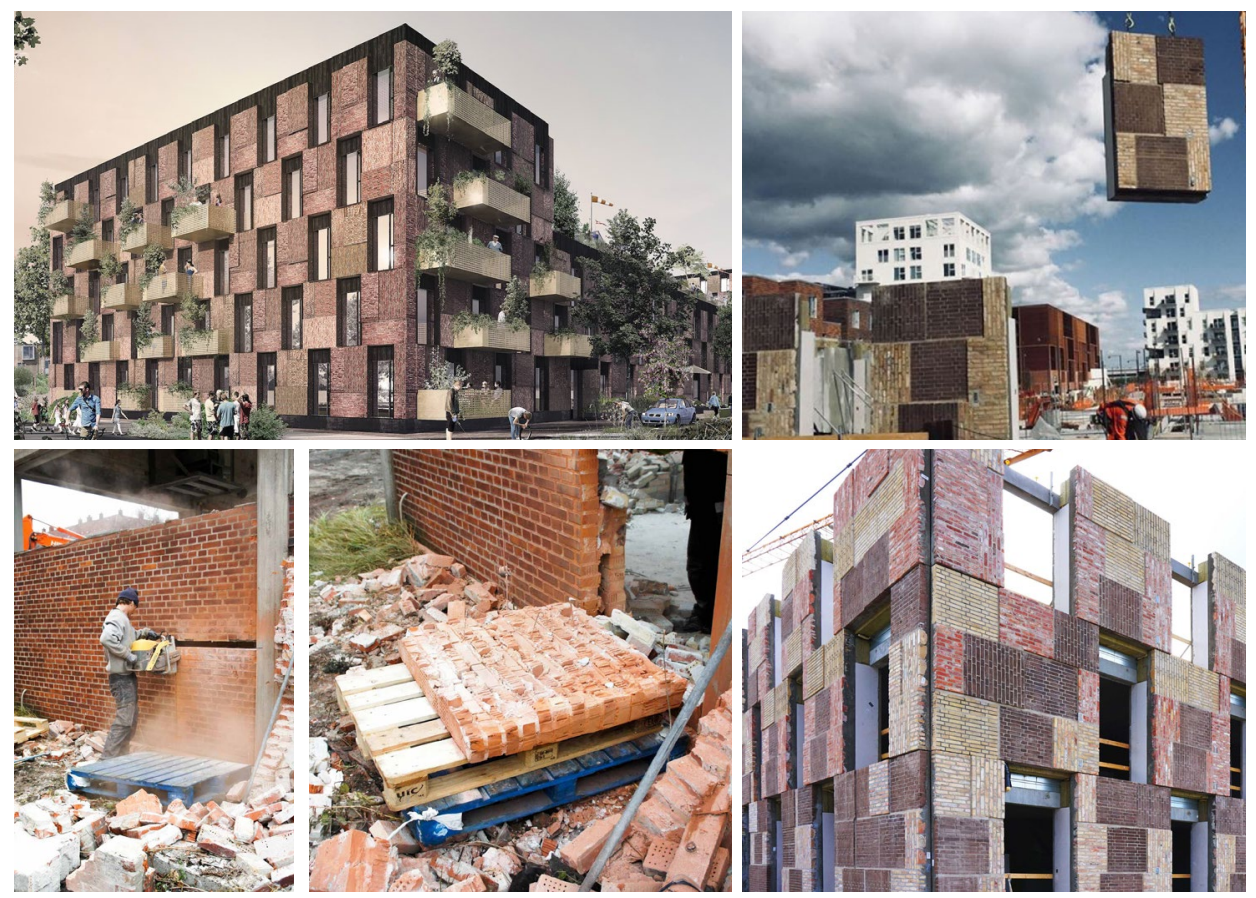

Figure 2.17: Resource rows project, from idea to realisation (Lendager group, 2018a, b). 


\section{Conventional design becomes conventional re-design after reuse}

The reuse of building products in ways they were not intended to be used for, whereby a product is being re-designed to fulfil a new function following a conventional design approach. The following example is considered a conventional re-design to support reuse and extend the functional life of unused products.

Abruptarhitectura, an Bucharest based architecture firm, reused obsolete prefabricated garages to create a house in Bucharest (Ghenciulescu, 2018). They saw that prefabricated garages that started to populate the empty spaces between apartment blocks in the $1990 \mathrm{~s}$ were being taken away, because municipalities started to forbid the use of these garages in cities, to create more space. The architects considered the garages as a big opportunity, because they could be bought for an insignificant price, while the garages by themselves were already a solved structure, containing four walls, a door opening and a roof with a minimum slope for water drainage. By placing the garages in juxtaposition they created a dwelling made up of four small houses and lifted one garage vertically to give intimacy and protect the inner courtyard. To overcome the low ceiling height they raised the garages on concrete base, which doubled as the foundation. Additionally, a layer of insulation, waterproof covering, entrance, square windows, installations and a connection between the modules had to be cut out and finished to form the dwelling. As the architects stated, the reuse of prefab concrete garages does not only make sense from environmental point of view, but also from a financial and time perspective, because the construction developed at an incredible speed and was cheaper than building a new house (Ghenciulescu, 2018).
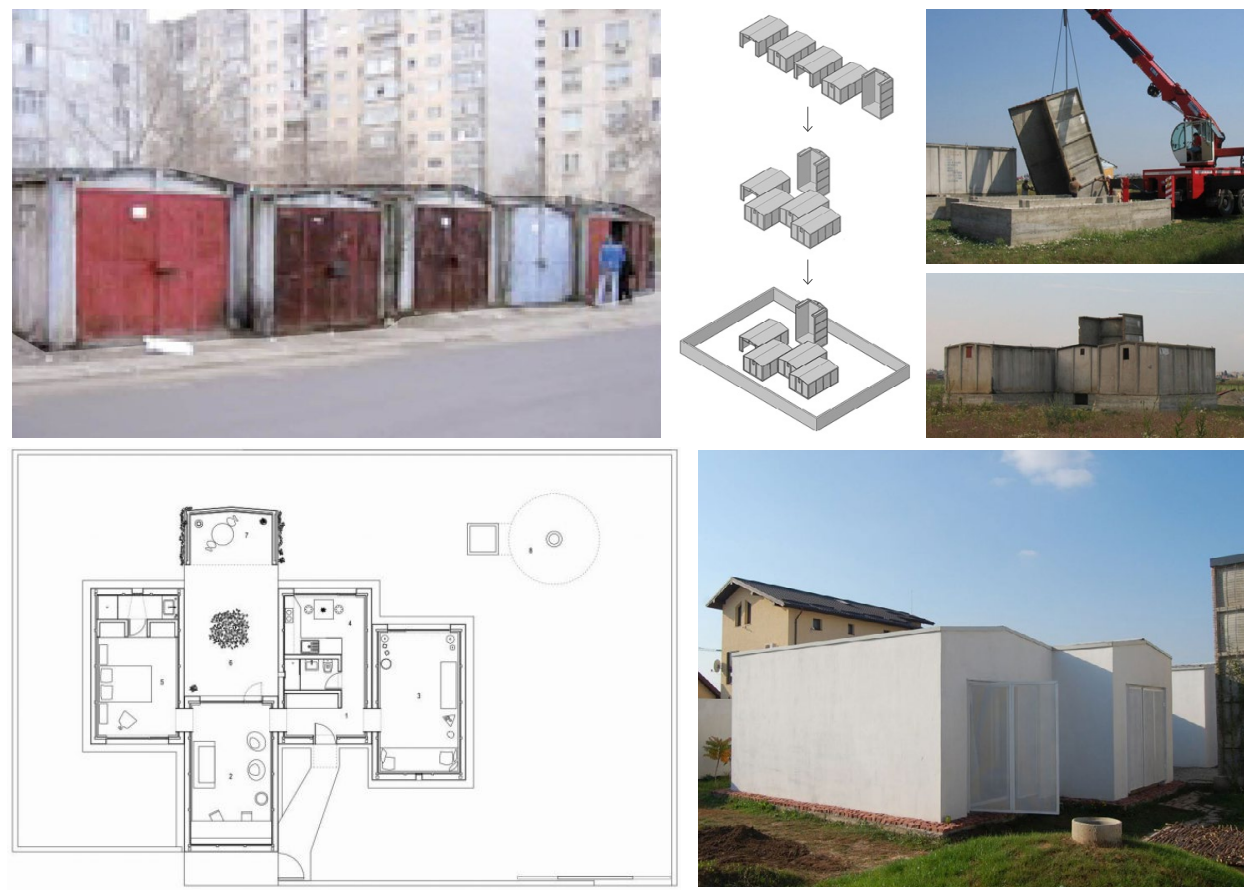

Figure 2.18: Reuse of prefabricated concrete garages to create a house (Ghenciulescu, 2018) 


\subsection{Conclusion}

This chapter presents an initial understanding of the circular economy concept and specifies its application to the construction industry by reviewing key concepts such as the theory of levels of change, functional decomposition and physical building entities, reuse processes, reuse changes and reuse design. Based on this foundation, this chapter answers RQ1 'How can circular building design be defined?'. The definition addresses the key resource flows that should be addressed in a circular economy, as identified in section 2.2. In this thesis, circular building design is defined as:

A design approach to create buildings that have the capacity to accommodate changing demands by taking into account all life cycle stages, to minimise resource input by narrowing resource flows, retain a high embodied value through design for disassembly, reparation and refurbishment and extend product life by slowing resource flows, utilise recyclable materials to enable closing resource flows, and eliminate leaking resource flows by continuously forming an incentive for future reuse.

Furthermore, to gain a better understanding of distinct reuse design methods and their related strategies, different reuse design approaches have been analysed, with the goals to answer RQ2: Which types of building reuse and building product reuse methods can generally be identified in the building practice? Based on this analysis a reuse design typology has been defined that provides an overview of different reuse design methods and their related reuse strategies. The reuse design framework is based on two important design characteristics, with on the $x$-axis the 'design intent', which distinguishes its reuse design as: 1. deliberate reuse or 2 . unintended reuse, and on the y-axis the 'type of configuration', which distinguishes its design as an 1. indeterminate configuration or 2. determinate configuration. The combination of both design characteristics resulted in four reuse design methods, namely: reversible building design, reversible re-design, conventional design and conventional re-design, which have been related to five key reuse strategies.

Additionally, it is important to understand the different transformations a reused product can undergo and understand the effect of their design solution on the potential for future reuse. Therefore, the reuse design typology has been transformed into a reuse design framework by adding the six possible transformations a product can undergo depending on the reuse strategies and its integration in its new context, as shown in Figure 2.10 with the arrows. This framework allows the categorisation of initial design and reuse design solutions to make the designers conscious about the effect of their reuse design solution on its potential for future reuse. Each of the six reuse transformations depicted in the reuse design framework has been clarified with the use of reuse examples from practice.

Since it is impossible to predict the future, it is impracticable to take into account the potential to reuse buildings and building products in unintended reuse alternatives. Therefore, the scope of the reuse potential evaluation method is aimed at the evaluation of the reuse potential to support deliberate reuse, whereby indeterminate configurations can be identified as the designs with the highest reuse potential. 


\section{Part II - Descriptive study I}

In the following two chapters descriptive study I is presented to improve the understanding of the research problem as described in section 1.1. Chapter 3 highlights the enablers, opportunities and barriers of building product reuse and the main causes and effects of factors that influence the decision making whether or not a building product will be reused are determined. In chapter 4, Design for Disassembly guidelines are reviewed to identify the key design strategies that support building and building product reuse. The result forms a theoretical basis for the development of the reuse potential evaluation method.

\section{Chapter 3 Building product reuse influences}




\section{3 | Building product reuse influences}

\subsection{Introduction}

The aim of this chapter is the development of a conceptual framework to gain a holistic view on the mechanisms and factors that influence the decision making whether or not a building product will be reused, to answer RQ5: How can the main factors of deconstruction and reuse be structured in a conceptual framework to evaluate the reuse potential of buildings and building products?. To improve the understanding of the factors that influence whether or not a building product will be reused, a literature review will be performed to the enablers, opportunities and barriers of deconstruction and reuse, to answer RO3: Which enablers, opportunities and barriers for deconstruction and reuse can be identified in literature? To understand the effect of the identified factors on the reuse potential of building products, the following research question will be answered, RO 4: What are the main causes and effects of the enablers, opportunities and barriers for deconstruction and reuse? Finally, the chapter will conclude with four generic mechanisms that influence the reuse potential of building products. Since only the first mechanism can be influenced based on the design of the building or building product, the reuse potential evaluation method should support designers in the operationalisation of the first mechanism.

\subsection{Method}

To review the enablers, opportunities and barriers for deconstruction and reuse, relevant scientific literature must be identified. Therefore, various searches have been conducted using the following terms: 'Design for Reuse', 'Design for Disassembly', 'Design for deconstruction', 'reuse', 'reclaim', 'recovery' in combination with one of the following terms 'enablers', or 'opportunities', or 'barriers', or 'advantage' and 'building' or 'building design', or 'building product', or 'build environment', with the publication date range between 2000 and 2017. After several searches, based on the key words, title, and abstract, 25 relevant publications have been selected for the literature review. Each publication has been analysed to identify enablers, opportunities and barriers for deconstruction and reuse, resulting in 48 enablers and opportunities and 49 barriers, with a total of 97 . To structure all enablers, opportunities and barriers, they are divided in six perspectives, namely: environmental, social, organisational, compliance and legislation, technical, and economical perspective. Furthermore, to gain a better understanding of the mechanisms that influence the decision making for deconstruction and reuse, the identified enablers, opportunities and barriers are translated into factors including their positive or negative relation in a cause-effect scheme. The understanding of the reuse mechanisms is in turn used to develop a conceptual reuse potential framework and to define four reuse mechanisms to influence the reuse potential of building products. 


\subsection{Enablers, opportunities and barriers for deconstruction and reuse}

In this section the results of the literature review are presented. In each sub-section one of the six perspectives will be described to answer RO 3 and RQ4.

\subsubsection{Environmental factors}

The environmental enablers, opportunities and barriers have been summarised in Table 3.06. Deconstruction and reuse of building products is commonly perceived as a way to: 1) prevent environmental impact by reducing the need for mining and harvesting of virgin natural resources, saving forests and natural areas from further degradation (Addis \& Schouten, 2004; Couto \& Couto, 2010; Guy \& Ciarimboli, 2008); 2) prevent materials from becoming waste, thereby reducing; the amount of materials being sent to landfill, the need for new landfill or incineration facilities, alleviating land stress and eliminating the concept of waste (Couto $\&$ Couto, 2010; Cooper \& Gutowski, 2017); 3) conserve the embodied energy and carbon that is invested in the products during production, reducing the energy demand and carbon output for new production and increasing the resource productivity of building products (Guy \& Ciarimboli, 2008). The reuse of building products allows the construction industry to comply with carbon emission regulatory targets (lacovidou \& Purnell, 2016). In addition, the reuse of

Table 3.06: Environmental enablers, opportunities and barriers for deconstruction and reuse

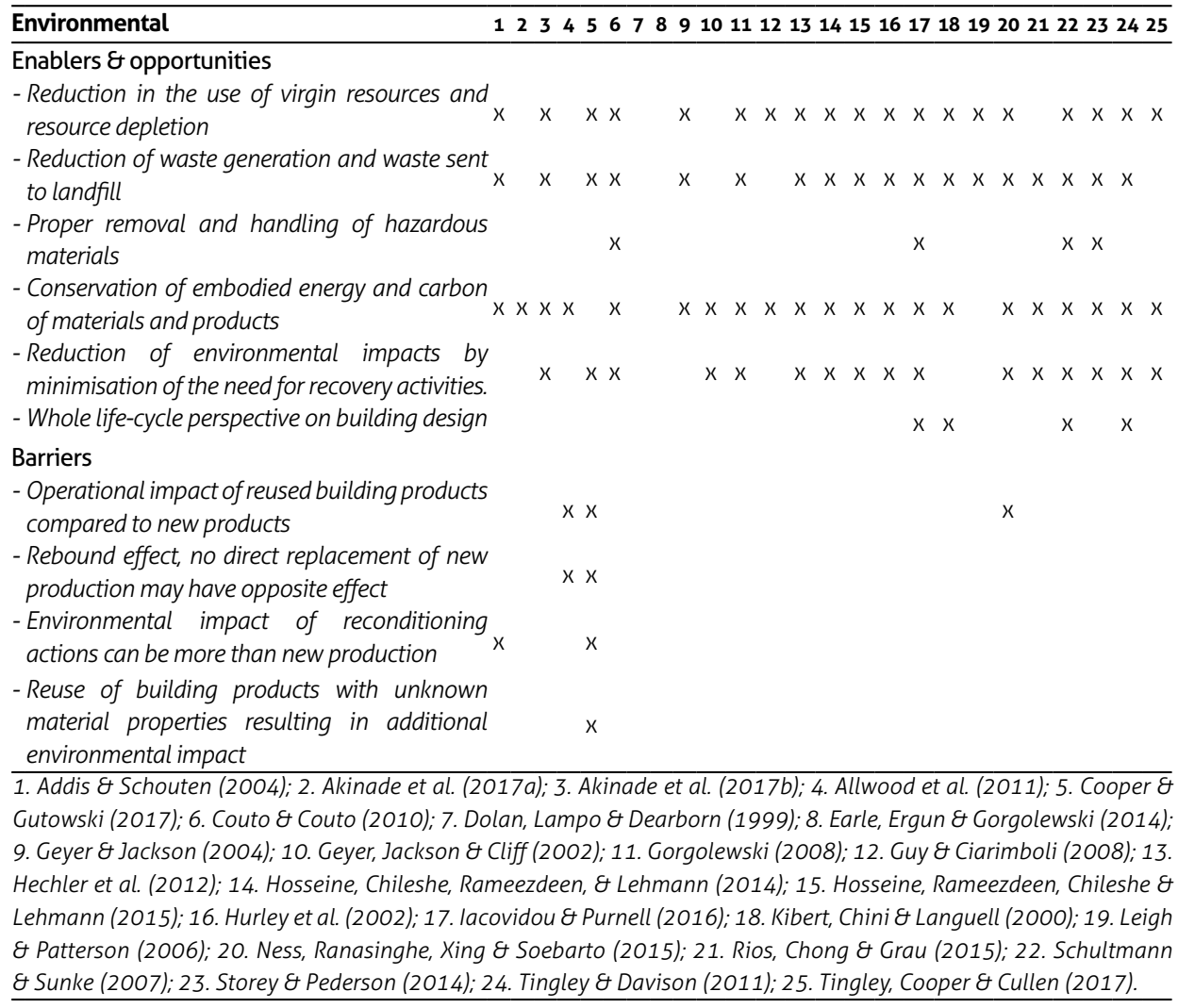


building products requires proper disassembly and handling to prevent the products from being damaged, the improved separation and handling of reusable building products may also support the separation of reusable materials from being contaminated with hazardous materials.

To address the environmental impact of buildings, the total life cycle energy should be addressed, which constitutes of operational energy as well as embodied energy (Dixit, Fernández-Solis, Lavy \& Culp (2012):

1. Operational energy refers to the energy that is consumed in the use-phase, such as heating, cooling, ventilation, lighting and operating building appliances and;

2. Embodied energy, consisting of: the initial embodied energy, the energy that is required to manufacture the building products, such as the extraction, processing and transportation of products; the construction of the building, such as the assembly on-site, prefabrication and transportation on-site and off-site; the recurring energy; the energy required during the use-phase to maintain the functionality of the building, such as maintenance, repair, replacement and refurbishments, and; the demolition energy, the energy required to demolish the building at the end-of-life (Dixit et al., 2012).

In Table 3.07 an overview is given of the life cycle stages defined in the European standard EN 15978 (2011) to assess the environmental performance of buildings. Although due to insufficient data, life cycle assessments of buildings rarely include all stages (Dixit et al., 2012; Moncaster \& Symons, 2013). Additionally, it is not entirely clear how to incorporate reuse of building products in the life cycle analysis of buildings. Since the overview of life cycle stages is merely given to provide an overview of the different stages that are defined in the European standard to assess the environmental impact of buildings, no further elaboration is given on this matter.

As buildings become more energy efficient in their use-phase requirement, stimulated by regulatory pressures, the proportion of the operational energy, relative to the embodied energy is decreasing, making the embodied energy in the total life cycle energy of buildings more prominent and increasing the importance of reuse strategies to reduce the total life cycle energy of buildings (Dixit et al., 2012; lacovidou \& Purnell, 2016; Cooper \& Gutowski, 2015). Additionally, with increasing resource scarcity of non-renewable materials, material extraction from less pure supply sources will be required, which

Table 3.07: Building life cycle stage as defined in the European standard EN 15978 (2011)

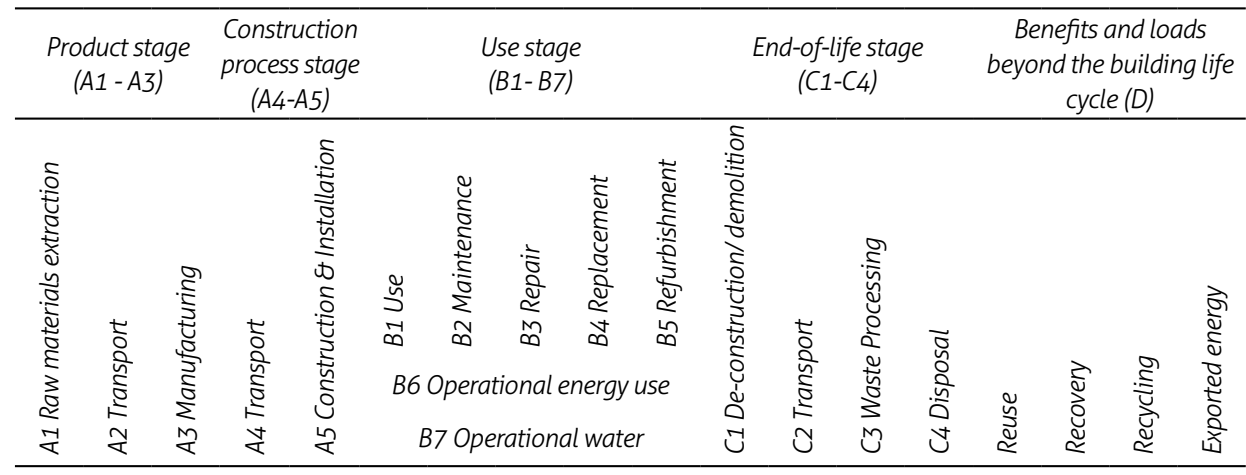


will result in an increased energy demand for the extraction of the same amount of raw resources, thus increasing the initial embodied energy of building products, stimulating material efficiency and reuse strategies even more (Allwood, 2011).

The incorporation of strategies that minimise the frequency of maintenance and replacement or upgrading of parts, reduce the use phase impact of buildings. Additionally, if changes are required and building products become available and can be reused with minimal need for recovery activities before re-application, the recurring energy need can be reduced significantly, thus reducing the environmental impact of the building (Tingley \& Davison, 2011). Taking a whole life-cycle perspective on building design is therefore of great importance to reduce recurring energy demand by taking into account all life-cycle stages (Kibert, 2002; lacovidou \& Purnell, 2016; Schultmann \& Sunke, 2007; Tingley \& Davison, 2011).

Although, Cooper \& Gutowski (2017) state that the reuse of a products does not guarantee an environmental benefit and attention should be given to the following: 1) products that are powered and prudent to improving efficiencies over time should be reused with caution, because the environmental impact of the use phase is likely to dominate initial production impacts, unless the product can be upgraded to modern efficiencies it may be better to replace the old product with new more efficient equivalents; 2) over-specification or over-capacity of products should be minimised to prevent it from having a knock-on effect on other parts that may require additional material, increasing the environmental impact, to enable the reuse of over-specified products, and; 3) sales of reused products must displace sales of new products to translate into a real reduction in environmental impacts and overcome the potential rebound effect.

As the environmental impact of reusing a building product depends on the processes that are required to return the product to a useful state and or location, and the impacts of operating the product for a second time. Cooper \& Gutowski $(2017$, p.8) state that it is safe to assume that reusing an "unpowered" product will have a lower impact than discarding it to landfill and producing a new product, because the life cycle impact will be dominated by embodied impacts, with the condition that it will be reused close to its origin. In the context of building products, it can be stated that the reuse of "non-powered" products or products that do not impact the operational energy efficiency of the building, thus the reuse of building products such as load bearing components and finishing components can be identified as best suited for immediate benefit when being reused close to their origin. While building products that directly impact the operational energy efficiency, such as the active building installation components e.g. lighting and water service components, should be restored to modern efficiency levels or the parts that determine its efficiency should be replaced to enable modern efficiency levels and prevent their operational impact from dominating the embodied energy benefit of reuse. Additionally, for building products that indirectly affect the energy efficiency, such as parts that are reused as enclosing components and impact the thermal insulation efficiency of the building, they should only be reused if the product can be upgraded to modern efficiencies.

In addition to the operational impact of reusing a product, the transportation impact to bring reclaimed product to its new destination can have a major impact on the environmental benefit of reuse (Thormark, 2000; Ness, 2015; lacovidou \& Purnell, 2016). The transportation impact depends 
on the transportation distance, mode of transportation and weight of transport, whereby the mode of transportation is often decided upon the size and weight of the parts and the accessibility of the location of the reclaimed products. The efficiency of transport is also of importance, referring to the amount of units the transportation impact can be divided e.g. transport of a single element or a full truck of elements to one destination. According to the Waste and Resource Action Programme (2008, p.12), the maximum transport distance by road that reclaimed products can be transported before having a greater impact than their virgin counterparts made locally can be calculated, as they describe for reclaimed tiles, slate, bricks, timber and steel can be transported 100, 250, 300, 1000 and 2500 miles respectively. It might be argued that the higher the embodied energy of a product, the higher the transportation distance may be before its transportation impact becomes greater than locally produced new equivalent building products.

The environmental benefit of reuse is best understood when comparing the reuse of a product with an alternative non-reuse scenario. According to Cooper 8 Gutowski (2015) the environmental benefit can be calculated as: "the net effect of "additional processes" required to reuse the item and "avoided processes" that would have been required to make the product from new materials and to deal with the old product waste" (Cooper \& Gutowski, 2015, p. 5). Thus the smaller the impact from additional processes to enable reuse, the greater the avoided processes are and the greater the environmental benefit of reuse will be.

Another factor that influences the environmental impact when reusing a product are the product characteristics of the reclaimed product the extent to which the new application utilises its capacities. As Lazarus (2003) noted, steel beams are often reused under the conservative assumption that they were made from the lowest structural steel grade when the material specification is unknown. The over-capacity of the steel beams is in this situation a wasted capacity, which may even require a larger foundation to support the oversized beams (Cooper \& Gutowski, 2017), resulting in a knock-on effect requiring additional material increasing the environmental impact when reusing a building product. In this case it would be better to perform structural tests to acquire the actual structural characteristics of the beam and reuse them as close as possible to their original capacity to avoid its capacity being waste and potentially increasing the impact of other parts requiring additional material.

Finally, if the reuse of reclaimed building product does not directly displace new production, it could be subject to the rebound effect, in which the reuse of reclaimed building products may actually increase environmental impacts, instead of the decreasing the environmental impact. As described by Cooper \& Gutowski (2015) "Rebound effects are where improvements in economic efficiency (providing a cheaper good or service) lead to either a direct rebound, increasing the demand for that good or service, or an indirect rebound, where the money saved is spent elsewhere in the economy, stimulating economic growth and resource use". To give an example, if the lower price of reclaimed building products allows someone to buy the building products, who would otherwise have done without, it has the effect that new production is not displaced and thus does not reduce the environmental impact, but increases demand for building products. Although, the result can be identified as a positive social outcome, it does not result in a reduced environmental impact.

When a building product is reclaimed and there is no demand for the product in its specific form and function, it might be transformed into another function for which a demand exists. To give an example, 
Initial embodied energy of reclaimed product

- Impact from resource extraction and harvesting

- Impact from manufacturing processes \& transportation

+ Impact of material type and amount of used materials

+ Ratio recycled content and virgin materials

Transportation impact of reuse

+ Transportation distance

+ Impact of mode of transportation

- Size of parts and location of reclaimed product

+ Weight of transportation

Reclamation, reconditioning and re-application impact for reuse

- Impact of equipment required for reclamation, reconditioning,

re-application

- Impact of additional materials required for reconditioning

+ State and quantity of reclaimed products

+ Product property match of reclaimed product with new application

Relative impact of reclaimed product compared to new product on operational energy use of building

+ Operational energy impact of reused product compared to new product

Impact to deal with the end-of-life of product

- Impact of reclamation, recycling and/ or disposal of product

+ Type of processes required for reclamation, recycling and/ or disposal

Impact to produce new equivalent product

- Impact from resource extraction and harvesting

- Impact from manufacturing processes \& transportation

+ Impact of material type and amount of used materials

+ Ratio recycled content and virgin materials

One-to-one displacement of virgin resources by reused products

- The extent to which the reclaimed product replaces virgin resources

- The extent to which the product remains close to its original

functionality in its new application

+ Type of buyer, would the buyer have done without if reuse was not available

+ Type of function the reclaimed product fulfils in its new application

Reuse of building products and materials

$\stackrel{++}{\longrightarrow}+$\begin{tabular}{|l|} 
Environmental benefits \\
- Virgin resource consumption \\
- Waste generation \\
-
\end{tabular}

Figure 3.19: Cause-effect scheme identifying the main factors that influence the environmental impact benefit and the associated environmental benefits of reusing building materials, within each main factor criteria have been identified that can influence the impact of the main factors.

if a structural beam is transformed into a kitchen counters or table top, the reuse of the timber structural beam will not result in a reduced need of virgin resources for timber beams, but might displace virgin resources required for kitchen counters or table tops. The displacement of virgin resources for table tops depends on the buyer, whether or not the buyer would otherwise have done without or would have bought a table top regardless of it being new or a reclaimed product. Additionally, one might argue that the use of timber with structural characteristics as a table top or kitchen counter is a waste of its original characteristics and such a cascaded use should only be considered when the structural capacity of the beam is deteriorated.

In Figure 3.19 the main factors that influence the environmental benefit have been summarised and described in a cause-effect scheme, describing the impact of an increase or decrease of the factor on the actual environmental benefit of reusing a building product. 


\subsubsection{Social factors}

The deconstruction and reuse of building products can be influenced by social factors, to gain an understanding of these different factors, the main enablers $\&$ opportunities and barriers have been summarised in Table 3.06. Finally, a framework has been developed based on the main factors that influence the reuse potential of building products from a social perspective.

From a social perspective deconstruction and reuse can provide multiple opportunities, such as the preservation of cultural and historic values of building products by reusing them (Couto \& Couto, 2010; lacovidou \& Purnell, 2016; Kibert, Chini \& Languell, 2000; Leigh \& Patterson, 2006), or the transition from conventional demolition to proper disassembly and careful handling, to reduce the amount of noise, dust and compaction that was usually associated with conventional demolition (Akinade et al., 2017a; Couto \& Couto, 2010; Guy \& Ciarimboli, 2008). Furthermore, the lack of recovery facilities to enable the reuse of building products provides many employment opportunities for small and medium-size enterprises to become involved in reuse processes and generate revenue through selling reclaimed and recovered building products. Since, the reclamation and recovery of building products are often labour-intensive processes it increases job opportunities significantly, compared to traditional mechanical demolition and recycling or disposal (Couto \& Couto, 2010; Gorgolowski, 2008; Allwood et al., 2011). For example, a study by ILSR (1998) estimated that on a per ton basis reuse operations generate 9 times more jobs than recycling and 38 times more than land-filling and incineration. Furthermore, it can also provide disadvantaged populations with workforce skills and business ownership opportunities (Leigh \& Patterson, 2006). Although, it should be noted that if the reuse of building products displaces new production, it might result in job losses from declining primary production. The loss of jobs in primary production can potentially be offset by the job opportunities to support deconstruction and reuse (Addis \& Schouten, 2004; Allwood et al., 2011).

The involvement of businesses in deconstruction and reuse of building products will also supports green image and reputation of businesses (Gorgolewski, 2008; Hosseini et al., 2014). Often reclaimed building products are being sold cheaper than new building products, which allows a broader range of consumers to access products they would otherwise not be able to afford, supporting low income communities. (Cooper $\&$ Gutowski, 2015; Couto \& Couto, 2010; Hechler et al., 2012; lacovidou \& Purnell, 2016).

The conservative nature of the construction industry and perceived risk of incorporating reuse has been identified by multiple authors as a major barrier that prevents a wider adoption of reuse (Allwood et al., 2011; Couto \& Couto, 2010; Earle, Ergun \& Gorgolewski, 2014; Geyer \& Jackson, 2004; Gorgolewski, 2008). This barrier is signified by the lack of awareness about the reuse potential of building products and their associated benefits, and the lack of knowledge about reuse processes and prevents building products from being deconstructed properly and reused (Earle, Ergun \& Gorgolewski, 2014; Hosseini et al., 2014; Leigh \& Patterson, 2006). If building products are not carefully disassembled 
Table 3.08: Social enablers, opportunities and barriers for deconstruction and reuse

\begin{tabular}{|c|c|c|c|c|c|c|c|c|c|c|c|c|c|c|c|c|}
\hline \multicolumn{17}{|l|}{ Social } \\
\hline \multicolumn{17}{|l|}{ Enablers \& opportunities } \\
\hline \multicolumn{17}{|l|}{$\begin{array}{l}\text { - Mitigation of noise, dust, and compaction } \\
\text { associated with conventional demolition }\end{array}$} \\
\hline \multicolumn{17}{|l|}{$\begin{array}{l}\text { - Job creation and opportunities for small and } \\
\text { medium-size enterprises in reuse processes }\end{array}$} \\
\hline \multicolumn{17}{|l|}{$\begin{array}{l}\text { - Job training in use of basic tools and } \mathrm{x} \\
\text { deconstruction techniques }\end{array}$} \\
\hline \multicolumn{17}{|l|}{$\begin{array}{l}\text { - Educate building industry stakeholders about } \\
\text { reuse processes }\end{array}$} \\
\hline \multicolumn{17}{|l|}{$\begin{array}{l}\text { - Green image and reputation of the businesses } \\
\text { involved with reuse }\end{array}$} \\
\hline \multicolumn{17}{|l|}{$\begin{array}{l}\text { - Provision of low cost material to low income } \\
\text { communities }\end{array}$} \\
\hline \multicolumn{17}{|l|}{$\begin{array}{l}\text { - Preservation of building and/ or (products) with } \\
\text { cultural and historical value }\end{array}$} \\
\hline \multicolumn{17}{|l|}{$\begin{array}{l}\text { - Perception of new materials being not as } \\
\text { durable as old materials }\end{array}$} \\
\hline - Successful showcases of reuse practices & & & $x$ & & & & & & & & & & $x$ & $x$ & & $x$ \\
\hline - Reuse as design statement & & & $x$ & & & & & $x$ & & & & & & $x$ & & \\
\hline \multicolumn{17}{|l|}{$\begin{array}{l}\text { - Designer leadership in promoting the use of } \\
\text { reclaimed building products in new designs }\end{array}$} \\
\hline \multicolumn{17}{|l|}{$\begin{array}{l}\text { - Clients role, the willingness to reuse reclaimed } \\
\text { building products }\end{array}$} \\
\hline \multicolumn{17}{|l|}{ Barriers } \\
\hline - Lack of awareness about reuse possibilities & & & & $x$ & & & & $x$ & $x x$ & & & $x$ & & & & $x$ \\
\hline - Lack of knowledge about reuse processes & & & & $x$ & $x$ & $x$ & & $x$ & r & $x$ & & $x$ & & & & $x$ \\
\hline $\begin{array}{l}\text { - Consumer preferences for new and perception } \mathrm{x} \\
\text { of reused products being inferior to new }\end{array}$ & & & $x$ & & $x$ & $x$ & & $x \times$ & $x x$ & $x$ & $x$ & & $x$ & $x$ & $x$ & $x$ \\
\hline incorporating reclaimed products & & $x$ & $x$ & $x \times$ & & $x$ & & $x \times$ & $x \times$ & $x$ & & $x$ & $x$ & $x$ & $x$ & $x$ \\
\hline $\begin{array}{l}\text { - Aesthetics and commercial desirability of } \\
\text { visibly reused products }\end{array}$ & & $x$ & & & & & & & & $x$ & $x$ & & $x$ & & & $x$ \\
\hline \multicolumn{17}{|c|}{ 1. Addis \& Schouten (2004); 2. Akinade et al. (2017a); 3. Akinade et al. (2017b); 4. Allwood et al. (2011); 5. Cooper \& } \\
\hline \multicolumn{17}{|c|}{$\begin{array}{l}\text { Gutowski (2017); 6. Couto \& Couto (2010); 7. Dolan, Lampo \& Dearborn (1999); 8. Earle, Ergun \& Gorgolewski (2014); } \\
\text { 9. Geyer \& Jackson (2004); 10. Geyer, Jackson \& Cliff (2002); 11. Gorgolewski (2008); 12. Guy \& Ciarimboli (2008); } 13 . \\
\text { Hechler et al. (2012); 14. Hosseini, Chileshe, Rameezdeen, \& Lehmann (2014); 15. Hosseini, Rameezdeen, Chileshe \& } \\
\text { Lehmann (2015); 16. Hurley et al. (2002); 17. Iacovidou \& Purnell (2016); 18. Kibert, Chini \& Languell (2000); 19. Leigh } \\
\text { \& Patterson (2006); 20. Ness, Ranasinghe, Xing \& Soebarto (2015); 21. Rios, Chong \& Grau (2015); 22. Schultmann } \\
\text { \& Sunke (2007); 23. Storey \& Pederson (2014); 24. Tingley \& Davison (2011); 25. Tingley, Cooper \& Cullen (2017). }\end{array}$} \\
\hline
\end{tabular}

and handled they may become unusable or damaged, require additional re-conditioning actions before reuse. To overcome this barrier it is important to educate the involved stakeholders how to make proper use of tools for deconstruction and identify reusable building products, to increase the amount of directly reusable building products and remove their preconceptions about reuse (Hosseini et al., 2015; Akinade et al., 2017a).

Gorgolewski (2008), Tingley, Cooper \& Cullen (2017), Hosseini et al., (2015) and Geyer and Jackson (2004) all indicated that the 'client role', their willingness and perseverance to commit to the reuse of reclaimed building products and accept that there are some 
additional risks and more time could be needed when reclaiming and reusing building products, is essential in order to allow and commit the design team to explore and apply reuse strategies. In addition, the designer or architect has also been identified as a key decision maker regarding material use and can have a significant impact on the amount of building products that are being reused (Hosseini et al., 2015; Tingley \& Davison, 2011). The designer ingenuity, the imagination of the designer how building products could be reused, can play a major role whether or not building products will be reused or not, especially for unintended reuse applications. The initiative to reuse building products should not be limited to the client and the designer, the builder, sub-contractors and consultants may also contribute to the process of identifying and proposing the reuse of building products if they happen to come across them. Furthermore, to increase the supply of reclaimed building products for reuse, salvaging and deconstruction companies are often in charge to identify whether or not to salvage them and make them available for reuse, and have a significant impact on the type of products that become available for reuse. The impact involved actors can have to stimulate and increase the reuse of building products can be summarised by the term 'actor initiative', the higher the actor initiative and involvement in reuse processes, the higher the adoption of deconstruction and reuse of building products will be.

Another factor that influences the reuse of building products is the aesthetics and commercial desirability of visibly reused products, which is often specified as a barrier that might prevent the incorporation of reclaimed building products in new design (Allwood et al., 2011; Hurley et al., 2002; lacovidou \& Purnell, 2016), additionally it is frequently mentioned that there exists a consumer preference to new, as new is often seen as better, while pre-used or reclaimed materials are considered as inferior to new (Heckler et al., 2012; Hosseini et al., 2015; Hurley et al., 2002; lacovidou \& Purnell, 2016; Rios, Chong \& Grau, 2015). Although, the opposite is also found in literature, where old materials are perceived as more durable or better for human health than new materials e.g. native hardwood, which is currently difficult to find and expansive or the off-gassing characteristics of old materials are better than new (Hechler et al., 2012; Storey \& Pederson, 2012). Additionally, Couto \& Couto (2010) noted that the reuse of reclaimed building products that contain certain aesthetic characteristics, which is often lacking in new materials, are more likely to be reused and often deliberately used as a design statement and increase the aesthetic appearance of its design. Furthermore, a growing number of successful show cases is regarded as a way to improve the overall acceptance and perception of reused building products (Couto \& Couto, 2010; Rios, Chang \& Grau, 2015; Tingley et al., 2017).

In addition to using reclaimed building products that have character as a design statement, there are also many reclaimable building products that do not necessarily have this characteristic but are of functional nature. To increase the reuse of these parts and overcome their barrier of being not desirable to be reused in a visible manner, these products are suitable for reuse as purely functional parts of the building and might be 
finished with other materials to overcome the aesthetic barrier when reusing building products. Thus, in general, two groups of reclaimed building products can be defined, products with aesthetic characteristics that lend themselves for 'visible applications', to be used as design statement and products without aesthetic characteristics that lend themselves for 'invisible applications' to support the reuse of reclaimed building products without compromising aesthetics.

Allwood et al. (2011) noted when reviewing literature on the symbolic drivers of consumption, that consumption is considered an indicator of status and a basic biological urge exists to develop a greater status, meaning consuming more, which making it difficult to encounter this urge. Additionally, Allwood et al. (2011) identified that products made from reclaimed material, or designed for future reuse, may be seen as less desirable if they symbolise thrift. To slow down this urge to consume Allwood et al (2011) determined that product replacement may be delayed if the product contains some emotional content so their disposal represents a personal loss. However, it is unknown how this effect translates to the use and reuse of building products.

In order to gain a better understanding of the intangible social factors, such as emotional, historical and cultural value, that influence how valued a building product is. A further literature study is performed to understand these specific values.

Michael Thompson (1979) did an in-depth study in his book "Rubbish Theory" to the social control of value, in which Thompson describes that in our culture objects can be assigned to one of two overt categories, 'transient' and 'durable'. "Objects in the transient category decrease in value over time and have finite life-spans. Objects in the durable category increase in value over time and have (ideally) infinite life-spans (Thompson, 1979, p.7)". Thus, the value of transient objects decays to zero and the value of durable objects increases to infinity. To fully understand the behaviour of objects, Thompson argues that there is a third covert category 'rubbish', which is not subject to a social control mechanism, which allows objects to move from the transient to zero value, into the rubbish category and from the rubbish category into the durable category and, as Thompson claims, no other transactions are possible. Furthermore, he argues that the value of a product is not only determined by its technical, physical or aesthetic properties, but that their value is influenced by their social malleability - "the idea that objects have the qualities that they have as the result of a social process of endowment" (Thompson, 1979, p. 50). To which he adds, "the same forces that confer these qualities may, in changed social circumstances, withdraw them" (Thompson, 1979, p. 50), thus the value of building elements is based on their social state, which is in a continual flux and so is their value.

This also accounts for buildings, according to the rubbish theory of Thomson objects always enter as transient objects that will decrease in value over time and only once they have reached the bottom, they can be transferred to the category of durable. To give an illustration of Thompson's theory the example as Till (2009) summarised it is given, which is the story of Sarah Wigglesworth's parents: 
"They were early pioneers in Islington, buying their large and decayed Georgian house in 1956 for almost nothing (cash), befitting its rubbish status. They immediately knocked- through the ground and basement floors. The house was later listed on the register of historic buildings and the surrounding area designated a conservation area, conferring the mark of durability. When the house was eventually sold in 2004 for a sum of money befitting its durable status (more than cash), the new owners immediately unknocked-it-through, putting back faux versions of the original cornices and restoring the dividing walls. Gordon Wigglesworth's rather masterful modernist interventions and knocking-through were clearly too much a reminder of the house's early rubbish era" (p.72).

The example describes how the house transforms from rubbish into the durable category. Another example that illustrates the power of social malleability on the real value of an object, is the literary and anthropological experiment that Rob Walker and Joshua Glenn devised, called: Significant Objects. For this experiment, 100 creative writers were asked to invent stories about nearly worthless objects and then sold them on eBay to see if the stories enhanced the value of the objects. The results of the experiment shows that the resale value of these objects was increased on average with 2700 percent (Glenn \& Walker, 2010), revealing the influence of emotional value through a story on the real value of objects. This experiment gives indication that the information about the history of an object, where it comes from, how it was used and what its purpose was, can have big influence on the actual value of the object, which may also be so when reusing building elements.

In the study of Boccadoro, a conceptual framework was identified that corresponds with the rubbish theory. Boccadoro (2008) studied how building elements, that have no relative history or embodied cultural value can transform into artifacts, that carry a heavy meaning, history and culture, which by reusing them can become cultural signifiers through their embodied sentimental, historical or cultural value. Based on Rossi's definition of an urban artifact and the breakdown of its composition (1966), Boccadoro (2008) showed how materials acquire value through the addition of time and influence of human interaction, and how the reuse of such artifacts that carry history ingrained within them preserve a culture's history and allows its culture and history to be transferred into the future, contributing to richer and more meaningful buildings.

The process how building elements increase in meaning and become cultural signifiers is described in his conceptual framework model of Boccadoro (2008, p.49), that follow the following sequence of events: 1) virgin materials are selected, based on costs, availability, style and aesthetic preferences that confirms with its culture or society and fits in its building context; 2) the material is used to form the building; 3) the building is used, in which both time and human interaction are ingrained upon the material, including physical changes such as weathering, human damage and wear (building is in a transient state); 4) the building falls into some form of disuse (acquires the state of rubbish) 5) based on the amount of time and human interaction infused into the building its meaning 


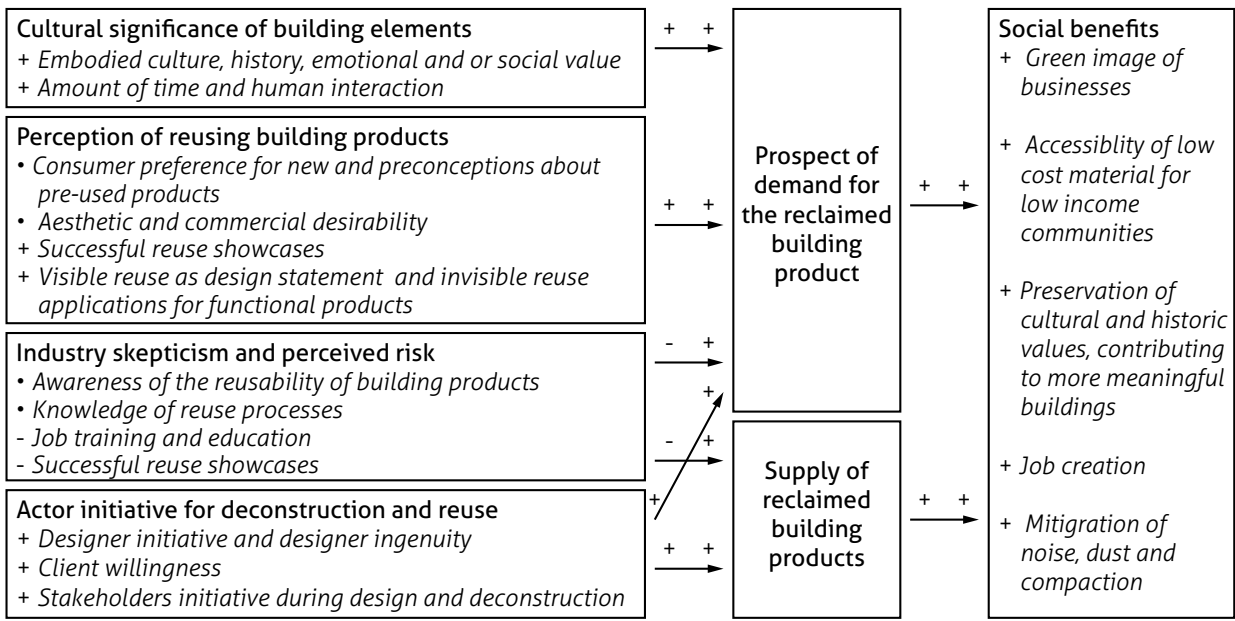

Figure 3.20: Cause-effect scheme identifying the main social factors that may influence the demand and supply of reclaimed building products and its social benefits, within each main factor, criteria have been identified that can influence the impact of the main factors.

and role as cultural signifier is strengthened, which determines its cultural value; 6 ) with the need for materials, building elements are reclaimed from the disused building; 7) the elements are reused in another building and transformed into cultural signifiers, whereby the reclaimed elements refer back to another period of time, event, or occurrence in that culture, which triggers observers and allows them to make a connection or association in the mind of them, establishing a cultural foundation for the new structure and signify the building's respective culture (reused building elements acquires the state of durable).

Thus it can be stated that the amount of time and human interaction increase the embodied culture and historical significance of the element, which influences how valued the element is. As Thompson (1979) describes, the lastingness of a building or building element is not imposed by the intrinsic physical properties, but by the social system. Although, it is impossible influence the cultural categories that influences the social system, or determine at what point the embodied cultural and historical value transform a building element into the 'durable' category or how much time and human interaction is required to bring the building element into the 'durable' category. It provides a better understanding of the underlying reasoning why certain building elements are valued more than other building elements and how the reuse of these elements can improve the design and contribute to richer and more meaningful buildings.

Finally, in Figure 3.20 the main social factors that may influence the demand and supply of reclaimed building products and its social benefit have been summarised, including the criteria that can influence the main social factors that support the deconstruction and reuse of building products. 


\subsubsection{Organisational factors}

There are multiple organisational factors that can affect the amount of effort that is required to reuse building products, which influences the decision making for building product reuse, thereby impacting the supply of reclaimed materials that become available for reuse and the demand for reclaimed materials. To gain a better understanding of these different factors, the main enablers $\&$ opportunities and barriers will be described and have been summarised in Table 3.06. As the demand and supply of reclaimed building products play an important role to enable successful reuse of building products and the amount of effort that is required to identify and select reclaimed building products. As Gorgolewski (2008) stated: "One of the principal problems with reuse is to coordinate demand with supply, and this can affect the whole design and construction process: reclaimed materials do not show up at the right time, in the right amount or the right dimension" (p.179). Therefore, the main factors that influence the supply and demand for reclaimed building products and the design complexity will be summarised in a cause-effect model.

To start, the limited supply or lack of developed market for reclaimed building products makes it on one hand difficult for users or designers to specify reclaimed building products and on the other hand risky for deconstruction companies to put in the effort to reclaim building products without knowing if a demand exists for the reclaimed building products, forming a lock-in situation. The supply of reclaimed building products is limited by the lack of deconstruction of existing buildings due to lack of demand and the demand is limited by the lack of supply of reclaimed building products. To overcome this barrier and increase the supply of reclaimed building products, it is important to create awareness about the demand for reclaimed building products, to enable deconstruction companies to respond to this demand. One way to overcome this barrier could be by the demonstration of the demand for reclaimed building products through e.g. web-based platforms (Tingley, Cooper \& Cullen, 2017). As the demand for reclaimed building products increases the uncertainties for deconstruction companies will reduce ( Leigh \& Patterson, 2006). As Ward (1994) notably said "Once a market exists, the material is no longer a waste but a commodity" (p.624). Therefore, it is important to raise the awareness about the reuse potential of building products and demonstrate the demand to support the development of a mature industry for reclaimed building products.

The industry of reclaimed building products, can due to its immaturity suffer from missing economies of scale and expansive reconditioning processes, due to the lack of recovery facilities and infrastructure for reuse processes (Couto \& Couto, 2010; Dolan et al., 1999; Geyer, Jackson \& Cliff, 2002; Leigh \& Patterson, 2006; Schultmann \& Sunke, 2007). Furthermore, the wide variety of origin points compared to supply channels of new products increases its transportation effort that is required to reuse building products (Hosseini et al., 2015).

The lack of a coordinated supply chain, which is often referred to as 'fragmented' and 'linear', is often regarded as a major barrier to the development of a reclaimed building product industry (Allwood et al., 2011; Couto \& Couto, 2010; Earle, Ergun \& 
Table 3.09: Organisational enablers, opportunities and barriers for deconstruction and reuse

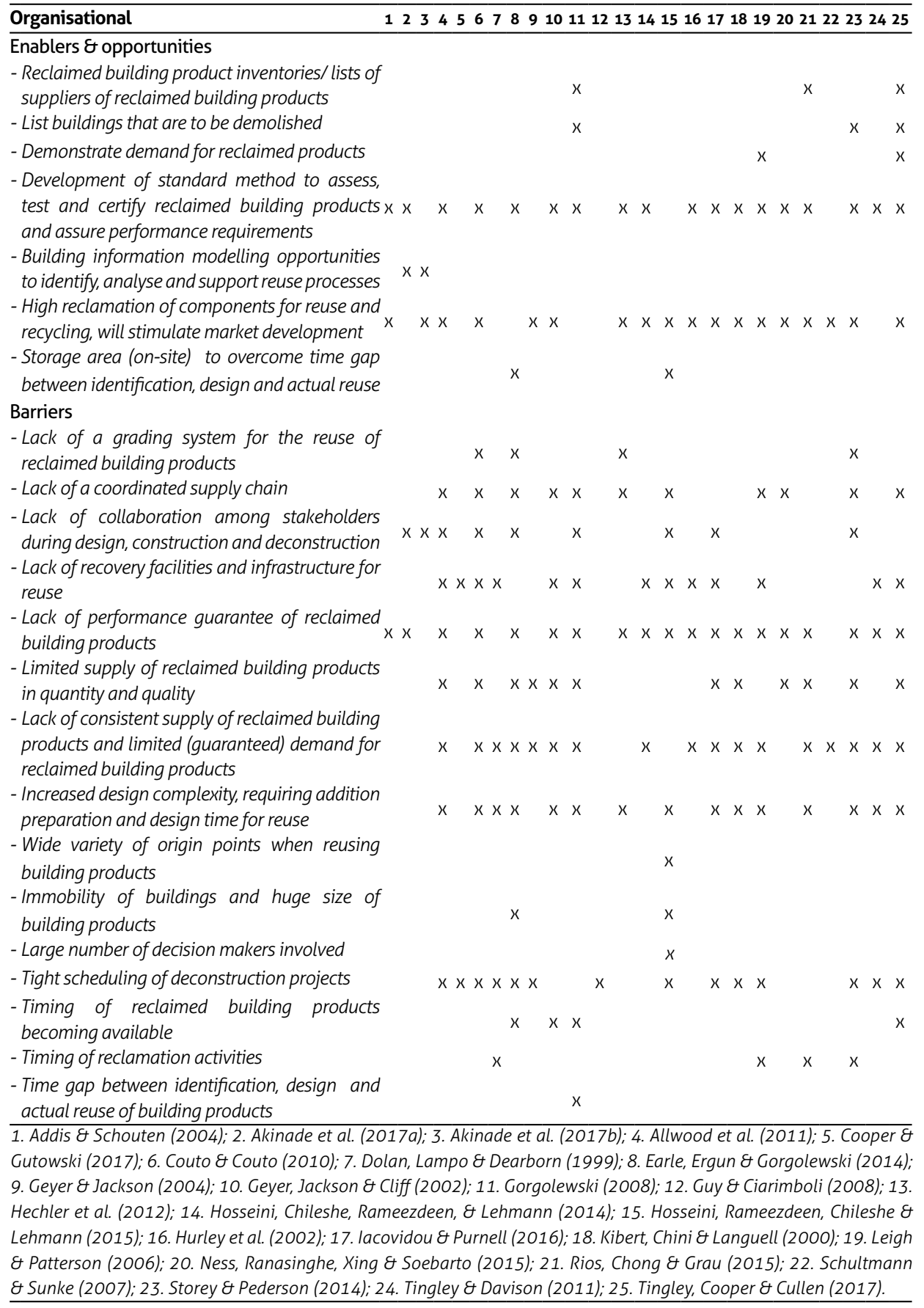


Gorgolewski, 2014; Hosseini et al., 2015). The fragmented nature and linearity of the construction process, that encompasses the sequential design, construction, operation and deconstruction processes and lack of collaboration among its stakeholders, makes it difficult to integrate reuse processes (Leigh \& Patterson, 2006; Hosseini et al., 205; Tingley et al., 2017).

Another barrier that impacts the demand for reclaimed building products is the uncertainty in availability of reclaimed building products and the inconsistency in performance of reclaimed building products (Gorgolewski, 2008; Tingley et al., 2017; Hosseini et al., 2015). The uncertainty in availability makes it difficult for designers to identify supply streams of reclaimed building products and select parts for their new design, requiring additional time to identify and select reclaimed building products, in addition to the increasing design complexity of having to deal with existing building products in new design (Allwood et al., 2011; Gorgolewski, 2008; Hechler et al., 2012; Tingley, Cooper \& Cullen, 2017).

Furthermore, the lack of performance guarantee of reclaimed building products, together with the lack of standards and building codes that address reuse, increases risks for contractors and designers and discourages the reuse of building products (Geyer, Jackson \& Cliff, 2002; Storey \& Pederson, 2003; Hosseini et al., 2015; Leigh \& Pederson, 2006). The development of standardised procedures and accepted specification and certification of reused building products is considered to not only save time and confusion during the approval process, but also provide reassurance in the reuse of building products (Gorgolewski, 2008; Storey \& Pederson, 2006). Additionally, the inconsistency in performance of reclaimed building products increase uncertainty about the amount of reconditioning that might be required before the product can be reused, forming also a barrier that discourages reuse (Kibert, 2000). As Storey \& Pederson (2003) noted: "For builders the main issue is the extra time and effort it takes to access and prepare pre-used materials in sufficient quantity, sizes and quality. It is obviously far easier and more convenient for them to ring up a single builder's merchant, than to access materials from a whole series of smaller outlets" (p.6).

To encourage reuse of building elements, lacovidou \& Purnell (2016) developed a typology system to assist contractors and designers in the selection and accountability of the performance of reclaimed building elements to support the uptake of reuse. The proposed typology system of lacovidou \& Purnell (2016) is mainly focused on: 1) the properties of the component (dimension, material, nominal loading capacity, expected residual capacity and connection details); 2 ) the nature of the recovery process (used type of end-of-life treatment, method used to reclaim the building parts) and the likelihood of damage or contamination during reclamation, and; 3 ) the nature of the original use (magnitude, frequency and duration of loading), exposure conditions (wind, snow, high temperatures, coastal or marine environments), and the match with new application based on structural form, loading, exposure. Additionally, Hosseini et al. (2014) stresses the need for accurate and on-time information exchange of reclaimed building products 
to reduce risks and uncertainties for reuse and above all increases the efficiency of reuse processes. Furthermore, Akinade et al. (2017b) suggests the use of Building information modelling to support the process of identify the amount of reclaimable building products available at the end-of-life of a building and to simulate reuse and disposal options.

For reuse to occur, reclaimed or reclaimable building products should be identified in an early design stage, to allow incorporation in the new design. Although, the time between early design stage and actual construction might take over a year (Gorgolewski, 2008). This difference in time between identification and actual need of the reclaimed building products can lead to identified materials that are sold in the meantime, forming an obstacle in the design process that can require multiple changes to the design and increase design costs.

Gorgolewski (2008) identified several methods to surpass the time gap barrier, such as the elimination of the time gap by identifying consistent supply streams of reclaimed building products or by utilising a more flexible design approach that allows the identification of the actual reclaimed building products to be delayed, so the actual parts can be identified just before its construction. While other ways to deal with the time gap barrier between design and actual construction were also suggested by Gorgolewski (2008), although this method may require high costs in early design stages, such as: 1) securing identified reclaimed building products through pre-purchasing and putting them in storage until actual construction, 2) purchasing a 'donor' building, a building that includes the required building products, 3) Introducing a reservation system that allows designers and contractors to secure their identified reclaimed building products in an early stage and prevent them from being sold until the actual construction starts. Although, the last option may result in long storage times before actual reuse.

Getting the timing right is in many perspectives crucial when reusing building products. For example, if reclamation is not arranged in advance of the approval of the contractual agreement with the demolition company, the deconstruction company may not get access or sufficient time to reclaim reusable building products (Dolan et al., 1999; Storey \& Pederson, 2003; Leigh \& Patterson, 2006; Rios et al., 2015). Therefore, deconstruction companies should get in touch with the owner of buildings that are to be demolished as early as possible to take optimal benefit of the available time to reclaim reusable building products and avoid conflicts with demolition contractors (Dolan, 1999).

Although, often the time between the decision to demolish and actual demolition is short, due to financial pressure to clear the site quickly and built anew, often leaving not enough time to enable careful deconstruction, which requires significantly more time than mechanical demolition (Kibert et al., 2000; Earl, Deniz \& Gorgolewski, 2014; Geyer \& Jackson, 2004; Couto \& Couto, 2010; Guy \& Ciarimboli, 2008). To overcome this time constraint, it is suggested to introduce a mandatory waiting period between approval for demolition and actual demolition, which allows deconstruction companies to reclaim reusable building elements, without interfering with demolition activities (Couto \& Couto; 
2010; Leigh \& Patterson, 2006; Kibert et al., 2000). The success of this approach was already demonstrated by several cities in the US, where they impose a 90-day demolition delay on buildings that are being demolished with an age over 45 years, to encourage deconstruction and reuse rather than demolition (Leigh \& Patterson, 2006).

For reclaimed building elements to be reused it is important to match the supply with demand, although, the demand for reclaimed building elements may not happen at the same time they become available, requiring storage space. To avoid multiple handling, storage space on-site is often mentioned in literature to increase the efficiency of reuse processes (Hosseini et al., 2014; Hosseini et al., 2015; Gorgolewski, 2008; Tingley et al., 2017). If there is not sufficient storage space on-site, it is suggested to identify 'out-of-the-way' locations for storage space or e.g. distribution hubs where reclaimed building products can be sorted, stored and reconditioned until demand arises, which enables improved transportation efficiencies by allowing multiple objects to be transported at the same time (Hosseini et al., 2014). Storage may increase costs for reuse of building products, forming a disincentive for reuse. To kick-start the reuse of building products Leigh \& Patterson (2006) suggested for governments to lease underutilized space to accommodate storage needs, which would allow the product for which no direct demand exists to store them until demand arises. To optimise such centres, much research has already been done by Krikke, Bloemhof-Ruwaard \& Wassenhove (2003) on how to identify the optimal number of facilities, geographical locations and layout of the facilities to enable efficient collection, reconditioning, transportation and reuse.

Finally, in Figure 3.21 the main organisational factors that influence the supply and demand for reclaimed building products, the design complexity and efficiency of reuse processes have been summarised, including the criteria that can influence the main organisational factors. 


\begin{tabular}{l}
$\begin{array}{l}\text { Transportation efficiency } \\
\text { + Economies of scale } \\
\text { + Distribution hubs of reclaimed building products } \\
\text { + Transportability of reclaimed building products (size and form) }\end{array}$ \\
$\begin{array}{l}\text { Recovery facilities and storage locations for reuse } \\
\text { + Availability of recovery facilities and storagte locations }\end{array}$ \\
\hline
\end{tabular}

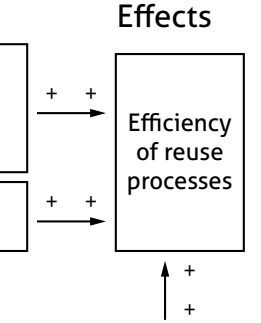
Awareness of potential supply and suppliers of reclaimed products
+ Demonstrate potential supply though lists of buildings and inventories of building products that are (becoming) available
+ List of suppliers and their available reclaimed building products

Ease of identification and reliability of information about reusable building products

+ Standard procedures to test and assure performance of reclaimed building products

+ Structured method to classify performance of reusable building products

+ Exchange of information about available products between involved stakeholders

Consistency in quality and quantity of reclaimed building products

+ Reconditioning facilities to ensure quality of reclaimed building products

+ Reuse hubs to support quantity of reclaimed building products

\title{
Consistency of supply of reclaimed building products
}

+ Maturity of reverse logistics and collaboration between involved stakeholders

Match between supply and demand
+ Integrated design approach to design, construction and deconstruction
+ Collaboration between stakeholders in the design, construction and deconstruction process

\begin{tabular}{l}
$\begin{array}{l}\text { Deconstruction and reclamation of building products } \\
\text { + Demonstration of demand through platforms, to guarantee demand } \\
+ \text { Maturity of reverse logistics, and reclamation and reconditioning technologies }\end{array}$ \\
$\begin{array}{l}\text { Available time for deconstruction } \\
+ \text { Mandatory waiting period between approval of demolition and actual demolition }\end{array}$ \\
\begin{tabular}{|l|}
\hline Permission to enable deconstruction and reuse \\
+ Timing application for permission to deconstruct and reuse
\end{tabular} \\
\hline
\end{tabular}

\author{
Available options to surpass time gap between design stage and actual construction \\ + Consistent supply streams of reclaimed building products \\ + Flexible design approach to allow selection reclaimed building products just before \\ construction \\ + Methods to secure parts for reuse during design stage \\ + Reservation system to ensure the product is available at for actual construction \\ + Pre-purchase products, and put them in storage \\ + Purchase a donor building that includes required building products
}

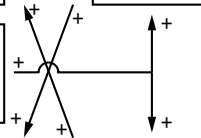

Figure 3.21: Cause-effect scheme identifying the main organisational factors and effects that may influence demand and supply of reclaimed building products, the design complexity and efficiency of reuse processes. Within each main factor criteria have been identified that can influence the impact of the main factors. 


\subsubsection{Compliance and legislation factors}

From a compliance and legislation perspective, standards, regulation and policies can have a significant impact on how materials are being used during all life cycles, thus also impacting whether or not a building product will be reused or not. In the literature many enablers, opportunities and barriers have been identified, in Table 3.10 an overview is provided. To provide a better understanding of the different measures that can be taken, the different enablers, opportunities and barriers have been analysed to identify main factors that influence the decision making for reuse.

In literature multiple barriers have been identified that discourage or form disincentives for reuse, such as the lack of standards and building codes that address reuse (Addis $\&$ Schouten, 2004; Geyer Jackson \& Cliff, 2002; Storey \& Pederson, 2003; Earl, Ergun \& Gorgolewski, 2014; Hosseini et al., 2014; Leigh \& Patterson, 2006; Tingley \& Davison, 2011) and existing legislation that forms a disincentive for reuse (Allwood et al., 2011; Cooper \& Gutowski, 2017). As was noted by Tingley \& Davison (2011) and Addis \& Schouten (2004), building codes generally encourage the specification of new materials, which limits the specification of reclaimed building elements. Furthermore, according to Storey \& Pederson (2003) and Allwood et al. (2011) the lack of building standards that are based on the specification of performances but rather material composition, makes it difficult for reclaimed building products to be re-certified and reused. Additionally, the application of reclaimed building elements often results in insurance and liability issues, increasing risks, which prevents firms from incorporating reclaimed building elements in new buildings (Leigh \& Patterson, 2006). Therefore, the development of standard procedures and building codes that enable the re-certification and reuse of building elements is essential to remove such disincentives and risks. As Hosseini and colleagues stated "regulation should eliminate some of the risks perceived by designers and builders, both at the deconstruction stage and for the use of salvaged materials in new construction" (2015, p.509).

Finally, the lack of legislative and policy strategies that provide incentives to boost design for deconstruction and deconstruction and reuse has been identified by many authors as a barrier for the uptake of reuse strategies. Tingley, Cooper \& Cullen (2017) noted, that the lack of government interest in reuse in the UK can be attributed to the legislative focus on operational rather than embodied emissions, lack of awareness of reuse as a strategy to reduce emissions and the general reluctance to legislate or overtly intervene in the construction sector. While by many authors, the government is identified as having a major role in achieving sustainability targets and promoting certain behaviour to increase deconstruction and reuse of building products (Akinade et al., 2015; lacovidou \& Purnell, 2016). For example, if the government would take initiative in requiring high levels of deconstruction and reuse in their own buildings, this could kick-start the deconstruction and reuse markets (Cooper \& Gutowski, 2015). As suggested by Leigh \& Patterson (2006) when the demand for reclaimed building products increases, the risks for deconstruction companies will decrease as reclaimed building products find wider markets. 
Table 3.10: Compliance and legislation enablers, opportunities and barriers for deconstruction and reuse

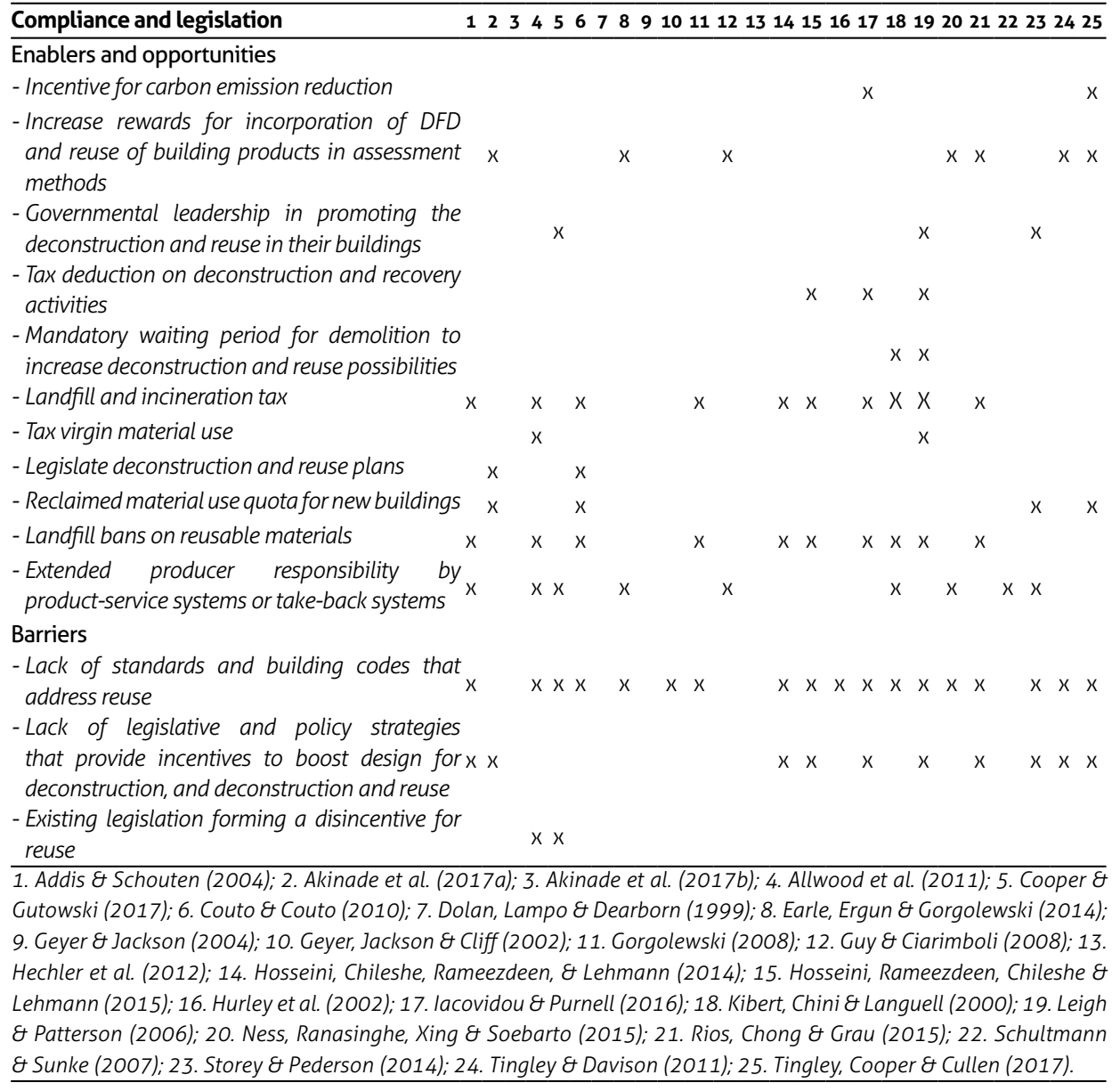

Before introducing compliance and legislation enablers and opportunities identified in literature, it is important to define the distinction between different types of measures that can be taken at legislative level, three types of measures have been identified, namely:

1. Stimulative measures, which are measures that seek to encourage positive behaviour, which would in the scope of this research be measures that encourage the reuse of reclaimed building products, by providing stimuli or incentives that trigger this behaviour;

2. Regulative measures, which are measures that discourages negative behaviour, which would in the scope of this research be measures that discourages incineration, disposal of reusable building products or virgin resource usage, by providing stimuli or incentives that make it more beneficial to seek for alternatives, such as the reuse of building products instead of discarding or incinerating them, and; 
3. Prohibitive measures, which are measures that restrict certain behaviour, for example, by imposing landfill bans of certain materials, which forces companies or individuals to identify alternative methods for these types of materials.

The distinction between each type of measure denotes the focus of each intervention, e.g. regulative measures focus on the prevention of certain behaviour, prohibitive measures focus on eliminating certain behaviour, forming the absolute minimum and stimulative measures focus on promoting 'positive' behaviour.

While reviewing different measures that are described in the literature to support the reuse of building products, it is recommended to ensure that existing legislation does not present disincentives (Cooper \& Gutowski, 2017), and that governmental support schemes do not contradict environmental practices (Allwood et al., 2011).

To start with prohibitive measures, in The Netherlands, the Dutch government issued a waste decree in 1995, which introduced a landfill ban for 35 waste categories including all combustible and biodegradable waste, which forced companies to identify alternative end-of-life treatment options for these types of materials, which proved to be a successful method to move away from sending materials to landfill towards more useful applications, such as recycling, composting and energy recovery (LCS, 2013).

In literature many types of regulative measures have been identified that involve the introduction, modification or increase of taxes or fees on activities, materials or emissions, to effectuate an increase in costs of existing practices to provides an incentive to identify cheaper alternative methods that are more environmentally responsible. One of the measures that is often mentioned in literature is the landfill tax (Addis \& Schouten, 2004; Allwood et al., 2011; Couto \& Couto, 2010; Hosseini et al., 2015). Kibert, chini \& Languell (2000) identified a correlation between the height of landfill taxes and the effort of the industry to find alternative waste disposal methods. While on the other hand they also observed that in some regions a higher landfill tax did not change the behaviour towards waste disposal, but the additional cost was considered the cost of doing the job, which is a potential risk when the focus is only put on increasing the costs of the unfavourable practices. To prevent this effect, in Denmark the money the government receives from landfill and incineration tax is used to fund technological advances in waste reduction and infrastructure required(Leigh \& Patterson, 2006). Furthermore, Denmark and Finland are moving towards a tax on virgin material use, which increases costs of virgin material use, thus creating an incentive for secondary markets to establish as cheaper alternatives (Allwood et al., 2011; Leigh \& Patterson, 2006). Stahel (2013) was more precise in his statement to accelerate the shift to a circular economy by a tax system that is based on the principles of sustainability:

"Not taxing renewable resources including human labour, work, but taxing non-renewable resources instead is a powerful lever. Taxing materials and energies will promote low-carbon and low-resource solutions and a move towards a 'circular' regional economy as opposed to the 'linear' global economy requiring fuel-based transport for goods throughput" (p. 1). 
Such a tax system will reduce the costs of labour-intensive deconstruction processes, increase the costs of energy intensive non-renewable primary material production processes, which increase the price of building products based on virgin resources and thus increase the competitiveness of reclaimed building products compared to new equivalent products. Furthermore, Tingley, Cooper \& Cullen (2017) identified that it is likely that the UK will face an increasing carbon price in the form of carbon taxes or emission trading systems. According to lacovidou \& Purnell (2016), incentives for carbon emission reduction will likely result in major changes how materials are being used, both pre-used materials and new building materials. Although, the impact such incentives as taxes and fees will have, depends on the height of the tax, the higher the incentive, the greater the benefits of alternative approaches and the more economic sense alternatives such as reuse will make and the more likely that reuse markets become mature established markets. Another measure that can support the supply of reclaimed building products is the increase of demolition permit fees (Leigh \& Patterson, 2006)

Other approaches to kick-start the establishment of reclaimed building product markets were suggested by multiple authors, which is governmental leadership in promoting the deconstruction and reuse in their buildings by introducing a minimum proportion of pre-used materials in all their new buildings (Cooper \& Gutowski, 2017; Leigh \& Patterson, 2006; Storey \& Pederson, 2003). Storey \& Pederson (2003), identified that such a measure would not only support the establishment of a stable and strong market for secondary materials, but also encourage companies to invest in equipment and training to improve their efficiency when reusing building products and provide demonstration projects that improves awareness of the potential to reuse building products in new design.

To support the supply of reclaimed building products, the Leigh \& Patterson (2006) suggested to increase the demolition permit fees, to increase incentive to deconstruct instead of demolish buildings, which can be supported by the introduction of mandatory waiting period between application for demolition and actual demolition, as the lack of time to enable proper deconstruction is often a barrier that prevents deconstruction and reuse to occur(Couto \& Couto, 2010; Storey \& Pederson, 2003; Guy \& Ciarimboli, 2008; Leigh \& Patterson, 2006; Earl, Deniz \& Gorgolewski, 2014; Geyer \& Jackson, 2004).

An extended producer responsibility in which the manufacturer is responsible for the entire product life cycle could be an effective method to promote efficient material use and stimulate reuse opportunities (Addis \& Schouten, 2004; Storey \& Pederson, 2003; Guy \& Ciarimboli, 2008; Kibert et al., 2000; Cooper \& Gutowski, 2015; Ness et al., 2015; Allwood et al., 2011; Earle, Ergun \& Gorgolewski, 2014; Schultman \& Sunke, 2007). The extended producer responsibility will stimulate manufacturers to design and make building products that are easy to maintain, repair and upgrade, but also to design them in such a way to allow them to be taken back, reconfigured and reused. Although, a major barrier of extended producer responsibility in building products is the long lifespan of buildings, construction companies may go out of business long before the building products come to the end of their lives. Several authors (Storey \& Pederson, 
2003; Kibert et al., 2000; Schultmann \& Sunke, 2007) suggest to apply extended producer responsibility to building products with a shorter lifespan and products that are routinely replaced, maintained and renovated (e.g. interior fit-out elements, lifts, installations, kitchen- and bathroom equipment).

Finally, Stimulative measures can be identified, which are measures that encourage reuse, for example, Tingley, Cooper \& Cullen (2017) suggest to require all buildings that register for demolition to perform a pre-demolition audit to identify reusable building materials and if a substantial carbon saving can be made the Local Authority Building Control could require deconstruction and material salvage. Multiple authors also suggested to increase the rewards or points given in sustainability assessment methods to incorporation of design for disassembly strategies and reuse of building products, to support reuse of reclaimed building products and the ability of future reuse (Akinade et al., 2017a; Earle, Ergun \& Gorgolewski, 2014; Guy \& Ciarimboli, 2008; Ness et al., 2015; Rios et al., 2015; Tingley \& Davison, 2011; Tingley, Cooper \& Cullen, 2017). Furthermore, Tingley, Cooper $\&$ Cullen (2017) suggests for the local government to incorporate design for deconstruction objectives into local planning regulation. In addition, Akinade et al. (2017) suggests to make deconstruction plans compulsory at the planning permission stage and to set targets for material recovery and reuse, to ensure the ability to reclaim building products in the future and to guarantee a certain level supply and demand for reclaimed building products. Although stimulative measures to support the reuse market can provide first steps to trigger reuse markets, regulating design for deconstruction objectives and reuse targets could significantly support the development of a mature reclaimed building market.

In Figure 3.22 the main compliance and legislation factors and effects that may influence the cost competitiveness of reclaimed building products compared to new equivalent products, supply and demand of reclaimed building products have been summarised. It should be noted that the identified factors can have other effects, although for clarity reasons the main focus on the direct links to economic benefits and supply and demand, the scheme is limited to these effects. 
Main compliance and legislative factors

Effects

Extraction and manufacturing processes

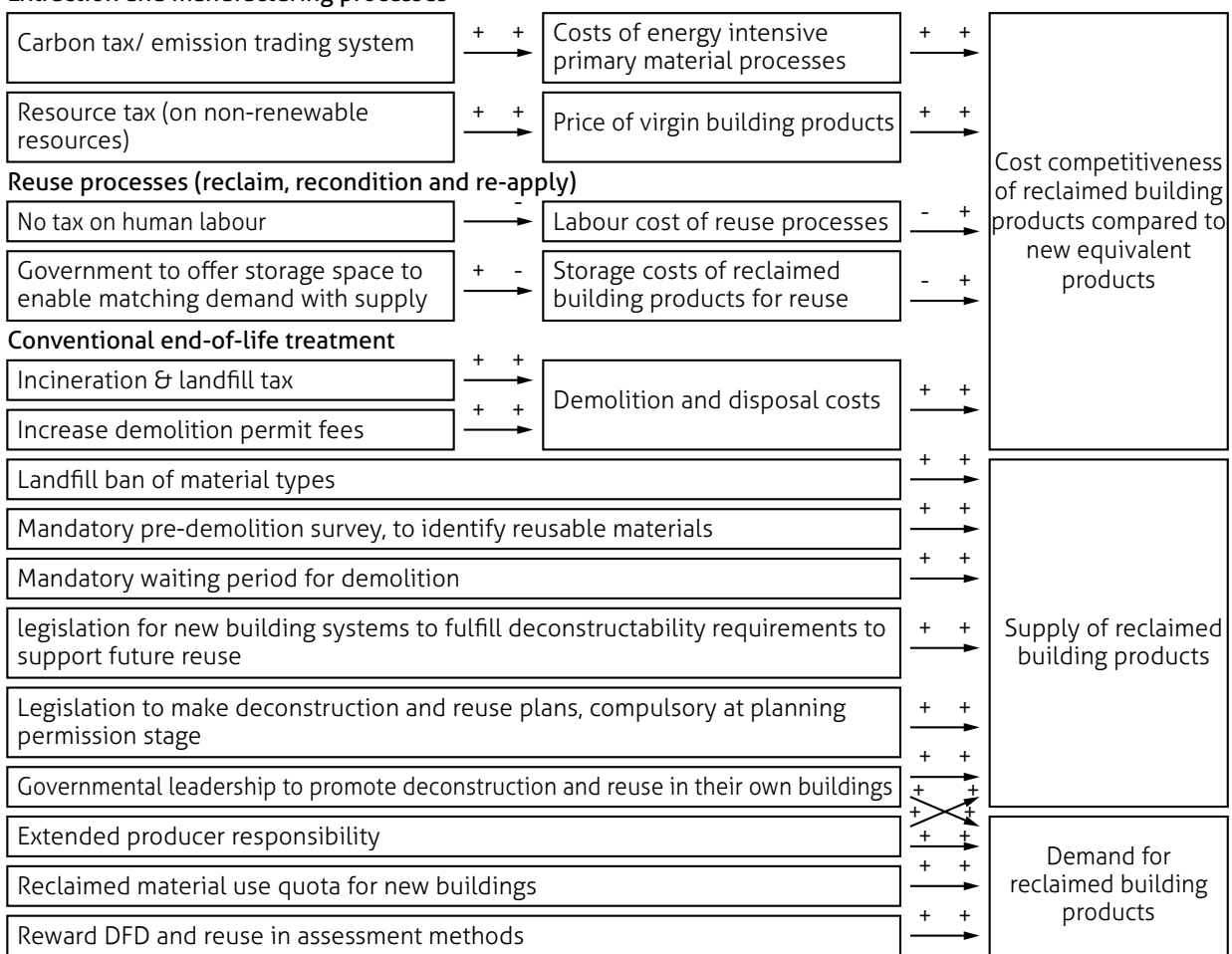

Figure 3.22: Cause-effect scheme identifying the main compliance and legislation factors and effects that may influence the cost competitiveness of reclaimed building products compared to new equivalent products, supply and demand of reclaimed building products. 


\subsubsection{Technical factors}

From a technical perspective, the ability to deconstruct without damaging the product is of major importance to allow the reuse of building products without the need of additional reconditioning processes. In literature multiple technical enablers, opportunities and barriers have been identified, which have been summarised in Table 3.11. To gain a better understanding of the different technical factors that influence the ability to reuse building products and the effort that is required to reclaim, recondition and re-apply building products, the enablers, opportunities and barriers have been analysed to identify these factors. To start, the main technical barriers that prevent building products from being reused are described, followed by the enablers and opportunities and finally the main factors that have been identified, which are described in a cause-effect scheme.

One of the most common barrier that is mentioned in literature is that most of the existing building stock is not designed for deconstruction and reuse (Allwood et al., 2011; Cooper \& Gutowski, 2017; Couto \& Couto, 2010; Earle, et al., 2014; Geyer \& Jackson, 2004; Geyer et al., 2002; Gorgolewski, 2008; Guy \& Ciarimboli, 2008; Hechler et al., 2012; Hurley et al., 2002; lacovidou \& Purnell, 2016; Rios, et al., 2015; Storey \& Pederson, 2014; Tingley et al., 2017), which makes it difficult if not impossible to deconstruct and reuse parts of these buildings without damaging them. Often designers conceive and design their buildings as timeless and permanent structures with the idea that they will stand forever, giving no attention to the end-of-life of the building and how the building could be adapted and reused (Akinade et al., 2017a; Kibert et al., 2000; Schultmann \& Sunke, 2007). The lack of deconstructability of existing buildings without damaging its parts can attributed to the large size and immobility of the structures (Hosseini et al., 2014; Hosseini et al., 2015; Schultmann \& Sunke, 2007), the type of joints, connection methods and the inaccessibility of joints that are used (Tingley $\&$ Davison, 2011), the complexity and heterogeneity of building structures (Schultmann \& Sunk, 2007; Addis \& Schouten, 2004) and the fact that they were not designed to be deconstructed. The previously identified factors are only a few factors that influence the ability and effort it takes to deconstruct and reuse building parts, in Chapter 4 an in-depth analysis to the different design for disassembly guidelines is performed to identify the major design factors that influence the effort that is required to deconstruct and reuse building products. Therefore, a more specific analysis is left out in this part of the research.

Often the deconstruction method that is used to remove the building at the end-of-life is identified as one of the determining factors in the amount and quality of building products that are being reclaimed for reuse (Hosseini et al., 2015; Schultmann \& Sunke, 2007; Gorgolewski, 2008). The lack of information, skills and tools how to properly deconstruct a building can increase deconstruction uncertainties and lead to unnecessarily damaging reusable building products and limit its reuse potential (Geyer \& Jackson, 2002; Akinade et al., 2017). The lack of documentation on building composition and product specification can significantly hamper the reuse potential of building products being unlocked, for example the lack of documentation about the origin, specifications and use history may 
Table 3.11: Technical enablers, opportunities and barriers for deconstruction and reuse

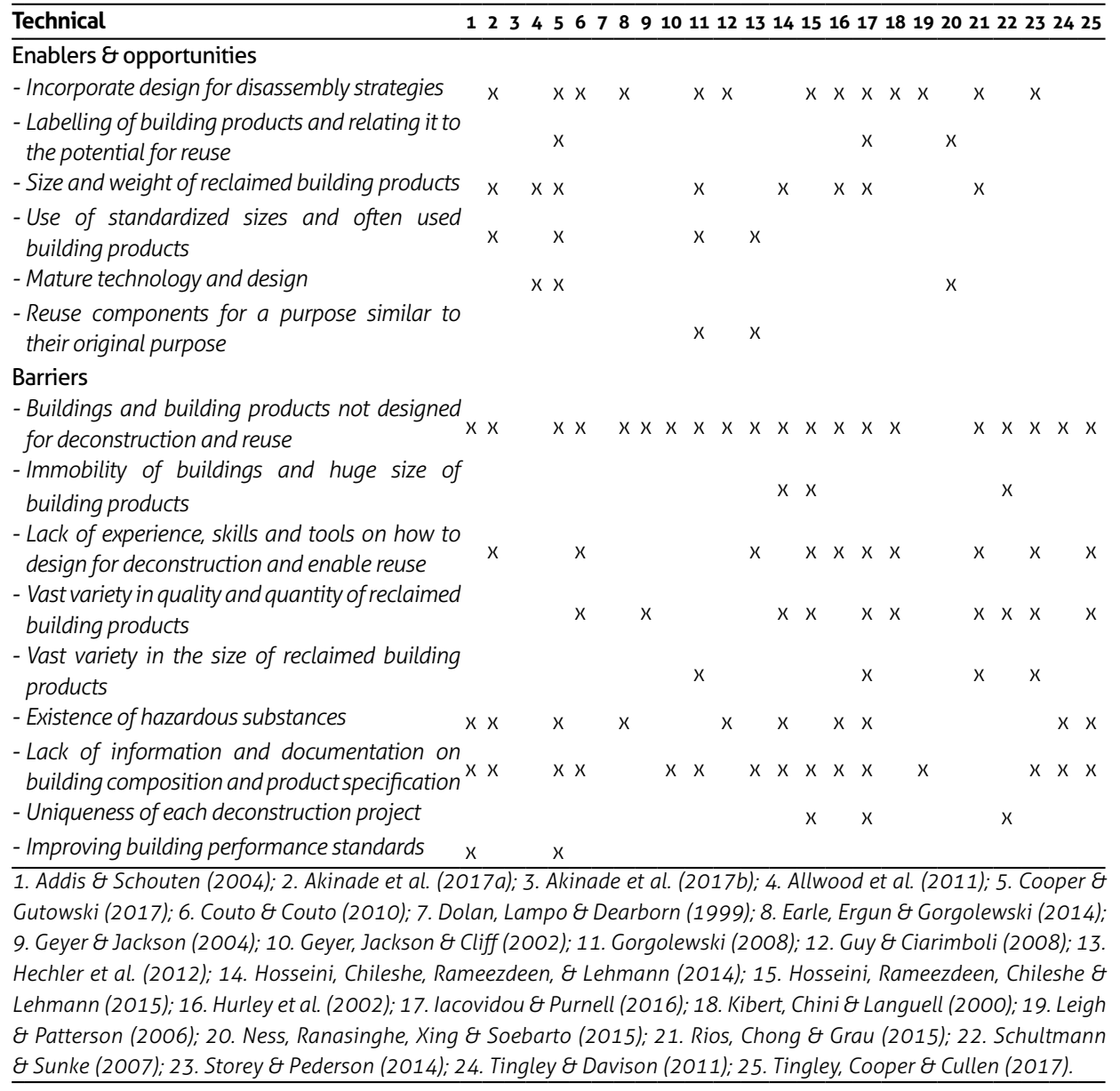

hamper its reuse due to uncertainty about the exact specification of the product and its performance, limiting the demand for such products (Hosseini et al., 2014; Geyer \& Jackson, 2002). The lack of information about building products used in existing building and uncertainty about the composition of these products can also be attributed to the long life of buildings, which increases uncertainty about the composition of the building and possible modifications that have been performed during its life (Leigh \& Patterson, 2006).

To overcome the lack of information it is suggested keep track of a revised and continually updated set of 'as built' digital drawings (Addis \& Schouten, 2004; lacovidou \& Purnell, 2016). Ness et al., (2015) even suggests to incorporate RFID chips that could be connected to CAD-based databases and Building Information Models, which could then be used to identify characteristics such as: expected life span in situ, embodied energy, warranty limitations, date of assembly. As Ness et al (2015) describes connecting RFID tags with 
BIM enables the components to be tracked, located, and even identified by designers on the internet as e.g. products that are available in the vicinity of its new site and import the product models into their model for reuse in new design. Although, it is essential that these models are continuously being updated when changes are being performed and securing that the technological developments does not limit the accessibility of opening these files. To prevent files from becoming obsolete, Gorgolewski and colleagues (2006) suggest a more robust technology to keep track of product properties, by stamping structural steel with a permanent bar code or number that can be used to identify the characteristics of the part.

Another barrier that restricts the reuse potential of building products are the existence of hazardous substances, which necessitates careful removal, increasing removal costs and poses risks to health and safety of workers (Allwood et al., 2011;Earle, Ergun \& Gorgolewski, 2014; Guy \& Ciarimboli, 2008). Furthermore, removal of hazardous materials should be done carefully to prevent other parts from becoming contaminated with hazardous substances. Additionally, it is possible for construction materials that are currently not considered hazardous, but will be reclassified as hazardous materials in the future, limiting future reuse (Addis \& Schouten, 2004; Schultmann \& Sunke, 2007; Cooper \& Gutowski, 2015).

In addition to building products potentially being reclassified as hazardous, improving building performance standards may also render building products obsolete, when unable to be upgraded to the latest performance requirements (Cooper \& Gutowski, 2017; Addis \& Schouten, 2004). This accounts especially for products that are part of a fast moving industry, such as IT, but also for parts that have to comply with building standards that are frequently being revised and improved, such as thermal insulation standards. While building products that are unlikely to change from design or efficiency, can be identified as mature technological building products, e.g. steel beams, which main design has remained the same in the last decades, thereby reducing the uncertainty that the product will becoming obsolete in the future (Cooper \& Gutwoski, 2017; Ness et al., 2017; Earle et al., 2014). To respond to these observations, Cooper \& Gutowski (2017) identified a classification framework to evaluate suitable design for reuse options, as shown in Table 3.12. Acknowledging the fact that design strategies that increase the reuse potential of products, such as greater durability, modularity or standardisation, will often require additional material increasing the environmental impact of the products, Skelton

Table 3.12: Framework for evaluating design for reuse options (adopted from Cooper \& Gutowski, 2015)

\begin{tabular}{|c|c|c|c|c|}
\hline & & & Design for ... & Design principles... \\
\hline \multirow{5}{*}{ 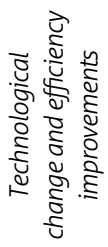 } & \multirow[t]{4}{*}{ High } & \multirow[t]{4}{*}{ Recycling } & Lightweight design \& & Minimize bending moments \\
\hline & & & design for recycling & Limited range of materials and coatings used \\
\hline & & & Component reuse & $\begin{array}{l}\text { Easy to disassemble and standardized components } \\
\text { and joints }\end{array}$ \\
\hline & & & Sub-assembly upgrade & Modularity and easy disassembly \\
\hline & Low & Life extension & Simple repair & Durability and easy access to worn components \\
\hline
\end{tabular}


\& Allwood (2013) identified that if a product fails before two thirds of its optimal life, 'built-in' redundancy that increases the embodied emissions of the product by $10 \%$ can be justified. For fast changing technologies and efficiency improvements the framework identified by Cooper \& Gutowski (2017) suggests designers to decrease material use by lightweight design and support effective recycling by limiting the range of materials and coatings used, while for slow or mature technologies the framework suggests designers to improve durability and allow access to worn components and support simple repair to enable them to be continuously be reused.

The suggestion to use lightweight design for parts that have a short technological life span corresponds to the findings of Gorgolewski (2008) who identified that lightweight nature of parts make them more susceptible to damage during deconstruction and thus less suitable for reuse. Furthermore, Allwood and colleagues (2011) identified that designers should make sure for optimised parts to be easily separated at the end-of-life, otherwise this might limit recycling. Additionally, Gorgolewski (2008) noted the size of components can increase their reuse benefits, as large sturdy parts are easier to reclaim and the higher value of larger elements make the effort to reuse them more cost effective. While in contradiction to the previous statement, Hechler and colleagues (2012) noted that small and lightweight building elements, make them easier to handle during assembly, disassembly, transport, reconditioning, re-assembly and increase their flexibility to integrate them in new design.

Another major barrier is the unique one-off nature of building structures (Hosseini et al., 2015; Schultmann \& Sunke, 2007). According to De Ridder (2011):

"every building is treated as a unique product. The world is covered with billions of unique buildings and unique structures. Each of them is not only the result of a unique project, but it is also developed by a unique combination of people, built under unique circumstances, delivered to a unique client, to be used by unique users, erected at a unique location, surrounded by a unique environment and constructed for a unique long lifetime" (p. 2).

The unique nature results in multiple complications, while for this research focus is put on the complications that arise when considering the existing building stock as the resources of tomorrows buildings, which results in every deconstruction project being a unique deconstruction project that has unique risks and specifications, resulting in increased deconstruction costs (Lacouvidou \& Purnell, 2016; Hosseini et al., 2015). Furthermore, it may results in a wide range of building products becoming available for reuse in varying quantity, quality and size (Gorgolewski, 2008; Couto \& Couto, 2010; Storey \& Pederson, 2003; Tingley et al., 2017), which may result in uncertainty about the amount of effort that is required to prepare reclaimed products for reuse (Geyer \& Jackson, 2004), require additional planning effort compared to traditional ordering of components (Schultmann \& Sunke, 2007), necessitate additional redesign time to suit the sizes of the available reclaimed building products to its new application, which potentially prevents building projects from meeting their primary objectives, i.e. time, cost, and quality (Hosseini et al., 
2015). Storey \& Pederson (2003) perfectly illustrated the difficulty of reusing building products in new design:

"For builders the main issue is the extra time and effort it takes to access and prepare pre-used materials in sufficient quantity, sizes and quality. It is obviously far easier and more convenient for them to ring up a single builder's merchant, than to access materials from a whole series of smaller outlets" (p. 6).

To overcome this barrier, extensive client commitment and perseverance is required to stick to the use of reclaimed building products (Gorgolewski, 2008; Geyer \& Jackson, 2004; Kibert et al., 2001; Hosseini, 2015).

Furthermore the dimension variation can result in dimensionally incompatible products, which makes it difficult to reuse them in new design and requires custom solutions (Hurley, 2002, Gorgolewski, 2008; Cooper \& Gutowski, 2017). To overcome dimensional incompatibility it is suggested to reuse the component for a similar purpose as their original purpose and in a similar context (Gorgolewski, 2008), although it might be difficult to find similar context due to the unique nature of each building. Hechler and colleagues (2012) stated, "only a fraction of construction elements can be reclaimed and reused for their original purpose" (p. 4).

Gorgolewski (2008) noted that when designing with reused elements sticking in the design phase to standard sizes and often used components it is more likely that they are available during actual construction, which implies that standard components are more likely to find a demand than unique building products.

To increase reuse potential of building products, the incorporation of design for deconstruction strategies is essential to support cost effective material recovery and reuse. Early design decisions can have a major impact on the end-of-life performance of building products. Despite this knowledge, there is still a lack of experience, skills and tools available that support the incorporation of design for deconstruction and reuse (Akinade et al., 2017a; Couto \& Couto, 2010; Hosseini et al., 2015; Tingley \& Davison, 2011; Tingley et al., 2017). The development of such tools that support the designer in the application of design for disassembly strategies and allow them to identify the reuse potential of specific building products is of major importance to increase the reusability of building products and remove the concept of waste, which is the main aim of this research.

In Figure 3.23 the main technical factors and effects that may influence the cost competitiveness of reclaimed building products compared to new equivalent products, and the prospect demand for the reclaimed building products have been summarised. It should be noted that the identified factors can have other effects, although for clarity reasons the scheme is limited to the direct links to economic benefits and the prospect of demand for the reclaimed building product. 
State of the reclaimed product

- Use duration and intensity of use

- Exposure conditions (outdoor/ indoor, environment type) +

- Use generation, number of times it has been reused

- Used reclamation method

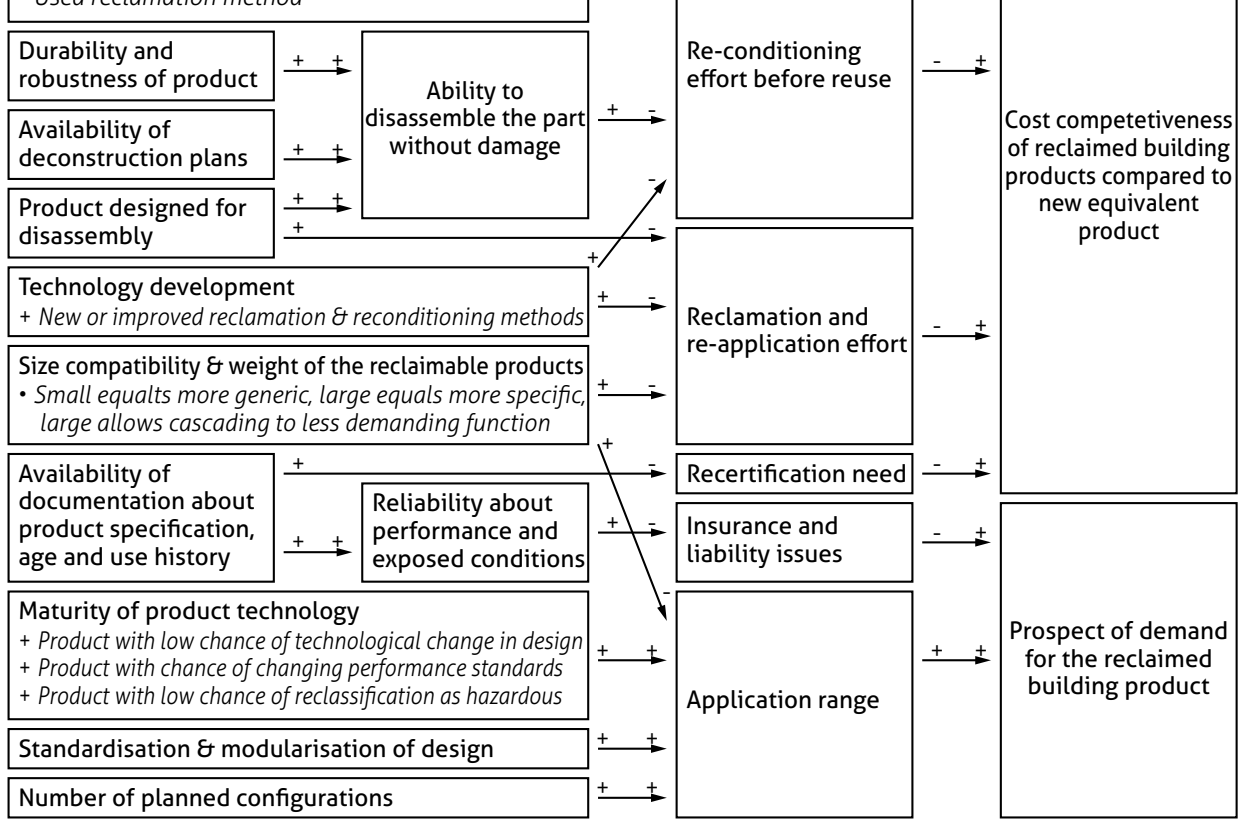

Figure 3.23: Cause-effect scheme identifying the main technical factors and effects that may influence the cost competitiveness of reclaimed building products compared to new equivalent products, and the prospect of demand for the reclaimed building product. 


\subsubsection{Economic factors}

In literature multiple economic enablers, opportunities and barriers for deconstruction and reuse have been identified, which have been summarised in Table 3.13. To gain a better understanding of the different economic factors that influence the economic viability to deconstruct and reuse reclaimed building products, the main barriers, enablers and opportunities have been described and analysed, resulting in a cause-effect scheme.

Whether a building product will be reused or not, is in the current valuation context greatly dependent on the economic benefit it has to offer in comparison with the purchase of a new building product with similar functionality (Couto \& Couto, 2010; Lacouvidou \& Purnell, 2016; Storey \& Pederson, 2003; Kibert et al., 2000; Dolan et al., 1999; Hosseini et al., 2014) or have characteristics that makes them unique to and interesting to the buyer (Kibert et al., 2000; Leigh \& Patterson, 2006; Hosseini et al., 2015; Earle et al., 2014). A survey in the UK by Geyer \& Jackson (2004) pointed out that: "many developers, architects and structural engineers would generally accept appropriate reclaimed and re-fabricated components but would expect them to cost less than new equivalents" (p. 68). One of the reasons for this is that the primary concern of businesses is to make profit (Kibert et al., 2000), without the incentive of cost savings, they are likely to choose new building products, which is considered to be more convenient and is perceived as having lower risks (Geyer \& Jackson, 2004). Furthermore, Geyer \& Jackson (2004) noted that only a small group of environmentally motivated developers and architects will choose the reuse of building products over new products as long as they are cost neutral. According to lacovidou \& Purnell (2016) "The only way for secondary markets to become competitive is by offering low prices and high quality standards for reclaimed components and materials, while liquidity requires that the quantity, availability, size and properties of components are properly inventoried and communicated to ensure the success of the market" (p. 802). The components highlighted by lacovidou \& Purnell are essential to mature the reclaimed building product market and points towards a few barrier that have to be overcome, such as inconsistent quality of reclaimed building products, the limited supply of reclaimed building products, vast variety in the size of reclaimed building products and the lack of collaboration and meaningful communication between different parties in the construction supply chain.

While on the other hand, several authors in different places of the world (e.g. Canada, New Zealand, United Kingdom and America), observed that niche markets that sell reclaimed building product with a certain historical, architectural, cultural or emotional value are profitable and endure (Earle, Deniz, Gorgolewski, 2014; Couto \& Couto, 2010; Addis \& Schouten, 2006 and Kibert et al., 2001). It is observed that the unique character of the embodied architectural, cultural or emotional value in these reclaimed building products makes them interesting to buyers and allows them to be sold for prices higher than new building products with equivalent functionality.

While the majority of building materials do have these unique characteristics that make them special. For these products one of the main economic barriers is that they have to 
Table 3.13: Economic enablers, opportunities and barriers for deconstruction and reuse

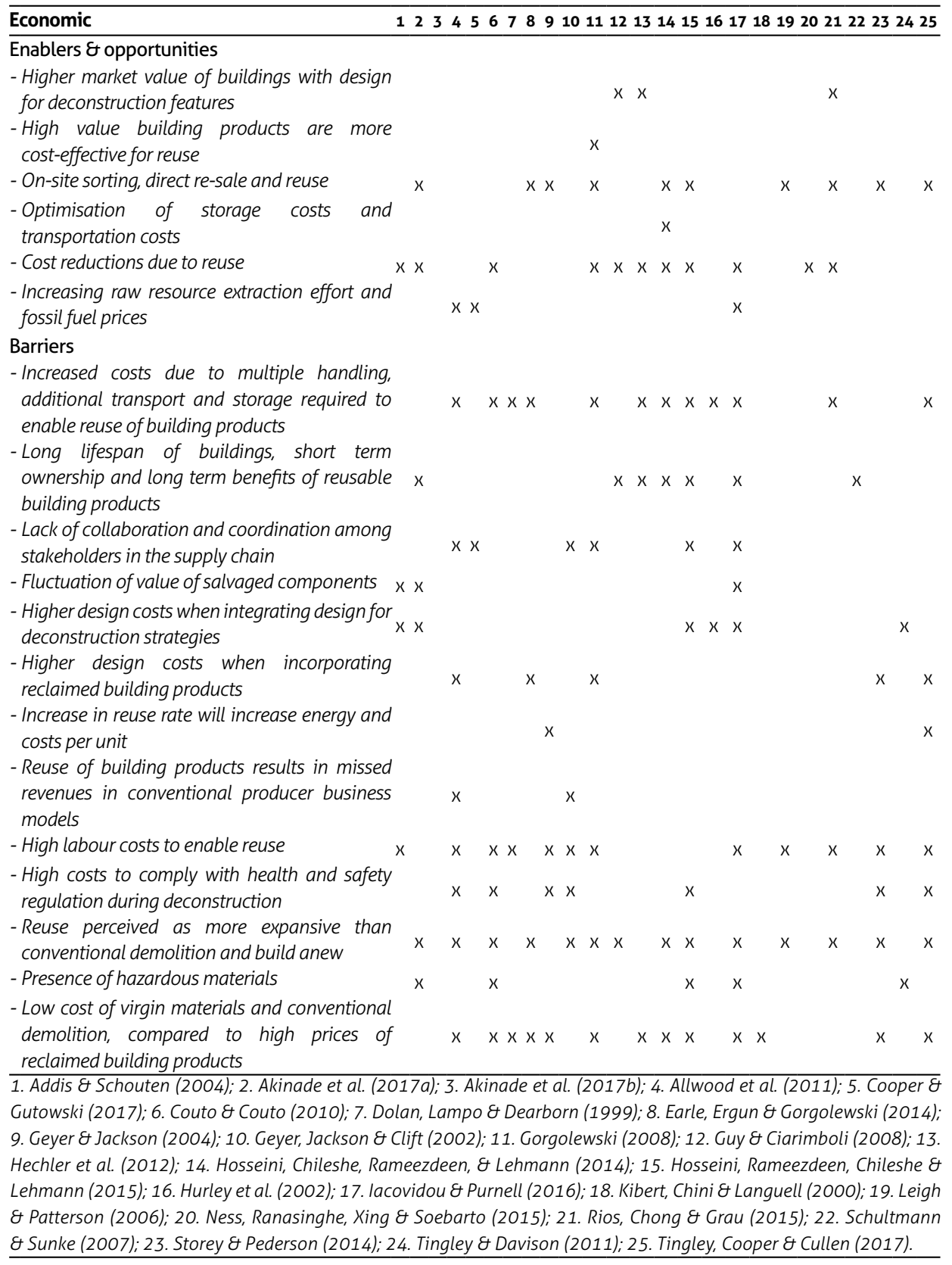

compete against the building industry as it is today, which evolved by its competitive nature into a mature well-established industry that continuously improved their cost effectiveness over many decades, resulting in readily available newly manufactured standard building products at extremely low prices (Allwood et al., 2011). This makes it for contractors far 
more convenient to buy readily available new materials in the required quantity, quality and dimensions from one large retailer, instead of the additional time and effort that is required to identify, locate, select and prepare reclaimed building products in sufficient quantity and quality from possibly multiple sources (Storey \& Pederson, 2003; Rios et al., 2015; Tingley et al., 2017). The main difficulty for reclaimed building products are the low prices of the newly manufactured products, which makes it extremely difficult for the reclaimed building product markets to be competitive in the current climate (Kibert et al., 2001; Earle, Deniz \& Gorgolewski, 2014; Lacovidou \& Purnell, 2016; Heckler et al., 2012; Gorgolewski, 2008; Storey \& Pederson, 2003; Dolan, Lampo \& Dearborn, 1999). As Storey \& Pederson (2003) pointed out, the lower the cost of raw materials the less stable and profitable reclaimed building product markets become. Furthermore, Dolan and colleagues (1999) identified the opposite, the scarcer a resource is, the more economically viable the reclamation and reuse of this resource will be. Additionally, it can be stated that the higher the costs to manufacture products from virgin resources the higher the incentive to reclaim and reuse building products will be (Dolan et al., 1999).

When looking at the global raw resource consumption, Cooper \& Gutowski (2015) pointed out that resource grades are declining over time, which may increase resource prices and make the resource extraction more energy-intensive. Furthermore, lacovidou $\&$ Purnell (2016) stated that inflation of fossil fuels prices is inevitable. As raw resource extraction processes are typically fossil-fuel based (Cooper $\&$ Gutowski, 2015), the prices of building products based on virgin resources are expected to increase immensely, which will improve the cost-competitiveness of resource conservation strategies, such as reuse.

Furthermore, Geyer \& Jackson (2004) point out that the demolition industry has become an integral part of the supply chain and their constant lookout for cost reductions, resulted in a wide range of available mechanized and automated demolition techniques that reduced costly manual labour to a minimum, which matured the demolition industry into a process of relatively low cost and is able to remove large buildings in short periods of time. Although, the demolition industry utilizes expensive specialized equipment resulting in high equipment costs, their overall demolition costs are reduced to a minimum (Geyer $\&$ Jackson, 2004, Couto \& Couto, 2010, Rios et al., 2015; Akinade et al., 2017). This makes it difficult for the immature deconstruction industry to compete against the mature demolition industry, considering deconstruction is much more time consuming and requires costly labour intensive manual work using cheap standard hand tools (Rios et al., 2015; Geyer, Jackson \& Cliff, 2002; Geyer \& Jackson, 2004; Storey \& Pederson, 2003; Couto \& Couto, 2010; Addis \& Schouten, 2004; Gorgolewski, 2008; Dolan,et al., 1999; lacovidou \& Purnell, 2016; Tingley et al., 2017; Leigh \& Patterson, 2006; Allwood et al., 2011). The high labour costs in developed economies is one of the forces that renders environmental friendly behaviour uneconomical and thus risky (Allwood et al., 2011). Together with the often limited time available between the decision for demolition and actual demolition, constraints the more time-consuming deconstruction and reuse processes (Kibert et al., 2000; Earl, Deniz \& Gorgolewski, 2014; Geyer \& Jackson, 2004; Couto \& Couto, 2010; Guy \& Ciarimboli, 2008). 
The high labour costs of deconstruction was confirmed in a study of Coelho and de Brito (2011), in which they estimated that the labour costs of deconstruction of a building could be about six times higher than conventional demolition. Furthermore, Couto \& Couto (2010) noted that specialized tools for deconstruction are often non-existent, which amplifies the labour intensity of deconstruction. Additionally, building construction is optimized for fast assembly in which building products are not designed for deconstruction and assembled using chemical connections rather than easily reversible connections (Addis $\&$ Schouten, 2004; Guy \& Ciarimboli, 2008; Hechler et al., 2012; Akinade et al., 2017). This lack of buildings and building products to be designed with deconstruction in mind, locks the potential of these building products to be reclaimed and reused (Guy \& Ciarimboli, 2008; Hechler et al., 2012; Akinade et al., 2017).

Furthermore, the costs to comply with health and safety regulations to which deconstruction companies have to comply, increase the costs of reclamation and thus the costs of reclaimed building products (Geyer \& Jackson, 2004; Storey \& Pederson, 2014; Couto \& Couto, 2010; Tingley et al., 2017; Hosseini et al., 2015; Allwood et al., 2011). Additionally, the risk of hazardous materials being present in the building, such as lead and asbestos, requires trained workforce for proper removal, increasing the costs and time required during deconstruction (Couto \& Couto, 2010; Hosseini et al., 2015; Akinade et al., 2017).

Multiple barriers enforce the perception of reusing building products being perceived as more expansive than conventional demolition and build anew (Akinade et al., 2017a; Rios et al., 2015; Geyer et al., 2002; Storey \& Pederson, 2003; Couto \& Couto, 2010). In turn this perception limits the supply and demand of reclaimed building products, whereby the lack of established markets for reclaimed building products can cause high price fluctuations, increasing risks to take on deconstruction projects (lacovidou \& Purnell, 2016; Addis \& Schouten, 2004; Akinade et al., 2017).

Despite the perception of deconstruction and reuse being more expensive, multiple studies have shown that this is not always the case (Rios et al., 2015; Chini, 2005; Kibert et al., 2000; Guy \& Ciarimboli, 2008; Gorgolewski, 2008). According to Rios and colleagues (2015), the deconstruction costs are dependent on the following variables: 1) material storage prior to final destination, 2) higher labour costs for deconstruction; 3) higher costs with workers insurance; 4) transportation of debris; 5) removal of hazardous materials; 6) training expenses; 7) local and regional market and demand for used materials; 8) state of materials; and 9) landfill fees, and could be reduced by: 1) the resale value of the reclaimed parts; 2) partnerships among public, private and non-profit organizations that can help to raise funding and share benefits; 3 ) financial incentives provided by governments; and 4) savings related to the use of equipments. Furthermore, they describe that the main variables that influence the cost-effectiveness of deconstruction include: 1 ) building type and composition; 2) labour cost and availability; 3) prevailing disposal costs; 4) availability of salvage markets; and 5) strength of market demand for used building materials. Guy (2000) summarized the deconstruction costs in the following expression: (Deconstruction + Disposal + processing) - (contract price + salvage value) $=$ net deconstruction costs. 
From a reuse potential perspective, Gielen (2018) described the reusability of building products with the following equation: (cost of dismantling + handling - extraction fee)* risk < market value. This equation includes the factor risk, which represents the risk the deconstruction company takes by investing in the dismantling and reclamation of building products minus the extraction fee, taking into account a certain revenue from the sales of the reclaimed building products, although the company might not be certain that it will sell the reclaimed building products for the price they accounted for, which is the risk the company takes. Gielen (2018) stated that the identification of a customer that will purchase the reclaimed building products before deconstruction starts is an effective method to reduce the risk of not selling the product after deconstruction, and if this is not possible the deconstruction and reclamation of parts that are in demand and are cost-effective based on previous experience also proved to be a successful method.

Based on the prospect that buildings which are designed for deconstruction will reduce the costs to deconstruct the building and allow the reclamation of its parts without damaging them and extend their functional life through selling and reusing them, many authors (Hechler, Larsen \& Nielsen, 2012; Webster, 2007; Guy \& Ciarimboli, 2008 and Rios et al., 2015) stated that it is safe to assume that buildings with design for deconstruction features have a higher market value and are more attractive as an investment. While the higher value has never been confirmed, it is considered to be a valid argument and could motivate building developers to require the integration of design for deconstruction strategies in new building developments. Furthermore, it should be mentioned that only when the higher market value for buildings with design for deconstruction features is reflected in their market value, investors are likely willing to pay for the higher design costs when incorporating design for deconstruction strategies to enable future reuse of building products. Although, the ignorance of the added value of design for deconstruction features is considered a barrier that restricts the higher design costs that are associated with the incorporation of design for deconstruction strategies (Addis \& Schouten, 2004; Akinade et al., 2017a; Hosseini et al., 2015; Hurley et al., 2002; lacovidou \& Purnell, 2016; Tingley $\&$ Davison, 2011). Furthermore, if the higher value of buildings with design for deconstruction features is not reflected in their market value, the long lifespan of buildings and its long-term benefits of reusable building products forms a barrier for short-term owners and investors (Akinade et al., 2017a; Guy \& Ciarimboli, 2008; Hechler et al., 2012; Hosseini et al., 2014; lacovidou \& Purnell, 201; Schultmann \& Sunke, 2007). Since the long lifespan of buildings coupled with the often short ownership may result in the benefits of a building that is designed to be easily deconstructed and reused elsewhere are not borne by the original owner. While the original owner has to pay for the additional design time required to incorporate design for deconstruction strategies that enables the future reuse of building products.

From a design perspective, the integration of reclaimed building products in the design of new buildings requires the design team to perform additional research in early design stages to identify, locate, inspect and select appropriate reclaimed building products 
and secure proper integration in new building design, the higher design costs are also considered a barrier for larger adoption of reuse practices (Allwood et al., 2011; Earle et al., 2014; Gorgolewski, 2008; Storey \& Pederson, 2014; Tingley et al., 2017). The additional design costs should be offset by the reduced price of using cheaper reclaimed building products. To increase the cost effectiveness, Gorgolewski (2008) noted that the high value of often larger building products make the effort to reclaim more cost-effective and could stimulate the reuse of (larger) high value building products. Although, the reclamation of larger building products can require special equipment for handling them, it can drastically reduce the amount of expansive manual labour.

Another barrier that has to be overcome was identified by Geyer \& Jackson (2004), who observed that demolition contractors currently only reclaim end-of-life sections that are easy to access and of very good quality. Additionally, Tingley et al., (2017) stated that the so-called 'easy-win' buildings, that are most suited for deconstruction, would occur first. This would imply that with rising reuse rates of building products, the technically more challenging buildings and building products will need to be reclaimed. This has as effect that the unit costs of reclaimed building products will increase with the rising reuse rate of building products and could imply that demolition would be economically preferred over deconstruction. As Tingley et al., (2017) noted, depending on the technical composition of the building an economically-informed limit to deconstruct and reuse a building could be determined. Although, once the required procedures to reuse building products become more mature and automated its labour requirement could decrease and may increase the cost-effectiveness of deconstruction and reuse, and push the economically-informed limit. To optimise the reuse processes it is often mentioned logistical effort can be reduced by eliminating double handling and perform on-site sorting and direct stimulate direct re-sale and reuse (Akinade et al., 2017a; Earle et al., 2014; Geyer \& Jackson, 2004; Gorgolewski, 2008; Hosseini et al., 2015; Tingley et al., 2017). Although, this method requires sufficient space on-site, which might not always be possible (Hosseini et al., 2015).

From a manufacturer perspective, their business model is often focused towards growing sales volumes to increase their profit. These type of business models favour product replacement to increase their sale volumes. If the reuse of products displace the sales of new produced products, the reuse of building products can result in missed revenues in conventional producer business models and thus form a disincentive or threat for their sales (Allwood et al., 2011; Geyer et al., 2002). Therefore, new business models are required to address the disincentive, such as lease or product-as-a-service models (Allwood et al., 2011).

For reuse to become economically viable, the additional processes that are required to reuse the product should not exceed the avoided processes that would have been required to make the product from new materials and deal with the old product waste. 


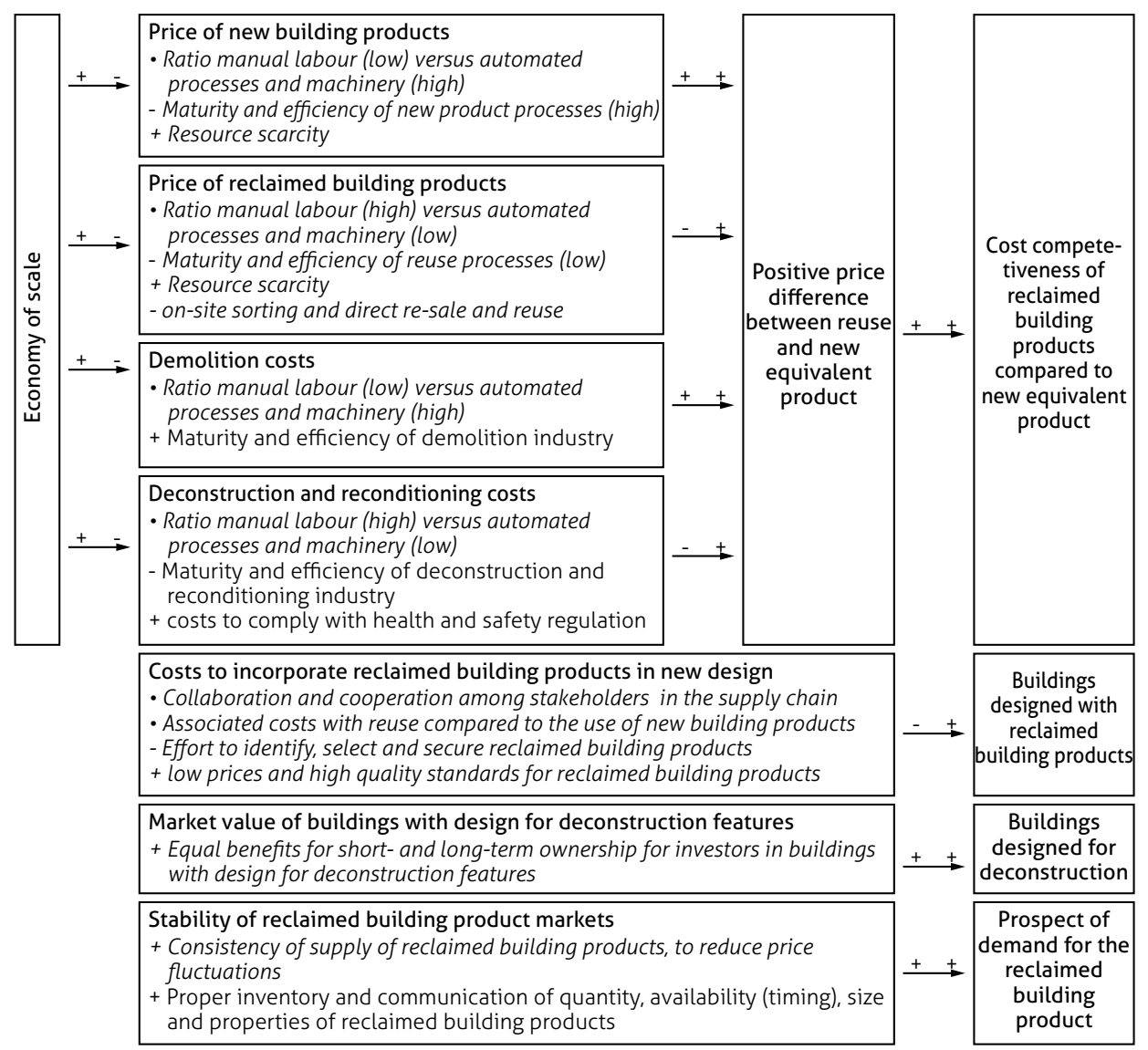

Figure 3.24: Cause-effect scheme identifying the main economic factors and effects that may influence the cost competitiveness of reclaimed building products compared to new equivalent products, adoption of buildings designed with reclaimed building products, designed for deconstruction and prospect of demand for the reclaimed building product

The reuse of building products has been identified as a way to offset the high deconstruction costs, whereby the reuse can lead to several cost reductions due to: 1) resale value of the reclaimed building product; 2 ) disposal costs savings; and equipment savings, based on the assumption that deconstruction requires less large mechanical equipment than conventional demolition.

As has been identified in the technical, organisational, social, compliance and legislation and environmental factors that influence the cost effectiveness of reclaimed building products, there are many factors that can support the economic viability of reuse 


\subsection{Reuse potential framework}

Based on the analysis of the opportunities, enablers and barriers for deconstruction and reuse, a conceptual reuse potential framework has been developed. The conceptual framework should provides a better understanding of the different factors that influence the reuse potential of buildings and building products and forms the basis for the development of the reuse potential evaluation method. Next to the framework, two calculations have been defined to identify the economic and environmental benefit of reuse compared to an alternative non-reuse scenario, which ultimately led to the identification of four reuse mechanisms and three strategies to increase the reuse potential of buildings, systems and products.

\subsubsection{Conceptual reuse potential framework}

The aim of the conceptual reuse potential framework is to provide an overview of the main indicators that can be used to explain the variance, between the potential to reuse buildings, systems or products in different design solutions. Therefore, it is important to identify the dependent and independent variables. The dependent variables can be defined as the variables the researcher wishes to explain and the independent variables are the variables that are expected to influence the reuse potential (Blessign $\&$ Chakrabarti, 2009).

To start, it is important to specify the independent variable, the building design, which is expected to influence the dependent variables. Since, the types of reuse that occur are diverse and can vary significantly per situation. It is important to identify commonly occurring reuse scenarios. Based on the literature review, four common reuse scenarios have been identified.

- Building reuse scenario. The functional lifespan of the building in its current location and form has ended and the building should make space for the redevelopment of the area. The building can potentially be relocated and reused in a location where the user requirements match the characteristics of the available building;

- System reuse scenario. One or more of the main building systems (load-bearing-, enclosing-, finishing- and/ or servicing system) do not fulfil the changing user demands and requirements. If the main building system cannot be adapted to fulfil the requirements and extend the functional lifespan of the building, the specific main building function needs to be replaced to comply with the changing user demands and requirements. The main building system that needs to be replaced can potentially be reused in other buildings whose user requirements comply with the characteristics of the available main building system;

- Product reuse scenario. One or more of the building sub-functions (foundation, structure, floors, facade open, facade closed, roof, (raised) floor, (lowered) ceiling, partitioning, stairs, water-, electrical-, heating-, ventilation installation) do not fulfil the changing user demands and requirements. If the building sub-function parts cannot be adapted 
to fulfil the requirements and extend the functional lifespan of the building, the specific sub-building function parts needs to be replaced to comply with the changing user demands and requirements. The sub-building function parts that needs to be replaced can potentially be reused in other buildings whose user requirements comply with the characteristics of the available sub-building function parts;

- Substance reuse scenario. The technical lifespan of the part has ended and can be re-claimed in a destructive manner to either be sorted, re-processed and reused as secondary material for new building products or for parts made of biodegradable biological materials they can sorted be returned into nature to rebuild natural capital.

Each reuse scenario has its own aim and requirements, therefore, the conceptual reuse potential framework should address each reuse scenario. To incorporate each reuse scenario in the conceptual reuse potential framework, each scenario has been translated into four reuse levels, whereby the following requirements can be specified per reuse level:

- Building level. Refers to the embodied value that is preserved during the relocation of the building and the amount of effort that is required to re-claim, re-condition and re-apply the building in another location;

- System level. Refers to the embodied value that is preserved during the reuse of main building functions and the amount of effort that is required to re-claim, re-condition and re-apply those main building systems;

- Product level. Refers to the embodied value that is preserved during the reuse of sub-building functions and the amount of effort that is required to re-claim, re-condition and re-apply those building product;

- Substance level. Refers to the embodied materials that are being preserved during the re-processing of the materials and the amount of effort that is required to re-claim (destructive) re-process and (re-)manufacture the product.

To support a holistic view on reuse, substance reuse level has been incorporated in the conceptual reuse potential model. However, since substance reuse scenario is aimed at the reuse of materials whereby all embodied values have been reduced to the raw materials, this scenario will not be addressed by the reuse potential evaluation method. Since this research is focused on the evaluation and support of buildings and building products with a high reuse potential by keeping the embodied value as high as possible.

In Figure 3.25 the conceptual reuse potential framework is presented, which extends upon the resource flows as identified in chapter 2 and builds upon the impacts identified by Cooper \& Gutowski (2015, p.5), who defined the impact 'additional processes' and the impact of 'avoided processes'. Based on the literature review in this chapter, two additional types of impact have been identified as dependent design variables that influence the reuse potential of the building and its parts, namely: impact of 'reuse on the embodied value', and impact of 'reuse on the operational value'. Resulting in the following four categories of dependent variables: 


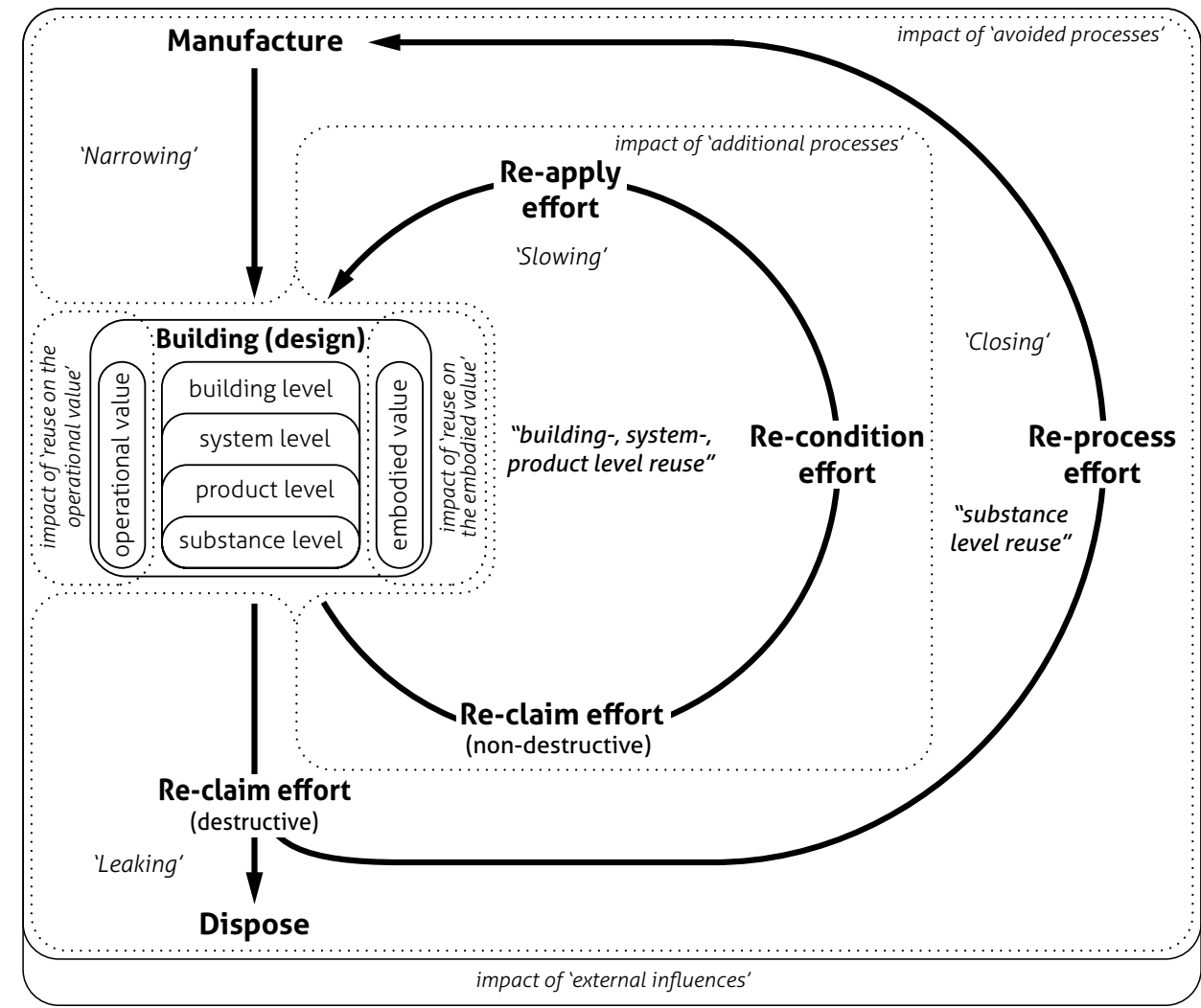

Figure 3.25: Conceptual reuse potential framework.

- Impact of 'additional processes'. Refers to the impact of the processes that are required to reuse the part, which is determined by the re-claim effort (non-destructive), re-conditioning effort and the re-apply effort;

- Impact of 'avoided processes'. Refers to the impact of the processes that would have been required if it the part would not have been reused, which is determined by the re-claim effort (destructive), dispose and/ or re-process effort and the impact to extract, harvest and manufacture a product from virgin materials, including the assembly of the part;

- Impact of 'reuse on the embodied value'. Refers to the embodied value, the economic, environmental, cultural and material value, that is being preserved during the processes to extend the useful life of the building, system or products.

- Impact of 'reuse on the operational value'. Refers to the impact that can be attributed to operating a reused building, system or product compared to an alternative non-reuse scenario.

In addition to the four impact categories that are dependent on the design, a fifth category has been identified, which is an independent variable that can influence the impact of all dependent impact categories, namely: 
- Impact of 'external influences'. Refers to factors extrinsic to the product, which are not part of the essential nature of the product and can influence all dependent variables.

The impact of 'external influences' is an independent external variable that may clarify variance between the reuse potential of buildings, systems and products and its actual end-of-life, which is determined by the situational context.

To clarify the conceptual reuse potential framework, all impact categories and the building characteristics will be discussed.

\section{Impact of 'additional processes'}

The impact of 'additional processes', is determined by the effort to re-claim, the disassembly, collection, separation and sorting or parts, the effort to re-condition, the maintenance, cleaning, reconfiguration, repair, refurbish, redistribution, remanufacture and cascading that is required for its new application and the effort to re-apply, the testing, certification, storage, stock-holding, market access, resale/ lease, redistribution, delivery, modification and re-assembly of the product. To support building, system and product reuse, the emphasis of the re-claim effort is put on the non-destructive disassembly of the parts by the addition of 'non-destructive' in the framework.

\section{Impact of 'avoided processes'}

The impact of 'avoided processes', is determined by the effort to re-claim the parts for disposal or re-processing the parts, which can be done using non-destructive or destructive disassembly methods. Since the 'avoided processes', often involves the fastest method to get rid of the material, the process often involves destructive disassembly methods, after which the materials are being disposed or re-processed and reused as secondary material for new building products or for parts made of biodegradable biological materials they can be sorted to be returned into nature to rebuild natural capital. Therefore, the emphasis of the re-claim effort for 'avoided processes' is put on destructive disassembly of the part by the addition of 'destructive' in the framework. In addition to the re-claim effort, the impact of 'avoided processes' is determined by the effort to re-process the re-claimed parts, to be down-cycled, functionally recycled, up-cycled or biodegraded and the impact to manufacture an alternative new non-reused part, which is determined by the effort to extract, harvest, manufacture a product from virgin or secondary materials, including the market access, sale/ lease, distribution, delivery, modification and assembly of the part.

\section{Impact of 'reuse on the embodied value'}

The impact of 'reuse on the embodied value', determines the value that is being preserved during reuse processes and determines whether or not the impact of 'additional processes' is worth the reuse of the building, system or product compared to an alternative non-reuse scenario. The embodied value refers to the energy, materials, economic and cultural values that are embodied in the physical entity. These values are often determined by tangible characteristics, such as size, weight, shape, material type, function, embodied energy, product composition, internal connections, external connections, planned 
configurations, state of the product, but also by intangible characteristics, such as the cultural and historical significance, quality perception and unplanned configurations.

Based on the literature review, it is argued that the higher the maintained embodied product values during reuse processes, the higher the benefits of reusing the product will be. Whereby the higher the benefits of reusing a product will be, the higher the likelihood will be that the product will be reused instead of producing a new equivalent. This implies that high embodied value equals a high reuse potential. To substantiate this statement, a few examples from literature are provided: from an economic perspective Gorgolewski (2008) noted that the higher the economic value of products, the greater the cost-effectiveness of its reuse will be; from an environmental perspective, WRAP (2008) identified that the greater the embodied energy of a product, the higher the impact of the processes that are required to bring the product in the required state and location may be, before jeopardising the environmental benefit when reusing a product; from a social perspective Boccadoro (2008) identified that the higher the cultural significance of an item, the more valued the item will be and the greater its contribution will be to make more meaningful buildings, additionally, as stated in Thompson (2017) by Greaber (2001) and Pederson (2008), "the greater the proportion of human labour and imagination, the more durable the value", whereby human labour increases human interaction and may clarify why high labour products are at later stage also valued higher than low labour mass produced products.

The embodied value that can be maintained or preserved during reuse processes is mainly determined by the building, system and product characteristics, based on the technical-, physical- and functional decomposition. Furthermore, the ability to re-claim and the effort it takes to re-claim the product determines the level to which the embodied value can be preserved during reuse processes. While the ability and effort it takes to re-condition the product, to bring the product to the required state and if necessary to bring the product to performance levels of new equivalent products, adds onto the embodied value. Furthermore, the project characteristics determine the amount of products that become available at the end-of-life, which may influences the economy of scale of the reuse processes, impacting the efficiency of these processes.

\section{Impact of 'reuse on the operational value'}

In addition to the impact of 'additional processes' and the impact of 'avoided processes', Cooper \& Gutwoski (2017) state: "The efficiency of a repurposed product (adaptive reuse) could be better than, equal to, or worse than the original efficiency given that it depends on the new function and operating conditions"(p. 10). This can ultimately result in a difference in the impact to operate the reused product compared to an alternative non-reused product, which is potentially more efficient in the operational phase. This is especially important for powered objects or products that impact the operational energy usage of the building. Furthermore, the operational impact is also determined by the maintenance intensity of the product, compared to the maintenance intensity of another non-reused 
product. Therefore, the impact of 'reuse on the operational value', has been added. Thus, the reuse of products that impact the operational impact of the building should be done with caution and if needed they should be upgraded to efficiency levels equal to new equivalent building products.

\section{Impact of 'external influences'}

The decision whether or not a building product will be reused cannot be isolated from external influences, the situational context. As Thompson (1979) stated: the "lastingness [of a building or building product] is imposed not [only] by intrinsic physical properties but by the social system" (p. 37). Thus it can be stated that the reuse potential is not only imposed by the intrinsic physical properties of the building design, but also by the social, economic, organisational, compliance and legislation and environmental context in which the product is used. Although, it is impossible to incorporate external influences in the evaluation of the reuse potential of buildings, systems and products. The designer should be aware that the actual decision about the fate of a building, system or product may differ from the identified reuse potential, which can be clarified by the impact of 'external influences'.

The impact of 'external influences' can affect all dependent variables in a positive and negative sense. To specify the impact of 'external influences', based on the analysis of the opportunities, enablers and barriers for deconstruction and reuse, the following examples of external influences have been identified, sub-divided in environmental, social, organisational, compliance and legislation, technical and economical factors (the given examples are not exhaustive):

\section{Environmental}

- Transportation efficiency improvements can reduce the transportation impact of reuse

- Local reuse reduces transportation impact of reuse

- Re-claim efficiency improvements can reduce the re-claim impact

- Re-conditioning efficiency improvements can reduce the re-conditioning impact

- Re-apply efficiency improvements can reduce the re-apply impact

- Extraction, harvesting and manufacturing process efficiency improvements can reduce the impact of products based on virgin resources, reducing the impact benefit of reuse Social

- The perception of product reuse, can support or discourage the reuse of products

- Reuse of parts with embodied cultural significance can preserve a culture's history and allow its culture and history to be transferred into the future, contributing to richer and more meaningful buildings, whereby the acknowledgement of the embodied culture is dependent of the context

- Actor initiative, can support the reuse of products

- Designer ingenuity, can support the identification of new ways to reuse products

- Industry scepticism can prevent the reuse of building products

- Awareness of availability, is necessary to identify the potential to reuse the product

- User behaviour can increase or reduce the operational impact of the building 


\section{Organisational}

- Maturity of reuse processes

- Technological development that improves the efficiency of reuse processes can reduce costs

- Available time to re-claim building products can support reuse

- Time-gap between reclaim and reuse, can result in additional storage costs

- Product specification availability, prevents over-specification in new application and potential rebound effects

- Maturity of reclaimed building product markets in quality and quantity to support demand and supply, can reduce risks to specify reused products and increase the amount of reused products

compliance and legislation

- Stimulative measures that support the establishment of reuse markets, by providing incentives to deconstruct and reuse products e.g. the significance of design for disassembly and reuse in sustainability assessment methods or governmental leadership to promote deconstruction and reuse in their own buildings

- Regulative measures that discourage negative behaviour, such as legislation or fees that increase costs to dispose or incinerate reusable materials, creating an incentive for companies to seek for alternative methods that are environmentally responsible, or tax reformations, such as e.g. carbon emission tax, no labour tax, non-renewable resource tax

- Prohibitive measures to restrict certain behaviour, e.g. landfill bans of certain material types.

Technical

- New product technologies can render older products technologies obsolete, reducing the potential for reuse

- Improving product standards and building codes may render the use of certain products obsolete or require upgrades, reducing the potential for reuse

Economical

- Economies of scale, can reduce the costs to reuse building products

- Stability of reclaimed building product markets can reduce price fluctuation of products and thus reduce risks and support reuse of products

- Changing business models, i.e. extended producer responsibility, product as-a-service models, can support the reuse of building products

- Resource scarcity/ resource grades, scarcity can result in increasing material prices

\subsubsection{Economic and environmental benefit of reuse}

Whether or not a building product will and should be reused, reuse should from an environmental perspective have a lower impact than the impact of an alternative non-reuse scenario and it is expected to cost less than- or equal to an alternative non-reuse scenario. As Cooper $\&$ Gutowski (2017) stated, the environmental benefit of reuse is best understood when comparing the reuse of a product with an alternative non-reuse scenario. To explore the potential for reuse to become environmentally and economically beneficial compared to an 
alternative non-reuse scenario, two calculation methods have been defined to calculate the environmental and economic benefit of reuse compared to an alternative non-reuse scenario.

The environmental impact and economic impact of reuse can be calculated in absolute values, e.g. the environmental impact in $\mathrm{MJ}$ and the economic impact in Euro. From an environmental perspective, the environmental impact to reuse a product can be calculated as the environmental impact of the 'additional processes' that are required to reuse the product, consisting of the environmental impact to re-claim, re-condition and re-apply the product, in MJ. If the environmental impact of 'additional processes' exceeds the embodied energy value, the embodied energy of the part to be reused in proportion to its remaining lifespan, the potential to reuse the product to reduce the environmental impact is low, thus the environmental benefit is marginalised.

For the reuse to be environmentally beneficial compared to an alternative non-reuse scenario, the environmental impact of 'additional processes' to reuse the product should not exceed the environmental impact of 'avoided processes', the environmental impact created to deal with the old product waste or to re-process the materials and the impact to make and apply an alternative product from new materials. The environmental benefit of reuse excludes the embodied energy value of the product that is being reused, since this impact has already occurred. As the environmental impact is not limited to the embodied energy, the impact of 'reuse on the operational value', the impact that can be attributed to operating a reused building, system or product compared to an alternative non-reuse scenario, should also be incorporated in the environmental benefit calculation. To enable an accurate comparison, the difference between the fraction of the operational impact the reused part can be accounted for and the fraction of the operational impact the alternative non-reuse product can be accounted for should be taken into account.

To guarantee an objective comparison of the variations between the reused product and the alternative non-reuse product, a functional unit has to be defined. According to ISO 14044, a functional unit is defined as a cluster of characteristics which is equal in order to compare different design options. This cluster of characteristics is related to functional or technical requirements, required by regulations or norms for the specific context of the building element. In the comparison of the environmental impact of product reuse compared to an alternative non-reuse scenario, the alternative non-reuse scenario should be able to cover the same area and functionality when utilising the reused product. The only difference that can be identified is the remaining technical lifespan of the reused product and the technical lifespan of the new product. Therefore, the environmental impact of the 'additional processes', should be divided by the remaining technical lifespan of the product, the environmental impact of the 'avoided processes' should be divided by the technical lifespan of the alternative non-reuse product and the environmental impact of 'operating the product' should be calculated in M] per year, to enable an objective calculation of the environmental impact benefit of reuse compared to an alternative non-reuse scenario in MJ per year. Thus, the environmental benefit of reuse compared to an alternative non-reuse scenario can be calculated according to equation 1.1. 
Equation 1.1 - environmental benefit of reuse compared to an alternative non-reuse scenario

$$
\mathrm{EE}_{\text {ben }}=\left(\frac{\mathrm{Adl} \mathrm{Idditional} \mathrm{processes}_{\mathrm{T}_{\text {remaining lifespan }}}}{\mathrm{Avl}_{\text {avoided processes }}}\right)+\mathrm{O \textrm {I } _ { \text { operational impact reuse } }}-\mathrm{O \textrm {I } _ { \text { operational impact new } }}
$$

With

$$
\begin{aligned}
& \mathrm{EE}_{\text {ben }} \quad \text { Embodied energy benefit of reuse compared to alternative non-reuse scenario }
\end{aligned}
$$

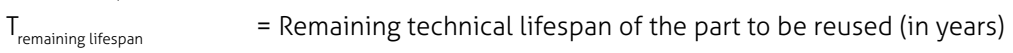

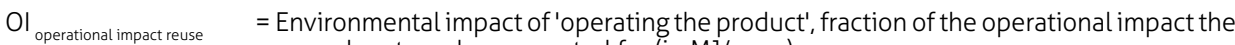

$$
\begin{aligned}
& \mathrm{Avl}_{\text {avoided processes }} \quad=\text { Environmental impact of 'avoided processes', sum of the environmental impact } \\
& T_{\text {lifespan }} \\
& \text { Ol operational impact new } \\
& =\text { Technical lifespan of alternative non-reuse part (in years) } \\
& \text { = Environmental impact of 'operating the product', fraction of the operational impact the }
\end{aligned}
$$

The environmental impact can be categorised according to the following conditions:

$$
\text { If } \begin{aligned}
\mathrm{EE}_{\mathrm{ben}}>0 & \begin{array}{l}
\text { The environmental impact of reuse is more than the alternative non-reuse } \\
\text { scenario, reuse has no environmental benefits and should be avoided. }
\end{array} \\
\mathrm{EE}_{\mathrm{ben}}=0 \begin{array}{l}
\text { The environmental impact of reuse is equal to the alternative non-reuse scenario, } \\
\text { reuse has the same environmental impact as non-reuse, reuse is preferred to reduce } \\
\text { resource consumption }
\end{array} & \begin{array}{l}
\text { The environmental impact of reuse is less than the alternative non-reuse scenario, } \\
\text { reuse has environmental benefits and should be stimulated. }
\end{array}
\end{aligned}
$$

From an economic perspective, the economic impact can be calculated in Euro and can be distinguished in two perspectives, namely: 1) the client in ownership of the product, and 2) the client not in ownership of the product. If the client is in ownership of the product, the costs to reuse the product can be calculated as the economic impact of the 'additional processes' that are required to reuse the part, consisting of the re-claim, re-condition and re-application costs. If the client is not in ownership of the product, the costs to reuse the product can be calculated as the sum of the embodied economic value (the residual value) of the product and the economic impact of the 'additional processes' that are required to reuse the part. If the costs of 'additional processes' exceeds the embodied economic value, the economic benefit of reusing the product is marginalised.

For reuse to be economically viable, there should be an economic benefit compared to an alternative non-reuse scenario. To calculate the economic benefit of reuse compared to an alternative non-reuse scenario (client not in ownership of the product), the sum of the embodied economic value and the costs of the 'additional processes' should not be higher than the costs of the 'avoided processes', the costs to deal with the old product waste or re-process the materials and the costs to make an alternative product from new materials. In contrast to the environmental benefit, this calculation includes the embodied economic value of the product that is being reused if the client is not in 
ownership of the product, but should be excluded from the calculation if the client is in ownership of the product. Similar to the environmental benefit calculation, the impact of 'reuse on the operational value' should be taken into account. Furthermore, the sum of the embodied economic value and the costs of the 'additional processes', should be divided by the remaining lifespan of the product, the costs of the 'avoided processes' should be divided by the technical lifespan of the new product and the economic impact of 'operating the product' should also be calculated in costs per year, to enable an objective calculation of the economic cost benefit of reuse compared to an alternative non-reuse scenario in Euro per year. Thus the economic benefit of reuse compared to an alternative non-reuse scenario can be calculated according to equation 1.2 and depending on the client ownership of the product, the embodied economic value should be incorporated (client not in ownership) or removed (client in ownership) from the equation.

\section{Equation 1.2 - economic benefit of reuse compared to an alternative non-reuse scenario}

$$
E_{\text {ben }}=\left(\frac{\left(E_{\text {value }}+A d l_{\text {additional processes }}\right)}{T_{\text {remaining lifespan }}}-\frac{A v l_{\text {avoided processes }}}{T_{\text {lifespan }}}\right)+O I_{\text {operational impact reuse }}-O I_{\text {operational impact new }}
$$

With

$$
\begin{aligned}
& \mathrm{E}_{\text {ben }} \quad \text { Economic benefit of reuse compared to alternative non-reuse scenario (euro / year) } \\
& \mathrm{EE}_{\mathrm{value}} \quad=\text { Embodied Economic value, the residual value of the part to be reused (in euro) }
\end{aligned}
$$

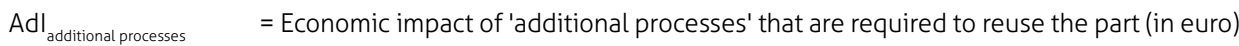

$$
\begin{aligned}
& \text { OI operational impact reuse = Economic impact of 'operating the product', fraction of the operational impact the } \\
& \text { reused part can be accounted for (in euro/ year) } \\
& \mathrm{T}_{\text {remaining lifespan }} \quad \text { = Remaining technical lifespan of the part to be reused (in years) }
\end{aligned}
$$

The economic benefit can be categorised according to the following conditions:

$$
\text { If } \quad \begin{array}{ll}
E_{b e n}>0 & \begin{array}{l}
\text { The economic impact of reuse is more than the alternative non-reuse scenario, reuse } \\
\text { does not have economic benefits - LOW reuse potential }
\end{array} \\
E_{b e n}=0 & \begin{array}{l}
\text { The economic impact of reuse is equal to the alternative non-reuse scenario - MEDIUM } \\
\text { reuse potential }
\end{array} \\
E_{b e n}<0 & \begin{array}{l}
\text { The economic impact of reuse is less than the alternative non-reuse scenario, resulting } \\
\text { in an economic benefit when reusing the product - HIGH reuse potential }
\end{array}
\end{array}
$$




\subsubsection{Reuse mechanisms}

In order to calculate the environmental or economic benefit of reuse compared to an alternative non-reuse scenario, a lot of data is required. This data is often not available, which makes it impossible to take full benefit of these calculations. To support the development of the reuse potential evaluation method, based on the calculation method to calculate the environmental and economic benefit of reuse with a non-reuse scenario and the analysis of the opportunities, enablers and barriers for deconstruction and reuse, four mechanisms have been identified that influence the reuse potential of building products, namely:

1. The reuse potential can be controlled by its building design through reducing: the impact of 'reuse on the embodied value' and reducing the impact of 'reuse on the operational value';

2. The reuse potential can be influenced directly by reducing the impact of 'additional processes';

3. The reuse potential can be influenced indirectly by increasing the impacts of 'avoided processes', and;

4. The reuse potential can be influenced indirectly by the impact of 'external influences'.

Each mechanism can be used to increase the reuse potential of buildings, systems and products, while only the first mechanism can be influenced based on the design, which is the aim of the reuse potential evaluation method. Each mechanism will be detailed below.

The first mechanism is aimed at the technical ability and effort that is required to enable effective and efficient deconstruction and reuse processes, which can largely be controlled through the incorporation of Design for Disassembly strategies and taking into account the functional-, technical- and physical decomposition of the design. To support the reuse of building products, the impact of 'additional processes' should not be higher than the impact of 'reuse on the embodied value'. The impact of 'reuse on the embodied value' refers to the preserved embodied value during reuse processes. For example, the energy, labour and costs it took to assemble the product are not part of the embodied value, since these impacts are being undone and lost, during reuse processes, to re-claim and reuse the product. Furthermore, products with a high embodied value allow for more 'additional processes', before the impact of 'additional processes' raises above the embodied value, and the impact of 'reuse on the operational value' should be reduced to a minimum, otherwise, the operational impact is likely to dominate the embodied impact benefit.

Therefore, as a general strategy to increase the reuse potential of building products is to "design buildings, systems and products: with high embodied value to allow for the impact of 'additional processes'; that maintain most of their embodied value during reuse processes, and; to allow the impact of 'reuse on the operational value' to be reduced to a minimum through upgrading the parts that impact the operational value". 
The second mechanism is aimed at the factors that directly influence the reuse potential of building products, which are the "additional processes" impacts, the impacts that are associated with the reuse processes that are required to enable the reclamation, reconditioning and re-application of the building products. In contrast to the first mechanism, this mechanism is aimed at the efficiency of the reuse processes. A general strategy to improve the reuse potential of building products is to: "reduce the impact of 'additional processes' through the improvement of the efficiency and effectiveness of reuse processes, by benefiting from external influences;". This would allow reuse benefits to be increased and support the competitiveness of reusing building products against newly manufactured products.

The third mechanism is aimed at the factors that indirectly influence the reuse potential of the building product, which are defined as the impact of the "avoided processes", the impact of the processes that would have been required to produce a new product and to deal with the old product waste. A general strategy to improve the reuse potential of building products is to: "increase the impact of 'avoided processes' by benefiting from external influences", such as tax revision, green legislation, resource scarcity and declining ore grades, which would improve the competitiveness of reuse.

The fourth mechanism is based on external factors that may disrupt the existing mechanisms that influence the reuse potential of building products, e.g. the removal of tax on human labour and move towards taxing the use of on non-renewable resources. This will increase the avoided processes impact and reduce the additional processes impact, which is mainly human labour based, thus improve the cost-effectiveness of building product reuse. Other examples are e.g. the recertification of existing products as hazardous to health, restricting its future reuse, or changing legislation or improving product standards, such as thermal insulation values or increasing the minimum door height, which restricts direct reuse of products that are conform former standards.

Four mechanisms have been identified that control or influence the reuse potential of building products, resulting in three general strategies to increase the reuse potential, which are summarised as:

- Design buildings, systems and products: with high embodied value to allow for the impact of 'additional processes'; that maintain most of their embodied value during reuse processes, and; to allow the impact of 'reuse on the operational value' to be reduced to a minimum through upgrading the parts that impact the operational value;

- Reduce the impact of 'additional processes' through the improvement of the efficiency and effectiveness of reuse processes, by benefiting from external influences;

- Increasing the impact of 'avoided processes' by benefiting from external influences

The impact of 'external influences' have been limited to the impact on 'additional processes' and the impact on 'avoided processes'. There are many more external influences that can be utilised to stimulate the reuse potential of building products, but this research 
is mainly focused on the first mechanism, how the reuse potential can be increased based on its design and how the reuse potential can be measured in an objective manner, to support designers in the design of buildings, systems and products with a high reuse potential.

\subsection{Conclusion}

In this chapter the enablers, opportunities and barriers that influence the decision making of deconstruction and reuse have been analysed from environmental, social, organisational, compliance and legislation, technical, and economical perspective (RQ3). To improve the understanding and the impact of different factors on decision making of deconstruction and reuse, the enablers, opportunities and barriers have been translated in cause-effect schemes (RO4). Based on the understanding of these factors a conceptual reuse potential framework has been developed (RO-5).

In addition, four generic mechanisms have been identified how the reuse potential of building products can be influenced, and how three strategies can increase the reuse potential. Since only the first mechanism can be influenced based on the design of the building or building product, the reuse potential evaluation method should support designers in the operationalisation of the first mechanism: "design buildings, systems and products: with high embodied value to allow for the impact of 'additional processes'; that maintain most of their embodied value during reuse processes, and; to allow the impact of 'reuse on the operational value' to be reduced to a minimum through upgrading the parts that impact the operational value".

In the following chapter the main principles and guidelines that support this mechanism will be identified to understand the different design strategies that can be incorporated to increase the reuse potential of buildings, systems and products. 
90 


\section{Chapter 4 Design strategies to support reuse}




\section{4 | Design strategies to support reuse}

\subsection{Introduction}

The aim of this research is to develop a method to evaluate and support the reuse potential of building products. In the conceptual reuse potential framework as outlined in chapter 3, four mechanisms have been identified that can influence the reuse potential of buildings, systems and products. Since this research mainly focusses on the mechanisms that can be influenced based on the design, the following strategy has been defined: "design buildings, systems and products: with high embodied value to allow for the impact of 'additional processes'; that maintain most of their embodied value during reuse processes, and; to allow the impact of 'reuse on the operational value' to be reduced to a minimum through upgrading the parts that impact the operational value".

In order to support the strategy defined above, it is important to identify and understand the effect of specific design strategies and guidelines on the reuse potential of buildings, systems and products. The design strategy 'Design for Disassembly' is considered the most important design strategy to support the reuse of building products. Design for Disassembly is defined as "a characteristic of a product's design that enables the product to be taken apart at the end of its useful life in such a way that allows components and parts to be reused, recycled, recovered for energy or, in some other way, diverted from the waste stream" (ISO 14021, 2016). Furthermore, according to Nordby (2009) Design for Disassembly implies the optimization of construction methods and connections between components and is viewed as a strategy to facilitate maintainability, adaptability, and end-of-life material salvage (p. 50).

In the last decades, much research has been conducted in the field of 'Design for Disassembly' to support architects in the design of adaptable, demountable and reusable buildings. This research often resulted in a list of design guidelines. A design guideline is considered a general rule that helps designers to make decisions regarding design parameters. Design guidelines are not absolute and can be adjusted based on their specific context (schmidt III, 2014). To get an overview of existing 'Design for Disassembly' guidelines, principles and their reasoning, and identify a departure point of this study, the following research question will be studied in this chapter: RQ4: Which 'Design for Disassembly' guidelines can be identified in literature to support reuse of buildings and building products and what is the guideline's reasoning?

To answer this research question, a comprehensive literature review will be performed to identify the main guidelines and principles and categorise them in groups to generate an overview of guidelines and principles that have a similar scope. The overview of Design for Disassembly guidelines and principles can be used as a reference frame speciying the main 
Design for Disassembly guidelines and their reasoning. Finally, this chapter will conclude with an overview of the Design for Disassembly strategies related to their respective resource flow impact and the main reuse process steps as identified in the reuse potential framework. The identification of this relation enables the specification of design strategies and design guidelines that are essential in the design of reusable building products and can be used as input for the development of the reuse potential evaluation method.

\subsection{Method}

To review existing Design for Disassembly guidelines and principles, relevant scientific literature must be identified that contain Design for Disassembly guidelines. Therefore, various searches have been conducted using the following terms: 'Design for Disassembly', 'Design for Deconstruction', 'Design for Reuse', 'Design for Deconstruction and Reuse', 'reuse', 'disassembly', 'deconstruction', in combination with one of the following terms 'guidelines' or 'principles' or 'strategies' and 'building design' or 'building' or 'build environment', with the publication date range from 2000 to 2017. Twenty-two sources have been selected as relevant to incorporate in the study. In order to identify an article as relevant it must explicitly mention design guidelines, principles or strategies.

Throughout the study of the 22 scientific sources, 106 design guidelines have been identified. The selection of 106 design guidelines incorporates a first grouping on the lowest level, meaning design guidelines that have the same aim or goal, but are phrased differently are coupled in one design guideline that best represents the meaning of the guideline. The full list of design guidelines and the sources that mention each design guideline can be found 'Appendix B - Design for Disassembly guidelines'.

Since a random list of 106 guidelines is difficult in use due to its size, the design guidelines will be categorised in three levels, 1) strategy groups, 2) principles, and 3) guidelines. Four strategy groups have been identified, namely: building strategies, system \& product strategies, material strategies, documentation strategies. Each strategy group is divided in design principles, which is a classification of multiple design guidelines that have a similar goal. When defining design principles it is important to avoid overlap between principles and reduce the amount of categories to an appropriate number. The main Design for Disassembly strategies and principles have been summarised in Table 4.14.

It should be noted that the aim of design principles and guidelines is not to achieving one single best design, they can be integrated in buildings with specific aims and demands, which may require emphasis on several specific design principles. Furthermore, it is possible to have contradicting principles, such as design to suit the means of handling, whereby it can be recommended to use small light weight elements to allow disassembly without the need for heavy equipment. This might be advantageous for users to perform changes in an informal manner, without involving a contractor. While to enable fast deconstruction of the building in a more formal setting, it would be far easier if the design was constructed from a few larger parts rather than many small parts, to reduce labour costs. Depending on the situation one may put emphasis on specific design principle. 


\subsection{Design for disassembly guidelines and principles}

In this section the result of the literature review is presented. This section is structured according to the Design for Disassembly strategy groups and design principles as defined in Table 4.14. All design principles will be described, including the incorporated design principles and their functioning. Each principle will conclude with a summary of the incorporated design guidelines.

In order to keep the texts clean from numerous references, the following numbers are used to refer to literature: 1. Addis \& Schouten (2004); 2. Akinade et al., (2016); 3. Chini \& Balachandran (2002); 4. Couto \& Couto (2010); 5. Crowther (2001); 6. Crowther (2002); 7. Durmisevic (2006); 8. Fletcher (2001); 9 . Guy \& Ciarimboli (2008); 10. Guy \& Shell (2002); 11. Hechler, Larsen \& Nielsen (2012); 12. Hradil et al. (2014); 13. lacovidou \& Purnell (2016); 14. Morgan \& Stevensen (2005); 15. Nordby (2009); 16. Pulaski et al., (2003); 17. Rios, Chong \& Grau (2015); 18. Sassi (2002); 19. Sassi (2009); 20. Thormark (2001); 21. Tingley (2012); 22. Webster \& Costello (2005); 23. Chini (2007); 24. Calkins (2008); 25. Leupen, (2013); 26. Schmidt III (2014), and 27. Brand, (1994).

Table 4.14: Design for Disassembly strategy groups and design principles

\begin{tabular}{|c|c|c|}
\hline \multicolumn{2}{|c|}{ Strategy groups and principles } & no. of design guidelines \\
\hline \multicolumn{3}{|c|}{ 1. Building strategies } \\
\hline 1.01 & Design for functional changeability & 4 \\
\hline 1.02 & Design for size changeability & 1 \\
\hline 1.03 & Design for internal changeability & 1 \\
\hline 1.04 & Design with passive design measures & 1 \\
\hline \multicolumn{3}{|c|}{ 2. System \& product strategies } \\
\hline & Part strategies & \\
\hline 2.01 & Design with independent building layers & 3 \\
\hline 2.02 & Modular and universal design & 4 \\
\hline 2.03 & Simple and legible design & 3 \\
\hline 2.04 & Design with parallel configurations & 2 \\
\hline 2.05 & Design with prefabricated configurations & 3 \\
\hline 2.06 & Design to suit the means of handling & 3 \\
\hline 2.07 & Design with durable components & 3 \\
\hline \multirow[t]{2}{*}{2.08} & Design with (local) reclaimed and reusable building products & 3 \\
\hline & Connection strategies & \\
\hline 2.09 & Design with demountable connections & 3 \\
\hline 2.10 & Design with standardized interfaces & 3 \\
\hline 2.11 & Design connections for fast disassembly speed & 2 \\
\hline 2.12 & Design with durable connections & 2 \\
\hline \multicolumn{3}{|c|}{ 3. Material strategies } \\
\hline 3.01 & Design for recyclable and biodegradable materials & 6 \\
\hline 3.02 & Design for pure and effective material recycling or biodegradability & 8 \\
\hline 3.03 & Design with recycled and recyclable materials & 2 \\
\hline \multicolumn{3}{|c|}{ 4. Documentation strategies } \\
\hline 4.01 & Maintenance plan & 2 \\
\hline 4.02 & Deconstruction plan & 2 \\
\hline 4.03 & Reconfiguration and reuse plans & 3 \\
\hline 4.04 & Integral and updated 'as built' BIM models or drawings & 3 \\
\hline 4.05 & Permanent identification & 2 \\
\hline
\end{tabular}




\subsubsection{Building strategies}

\subsubsection{Design for functional changeability}

If a building is designed in such a way that it contains a high passive capacity to change from one function to another in the course of time with minor structural adjustments, it is more likely that the building as a whole will be preserved and remains functional in the longer timespan (7). The positioning of structural elements and the main service distribution systems is of major importance to allow the building to change function without major adjustments $(7,9)$. There are multiple approaches feasible to design such structures, e.g. design of an 'open space' construction system, that allows for change in the compartmentalization of the building through repositioning of partitioning walls ( 2 , $4,26)$, specification of the fixed, unchangeable parts and changeable parts, such as the separation of the structural parts from the non-structural parts $(3,7,9,10,12,15,16$, $22)$, consolidation of main distribution systems in core units, to minimize runs and hence unnecessary entanglements, that make change of function or use difficult (9).

Design guidelines

- Design to allow change of functionality over the course of time;

- Design for maximum flexibility, e.g. choose an 'open space' construction system;

- Separate fixed and changeable parts e.g. structural from non-structural parts;

- Consolidate installation systems into core units.

\subsubsection{Design for size changeability}

The ability of a building to expand or shrink can have a big influence on the users of the building, whether they will move to a new building or not, e.g. if the building cannot grow or shrink together with the growth or shrinkage demand of the user over time, they might be forced to move to a bigger building or smaller building, in order to fit their demands and financial requirements (7). The principle design for size changeability should allow buildings to change in size over time and make it easier to extend or shrink the capacity of the building.

Design guideline

- Design to allow the building to be scalable in size.

\subsubsection{Design for internal changeability}

Design for internal changeability should allow the building to adapt their internal partitioning of one functional zone into sub-zones (7). This allows the building to fulfil multiple use strategies within one function, e.g. the change of an open office typology to a cellular office typology.

Design guideline

- Design to allow the building to be sub-divided into multiple units and merged into larger units. 


\subsubsection{Design with passive design measures}

The use of passive design measures have the potential to decrease the amount of required active service components $(8,14,21)$, which has the potential to decrease the operational energy use, and ease the deconstruction and entanglement of installations through building components. This will not only benefit the deconstruction phase, but also increase the reuse potential of building components that are prevented from being affected by the integration of installations. Furthermore, passive design measures usually have a longer life-span than active service components $(8,14)$ and thus has the potential to decrease the need for resources in the use phase. Examples of passive design measures could be, the use of thermal mass for cooling, passive solar gain for heating and the use of a solar chimney to allow for natural ventilation.

Design guideline

- Design with use of passive design measures to reduce the need for active services components.

\subsubsection{System \& product strategies}

The system \& product strategies have been sub-divided into part strategies, which focus on the design of the parts and products that can be distinguished in the building itself, and connection strategies, which focusses on strategies related to the design of connection types, to support disassembly and reuse.

\section{Part strategies}

\subsubsection{Design with independent building layers}

According to Brand (27), a building can be seen as a collection of functional layers, each with a different functional life, which should be designed to enable change independent from each other. He identified the following layers and changing rates: site (eternal); structure (30-300 years); skin (20 years); service (7-15 years); space plan (3-30 years) and stuff (daily- monthly). The arrangement of the components according to their functional and technical lifespan is of major importance in order to allow adaptability, repair, replacement and reuse $(1-5,7-15,19,21,22)$. This means that components with a short life expectancy should be easily accessible and disassembled and components with longer life expectancy may be less accessible or less easy to be disassembled (7). Although, all building products should be able to be accessible and removable (1, 2-6, 8, 9, $13,14,18,19,21)$, to facilitate reuse when the building' configuration becomes obsolete.

\section{Design guidelines}

- Arrange the building elements and components according to their functional and technical lifespan;

- Design building elements and components of different functional and technical lifespan to be separated;

- Design all building component and elements to be accessible and removable, with the emphasis on the accessibility of parts with a shorter life cycle. 


\subsubsection{Modular and universal design}

In order to design building products that are compatible with other building products, their dimensional compatibility is of great importance and could be achieved through use of modular designs $(1,2,5-13,15-17,19-21)$. The propagation of a standardized structural grid sizes (1-5, 7-9, $11,15,17,21,22)$ and standard element and component dimensions $(2,3,7,9-11,15)$ will allow building products to be easily reused in other buildings that have a similar modular coordination. The use of modular designs and the minimization of the different types of components $(1,2,4-6$, $8-12,15,18,19,22)$ will result in larger quantities of the same or similar building products, which can also be called universal building products, which increases their potential for reuse.

\section{Design guidelines}

- Design with use of modular designs, standard structural grid dimensions and components $\&$ elements based on dimensional coordination;

- Design with similar and repetitive building components;

- Minimize the number of different types of components;

- Minimize the number of components.

\subsubsection{Simple and legible design}

When the building is designed in such a way that their composition and assembly is visible, clear and legible $(4,5,8,13,17,22)$, and has a regular repeating pattern throughout the building $(1,2,7,13)$, the deconstruction steps are easy to identify and will simplify the deconstruction, sorting and reuse processes. This could be achieved through the use of simple geometries and common standard shapes $(1-4,6,8,9,11-13,15-17,21,22)$, since these are easier to understand than complex building shapes or combinations of multiple systems in one building (1). Additionally, it could be stated that the use of custom and non-standard components may have more difficulties in finding a second application in other buildings.

Design guidelines

- Design legible building systems;

- Design with simple geometries and common standard shapes;

- Avoid using multiple types of structural systems.

\subsubsection{Design with parallel configurations}

The ease of assembly and disassembly of a building depends on the type of assembly and amount of sequential steps that are required to disassemble building parts or the entire building. To ease the assembly and disassembly process the design should allow for parallel disassembly rather than sequential disassembly $(1,3-7,9,13-15,18,19)$. Furthermore, the numbers of levels of deconstruction to remove components or elements should be minimized (1). The use of parallel configurations enables building components or elements to be removed without disrupting other components or elements.

\section{Design guidelines}

- Design to allow parallel disassembly rather than sequential disassembly;

- Minimize the number of levels of deconstruction to remove products or elements. 


\subsubsection{Design with prefabricated configurations}

Design with prefabricated configurations $(1-3,6,7,9,11,12,16,17,21)$ offers great potentials to decrease construction costs, by decreasing the assembly and disassembly time and their increased quality, which is often achieved with off-site construction and results in an increased potential for reuse. Prefabricated configurations that can easily be assembled and disassembled as independent clusters of elements and components are highly cost effective for reuse, in comparison with small scale elements that have to be assembled and disassembled one part at a time and thus require large amounts of labour. The usual prefabricated configurations do not allow for changes in their design, which decrease their applicability and exchangeability with changing contexts. Therefore, the configurations should be designed in such a way that they can be adapted to changing functional and dimensional requirements while maintaining their stability and integrity. This could be facilitated by constructing independent clusters of smaller sized components, which can easily be reconfigured, adapted and replaced to increase possible variations (7) and thus their applicability and exchangeability of the cluster in different contexts. Furthermore, the use of base elements that allow the smaller sized elements and components to be removed as a whole and serve as an intermediary between clusters (7) will be of great benefit in deconstruction, e.g. to allow large cluster to be disassembled and reused directly as a whole in a different location, or transported to off-site manufacturing facilities that can reconfigure and adapt the clusters in an effective manner to the required configuration. Finally, the configurations should not only allow upgrade, adaptation, repair and replacement of parts when the cluster is disassembled, but also in its assembled state up to a certain degree to ease maintenance.

Design guidelines

- Design with prefabricated configurations;

- Design independent clusters with smaller sized elements to create variation, to increase its applicability and exchangeability in different contexts;

- Design with base elements to form independent clusters of components and elements; and function as intermediary between clusters.

\subsubsection{Design to suit the means of handling}

The size of building elements and components should be designed in such a way that they allow various possible handling options at all stages of assembly, disassembly, transport, remanufacturing and re-assembly $(1,2,4-7,9,10,16-19,21,22)$. This could be done by designing the building with a smaller number of larger parts, which allows the structure to be removed quickly $(10,13,19,22)$. Although, this might require large equipment to handle large building parts, which could be impractical if building parts have to be removed from inside the building, but make it easy to disassemble the whole building. The use of small and light-weight elements $(11,15)$ are more easily handled during disassembly, transport and reprocessing and has by its size a wider range of applications. Furthermore, it allows for self-building and local reuse. These two approaches to the sizes are in contradiction and should be sought for the optimum. 


\section{Design guidelines}

- Size components to suit the means of handling;

- Use small and light weight elements;

- Use few large parts rather than many small parts.

\subsubsection{Design with durable components}

The design of components and elements should be durable $(1,2,5,9,11,13-15,19,21)$, in the sense that they can withstand repeated assembly and disassembly, to facilitate reuse. Furthermore, the use of adequate tolerances $(1,3-7,9-11,15,18,19,21)$ should minimize the need for destructive methods that can impact adjacent components during repeated disassembly and reassembly procedures. Patchable detailing can support in the product life extension through partial replacement rather than whole product replacement, if a part of the product is damaged or deteriorated (14).

Design guidelines

- Design components to be durable to withstand repeated assembly and disassembly;

- Design with adequate tolerances to allow reuse without damages;

- Design using patchable detailing.

\subsubsection{Design with (local) reclaimed and reusable building products}

Design buildings with local reclaimed materials $(8,9,13,13-15,17,22)$, will preserve the embodied energy, labour and materials, reduce the need for virgin resources and reduce the impact related to transportation of virgin resources. Another benefit of reclaimed materials is the fact that if a component or element was reclaimed once, they are likely able to be reclaimed again and it encourages the markets for salvaged materials (22). Furthermore, when building products are technically not able to be reused anymore, they should be recycled to form the input for equivalent building products. If there are not sufficient reclaimed building products available, the use of locally sourced materials ( 3 , $11,13,21,22)$, recycled materials $(4,5,8,11,20)$ and materials with reuse potential based on current practice $(1,2,8,11,12,16,22)$ should be considered.

The principle design with (local) reclaimed and reusable building products has the potential to boost the development of markets for reclaimed building materials and decrease waste streams from existing infrastructure significantly.

Design guidelines

- Design with locally reclaimed materials;

- Design with locally sourced materials;

- Design with materials that have a reuse potential based on current practice. 


\section{Connection strategies}

\subsubsection{Design with demountable connections}

A reversible connection is a physical relationship or link between two elements that can be undone without damaging the components or elements they connect. The use of mechanical (reversible) connections rather than chemical (irreversible) connections allows building products to be assembled and disassembled multiple times without damaging the components or elements they connect $(1-5,7-19,22)$. The use of adhesives, resins, coatings and secondary finishes that cover connections should be avoided $(3,7,9,10,12-14,16$, 20-22), because they require special attention during deconstruction, requiring additional time and costs for disassembly or does not allow deconstruction at all. Furthermore, covered connections with secondary finishes make it difficult to locate connection points. If the use of chemical connections is unavoidable they should be made weaker than the parts being connected $(3,4,10,11,16,18,19)$. When chemical bonds are made weaker than the parts being connected, it allows bonds to break during disassembly rather than the components, e.g. if the used mortar between bricks is significantly weaker than the bricks it will facilitate the separation of the individual bricks and eventual reuse.

Design guidelines

- Design with mechanical (reversible) connections rather than chemical (irreversible) connections;

- Avoid the use of adhesives, resins, coatings and secondary finishes that cover connections;

- When chemical connections are unavoidable they should be made weaker than the parts being connected.

\subsubsection{Design with standardised interfaces}

Standardised or generic interfaces will simplify disassembly and increase compatibility with different contexts and support reuse in multiple applications $(1,3,4,6,9-11,14$, $16,19,22)$. The use of project specific interfaces would unnecessary complicate the reuse of such building products and should thus be avoided. Furthermore, the variety of different kinds of connections in a building should be minimized $(1-5,7,9,11,12,15$, $16,18-22)$, which will further increase the applicability and exchangeability of generic and standardized interfaces. Furthermore, standardised interfaces that allow the use of common (hand) tools will simplify the disassembly and reassembly of the parts and allow them to be easily reused in different building systems. Furthermore, the use of common (hand) tools can reduce preparation costs (specialist tools may not be identified or have to be purchased/ rented), lower the equipment costs and no special training is required, which will stimulate self-building and local reuse.

Design guidelines

- Design with use of generic and standardized interfaces;

- Design with a minimal amount of different types of connections;

- Design the connection to allow use of common (hand) tools for assembly and disassembly. 


\subsubsection{Design connections for fast disassembly speed}

The faster and easier it is to disassemble a component or element, the less labour and costly the disassembly process will be and make it more attractive to reuse building products. Therefore, easily locatable, accessible and removable fasteners and joints (1, 3-22) will ease the planning of dismantling and the dismantling process and thus the likeliness of the building products to be disassembled and eventually being reused. This in contrast to complex, unique, unidentifiable and inaccessible connections that increase assembly and disassembly time and complicate the deconstruction process. Furthermore, the number of connections between different functional layers and within one functional layers should be minimized $(1,5,8-10,12,13,15,16,18-22)$, this will lead to an increased disassembly speed and thus reduce costs.

Design guidelines

- Design connections to be easy to locate, access and remove;

- Design with a minimal amount of inter $\&$ intra building system connections.

\subsubsection{Design with durable connection}

To be able to directly reuse parts without the need for new fasteners or reparation of joints, the connection should be durable and be able to withstand repeated assembly and disassembly $(1,2,5,7,9,13-15,18,19,20)$. To support durability of connections, the use of independent third elements that function as an intermediary between the two elements or components that are being connected will allow the element or component being assembled or disassembled, without affecting the integrity of the structure (7) and increase durability.

Design guidelines

- Design joints and connections that are able to withstand repeated assembly and disassembly;

- Design connections with the use of independent interfaces as the intermediary between individual components or elements.

\subsubsection{Material strategies}

\subsubsection{Design for recyclable and biodegradable materials}

If reuse of building components and elements is technically not feasible anymore, long cyclic materials (technical materials) should be easy to separate $(8-10,12,21,22)$ and allow them to be recycled or up-cycled $(2,5,8,11,16,18-20)$. Recycling is a transformation process that enable subsequent use of materials involving similar purposes in which the quality, durability and economic value is maintained, and upcycling is a transformation process in which materials are converted into new materials of higher quality with an increased functionality and economic value $(23,24)$. The process in which materials are converted into new materials whose quality, durability and economic value have been reduced, also known as down-cycling, should be eliminated to allow for continuous closed material loops $(23,24)$. 
To support the recycling process, two parts that cannot be recycled together should be easy to separate (20). Furthermore, hazardous materials should be easy to remove $(9,11$, $16,17,20)$. If it is not possible to separate two parts, they should be made from the same material to allow them to be recycled together $(1,2,3,5,8,9,10,18,19,20)$ and reduce the need to disassemble the parts. To enable two parts to be recycled without disassembly, it is important to use joints and fasteners of material compatible with the parts connected, otherwise they may complicate the recycling process $(7,20)$. For short cyclic materials (biological materials) it is of great importance to allow them to be cascaded, which is the gradual degradation of material order at their end-of-life and finally allow them to be safely returned into nature, to rebuild natural capital.

Design guidelines

- Design with materials that can easily be separated;

- If two parts cannot be recycled together, make them easy to separate;

- Hazardous materials should be easy to remove;

- Make inseparable sub-assemblies from the same material;

- Try to use joints and fasteners of material compatible with the parts connected;

- Design with biological materials that can be cascaded and finally be returned back into nature.

\subsubsection{Design for pure and effective material recycling or biodegradability}

In many recycling processes additional virgin feedstock is required to ensure adequate material quality and to make up a loss of material mass associated with the recycling process. These material losses during the recycling processes should be kept to a minimum to support closed material loops (19).

In addition, the use of bonded materials, additives, secondary finishes or treatments could compromise the quality of the recycled materials. As indicated by Sassi (19), small amounts of different materials may not compromise the quality of the recyclate. Although, to prevent them from reaching quantities that compromise the quality of the recycled materials, the use of bonded materials, additives, secondary finishes and additives that could compromise the quality of the recyclate should be avoided $(1-5,7-11,13,15,18$, $19,22)$. The use of composite materials should also be avoided, because these elements are often very difficult or even impossible to recycle $(2,7-9,11,18,19,22)$.

If materials are easy to identify and of a minimal amount of different types of materials it is easier to recycle them. Therefore, it is recommended to minimize the number of different materials $(1,3-5,8-13,15,16,19-22)$, since the more homogeneity there is between the materials in a structure the easier it will be to sort materials on site and reduce transportation to separate reprocessing plants. Furthermore, it makes reuse and recycling more attractive due to greater number of fewer material types. As eloquently stated by Webster \& Costello (22), "better to have one large batch of similar material than many smaller batches to simplify sorting and identification efforts and increase resale value." Furthermore, materials that look similar but have different properties should be 
avoided, because this may potentially create a confusing array of materials that may not be as effectively reused as materials from a building constructed using a single material grade, because of the difficulty to identify the differing material grades. Though, this issue could be overcome by consequently providing permanent identification of materials, the benefit of having one large batch of similar materials instead of many smaller batches is of a greater benefit in their reuse, due to the economy of scale benefits.

For short cyclic materials (biological materials) it is of great importance to allow them to be cascaded. A fundamental criteria for biological materials to allow them to be returned safely into nature is to avoid toxic and hazardous materials $(1-5,8-13,15,16,18,19,22)$ or materials that could contaminate the ground (19). Therefore, the toxic content should be avoided or at least be minimised. If the use of hazardous material is unavoidable, they should be easy to remove and able to be released in a controlled manner (19). Another aspect to take into consideration are the processes that could be required before safely returning the materials into nature, such as the separation from non-biological materials. This can be a time consuming task, leading to significant cost increases. Therefore, the preparation time to allow the materials to be returned into nature should be reduced to a minimum (19).

Design guidelines

- Design with materials that have a minimal material loss during recycling processes;

- Avoid use of bonded materials, additives, secondary finishes or treatments that could compromise the quality of the recycled materials;

- Avoid the use of composite materials that cannot be recycled;

- Design with a minimal number of different material types;

- Avoid the use of different material grades that potentially confuse identification;

- Avoid toxic and hazardous materials or materials that could contaminate the ground;

- Minimize toxic content, if toxic content is unavoidable ensure the ability to release it in a controlled manner;

- Design with biological materials that require minimal preparation before they can safely be returned into nature.

\subsubsection{Design with recycled and recyclable materials}

The use of recycled in contrast to virgin materials will stimulate the demand for recycled materials and thereby stimulate the development of recycling processes to fulfil the demand for recycled materials and decrease waste streams from existing infrastructure. Furthermore, the use of recyclable materials will support the creation of closed material loops.

Design guidelines

- Design with recycled materials;

- Design with recyclable materials. 


\subsubsection{Documentation strategies}

\subsubsection{Maintenance plan}

A maintenance plan should describe the flexibility routes that are incorporated in the design to enable them to be easily accessed and maintained, without affecting surrounding parts $(5-8,10,12,14,18,21)$. Furthermore, information about the maintenance requirements should be carefully preserved and updated $(1,3,4,6,9,12,14,15,18)$. This will ease maintenance and keep track of the maintainability of the building.

Design guidelines

- Plan service routes to be easily accessed and maintained.

- Preserve information about the maintenance requirements.

\subsubsection{Deconstruction plan}

During the design phase a deconstruction plan should be developed (1-4, 6, 8-12, 14-19, 21 , 22). This plan could prevent reusable building elements and components from being damaged or destroyed during its deconstruction. Furthermore, the deconstruction plan should take safety measures into account $(1,8-12,14,16-19,21,22)$, e.g. stability during deconstruction is an important factor to enable safe a deconstruction $(12,16,20)$. The deconstruction steps and aids should be ordinary (e.g. crane usage can be impractical for certain steps). Furthermore, points of attachment for lifting equipment as well as temporary supports, special handling instructions, transportation and storage requirements should be documented. BIM software could facilitate in the deconstruction process, e.g. to simulate the disassembly sequence (2), which could prevent components and elements from being damaged during disassembly.

Design guidelines

- Develop a deconstruction plan.

- The deconstruction plan should allow for safe deconstruction.

\subsubsection{Reconfiguration and reuse plans}

Each building system or set of elements should contain reconfiguration and reuse plans that reveal the potentials to adapt them to changing needs and requirements for current and future use. Furthermore, the plan should provide a clear overview which elements have high potential to be reconfigured and reused, and which elements are more difficult to change to facilitate the changing demands. The establishment of reconfiguration and reuse targets could stimulate and increase the amount of elements and components that allow reconfiguration and reuse without damage. The building could also include storage space for spare parts $(4-6,9,21)$. This allows for minor alterations to the building design, replacement of broken or damaged components or the reuse of a whole component when only a sub-component part is damaged. Whether to include storage space and spare parts can depend per building, e.g. if the building contains more specialized parts it could be worthwhile to produce a set of spare parts at the initial manufacturing phase, and if the applied components or elements are standardized and readily available on the market, the inclusion of spare parts can be considered as a burden, since there is always the chance that the spare parts will not be used. 


\section{Design guidelines}

- Develop reconfiguration and reuse plans that describe the potentials of all used building products.

- Set a target, a percentage of elements and components that have a reuse potential above a defined or measurable level.

- Decide whether to provide storage space for spare parts.

\subsubsection{Integral and updated 'as built' BIM models or drawings}

To ease maintenance, deconstruction and reuse of the building and its separate parts an integral set of updated 'as built' BIM models or drawings are required (1-5, 7-11, 13-15, 18, 19, 21, 22). Furthermore, a full inventory of all elements and components used in the building (1, 7-9, $11,13-15,17,21)$, including their technical service life and remaining technical service life should be available $(1,3,4,6,8-11,13,14,21)$, to facilitate in maintenance, reconfiguration and reuse decisions, when changes are made to the building or parts of the building. Knowledge about the performance and remaining technical lifespan of building elements and components is essential to decide at the end-of-first-life whether the building product could be reused directly or should be remanufactured or recycled. Another advantage of tracing down all materials and changes in the building is the possibility to monitor the performance of different building products and generate new data about their technical service lives and changing rates, which could help in understanding the dynamics of different building typologies and functions.

Design guidelines

- Develop an integral set of 'as built' BIM models or drawings and keep them updated.

- Provide a full inventory of all elements and components used in the building, including their technical service life and remaining technical service life.

- Monitor the performance of all elements and components.

\subsubsection{Permanent identification}

Permanent identification of material, element and component types (1-5, 7-9, 11, 13, 15 , 18-22) will ease maintenance, sorting and reuse processes in the initial use phase and future use phases. The permanent identification should be able to identify each unique building product, this can be done with e.g. a barcode, stamp, mark, label or RFID chip, that refers to the related material passport that includes information about the content (material type, characteristic properties, origin, place, manufacturer, date of production, -installation and -reconfiguration, dimensions, strength, toxic risks and any special handling instructions) use (suitable uses of the material, indoor/ outdoor), use phase (financial model), deconstruction (handling and suitable storage options) and next use. The permanent identification mark could differ per component and element type, since the lifespan of each element can differ between e.g. one and three hundred years and will thus have differing wear requirements.

Design guidelines

- Provide permanent and unique identification of all materials, elements and components.

- Link all identified materials, elements and components to a material passport. 


\subsubsection{Reuse processes}

In addition to all previous principles and guidelines, during the literature analysis, principles and guidelines that are aimed at the reuse process have also been identified. Since these guidelines and principles have no impact on the design, they have been left out of this chapter.

\subsection{Conclusion}

This chapter provides an overview of the main Design for Disassembly guidelines from literature, which are structured in Design for Disassembly strategy groups and design principles. Each design principle is linked to Design for Disassembly guidelines and their reasoning. This forms the answer to RQ4: Which 'Design for Disassembly' guidelines can be identified in literature to support reuse of buildings and building products and what is the guideline's reasoning? To understand which design guidelines can be used as input for the development of the reuse potential evaluation method, in Table 4.15 all Design for Disassembly strategies and principles have been linked to its resource flow impact and the main reuse process steps as identified in the reuse potential framework. Since the aim of the reuse potential evaluation method is 'slowing resource flows', the most relevant design principles and design guidelines are: building strategies, system \& product strategies and documentation strategies. In addition it should be noted that the impact of the reuse potential evaluation method is limited to design parameters. This means that especially the building strategies and system \& product strategies that are related to slowing resource flows should be taken into account in the development of the reuse potential evaluation method. 
Table 4.15: Design for Disassembly and reuse strategies related to its resource flow impacts

Resource flow impact/ Life cycle stages

Strategy groups and design principles

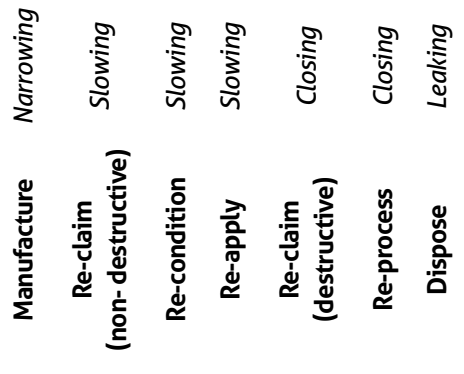

\begin{tabular}{ll}
\hline 1. Building strategies & \\
\hline 1.01 Design for functional changeability & $x$ \\
1.02 Design for size changeability & $x$ \\
1.03 Design for internal changeability & $x$ \\
1.04 Design with passive design measures & $\times \quad \times$ \\
2. System \& product strategies &
\end{tabular}

2. System \& product strategies

2.01 Design with independent building layers

2.02 Modular and universal design

2.03 Simple and legible design

2.04 Design with parallel configurations

2.05 Design with prefabricated configurations

2.06 Design to suit the means of handling

2.07 Design with durable components

2.08 Design with (local) reclaimed and reusable building products

$\begin{array}{cccc} & x & & \\ x & x & x & x \\ x & x & x & x \\ x & x & x & \\ x & x & x & \\ & x & & x \\ x & x & x \\ & x & & x \\ & & & \\ & x & & x \\ x & & x \\ & x & x & x\end{array}$

2.09 Design with demountable connections

2.10 Design with standardized interfaces

2.11 Design connections for fast disassembly speed

2.12 Design with durable connections

3. Material strategies

3.01 Design for recyclable and biodegradable materials Design for pure and effective material recycling or

3.02 biodegradability

3.03 Design with recycled and recyclable materials

$x$

$x$

$x$

4. Documentation strategies

4.01 Maintenance plan

4.02 Deconstruction plan

4.03 Reconfiguration and reuse plans

4.04 Integral and updated 'as built' BIM models or drawings

4.05 Permanentidentification

火

$x$

$x \quad x \quad x$

$x \quad x \quad x$

$x \quad x$ 


\section{Part III - Prescriptive study}

In this chapter, the prescriptive study is presented, the development of the reuse potential evaluation method. Starting with a description of the aim and scope of the evaluation method, a brief review of existing evaluation methods, followed by a description of the proposed design support method that is based on technological rules to improve design-based action.

\section{Chapter 5 Reuse potential evaluation method}




\section{5 | Reuse potential evaluation method}

\subsection{Introduction}

The goal of this project is to contribute to the transition of the construction industry into a circular building industry that: 1 ) creates building products with an increasing resource productivity; 2 ) is less dependent on virgin resources and; 3 ) contributes to the elimination of the concept of waste. To contribute to this goal, a method to evaluate the reuse potential of buildings and building products is proposed, this evaluation method will provide design knowledge to support designers and engineers to increase the reuse potential of their designs. If the evaluation method is applied properly, the designers will be able to identify how the reuse potential of their designs can be increased. In addition, an evaluation method allows clients to set a minimum level of reusability to guarantee a certain level of reusability and thereby contribute to the establishment of a circular building industry.

This chapter aims to answer RQ8: How does an evaluation method that enables the assessment of the reuse potential of buildings and building products and provides design support to designers and engineers look like? In previous chapters, understanding of reuse processes, reuse changes and reuse influences from multiple perspectives has been developed, resulting in a conceptual reuse potential framework and four reuse mechanisms that describe factors that influence the reuse potential of building products. In addition, existing design support methods and their heuristics have been studied, in the form of design for disassembly guidelines, to identify design strategies and guidelines that can be used to increase the reuse potential of buildings and building products. The design knowledge and conceptual framework developed in previous chapters will be applied in this chapter for the development of the reuse potential evaluation method to support circular building design.

To start, based on the previous chapters, the aim, scope and requirements of the reuse potential evaluation methods is defined in section 5.2. Secondly, the research method that is used for the development of the reuse potential evaluation method is specified in section 5.3. Existing evaluation methods are analysed in section 5.4 to answer RQ7: What existing methods can be identified in literature to evaluate the reuse potential of buildings and building products? Section 5.5, defines how the building composition can be utilised for automated assessment of the reuse potential of buildings and building products. Based on existing evaluation methods and a review-based understanding of the reuse potential, as presented in previous chapters, the reuse potential evaluation method and its assessment criteria are defined in section 5.6. Finally, the conclusions to this chapter are presented in section 5.7 . 


\subsection{Scope of the reuse potential evaluation method}

In this section, the aim and scope of the reuse potential evaluation method are defined, resulting with a conceptual reuse potential assessment framework in which the main indicators of the reuse potential evaluation method are specified. Finally, the requirements of the reuse potential evaluation method will be specified.

\subsubsection{Aim of the evaluation method}

The aim of the reuse potential evaluation method is to develop an objective method that can be used to evaluate and explain the variance between the potential to reuse buildings, systems or building products. The main objective of the reuse potential evaluation method is to:

1. Enable the assessment of the reuse potential of buildings, systems and building products in the design stage and existing buildings.

2. Provide design knowledge, to support designers and engineers in the design of new buildings and building products with a high reuse potential;

3. Allow clients to set a minimum reuse potential score to ensure a defined reuse potential level of the building, building system and its building products, to facilitate in circular building design objectives;

The main actors who benefit from this method are assumed to be designers, engineers and engineering consultants. They can have the necessary knowledge to operate the method and benefit from the feedback that can be applied to improve its design to increase the reuse potential of the building or building product or identify existing reusable building products. In addition, the method can be used by clients and policy makers to set a minimum reuse potential score and implement circular economy objectives in building projects.

\subsubsection{Reuse types}

The types of reuse that occur are diverse and can vary significantly per product and context in which reuse occurs. Therefore, it is important to define the scope of the reuse potential evaluation method. In addition, the scope will support in a better understanding of the outcomes and limitations of the evaluation method. In section 2.7, two distinct reuse types have been identified, based on the design intention, namely:

- Deliberate reuse, the reuse of products in a way it was intended for and expected to be used for, and;

- Unintended reuse, the reuse of products in ways the designer could not have anticipated at in their initial design

As it is impossible to predict the future, it is impracticable to take into account the potential to reuse building, systems and building products in unintended reuse alternatives. Therefore, the reuse potential evaluation method is limited to the evaluation of the potential to support deliberate reuse. Furthermore, the evaluation method aims at the development of indeterminate configurations, rather than determinate configurations. 


\subsubsection{Reuse potential variables}

To specify the main variables of the reuse potential evaluation method, it is important to define the dependent and independent variables (Blessign \& Chakrabarti, 2009). Two categories of independent variables can be identified, namely: 1 ) internal independent variables, which are the variables that are being measured and can be manipulated, which is the main focus of the reuse potential evaluation method, the building (design), and 2) external independent variables, which are variables outside the scope of the analysis, but could be used to explain the variance between the reuse potential and the actual end-of-life decision, e.g. changing legislation regarding reuse, changing business models, tax reformation and/ or the maturity of reclaimed building product markets. The external independent variables are of importance when comparing the results of the reuse potential evaluation method with the actual reuse actions. In such a situation it is important to isolate the internal independent variables from the external independent variables. Although, this is not always possible, it is important to take into account the external independent variables to raise awareness of external influences that could have supported the end-of-life decisions.

Since, the aim of the reuse potential evaluation method is to support high quality building-, system- and product reuse, the reuse potential evaluation method is focused at the dependent variables that impact building-, system- and product reuse. Therefore, the reuse potential evaluation method is focused on the impact of 'additional processes' and excludes the impact of 'avoided processes', which is aimed at substance reuse through re-processing of parts, e.g. recycling. The dependent variables, which are based on the impact of 'additional processes', can be divided into known and unknown dependent variables. Whereby the known dependent variables refer to variables that can be identified based on the building (design), re-claim effort (non-destructive) and re-condition effort, and the unknown dependent variables refer to variables that cannot be based on the building (design), but depend on its new reuse application, the re-apply effort. This makes it impossible to incorporate the unknown dependent variable, the re-apply effort. Therefore, the reuse potential evaluation method has been limited to the assessment of known dependent variables. In Figure 5.26 an adapted conceptual reuse potential framework is depicted that specifies the scope of the reuse potential evaluation method, namely: 1) the internal independent variables of the building (design), in specific, building level, system level and product level; 2 ) the dependent variables of the building (design), the operational value and embodied value, and; 3 ) the known dependent variables, the re-claim effort (non-destructive) and the re-condition effort.

To understand the limitation of the scope of the reuse potential evaluation method, it should be noted that the re-apply effort, which is outside the scope of the reuse potential evaluation method, depends on the effort it takes to modify the reclaimed product to its new context and the potential demand for the re-claimed building product. The demand for the re-claimed building product can be influenced based on the application range. The application range, which can be increased based on the ease of adaptation or commonality of the product. For example, the standardisation of dimensional coordination of building products can improve the compatibility of the product with in new reuse contexts and reduce the effort required to re-apply the building product (Beurskens \& Durmisevic, 2019). Although, since the dimensional coordination is 


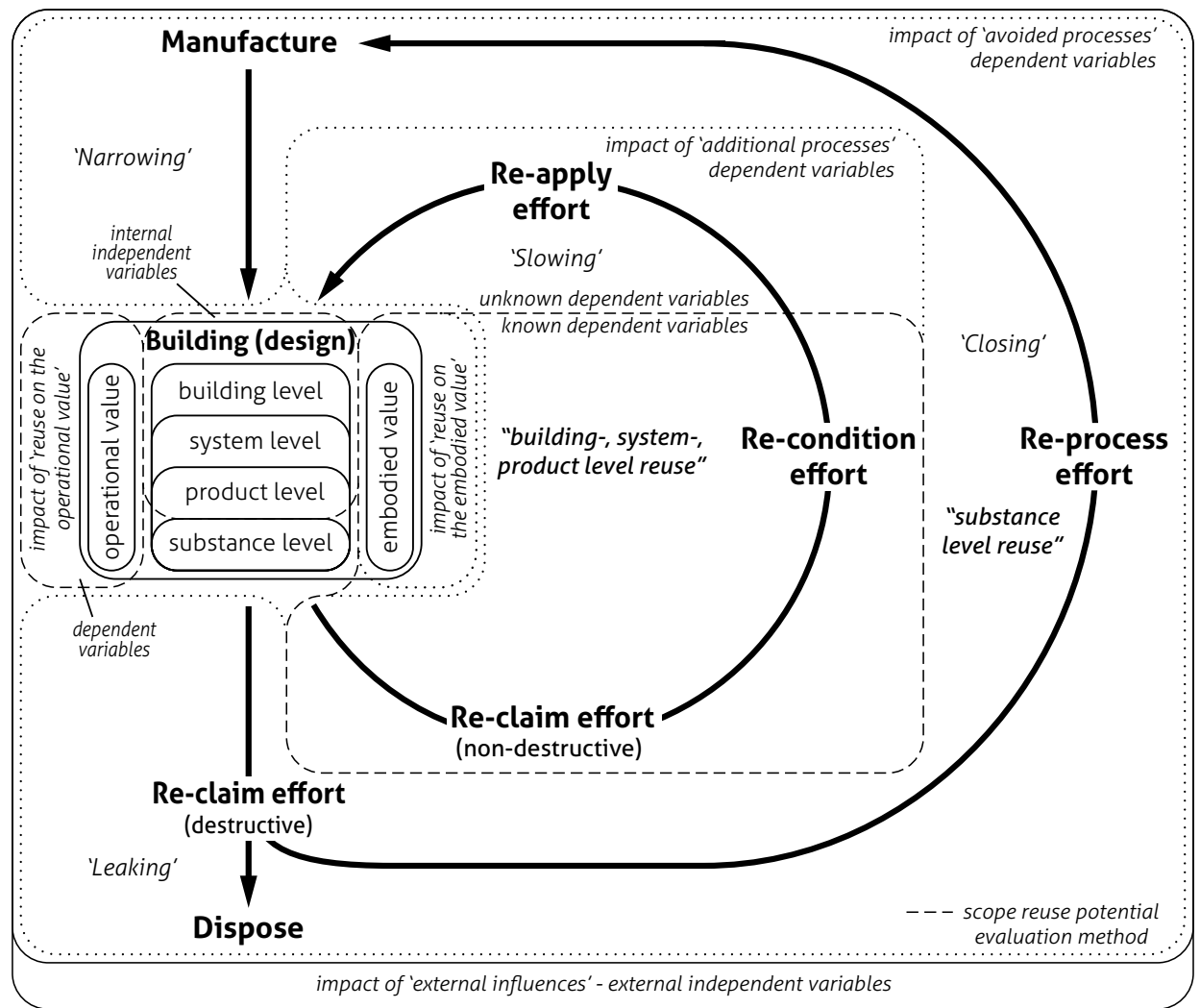

Figure 5.26: Adapted conceptual reuse potential framework, defining the scope of the reuse potential evaluation method

context dependent, this criteria is left outside the scope of the analysis. To illustrate the context dependency, an example of the standardisation of dimensions is given, whereby several types of dimensional standardisation can be identified, namely: standardisation based on industry standards, which increases the potential for reuse significantly, due to the industry wide compatibility of the product; standardisation based on manufacturer portfolio, which means that the product can easily be reused within other buildings and new buildings that are constructed by the same manufacturer; standardisation based on client portfolio, which would support easy reuse within the limited client portfolio, due to compatibility within the client's portfolio, or; project based standardisation, whereby the product dimensions are standardised for one specific project, which means that the products can easily be reused when the project specific parts are kept together, but limits application in other building types, and; no dimensional standardisation, the part is not standardised and forms a unique part of the building, which makes the reuse of the part in new contexts difficult. In order to specify the type of dimensional standardisation, the following context dependent criteria should be identified: industry standards, manufacturer portfolio standards, client portfolio standards, which makes it impractical to incorporate the application range in the reuse potential evaluation method and is therefore, left outside the scope of the analysis. 


\subsubsection{Requirements of the reuse potential evaluation method}

To be able to verify the functioning of the reuse potential evaluation method, requirements to which the evaluation method should comply should be defined (Blessign \& Chakrabarti, 2009). To start, the aim is to evaluate the reuse potential of buildings, building systems and building products, therefore, the method should be applicable on any type of building. Secondly, the method should be able to represent the entire building structure, instead of merely individual object analyses. Thirdly, the method should address building level reuse, building system level reuse and building product level reuse, to identify the most suitable reuse approach and whether or not the reuse type matches the aim of the building design. Fourthly, the reuse potential evaluation method should incorporate the embodied value, re-claim effort and re-condition effort (i.e. the known dependent variables), to identify the economic, cultural, material and embodied energy value in contrast to the effort it takes to re-claim and re-condition the part to allow the part to be reused. Fifthly, the input data should be communicated in an accessible and transparent manner, to be able to verify the used input data and allow the user to identify specific criteria that could be improved upon. Sixthly, the reuse potential evaluation method should enable an objective assessment and consistent evaluation. To support the development of an objective evaluation method, manual adjustment of criteria should be minimised. Finally, the evaluation method should allow for customisation through weighting factors, to allow users to adjust the weighting of certain criteria based on their aim of the reuse potential. In Table 5.16 all requirements are summarised.

Table 5.16: Requirements for the reuse potential evaluation method

\begin{tabular}{l} 
Reuse potential evaluation method requirements \\
\hline 1. Allow the assessment of all types of buildings \\
2. Assessment should be representative for the entire building structure \\
3. Address all three reuse potential levels: building level, building systems level and building product level \\
4. Address the embodied value, re-claim effort and re-condition effort. \\
5. Input data should be verifiable, accessible, transparent and automated based on the building's composition \\
6. Consistent output, minimum manual criteria input and modifiable \\
7. Enable customisation through adjustment of weighting factors
\end{tabular}




\subsection{Method}

The goal of this research is the development of an evaluation method that is based on scientific knowledge that allows for an objective assessment, and provides insight and knowledge that can be used to improve design-based actions, the design of reusable buildings and building products. According to Bunge (1967), an appropriate solution would be the development of so-called technological rules, which is defined by Bunge (1967, p.132) as: "an instruction to perform a finite number of acts in a given order and with a given aim". Van Aken (2004, p. 228) defines a technological rule as: "a chunk of general knowledge, linking an intervention or artefact with a desired outcome or performance in a certain field of application". 'General' in this definition means that it is not a specific solution for a specific situation, but a general solution for a type of problem. This corresponds with the goal of the reuse potential evaluation method, the development of a general method that can be applied to improve the reuse potential of buildings and building products, to reduce construction and demolition waste and increase resource productivity.

Therefore, the reuse potential evaluation method should be developed with the use of technological rules that are based on grounded or field tested knowledge to improve design-based action. A technological rule follows the logic of "if you want to achieve $Y$ in situation $Z$, then perform action $X^{\prime \prime}$. Here $X$ is the general solution concept for a type of field problem (Van Aken, 2004).

The scope of the reuse potential evaluation method is defined in section 5.2. The main factors that should be taken into account in the development of the reuse potential evaluation method have been specified in an adapted reuse potential framework (Figure 5.26) and the requirements for the evaluation method are specified in Table 5.16.

To start, in section 5.4 existing evaluation methods to assess the potential for disassembly, reuse and recycling will be studied (RQ7: What existing methods can be identified in literature to evaluate the reuse potential of buildings and building products?), to identify criteria or technological rules that can be adopted for the reuse potential evaluation method.

Secondly, the development of a method to represent the composition of building structures and identify multiple reuse levels is of major importance to enable an automatic assessment that takes into account the building structure. Therefore, existing methods to represent product structures will be analysed in section 5.5, to identify a suitable method to represent building structures and incorporate assessment criteria.

Finally, based on existing evaluation methods and a review-based understanding of the reuse potential, as presented in previous chapters, the reuse potential evaluation method and its assessment criteria are defined in compliance with the adapted conceptual reuse potential framework, in section 5.6. 


\subsection{Existing evaluation methods}

In literature, multiple assessment methods have been developed to assess the potential for disassembly, reuse and recycling, often built upon design for disassembly and reuse guidelines. For example: Thormark (2001), provides an outline of a method to asses the ease of disassembly, with the focus on material recycling and combustion; Sassi (2002), presented a method to assess the suitability for reuse/ recycling/ down-cycling, whereby technically linked criteria are weighted higher than cost linked criteria, while the possible scores are distributed evenly among the criteria; Nordby (2009), presented an assessment method that identifies a direct link between the guidelines and the assessed parameters, relating design strategies with: scale of application, operational criteria and objectives such as recycling, reuse, relocation, adaptation and maintenance, with the main focus on the environmental aspect; and Durmisevic (2006), introduced a knowledge model for assessing the Transformation Capacity of structures, with the main focus on the disassembly potential, which is being assessed based on seventeen determining factors, sub-divided into functional-, technical- and physical decomposition.

The assessment method introduced by Thormark (2001) is a generic method, but due to its unspecified assessment values, the method leaves room for interpretation, which makes comparison of different building products difficult due to the high degree of interpretation and does not take into account the composition of the building structure. Similarly, the method of Sassi (2002), leaves a lot of space to the interpretation of the assessor. Both methods exclude clear examples when each rating is applied and does not include the building's composition. The assessment method introduced by Nordby (2009) creates a clear link to the guidelines that support its objective (e.g. reuse), whereby a maximum per sub-criteria is defined and a total of 24 points are given to each criterion. In the assessment method defined by Nordby (2009) the scores are based on judgements made by the authors, which makes them subjective to interpretation, whereby the total number of points for each case object are not added up, because the criteria are considered to represent different aspects of reusability. Furthermore, the assessment of Nordby (2009) is mainly focused on environmental aspects, excluding economic factors, such as the number of disassembly steps andd time it takes to disassemble a part, which is important to define the economic feasibility of reuse. Furthermore, all three assessment methods are focused on the assessment of components, elements and materials, and reduce the complexity by limiting the assessment to the assessment of individual objects. The assessment of individual objects makes it difficult to understand the effect of design changes on other parts of the building. Therefore, the incorporation of the building structure is considered of major importance. The assessment method introduced by Durmisevic (2006) comprises of a method to reflect upon the entire building structure by developing a relational pattern of the entire structure, which makes it possible to take into account the effect of certain design changes on the entire building structure. Furthermore, the transformation capacity assessment method of Durmisevic (2006) is considered as an indicator of the disassembly potential and is based on seventeen performance indicators, as shown in as shown in Table 5.17. In terms of reuse potential, the disassembly potential 
Table 5.17: Transformation capacity assessment criteria (Durmisevic, 2006, p.209)

\begin{tabular}{|c|c|c|c|}
\hline Type of decomposition & Design for Disassembly Aspects & No. & Determining factors \\
\hline \multirow[t]{4}{*}{ Functional decomposition } & Functional decomposition & 1. & Functional separation \\
\hline & & 2. & Functional dependence \\
\hline & Systematisation & 3. & Structure of material level \\
\hline & & 4. & Type of clustering \\
\hline \multirow[t]{5}{*}{ Technical decomposition } & Base Element & 5. & Type of base element \\
\hline & Life cycle coordination & 6. & Use life cycle coordination \\
\hline & & 7. & Technical life cycle coordination \\
\hline & & 8. & Coordination of life cycle and size \\
\hline & Relational pattern & 9. & Type of relational pattern \\
\hline \multirow[t]{8}{*}{ Physical decomposition } & Assembly process & 10. & Assembly direction \\
\hline & & 11. & Assembly sequences \\
\hline & Geometry & 12. & Geometry of product edge \\
\hline & & 13. & Standardisation of product edge \\
\hline & Connections & 14. & Type of connections \\
\hline & & 15. & Accessability to fixings \\
\hline & & 16. & Tolerance \\
\hline & & 17. & Morphology of joints \\
\hline
\end{tabular}

can be used to identify the re-claim effort. Therefore, the knowledge model of Durmisevic (2006), as shown in Table 5.17 is adopted and further specified in the development of the reuse potential evaluation method. Although the exisiting model of Durmisevic (2006) does not comply with all reuse potential assessment requirements, it provides a theoretical basis for the reuse potential to extend upon. Barriers in the knowledge model of Durmisevic (2006), which are to be addressed by the reuse potential assessment method are: 1) a uniform method to address the building structure and type of connections conform the identified reuse potential levels; 2 ) the assessment of the embodied value and re-condition effort; 3 ) development of an automated assessment model. Therefore, in the following sections the previously described barriers will be addressed. 


\subsection{Building composition to automated assessment}

For the reuse potential evaluation method it is of major importance to identify a systematic approach to represent the composition of building structures, to enable an automatic assessment of the building structure. Therefore, existing methods to represent product structures will be described to identify a suitable method to represent building structures and incorporate assessment criteria.

\subsubsection{Connection diagram}

In product design a common method to graphically represent the topological relationships between the elements of a product is the connection diagram also known as a liaison diagram (Lambert \& Gupta, 2004). A connection diagram is an undirected graph in which the nodes represent elements and the lines represent connections. The example of Lambert \& Gupta (2004) will be used to describe different interpretations of the connection diagram, as shown in Figure 5.27. The example consists of three elements, part $A, B$ and $C$ and two fasteners, part $D$ and $E$. Part $A$ and $B$ represent mating elements that are connected with a strip $C$. The strip is connected to part $A$ via a weld $D$ and to part $B$ via screw $E$. In the most extended form element $A, B$ and $C$ including the fasteners $D$ and $E$ can be considered as elements and can be depicted as shown in Figure 5.28a. While, it can be argued that part $D$ is not an element at all and should be depicted as shown in Figure 5.28b, whereby part $D$ is not depicted at all and part $E$ (screw fastener) is depicted with dashed lines, which is used if the fastener is of minor importance. If the connections are not considered as elements at all, the minimal connection diagram of Figure 5.28c results. This would be the best way to represent building structures. While, a further reduction might be desired, if e.g. the material content of strip $C$ is only attached to immobilize the parts and is not considered relevant, as shown in Figure 5.28d.

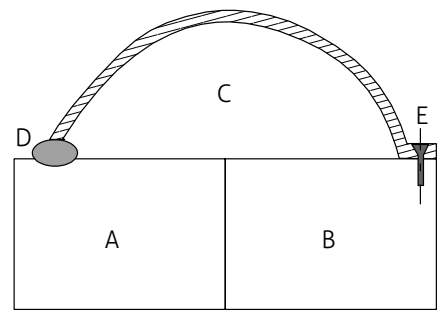

Figure 5.27: Example product (Lambert \& Gupta, 2004, p.86)

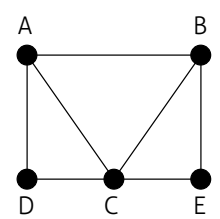

а)

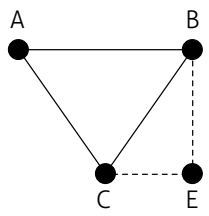

b)

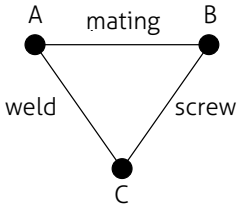

c)

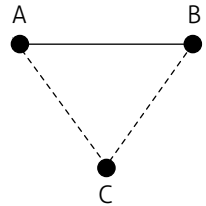

d)

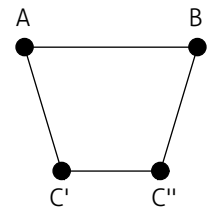

e)

Figure 5.28: Connection diagrams of the example product (above): a) Extended; b) reduced; c) minimal; d) reduce with strip ( considered irrelevant; e) destructive disassembly of the strip (Lambert \& Gupta, 2004, p.87) 
Furthermore, if one wants to reuse the parts using destructive disassembly methods, by cutting strip C into two sub-elements C' and C', the connection diagram can be depicted as shown in Figure 5.28e.

As stated by Lambert \& Gupta (2004), there is some flexibility as well as arbitrariness in generating the connection diagram, which allows the user to adapt the connection diagram for any desired purposes. Connection diagram c from Figure 5.28 is identified as most suitable to depict building structures. And connection diagram e is suitable to identify the impact of product changes for reuse, as shown in Table 2.04.

\subsubsection{Disassembly precedence graph}

To be able to identify the assembly and disassembly steps that are required to assemble and re-claim an element, it is important to move from an undirected graph, into a directed graph that represents the order in which tasks have to be performed to assemble and disassemble certain parts, such as a precedence graph. To illustrate the idea of the precedence graph, the example of Lambert $\&$ Gupta (2004) is used, which is a cylindrical product that has three components: A, B and C. In Figure 5.29 the assembly drawing of the product and its disassembly precedence graph is depicted. In the precedence graph Symbol $P$ is assigned to the complete product and the letter $A$ or $B$ refers to the parts that can be disassembled first and $C$ indicated with 'or' can only be disassembled once part $A$ or $B$ is detached, resulting in hypothetically four possible sequences: $A B C, A C B, B A C$, and BCA.

While, in the real world there are often forces in place limiting the number of feasible disassembly sequences, especially for buildings in which parts often cannot be accessed from all sides. Furthermore, one major drawback of the precedence graph is that not all disassembly sequences of a specific product are necessarily included in the graph (Lambert \& Gupta, 2004). A more popular method in product design to represent the disassembly process is the disassembly tree and includes all parts in the graph. In Figure 5.30 three methods to depict disassembly trees defined by Lambert \& Gupta (2004) have been presented. It should be noted that the first notation allows for two possible sequences and the second and third example only allows for one sequence.
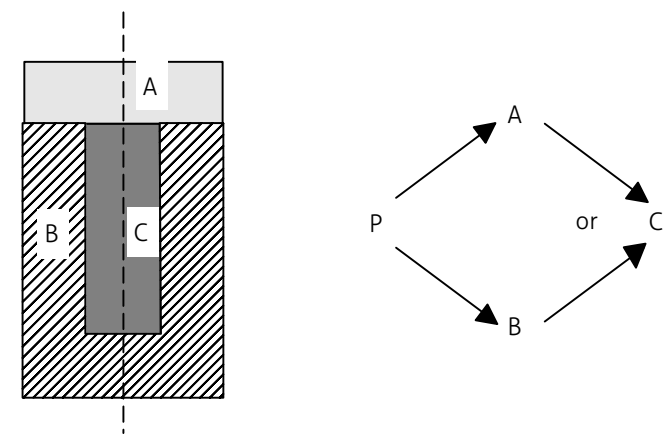

Figure 5.29: Example of a disassembly precedence graph (Lambert \& Gupta, 2004, p.122) 


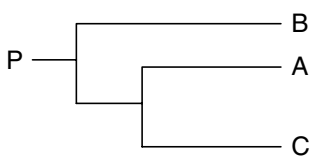

(a)

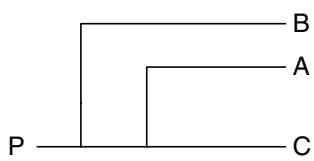

(b)

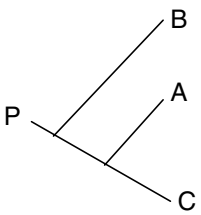

(c)

Figure 5.30: Three graphical representations of a disassembly tree a) disassembly tree; b) ordered disassembly tree, and; c) fishbone tree for the (Lambert \& Gupta, 2004, p.87)

\subsubsection{Relational pattern}

In the research of Durmisevic (2006) a method is defined to graphically represent the composition of building structures, which is referred to as a relational pattern. A relational pattern can be considered an abstract directed connection diagram, in which the nodes represent functional layers that can be assembled and disassembled as one entity or repetitive elements and the lines between the nodes represent the connections between the functional layers. For additional structure, the nodes are arranged according to the functional decomposition in the horizontal direction and the technical decomposition in the vertical direction (Durmisevic, 2006). The relational pattern provides insight in the hierarchy of the elements and its dependencies, which can be used as the basis for the assessment of multiple rules of the reuse potential evaluation method.

To be able to develop coherent relational patterns of building structures, special attention should be given to the scope of the relational pattern. As the relational pattern will become the basis for the assessment, it is of importance to understand how a relational pattern for any type of building can be made. To define the scope of the relational pattern, it is important to understand the purpose of the relational pattern. Since the reuse potential evaluation method is aimed at the evaluation at building, system and product level, it should represent the parts that are required to be identify for each level. Furthermore, the goal is to develop a systematic approach in which the composition of buildings can be defined to evaluate a set of rules. Often the building consists of many repetitive elements, therefore, it would make no sense to identify all physical elements of the building in the relational pattern, but limit the scope to one representative section of the building that contains the main elements of the building. Furthermore, it is important for the relational pattern to represent the different physical entities that are present in the building.

To exemplify the difference between the connection diagram and the relational pattern, an example will be given of a closed facade frame, as shown in Figure 5.31. To start, each unique part has been given a unique identification code, which is required to develop an undirected connection diagram. In Figure 5.32 an undirected connection diagram has been shown of the closed facade frame, which shows all relations between the identified elements. The relatively simple example resulted in a complicated connection diagram, which makes it difficult to understand the composition of the structure. In Figure 5.33 two types of relational patterns are shown, representing the same example, whereby the 

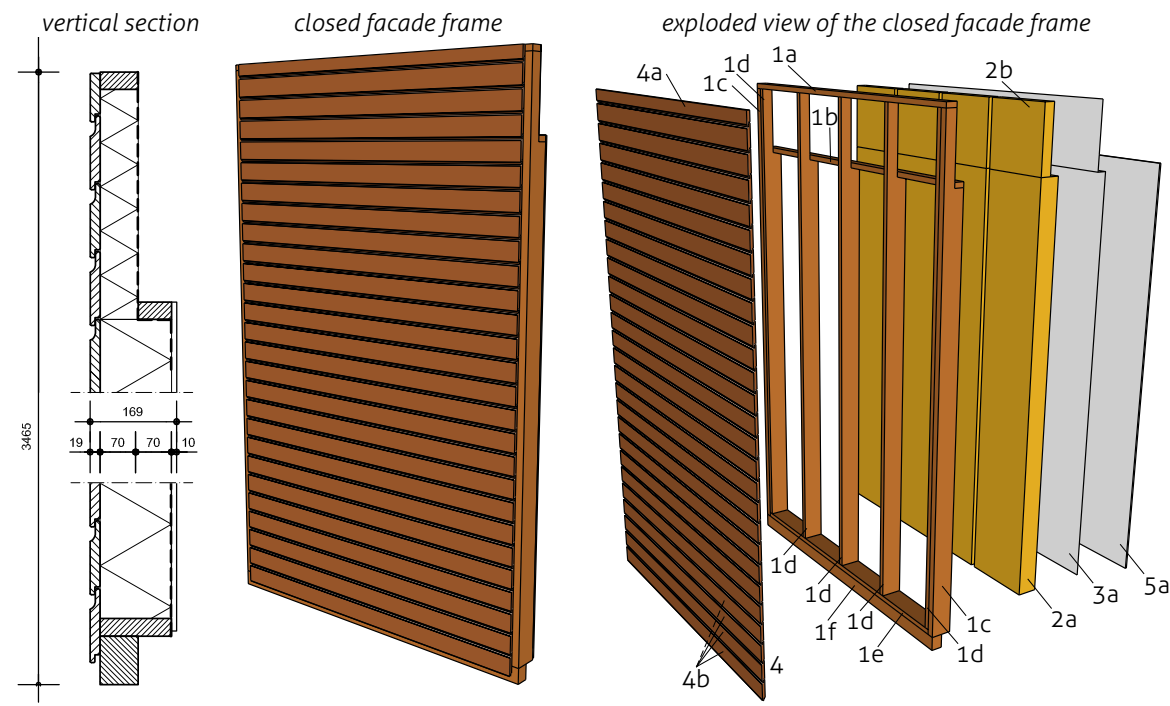

Figure 5.31: Example of a closed facade frame

\section{Legend - Closed facade frame}

1. t.str. Timber structure - timber parts $(1 a, 1 b, 1 c, 1 d)$

2. ins. Insulation - glass-wool (2a, 2b)

3. vap. Vapour barrier (3a)

4. ex. f. Exterior finishing - timber cladding (3a)

5. int. f. Interior finishing - gypsum plate (5a, 5b)

\section{Basic element function}

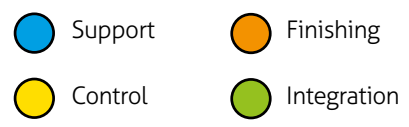

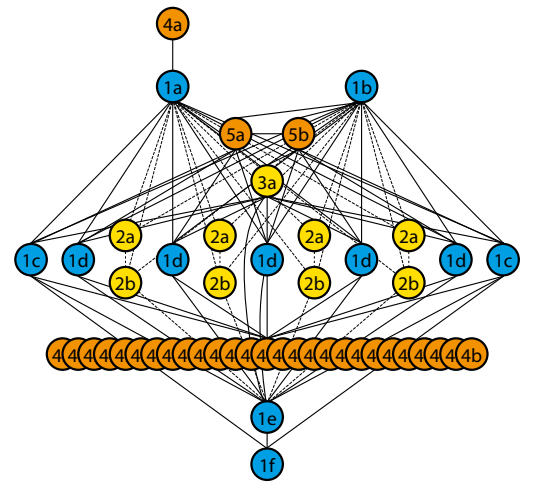

Figure 5.32: Relational pattern representing all physical elements of the closed facade frame example

a)

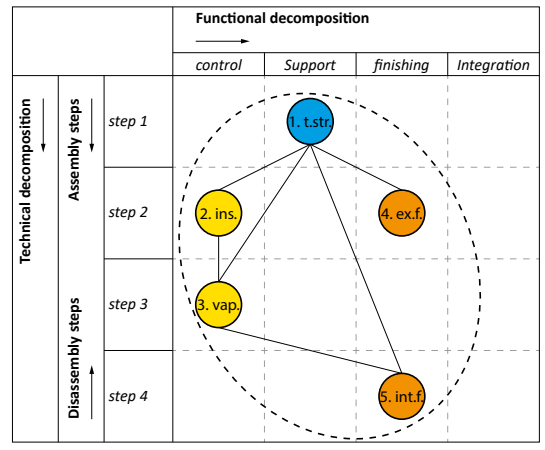

b)

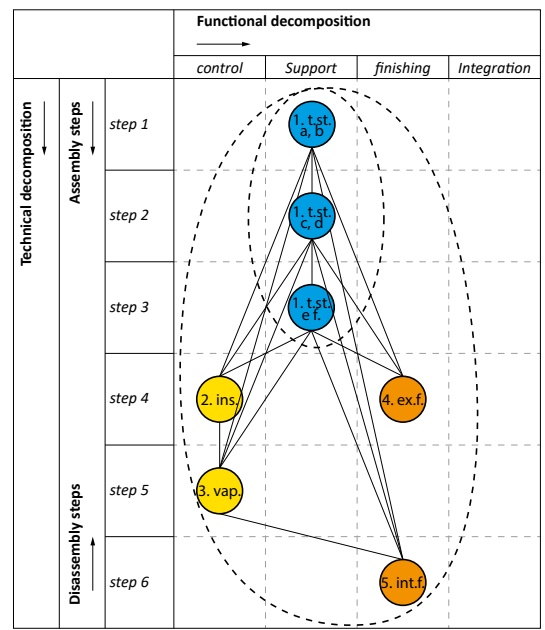

Figure 5.33: Relational pattern of the example above: a) reduced representation, b) element representation. 
nodes represent the functional layers and the lines the relations between the functional layers. The main difference between the connection diagram and the relational pattern can be identified by: 1) the abstract representation of the building in functional layers rather than individual physical parts, and 2 ) the directed representation to represent the assembly and disassembly process steps.

In Figure 5.33, two types of relational patterns have been depicted: a) depicts the reduced representation, in which the nodes: 2 . ins., 3. vap. 4. ex. f. and 5. int. f. represent functional layers that consist merely of elements and 1 .t. str. represents a functional layer that consists of multiple elements that form one component; b) depicts the element representation, in which the t.str. component representation has been divided into three types of elements, namely the bottom beam element layer, stud element layer and top beam element layer. In both representations the dashed circle around the nodes represent physical entities that can be assembled and disassembled at once. Depending on the aim and purpose of the relational pattern, one may decide to use the reduced or non-reduced representation. Since the disassembly of such timber frame components will reduce the embodied value to merely its individual parts, which takes a lot of disassembly effort, such disassembly processes are often economically not feasible.

To develop a relational pattern of a building, an arbitrary boundary for the system of interest should be defined by determining a representative section of the building. In Figure 5.34, an example building of De Groot Vroomshoop is shown, whereby the representative section is marked with a red square. The building is composed of prefab concrete floor plates, steel columns, a timber roof frame and facade frames. Based on the technical detailing, the relational pattern has been defined as shown in Figure 5.35. In the representative section, four repeating closed facade frames can been identified, but to limit the number of repetitive elements in the relational pattern, the relational pattern is limited to closed facade frame one and four and number two and three have been indicated with the dashed line circles between the closed facade frames. In the relational pattern, each line between the nodes represents a type of connection.

Thus the relational pattern is an abstract representation of the composition of the building structure, in which a) the nodes represent functional layers that represent physical entities i.e. elements or components and dashes circles are used to identify larger physical entities such as assemblies and chunks and b) the lines represent connections. A physical entity can be assembled and disassembled at once and keep their properties, i.e. functionality and material properties after being detached from the building. A connection is defined as the physical link between two elements, which restricts the freedom of motion of the elements involved and ensures that the element stays in its intended place (Vongbunyong $\&$ Chen, 2015). To gain full understanding of the re-claim effort, it is important to identify all connection types that are present in the relational pattern in a systematic manner. 

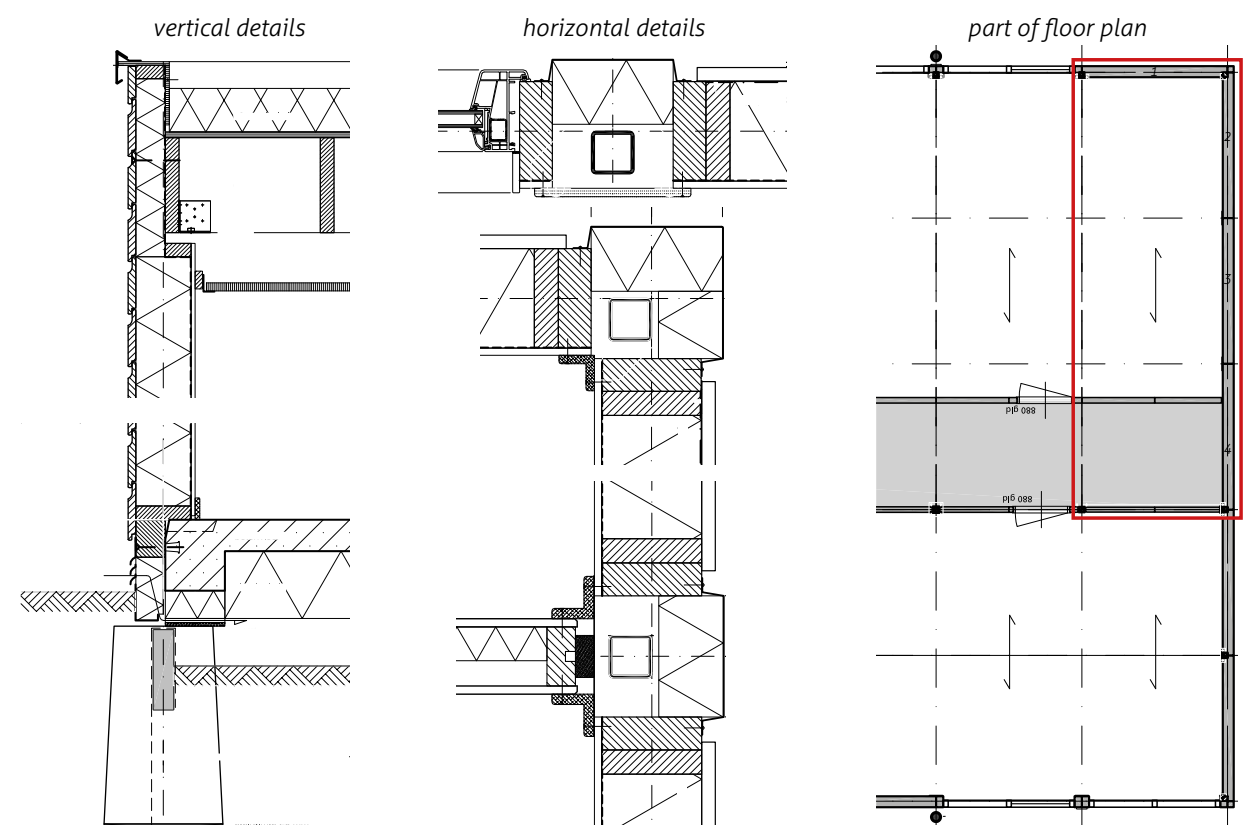

Figure 5.34: Example building, building system of De Groot Vroomshoop, with representative section indication

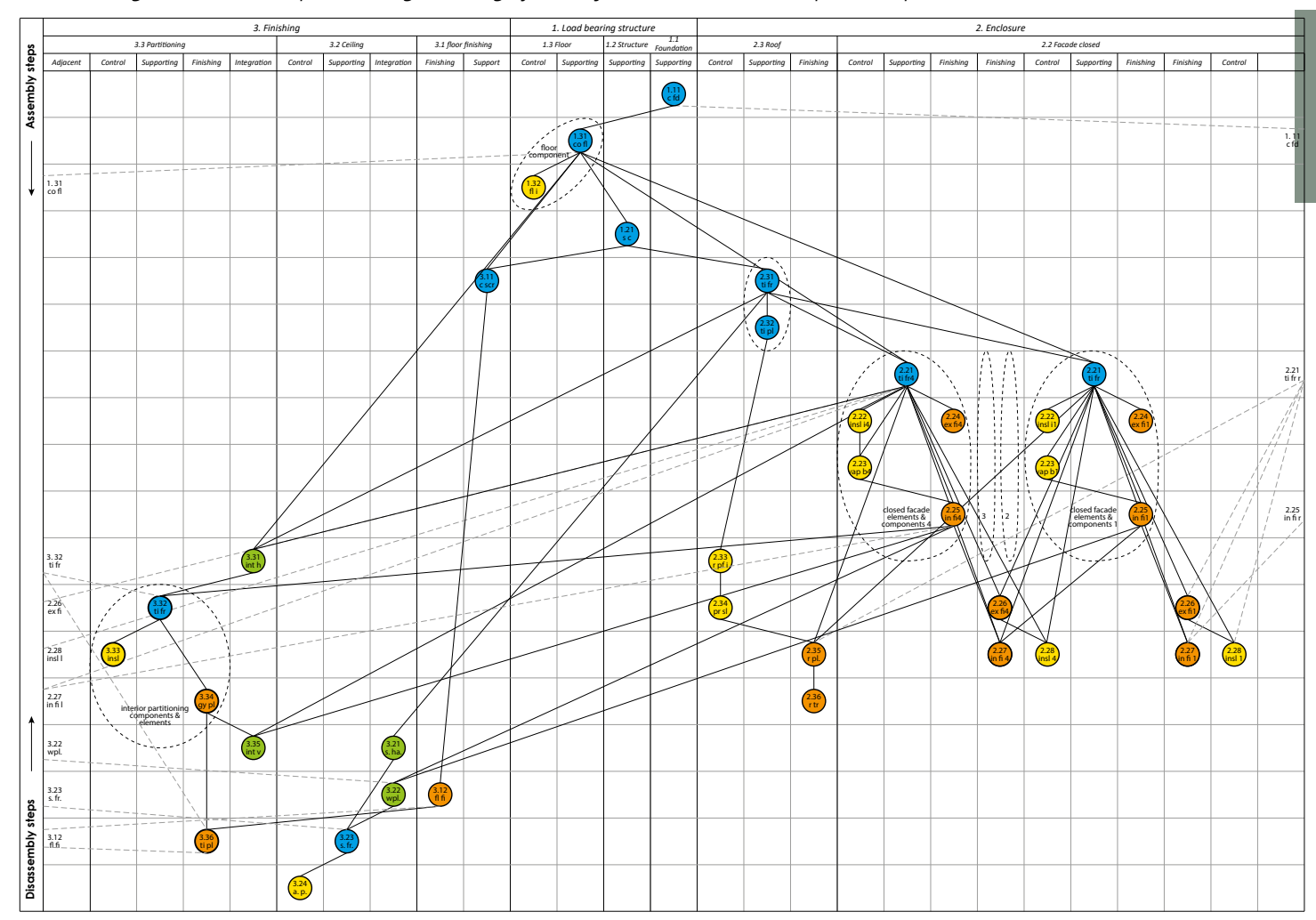

Figure 5.35: Relational pattern of the example building system of De Groot Vroomshoop. 


\subsubsection{Connection types}

In the construction industry a huge amount of different building products are used in combination with an indefinite amount of connection typologies. To understand the impact of the connection type on the reuse potential, it is important to understand the benefits and constraints of connections on the reuse potential of the connected parts. Therefore, a literature analysis has been performed to identify the different types of connections typologies and their impact on the connected parts.

In literature multiple types of connection typologies have been identified, a brief description from the different typologies defined in literature will be given below.

From a product design perspective, Lambert \& Gupta (2004) identified thirteen types of fasteners, sub-divided in a typology of fasteners, containing six categories. The typology of fasteners proposed by Lambert $\&$ Gupta (2004) identifies a distinction between fasteners as discrete components (e.g. screws and bolt and nut connections) and non-discrete material objects (e.g. snap fit, weld and solder connections), resulting in the following typology:

1. Discrete components, which are not deformed (e.g. bundling connections, spring connections, screw connections, and bolt and nut connections)

2. Discrete components, which are reversibly deformed (e.g. cotter pin, staple, and related connections)

3. Discrete components, which are irreversible deformed (e.g. rivet connections, and glue and seal connections)

4. Parts of components, reversible connection (e.g. Mating connections, press fit connections, and snap fit connections)

5. Parts of component, irreversible connection (e.g. press fit connections, glue and seal connections, mould connections, and seam fold connections)

6. Virtual components (e.g. solder connections, and weld connections)

Lambert \& Gupta (2004) state that the advantage of their typology of fasteners is that any deviant type of fastener can be accommodated within their typology.

From a construction perspective, Timmermans \& Zwarts (1985) performed an extensive study to identify the different types of connections and their possible applications, which has been documented in an encyclopedic character. In their connection typology a distinction is made between three main connection categories, namely:

- Form connections. The joining of two or more elements in which the connection is established by means of its shape (e.g. form-lock connections or mating connections, snap fit connections, press fit connections and seam fold connections), and;

- Object connections. The joining of two or more elements by the provision of an additional object, in which the object refers to the means by which the elements are connected (e.g. screw connection, bolt and nut connection, beam anchors, plugs, 
staple, bundling connection, wire nail and blind rivets)

- Material connections. The joining of two or more elements in which the connection is established by means of a liquid or plastic material, which may or may not be added and forms a close bond with the elements (e.g. welding, soldering, glueing, sealing, vulcanization, cement and lime mortar connections, moulding and casting);

Within the three defined main connection categories, seven arch type connections were identified, as shown in Table 5.18. In addition, Timmermans \& Zwarts (1985) defined fourteen additional connection types that are variations of the seven main connection types defined above, including specific connections to attach specific functions to an element or to secure cables and pipes, but also connections that make use of a third element to secure an element. Although, the additional connection types defined by Timmermans \& Zwarts (1985) provide more specific applications, they have been left out for clarity.

Meijs \& Knaack (2009) distinguish internal connections, the connections between the parts that make up a system or type, such as the connection between bricks and external connections, the connections between elements that are not part of the same system or type, such as the connection between window frame and a wall. Furthermore, they characterise connections based on the type and function of the connection, namely:

1. Joint according to positioning of elements. The position of the two parts in relation to each other, which can be: a) butt joint, b) open joint, c) overlapping joint or crossing joint;

Table 5.18: Seven arch type connections (Timmermans \& Zwarts, 1985, pp. 10, 11).

Type of connection
Form connections


2. Joint according to the form of elements, the connected parts possess a particular shape, which can be: a) direct, b) indirect or c) mixed, a combination of both;

3. Joint according to the material of elements, which can also be: a) direct, such as welding of steel parts or b) indirect with a third material creating the bond between the elements.

In addition, they defined a second way of looking at connections based on the type of fixation that is used, namely:

- Fixation through position. The fixation of the individual element is based on the arrangement in relation to the adjacent elements, whereby the binding power is provided by gravity, e.g. a drystone wall.

- Fixation through form. The fixation of the element is based on a positive-locking connection, which is based on the shape that positively locks into the other object, which can be a direct form-locking connection or indirect form-locking connection, which utilises an additional object to secure the element in place.

- Fixation through material. The fixation is provided by a physical-chemical bond between the objects being connected, which can be directly, e.g. welding, casting, moulding and coating, or indirectly e.g. soldering, gluing, cement and lime mortar.

In the study of Durmisevic (2006) key technical capabilities are defined which should be incorporated in the design of connections to enable transformation and reuse, namely: decomposition, re-composition, incorporation, and plugging-in. Based on which Durmisevic (2006) defined a method to classify connections according to the degree of flexibility ranging from fixed to flexible, as shown in Table 5.19.

Table 5.19: Seven principles of connections ranged from fixed to flexible (Durmisevic, 2006, p.183)

Type of connection
Direct chemical connection
Two elements are permanently fixed
Direct connection between two pre-made elements
Two elements are dependent in assembly and
disassembly
Indirect connection with third chemical material
Two elements are connected permanently with third
material


In order to identify all connection types that are present in the relational pattern in a systematic manner, a connection is defined as the physical link between two elements, in contrast to the definition of Timmermans \& Zwarts (1985) and Durmisevic (2006), who include third elements as part of one connection. It should be noted that discrete fastener are not regarded as elements. While building upon the connection classification methods defined by Lambert \& Gupta (2004), Timmermans \& Zwarts (1985), Meijs \& Knaack (2009) and Durmisevic (2006) a connection typology has been defined, which can be used to classify all types of connections in the relational pattern. Third elements should be included in the relational pattern as nodes with the basic element function 'integration'. In the defined connection typology four generic connection categories and thirteen connection types have been specified, as shown in Table 5.20. The four generic connection categories are defined as:

- Position based connections, are connections in which the fixation of the element is based on the arrangement in relation to adjacent elements and the binding power is provided by gravitational forces or forces applied by binding fasteners, such as tie-down straps, tension belts and cable ties, to provide resistance against forces other than gravity. These connections are often easy to assemble and disassemble and commonly do not affect the connected parts.

- Geometry based connections, are connections in which the fixation of the element is based on the shape of the element that forms a positive-locking connection. This can be a form-locking connection, a connection that is formed with two objects that directly lock into each other due to their shape, such as tongue and groove connection, and bridle joints. Mostly these connections have at least one-degree of freedom, to secure the connection. Or a form-locking connection with fastener, a connection that is formed with two objects that directly lock into each other, which are secured by a fastening part, such as the Japanese stub tenon joint, lapped rod mortise and tenon joint or wedged blind tenon joint (Seike, 1977). While it is also possible that a fastener such as a screw or nail are used. Basic form-lock connections are often easy to assemble and disassemble and do not affect the connected parts, but form-lock connections with fastener may affect the connected parts and can be more difficult to disassemble.

- Fastener based connections, are connections in which the connection's main fixation is based on a discrete fastener. Five fastener based connections can be defined, which will be described, starting with the connection that is the easiest to disassemble with almost no impact on the connected elements to the connection that is the most difficult to disassemble and increased impact on the connected elements, namely: 1) two access connection (e.g. bolt and nut connections); 2) one access threaded connection (e.g. screw connections); 3) one access non-threaded connection (e.g. nail or staple connections); 4. hidden dowel connection (e.g. hole and dowel connection); 5. irreversible one access connection (e.g. blind rivet connections). 
- Material based connections are connections in which the fixation of the elements is based on a physical-chemical bond between the objects that are being connected, which can be formed directly, without the addition of other types of material or indirectly, with the application of a third material that activates the bond between the two parts. Furthermore, the material connection can either be stronger than the connected elements or weaker that the connected elements. If the material connection is stronger than the connected parts, it is very difficult to undo the connection without breaking the connected element, reducing the reuse potential of the connected elements.

Based on the disassembly effort and disassembly damage the connection types have on the connected parts, the type of connections are ranged from flexible to fixed connections, as shown in Table 5.20. Furthermore, it should be noted that there are exceptions in which combinations of connection types are used, such as a dowel connection that is secured with glue. In such a situation the connection should be identified as the worst type of connection of the combination, which is a indirect material connection weaker than connected part, the glue connection. The icons as shown in Table 5.20 are used to graphically represent the type of connection in the relational pattern, and should be placed between two nodes.

Table 5.20: Connection typology ranged from flexible to fixed

\begin{tabular}{|c|c|c|c|}
\hline \multirow[t]{2}{*}{ Icon } & \multicolumn{2}{|c|}{ Type of connection } & \multirow[t]{2}{*}{ Examples } \\
\hline & A & Position based connections & \\
\hline 市 & A1 & Force connection & Drystone wall \\
\hline \multirow[t]{2}{*}{ 守 } & A2 & $\begin{array}{l}\text { Force connection from fastener } \\
\text { connection }\end{array}$ & $\begin{array}{l}\text { Tie-down strap, tension belt connection, cable tie connection, binding } \\
\text { thread, clamp }\end{array}$ \\
\hline & $B$ & Geometry based connections & \\
\hline & B1 & Form-lock connection & $\begin{array}{l}\text { Mating connection, bridle joint, snap fit or press fit connection, seam } \\
\text { fold connection }\end{array}$ \\
\hline \multirow[t]{2}{*}{5} & B2 & $\begin{array}{l}\text { Form-lock connection with } \\
\text { fastener }\end{array}$ & $\begin{array}{l}\text { Japanese timber connection with wedge or pin, beam anchor joint with } \\
\text { fastener }\end{array}$ \\
\hline & C & Fastener based connections & \\
\hline$\triangleright \triangleleft$ & C1 & Two access connection & Bolt and nut connection, cotter pin connection \\
\hline$\infty$ & $\mathrm{C} 2$ & $\begin{array}{l}\text { One access threaded } \\
\text { connection }\end{array}$ & Screw connection \\
\hline & $\mathrm{C} 3$ & $\begin{array}{l}\text { One access non-threaded } \\
\text { connection }\end{array}$ & Staple connection, wire nail connection \\
\hline & $\mathrm{C} 4$ & Hidden dowel connection & Cavity anchor, hole and dowel connection \\
\hline \multirow[t]{2}{*}{$\diamond \triangleleft$} & $\mathrm{C} 5$ & $\begin{array}{l}\text { Irreversible one access } \\
\text { connection }\end{array}$ & Hollow wall plug, (blind) rivet connection \\
\hline & D & Material based connections & \\
\hline & D1 & $\begin{array}{l}\text { Indirect material connection, } \\
\text { weaker than connected part }\end{array}$ & $\begin{array}{l}\text { Soldering, gluing, cement and lime mortar, adhesive bonding and } \\
\text { sealing. }\end{array}$ \\
\hline & D2 & $\begin{array}{l}\text { Direct material connection, } \\
\text { weaker than connected part }\end{array}$ & Welding, casting, moulding and coating, vulcanization \\
\hline & D3 & $\begin{array}{l}\text { Indirect material connection, } \\
\text { stronger than connected part }\end{array}$ & $\begin{array}{l}\text { Soldering, gluing, cement and lime mortar, adhesive bonding and } \\
\text { sealing. }\end{array}$ \\
\hline & D4 & $\begin{array}{l}\text { Direct material connection, } \\
\text { stronger than connected part }\end{array}$ & Welding, casting, moulding and coating, vulcanization \\
\hline
\end{tabular}




\subsubsection{Design Structure Matrix}

To ensure a consistent and objective evaluation method that can be automated using computational analysis, the Design Structure Matrix (DSM) method has been identified. A Design Structure Matrix (DSM) is a network modelling method used to represent the elements comprising a system and their interactions, highlighting the system's architecture or designed structure (Eppinger \& Browning, 2012).

Since the 1990s DSM and has been used to represent product architecture, organization architecture, process architecture and multidomain architectures (Browning, 2015, Eppinger $\&$ Browning, 2012). DSM is also known as a $\mathrm{N} \times \mathrm{N}$ matrix in which the interactions among the set of $\mathrm{N}$ elements are defined, in which $\mathrm{N}$ represents the number of elements. A DSM highlights relationships between elements within a single domain, which can be used to analyse specific functions. For example, in a product architecture DSM the hierarchy of the structure, clustering, interactions and type of interactions can be analysed and improved upon using a DSM.

A product architecture DSM is therefore identified a highly suitable method to provide a concise way of visualising a building's composition and interactions. A DSM can be read with inputs in rows (IR convention) and outputs in columns, or inputs in columns (IC convention) and outputs in rows. Both conventions convey the same information and both are widely used. In this research the IR convention is adopted.

In Figure 5.36 an example of a binary DSM (IR convention) with row and column labels and its equivalent node-link diagram is shown (Browning, 2015, p.2). The elements 1-6 in the node-link diagram are labelled 1-6, which are also labelled on both the rows and columns 1-6. As can be seen, 1 has a link with 2, 4, 5 and 6, which is shown by the marks in the DSM. The mark simply indices the presence or absence of an interaction. Often the binary approach has been extended in a large variety of ways by including further attributes to represent different type of interactions, e.g. number of interactions, importance, impact or strength, by using numerical values, symbols or colors. The extended form of DSM is called numerical DSM. The application of numerical DSM provides great opportunities to include additional information in addition to the presence of a relation between parts.
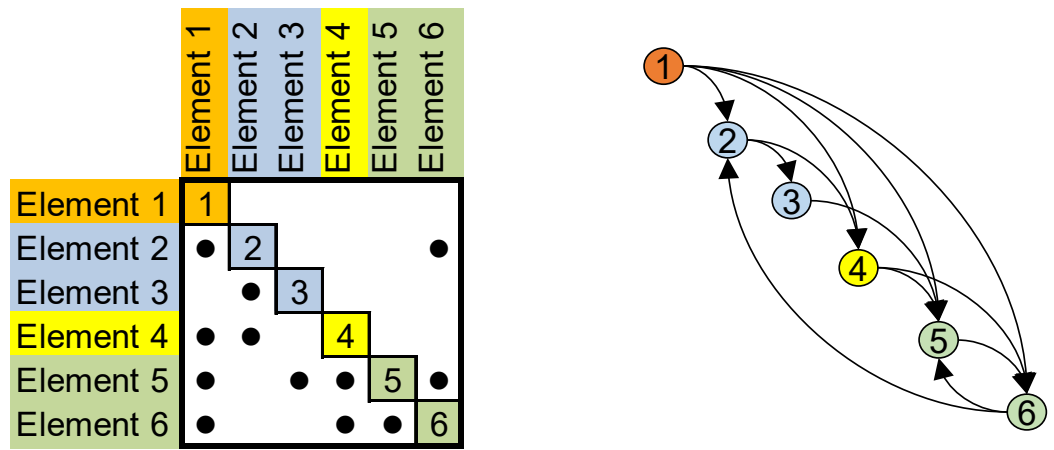

Figure 5.36: Example of a binary DSM (IR convention), with row and column labels and its equivalent node-link diagram (Browning, 2015, p. 2) 
The numerical approach has been adopted in the reuse potential assessment method to include the type of connection that is used between the related parts. The connection types defined in Table 5.20 are used to specify the type of connection.

The DSM allows the translation of the relational pattern, which is an abstract representation of the composition of the building structure, in a systematic manner that allows the assessment of multiple automated assessments. In Figure 5.37 an example is given of the relational pattern of a modular building, which has been translated into a DSM input matrix. In addition to the type of connections, the product levels, chunk, assembly, component can also be represented in the DSM, using different colours. Furthermore, the disassembly sequence can be identified based on the sequencing algorithm, called path searching based on Steward's (1981, p.54-55) algorithm. This method has been summarized and further explained by Gebala and Eppinger (1991) and has been integrated in the reuse potential assessment method to identify the disassembly sequences. The disassembly sequence depends on the disassembly depth, for example to relocate a building that is composed of chunks it is not necessary to disassemble the chunks into its assemblies, components and elements, while to replace a defect part in the chunk it might be required to disassemble the chunk into lower levels. Therefore, the distinction in disassembly depth based on the product levels is included in the reuse potential evaluation method and allows the initial DSM to be translated in three different disassembly level DSM models, as shown in Figure 5.38.
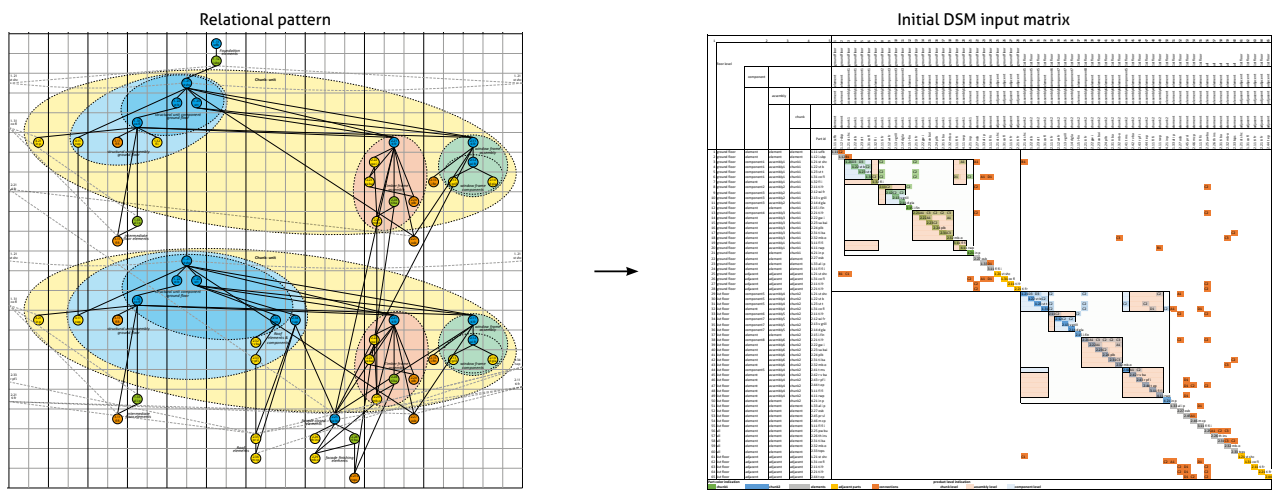

Figure 5.37: Example of a relational pattern translated into a DSM

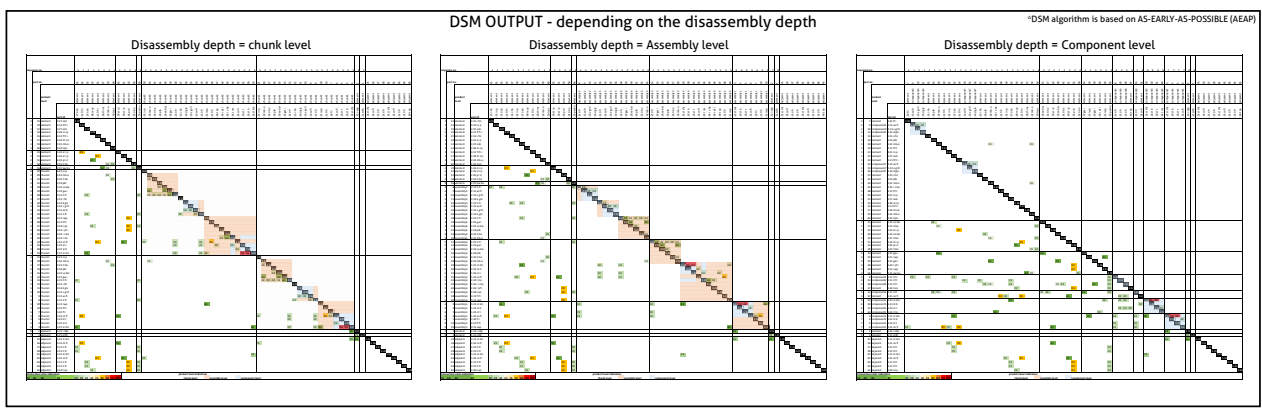

Figure 5.38: Example of a DSM output depending on the disassembly depth. 
In Figure 5.39 a DSM model is shown to clarify the DSM. In the DSM input matrix each part is given a unique part number and part ID to recognise the part, which is also shown in the DSM output model (Figure 5.39). Furthermore, its type of product is defined in the input matrix, to enable the distinction between different product levels and clusters of parts that can be disassembled as a whole. Based on Steward's sequencing algorithm the input DSM is sorted into an organized and clustered DSM in which the parts that can be assembled and disassembled at once are given a color to indicate its product level. In a DSM in vertical direction the relations or connections of the part are shown and in the horizontal direction the dependencies of the part are shown. Each connection is rated based on the type of connection as defined in Table 5.20. Furthermore, each cell that defines a connection is colored from green to red based on its how fixed or flexible the connection is. In Figure 5.39 the disassembly sequence number is shown in yellow and in addition, the parts that can be disassembled in parallel are also marked yellow. At every addition of a disassembly sequence number a vertical/ horizontal line is generated to provide clear distinctions between assembly and disassembly sequences. By addressing chunk, assembly and component level it is possible to distinguish three different disassembly levels in the DSM model, which is considered essential in addressing all three reuse levels.

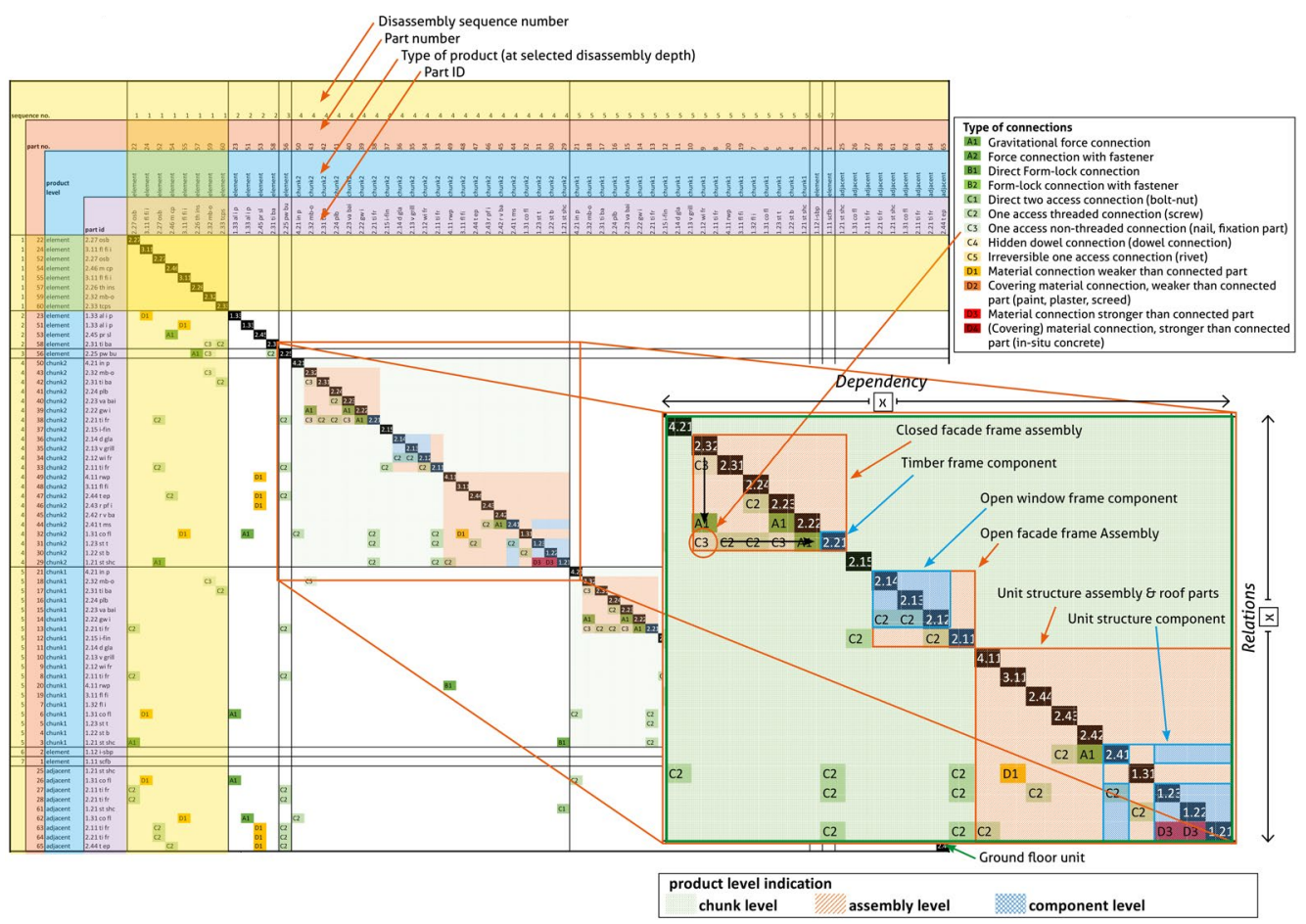

Figure 5.39: DSM output model explained 


\subsubsection{Reuse potential scoring system}

The reuse potential scoring system extends on the four reuse scenarios defined in section 3.4.1, based on which four reuse levels have been defined. The reuse potential evaluation method is aimed at slowing resource flows by supporting high quality building-, systemand product level reuse, and excludes closing resource flows, i.e. substance level reuse, the reuse of materials by re-processing them. Depending on the reuse level, different connections and physical entities are identified and taken into account, namely:

- Building reuse. The building reuse score represents the amount of effort, damage and repair that is required to reuse the entire building, through relocating the building by keeping the embodied values as high as possible, meaning the disassembly of the minimum number of connections to enable the building to be relocated.

- System reuse. The system reuse score represents the amount of effort, damage and repair that is required to reuse the separate main building systems (e.g. load-bearing, enclosing, finishing or servicing), through removing the selected main building system from the building and keeping the embodied values as high as possible, meaning the disassembly of the least amount of connections that are required to disassemble the selected main building system, to allow the system to be reused directly.

- Product reuse. The product reuse score represents the amount of effort, damage and repair that is required to reuse the separate building products, through disassembly of all connections and reducing the embodied values to the separate parts. This identifies the amount of effort, damage and repair that is required to allow reuse of its separate parts, and includes the potential to modify the parts for reuse.

All criteria are rated at building reuse, system reuse and product reuse level, to enable a full judgement of the reuse potential of the building at all three levels. To clarify the differences between each reuse level, in Figure 5.40 a conceptual representation of a building is shown in which the relations that are taken into account at each level are shown in red.

Next to the disassembly reuse levels, two scoring methods are possible, function based or physical entity based. Function based means that a set of predefined functions will be determined to assess all criteria for the elements that can be attributed to that function, while physical entity based, means that depending on the composition and identifiable physical entities a dynamic model identifies the physical entities that are assessed. This would provide more specific insight in the reuse potential of specific parts (e.g. assemblies) of the building, but due to the dynamic physical entity identification comparison of the physical entities of one building with another building is ambiguous. While the function based approach, which is the assessment of all parts that are assigned to that function are taken to assess the different criteria, would allow for comparison at each reuse level and for each specific function. Furthermore, it allows the identification of specific building (sub-) functions that could be improved upon or are rated high. Since the aim of the reuse potential evaluation method is to provide insight in the impact of design decisions and enable objective comparison, the function based approach is selected for the reuse 


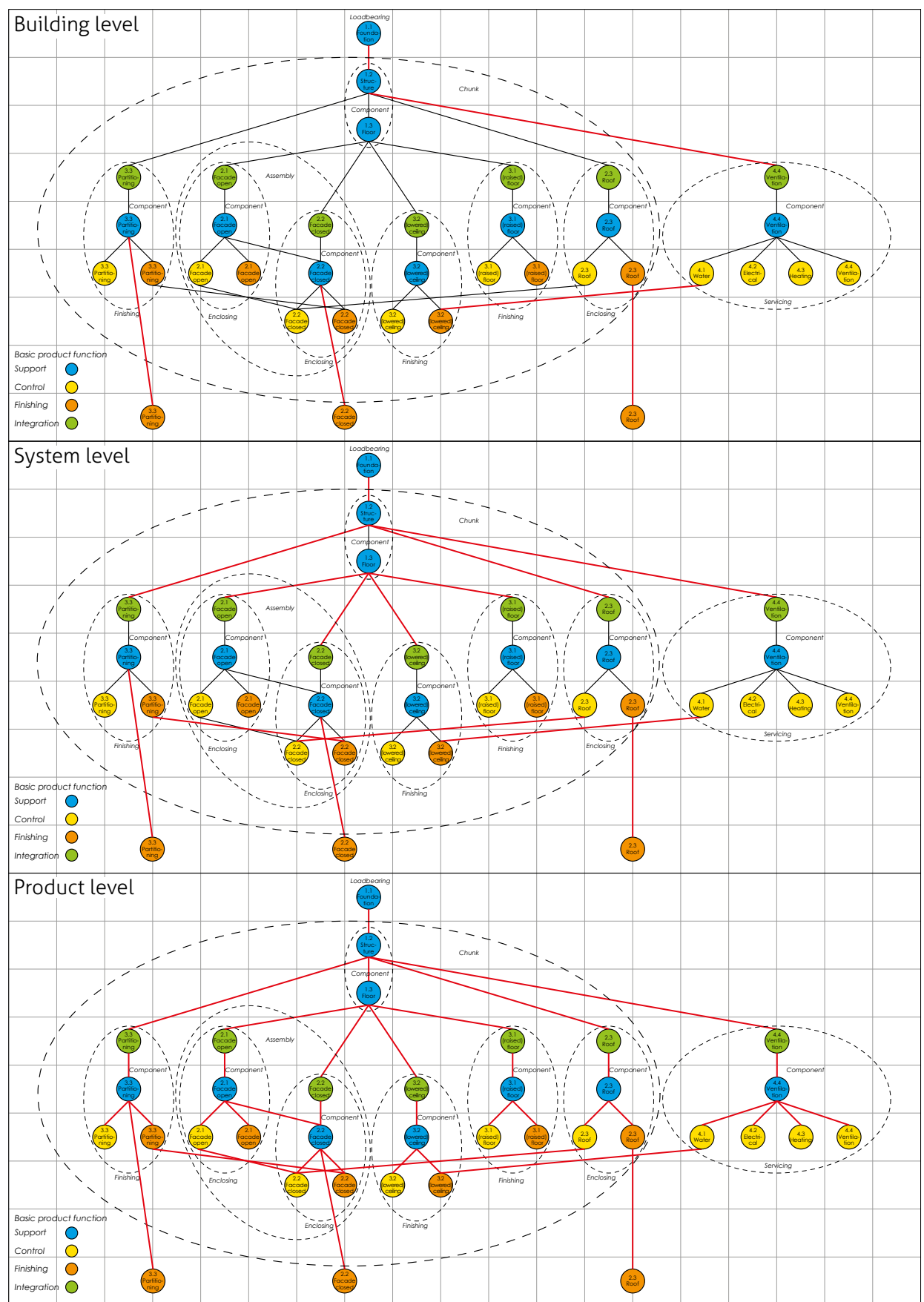

Figure 5.40: Conceptual representation of a building, depicting the relations that are taken into account at building-, system-and product level scores in red 
potential evaluation method. With a function based scoring system three scoring levels can be defined, namely:

- Building score, to identify an overall score for the reuse potential of the building, which is based on the average of the main building systems;

- System scores, to identify an overall score for each main building system, which is based on the average of the sub-building functions of each main function, and;

- Product scores, to identify product specific scores for each building sub-function.

The differentiation in the three different types of scores allows the scores to be used for different purposes. For example, the developer or client of a building can set a minimum level of Reuse Potential building scores (for each reuse level) to steer the design team and ensure a high reuse potential. While the product scores can be used by the design team to gain understanding of the specific parts that require improvement to increase and comply with the Reuse Potential scores. While to be more specific, the developer or client could also set specific system scores or product scores to ensure a high reuse potential of certain building systems or sub-functions of the building.

The main indicators of the reuse potential evaluation method are:

1. Embodied value;

2. Re-claim effort, and;

3. Re-conditioning effort.

The average of all three main indicators defines the reuse potential, which is specified for all three reuse levels. To gain a better understanding of the different indicator values and reuse potential value, in Figure 5.42 the assessment rating system is specified in a qualitative manner. The assessment of each sub-criteria is calibrated in such a way that the indicator values correspond to the specification in Figure 5.42. The sub-criteria assessment values specified in the next section are calibrated based on testing with the building example of Figure 5.34.

To provide a better understanding of the reuse potential evaluation method, two case studies will be described, analysed, tested in the next chapter to verify the assessment method and the reuse potential rating systems. 

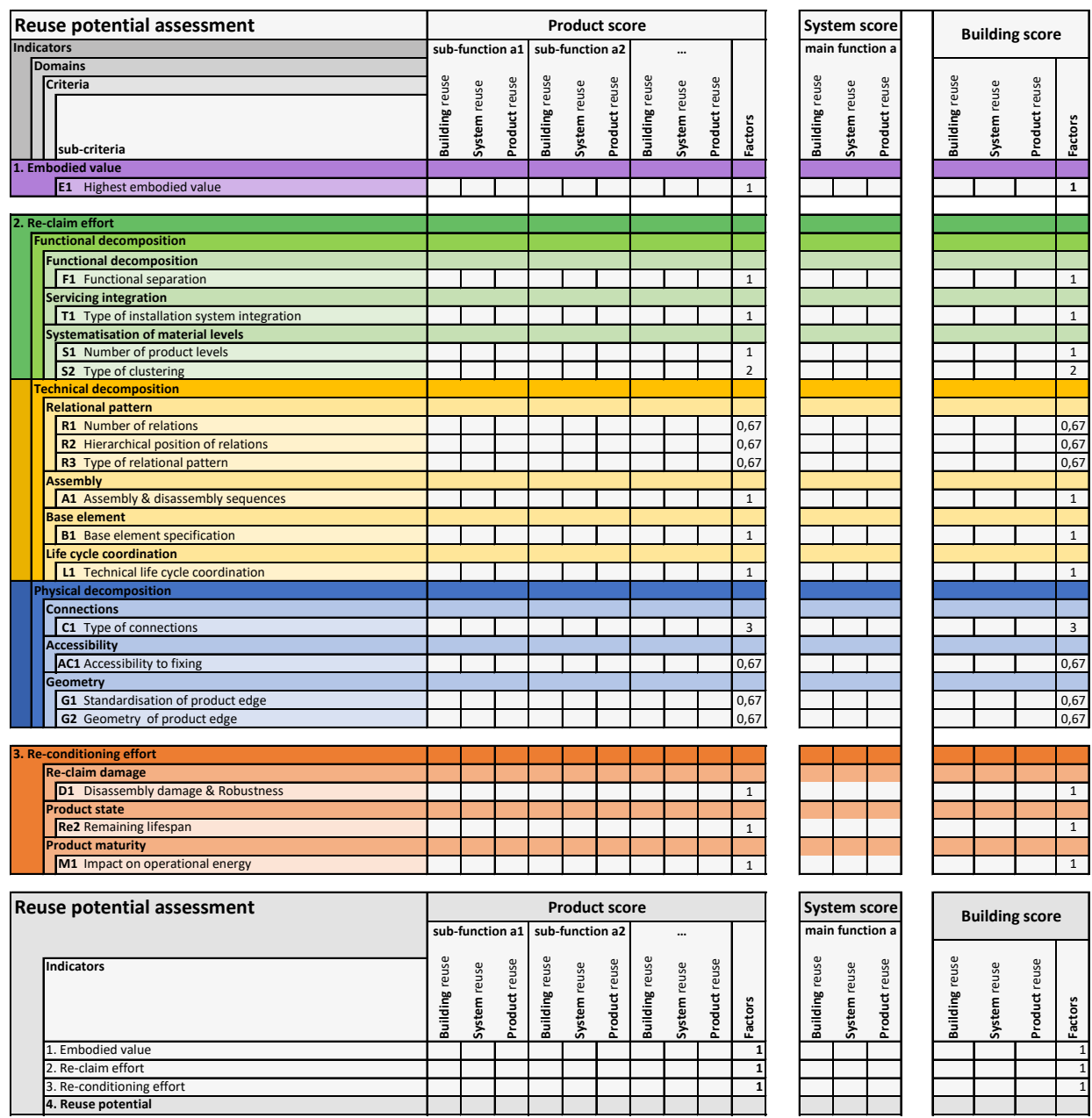

Figure 5.41: Empty example overview form of the reuse potential assessment scores

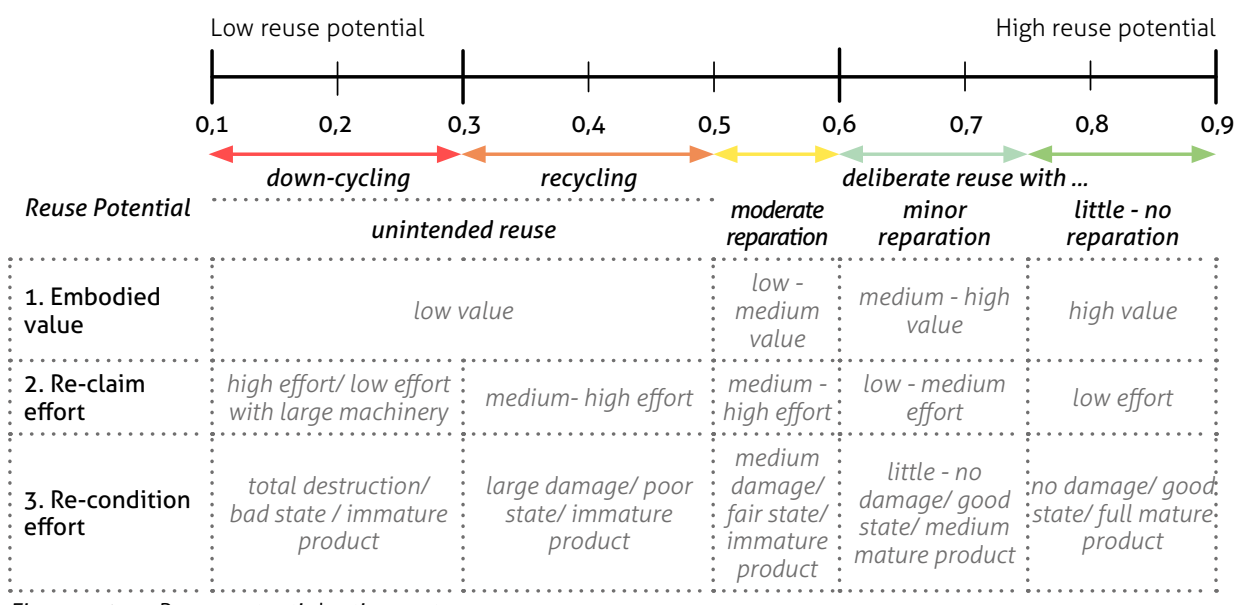

Figure 5.42: Reuse potential rating system 


\subsection{Development of the reuse potential evaluation method}

To increase the reuse potential from a design perspective, the following strategy has been defined in section 3.4.3:

- Design buildings, systems and products: with high embodied value to allow for the impact of 'additional processes'; that maintain most of their embodied value during reuse processes, and; to allow the impact of 'reuse on the operational value' to be reduced to a minimum through upgrading the parts that impact the operational value;

The impact of 'reuse on the embodied value', determines the value that is being preserved during reuse processes and determines whether or not the impact of 'additional processes' is worth the reuse of the building, system or product compared to an alternative non-reuse scenario. Thus, the impact of 'additional processes' should be at least equal or lower than the preserved embodied value for reuse to be environmentally beneficial and economically viable, which should be taken into account when assessing the reuse potential. Furthermore, the impact of 'reuse on the operational value' should be reduced to a minimum. As was stated previously, this is especially important for powered products and products that impact the energy performance of the building. In order to reuse such products, they might require re-conditioning to bring them to the required performance level.

In order to evaluate the reuse potential a method is proposed that incorporates the key criteria as identified in the design strategy, namely: embodied value and the impact of 'additional processes', as shown in Figure 5.43. In section 3.4, the embodied value is defined from four perspectives, namely: economic-, cultural-, material- and energy value perspective. Whereby, the highest value is considered as the normative value and should be contrasted with the impact of 'additional processes'. The impact of 'additional processes' is determined by: re-claim effort (non-destructive), re-conditioning effort and the re-apply effort.

The re-claim effort extends upon the determining factors defined by Durmisevic (2006), which are sub-divided in three domains, functional-, technical- and physical decomposition. Each domain is sub-divided in multiple sub-criteria to assess the re-claim effort.

Furthermore, the re-conditioning effort can be determined based on the re-claim damage, product state and product maturity. Whereby the re-claim damage is a result of the robustness of the product and the disassembly damage. The product state can be determined from a theoretical perspective, based on the remaining (technical) lifespan. The product maturity refers to the expectancy of the product to become obsolete or require upgrades to support reuse. For example, steel beams have reached a mature level and do not change much anymore and are expected to also not change in the near future, while the energy performance of buildings is continuously improving, which means that the products that determine the energy performance are not mature and require them to be easily upgradable to the improving standards. Furthermore, the impact of 'reuse on the 


\begin{tabular}{|c|c|c|c|c|}
\hline \multicolumn{5}{|c|}{ Reuse Potential } \\
\hline \multirow[t]{2}{*}{ Embodied value } & \multirow[t]{2}{*}{$\geq$} & \multicolumn{3}{|c|}{ Impact of 'additional processes' } \\
\hline & & $\begin{array}{l}\text { Re-claim effort } \\
\text { (non-destructive) }\end{array}$ & Re-condition effort & Re-apply effort \\
\hline $\begin{array}{l}\text { embodied value } \\
\text { - Embodied } \\
\text { economic value } 3 \\
\text { - Embodied } \\
\text { cultural value } 3 \\
\text { - Embodied } \\
\text { material value } 3 \\
\text { - Embodied } \\
\text { energy value }\end{array}$ & & $\begin{array}{l}\text { Functional decomposition } \\
\text { - Functional separation }{ }^{1} \\
\text { - Type of installation system integration }{ }^{1} \\
\text { - Number of product levels }{ }^{2} \\
\text { - Type of clustering }{ }^{2} \\
\text { Technical decomposition } \\
\text { - Number of relations }{ }^{3} \\
\text { - Hierarchical position of relations }{ }^{1} \\
\text { - Type of relational pattern }{ }^{1} \\
\text { - Assembly } \text { \& disassembly sequences }{ }^{2} \\
\text { - Base element specification }{ }^{1} \\
\text { - Technical Life cycle coordination }{ }^{2} \\
\text { Physical decomposition } \\
\text { - Type of connections }{ }^{2} \\
\text { - Accessibility of fixing }{ }^{2} \\
\text { - Standardisation of product edge }{ }^{1} \\
\text { - Geometry of product edge }{ }^{1}\end{array}$ & $\begin{array}{l}\text { - Disassembly damage } 3 \\
\text { - Robustness } 3 \\
\text { - Remaining lifespan } 3 \\
\text { - Impact on operational } \\
\text { energy }^{3}\end{array}$ & \begin{tabular}{|l} 
- application range \\
$-\ldots$
\end{tabular} \\
\hline
\end{tabular}

Figure 5.43: Assessment criteria to evaluate the reuse potential of buildings, systems and products. ('adopted from Durmisevic (2006), ${ }^{2}$ adapted from Durmisevic (2006), ${ }^{3}$ defined by author)

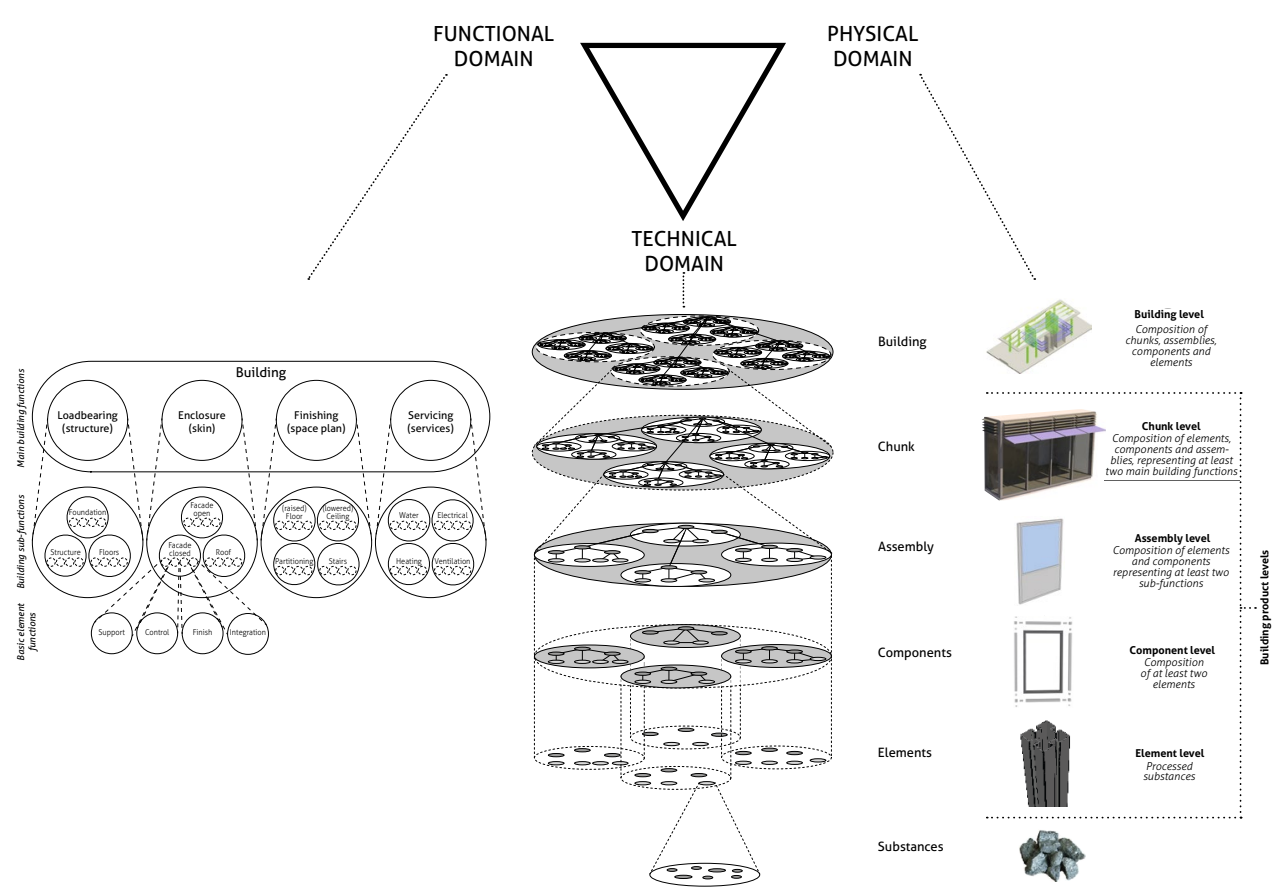

Figure 5.44: Functional-, technical- and physical design domain, based on Durmisevic (2006), modified to determine the re-claim effort (non-destructive). 
operational value' is included by product maturity, and is determined by the amount of re-conditioning effort that is required.

Finally, the assessment of the re-apply effort is excluded from the evaluation method, because it is impossible to predict the future and take into account its re-apply effort.

To clarify the contributions of this research the assessment criteria indicated with ${ }^{1}$ in Figure 5.43 are adopted from Durmisevic (2006), meaning the technological rule has not changed. It should be noted that all criteria have been reinterpreted to enable automated assessment based on the compositional information of the building stucture and multiple criteria have been extended to enable an evaluation on multiple disassembly levels, as shown in Table 5.40. Furthermore, the assessment criteria indicated with ${ }^{2}$ in Figure 5.43 have been updated based on the findings in this research and the criteria indicated with 3 in Figure 5.43 have been defined in this research.

Furthermore, it should be noted that the following determining factors specified by Durmisevic (2006) have been left out of the proposed reuse potential assessment method: use life cycle coordination, because it is not possible to predict use life of each part; lifecycle of components and elements in relation to the size, due to lack of clarification; tolerance, due to lack of clarification, and; morphology of joint, due to lack of clarification.

In the next sections, each sub-criteria will be defined and further specified into technological rules with measurable values to define the reuse potential evaluation method. The assessment values are under embargo. Therefore, the specified values are kept out of the main texts in the thesis. In 'Appendix C - Assessment values of the reuse potential evaluation method', the values are added. This appendix can be supplied upon request.

\subsubsection{Embodied value specification}

The embodied value refers to the embodied energy value, embodied material value, embodied economic value and embodied cultural values, which are values that remain embodied in the product after reclamation. It is argued that the height of the embodied values determines the amount of effort the 'additional processes' may be before the impact of 'additional processes' raises above the reclaimed embodied values, thus the higher the embodied values, the higher the potential to reuse the product will be.

The aim of the embodied value specification is to provide an indication of the embodied value of the reclaimed physical entities, rather than an exact value in euro or MJ, because these values can change over time due to changing economies or adapted processes. Although the embodied value from a cultural or material value is a subjective criterion. Four assessment criteria have been determined to indicate the embodied economic value, embodied cultural value, embodied material value and embodied energy value. The aim of the embodied value specification assessment method is to provide an indication of the embodied values, to limit the time required to perform the assessment. The assessment methods are defined in Table 5.21 and should be defined for each identified part in the DSM. 
Furthermore, it is argued that the highest of all four previously mentioned embodied values is determinative for the embodied value of the product and defines the embodied value for the reuse potential evaluation method. It should be noted that depending on the disassembly level (building, system or product level), the embodied value of the physical entity can vary and will be determined based on the identifiable product entities at each disassembly level.

Table 5.21: Assessment method to determine the embodied economic-, embodied cultural-, embodied material- and embodied energy values.

\section{E 1 Highest embodied value}

\section{E 1.1 Embodied economic value}

The embodied economic value is based on the economic value of the re-claimed physical entity and is determined low, medium or high, based on the specified values below.

1. Low Economic value of physical entity is lower than the value of 1 man hour

2. Medium Economic value of physical entity is between the value of $1-2,5$ man hour

3. High Economic value of physical entity is higher than the value of 2,5 man hour

\section{E 1.2 Embodied cultural value}

The embodied cultural value is based on the age and history of the re-claimed physical entity and is determined low, medium or high, based on the specified values below.

1. No The physical entity has no cultural significance or historical value

2. Moderate The physical entity has some cultural and historical significance

3. High The physical entity is of high cultural and historical significance

\section{E 1.3 Embodied material value}

The embodied material value is based on the size of the re-claimed physical entity and is determined low, medium or high, based on the specified values below.

\begin{tabular}{ll}
\hline 1. Small The physical entity can be relocated by one person \\
2. Medium & The physical entity can be relocated by more than one person \\
3. Large & The physical entity can only be relocated with specialized equipment \\
\hline
\end{tabular}

\section{E 1.4 Embodied energy value}

The embodied energy value is based on the initial embodied energy of the re-claimed physical entity and is determined low, medium or high, based on the specified values below, which are based on ICAEN (2009, p. 98). The embodied energy value can be determined by the following formula: weight physical entity $x E E$.

\begin{tabular}{ll}
\hline 1. Low & $x \leq 0,5 \mathrm{GJ} /$ tonne \\
2. Medium & $0,5<x \leq 5 \mathrm{GJ} /$ tonne \\
3. High & $x>5 \mathrm{GJ} /$ tonne \\
\hline
\end{tabular}




\subsubsection{Re-claim effort specification}

The assessment method to determine the re-claim effort extends upon the transformation capacity model of Durmisevic (2006) that distinguishes a functional, technical and physical domain, addressing 8 indicators and their determining factors (updated during EU BAMB 2020 project). These indicators and their assessment values are elaborated in this section. The assessment method has been adapted to enable an automated assessment using the Design Structure Matrix. Depending on the type of criterion, a formula is used to calculate the specific assessment value based on its input in a dynamic manner or an assessment based on pre-defined assessment values, which are rated from most preferred to least preferred.

\subsubsection{Functional domain}

The functional domain deals with functional decomposition and allocation of functions into separate products, to allow them to be adapted, replaced and upgraded independently and allows them to be change according to their differing changing rates. The functional domain defines functional dependencies.

The allocation of functions to physical products is essential and according to Ehrens and Verhulst (1997), a distinction can be made between modularity and integration, modularity corresponds to flexibility and changeability, while integration corresponds to stability and optimisation. Ehrens and Verhulst (1997) defined four types of allocating functions to physical products, namely:

- Modular design (1:1). One function is allocated to one module. This is modular design.

- Function distribution (1:N). One function is mapped to several modules, distribution of a function over several modules results in an integrated design on that level.

- Function sharing (N:1). Several functions are allocated to one module, function sharing increases the level of integration.

- Integrated design (N:M). Several functions are allocated to several modules, functions are distributed and shared, thereby further increasing the level of integration.

Durmisevic (2006) integrated a similar distinction in the transformation capacity model. To enable building systems and building products to be adapted, replaced and upgraded independently, the basic element functions (support, control, finish and integration) should be separated at product level, and the building sub-functions should be separated at system level.

\section{F1 Functional separation}

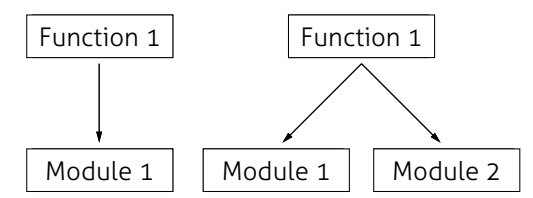

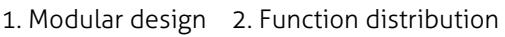

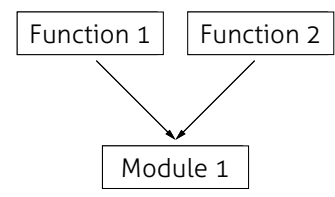

3. Function sharing

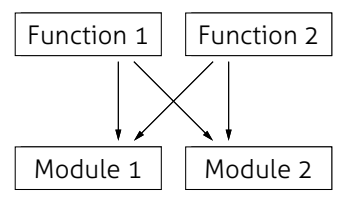

4. Integrated design

Figure 5.45: Erens and Verhulst's (1997) four types of product architecture 
The functional separation is defined to determine the extent to which the allocation of functions is based on a modular design or integrated design. The separation of functions would for example allow a deteriorated part to be replaced or substituted without prematurely replacing other functions. While if the part integrated multiple functions, the substitution of the specific deteriorated part would not be possible and result in premature replacement of parts. Additionally, at the higher building levels, assemblies and components are preferred to be of generic nature, which means that they are designed in such a way that they are applicable in multiple ways. When assemblies and components are designed as generic products the application range increases, which results in a higher reuse potential.

To enable a comprehensive assessment of the functional separation, the assessment consists of three parts, as shown in : 1) are the used assemblies and/or components of generic nature or not 2) is the part dedicated to only one sub-function (Foundation, structure, floor, façade open, façade closed, roof, (raised) floor, (lowered) ceiling, partitioning, stairs, water installation, electrical installation, heating or ventilation), and 3) can the element be allocated to one basic element function (support, integration, control or finishing), representing a modular design or multiple basic element functions, representing an integrated design. The integration of the basic element function support and finishing is allowed, since this integration will reduce the need of additional material e.g. finishing layer and if required a finishing layer can still be added.

To perform the analysis, each part that is specified in the DSM is determined as one main basic element function and if the element also functions as a second function, the second function should be specified in the model, which should also be done for the sub-functions, and the generic product functionality. In Figure 5.46 an example input table from the reuse potential evaluation method is shown. The final assessment is performed according to the assessment values specified in Table 5.22.

\begin{tabular}{|c|c|c|c|c|c|c|c|c|}
\hline \multicolumn{9}{|c|}{$\begin{array}{l}\text { Input - Building level / System level - Generic functionality of sub-systems and components } \\
\text { Is the component or sub-system designed in such a way that it can be directly reused as another sub-function? }\end{array}$} \\
\hline \multicolumn{4}{|c|}{ Building system and floor indication } & \multicolumn{5}{|c|}{ Building system and floor indication } \\
\hline Sub-system & Generic product & Component & Generic product & Sub-system & Generic product & Component & Generic product & \\
\hline \multicolumn{4}{|c|}{ Bottom floor } & \multicolumn{5}{|l|}{ Top floor } \\
\hline \multicolumn{4}{|c|}{ 1. Loadbearing } & \multicolumn{5}{|c|}{ 1. Loadbearing } \\
\hline Assembly1 & yes & & & Assembly2 & yes & & & \\
\hline & & Component2 & yes & & & Component4 & yes & a \\
\hline
\end{tabular}

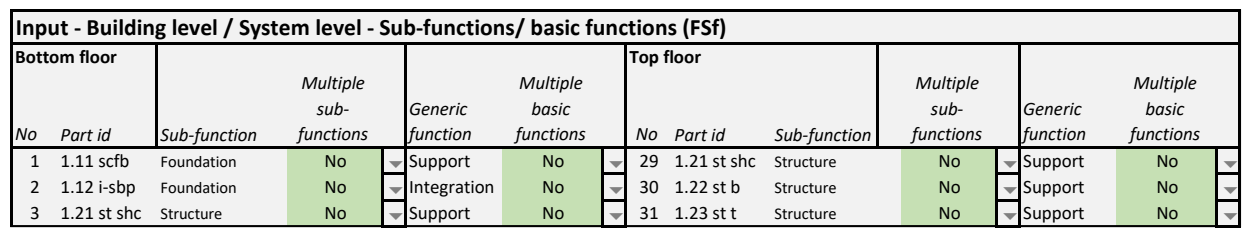

Figure 5.46: Functional separation input table example from the Reuse Potential evaluation method. 


\section{F1 Functional separation}

\section{Functional separation - generic functionality}

- Rating is based on the percentage of sub-systems or components that are designed in such a way that they can be directly reused as another sub-function, according to formula 1 and 2 , which allows the assessment value to be increased with 0,2 if $30 \%$ or more is identified as a generic function.

Functional separation - sub/basic functions

- Rating is based on the percentage of parts that represent multiple sub-functions or multiple basic element functions (except for parts with another basic element function being finishing), according to formula 3 and 4.

Functional separation assessment

- Rating according to formula 5.

\begin{tabular}{|c|c|c|}
\hline Formulas & Abbreviation & \\
\hline 1. $F S g f(x)=F S g f(x) / \Sigma P(x)$ & $P(x)$ & Number of parts \\
\hline 2. $F S g f A(x)=(F S g f(x) / \operatorname{Max} F S r) * D v(1)$ & $\operatorname{Max} F S r(x)$ & Maximum functional separation rating \\
\hline 3. $F S f(x)=F S f(x) / \Sigma P(x)$ & $\operatorname{Dv}(x)$ & Discount value \\
\hline 4. $F S f A(x)=0,7-(F S f(x) / \operatorname{Max} F S r) * D v(3)$ & $F S g f(x)$ & Products with generic functionality ratio \\
\hline $\begin{array}{l}\text { 5. FSA }(x)=(\text { FSfA (sub-functions) }(x)+F S f A \text { (basic functions) } \\
(x)) / 2+F S g f A(x)\end{array}$ & FSgfA & $\begin{array}{l}\text { Functional separation - generic } \\
\text { functionality assessment }\end{array}$ \\
\hline & $F S f(x)$ & $\begin{array}{l}\text { Parts with more than one sub-/ } \\
\text { basic-function ratio }\end{array}$ \\
\hline & FSfA $(x)$ & $\begin{array}{l}\text { Functional separation - sub-/basic functions } \\
\text { assessment }\end{array}$ \\
\hline & $F S A(x)$ & Functional separation assessment \\
\hline Types of functional separation & Max FSr & Rating (at $100 \%$ ) \\
\hline 1. Component with generic functions & & \\
\hline 2. Elements with one function & & \\
\hline 3. Element with more than one sub/basic function & & \\
\hline
\end{tabular}

Table 5.22: Assessment values of the functional separation.

\section{T1 Type of installation system integration}

The type of installation system integration is defined to determine how the different types of installations systems are integrated in the building. Depending on the type of incorporation the building installation system can be modified in a non-destructive or destructive manner with a low or high effort, which in turn would allow the subtracted building products to be reused. To assess the incorporation of installation systems in a building, based on Durmisevic (2006) five types of integration have been defined, which are used to evaluate the integration of both, the main distribution and sub-distribution of all four types of installations (water, electrical, heating and ventilation system), as shown in Table 5.23 (based on Durmisevic, 2006, p.166), namely: 1) No dependency, is used when there is no dependency between the installation and the sub-function, 2) Modular zoning, a dedicated area is used to cluster different types of installations, which allows for easy access or modification, 3) Planned integration, a specific area is dedicated to the installations and allows for small modifications or additions, 4) installations are integrated with other building functions with no excess space for future modifications or additions, and 5) the installation is entirely integrated in other building functions and does not enable access without destructive operations.

In Figure 5.47 an example input table from the reuse potential evaluation method is shown. The final assessment is performed according to the assessment values specified in Table 5.23. 


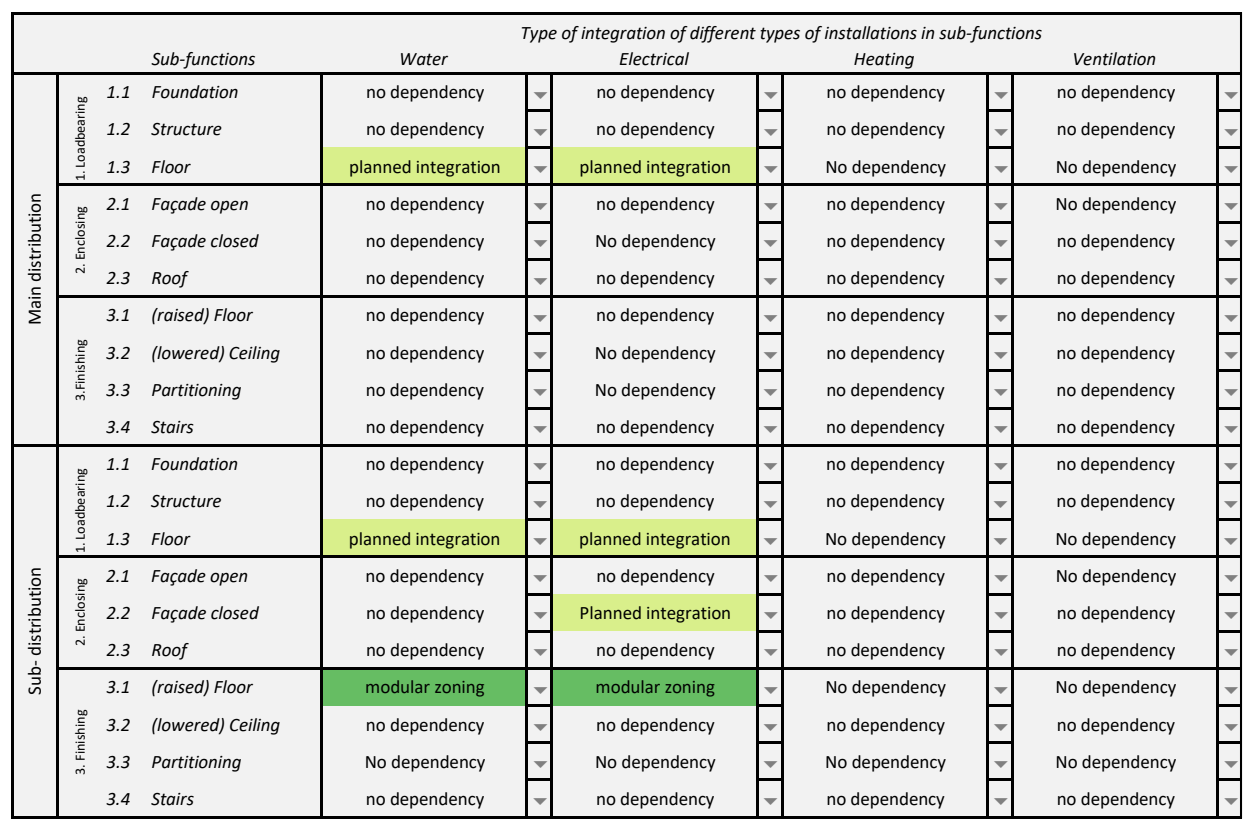

Figure 5.47: Type of installation integration input table example from the reuse potential evaluation method.

Table 5.23: Assessment values of the type of installation system integration (based on Durmisevic, 2006, p.166)

\section{T1 Type of installation system integration}

1. No dependency Installation system has no dependency or relation with the determined building

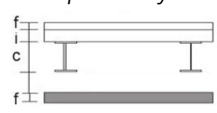

2. Modular zoning

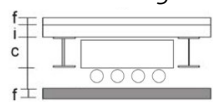
function

3. Planned integration

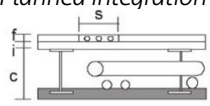

Dedicated area is used where installations are clustered and easily accessible for modifications

4. Unplanned integration Installation is accessible, but integrated with no excess space for future

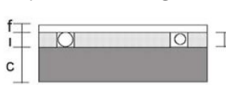
modifications or additions

Specified area is dedicated for the installations, which allows for minor modifications or additions

5. Total dependence

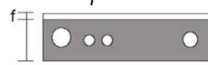

Installation is entirely integrated in the buildings, only accessible in a destructive manner

Legend of graphs - Functions within a floor system: c - structure; $f$ - finishing; $s$ - servicing; i - control 


\section{Systematisation of product levels}

The systematisation of product levels is a combination of the number of product levels and the type of clustering, to determine the number of product levels that are present in the representative section of the building and the consistency in which the product clusters are used in the representative section. Product clusters refers to the parts that can be identified as a component product entity or higher.

\section{S1 Number of product levels}

The number of material levels criteria assesses the type of building products the building is composed and provides an indication of the largest demountable entities that are used in the building, which will ease the disassembly of the building. If a building is composed of elements and components the number of disassembly step that are required to demount the building will be much greater than a building composed of elements, components, assemblies $\&$ chunks, as shown in Figure 5.48. According to the different building levels the number of product levels will be assessed based on the identified product levels, which are identified in the DSM of the reuse potential evaluation method at level of prefabrication and will be assessed according to the assessment criteria shown in Table 5.24.

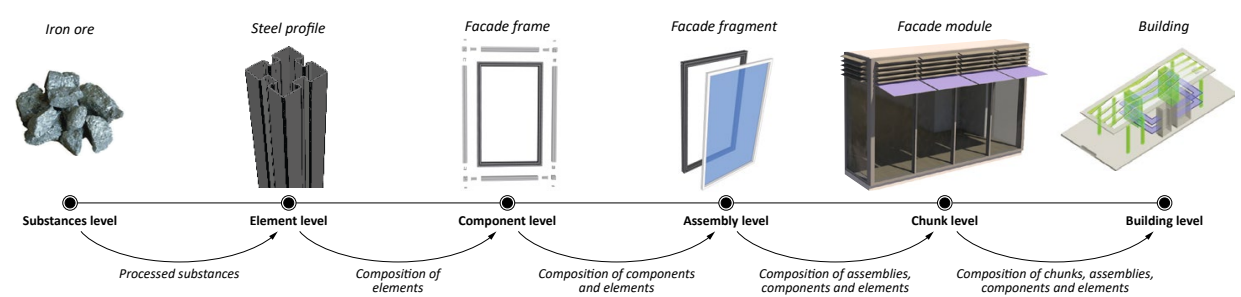

Figure 5.48: Building product levels

Table 5.24: Assessment values of the number of product levels

S1 Number of product levels

Building level and system level assessment

Rating

1. Elements, components, assemblies \& chunks

2. Elements, components, assemblies

3. Elements, components

4. Elements

5. Materials

Product level assessment

Rating

1. Components

2. Elements \& components

3. Elements

4. Materials

\section{S2 Type of clustering}

In addition to the number of product levels to assess the extent to which building parts are part of components, assemblies and chunks, the ratio clustered parts (chunks, assemblies and components) versus non-clustered parts (elements) is calculated, to determine the significance in which clustered parts are being used in the building. The ratio of clustered 
Table 5.25: Assessment values of the type of clustering

\begin{tabular}{ll}
\hline S2 Type of clustering & Rating \\
percentage of clustered parts & \\
\hline 1. $70 \leq x$ & \\
2. $40 \leq x<70$ \\
3. $20 \leq x<40$ \\
4. $20>x$
\end{tabular}

parts will be assessed according to the assessment criteria shown in Table 5.25.

\subsubsection{Technical domain}

Technical domain deals with hierarchical arrangement of building materials and products, and relations as well as with hierarchical dependences between product levels. This includes the relational pattern, assembly, base element and life cycle coordination.

\section{Relational pattern}

In the relational pattern criteria the dependencies between the building products the building is composed of are determined. This criteria is sub-divided into three sub-criteria, namely: 1. number of relations, 2. hierarchical position of relations and 3. type of relational pattern. Based on these three sub-criteria the extent to which the relational pattern is structured to enable easy modification to adapt and reuse building products, systems or the entire building is determined.

\section{R1 Number of relations}

The number of relations defines the interrelatedness of each part. Depending on the disassembly level, the number of relations that are required to be disassembled can vary. Therefore, the number of relations are calculated at building level, system level and product level. In Figure 5.40 the relational pattern of a conceptual building is shown to depict the relations that are accounted for at each disassembly level. The higher the number of relations, the more difficult its disassembly will be. Based on the number of relations, the DSM is used to identify the number of relations for each disassembly level, which are assessed according to the assessment values shown in Table 5.26. To enable a fair assessment, different assessment values are defined for building level assessment and system- and product level assessment.

Table 5.26: Assessment values of the number of relations

\begin{tabular}{|c|c|}
\hline \multicolumn{2}{|l|}{ R1 Number of relations } \\
\hline Building level assessment-average number of relations per part & Rating \\
\hline \multicolumn{2}{|l|}{ 1. $x \leq 3$} \\
\hline \multicolumn{2}{|l|}{ 2. $3<x \leq 5$} \\
\hline \multicolumn{2}{|l|}{ 3. $5<x \leq 7$} \\
\hline \multicolumn{2}{|l|}{ 4. $7<x$} \\
\hline System level and product level assessment - average number of relations per part & Rating \\
\hline \multicolumn{2}{|l|}{ 1. $x \leq 2$} \\
\hline \multicolumn{2}{|l|}{ 2. $2<x \leq 4$} \\
\hline \multicolumn{2}{|l|}{ 3. $4<x \leq 6$} \\
\hline 4. $6<x$ & \\
\hline
\end{tabular}




\section{R2 Hierarchical position of relations}

In order to evaluate the interrelatedness between the different main building systems and building sub-systems, the hierarchical position of relations is defined. Hierarchical relations are relations between the main building structure system and enclosing, servicing and finishing building systems and non-hierarchical relations are relations between the enclosing, servicing and finishing building systems, which increase the interrelatedness between the main building systems. The higher the non-hierarchical relations, relations between parts with a control, finishing function instead of via supporting or integrating functions, the higher the complexity will be to separate the main building systems and allow them to change according to their own rates of change without damaging its parts and its connected parts. Therefore the interrelatedness between the main building functions and sub-building functions should be kept as low as possible. For example, an enclosing part that is connected to a finishing or servicing part will be taken into account and calculated to assess its impact, as shown in Figure 5.49. The DSM is used to identify the non-hierarchical relations number of relations for each disassembly level, which are assessed according to the assessment values shown in Table 5.27.

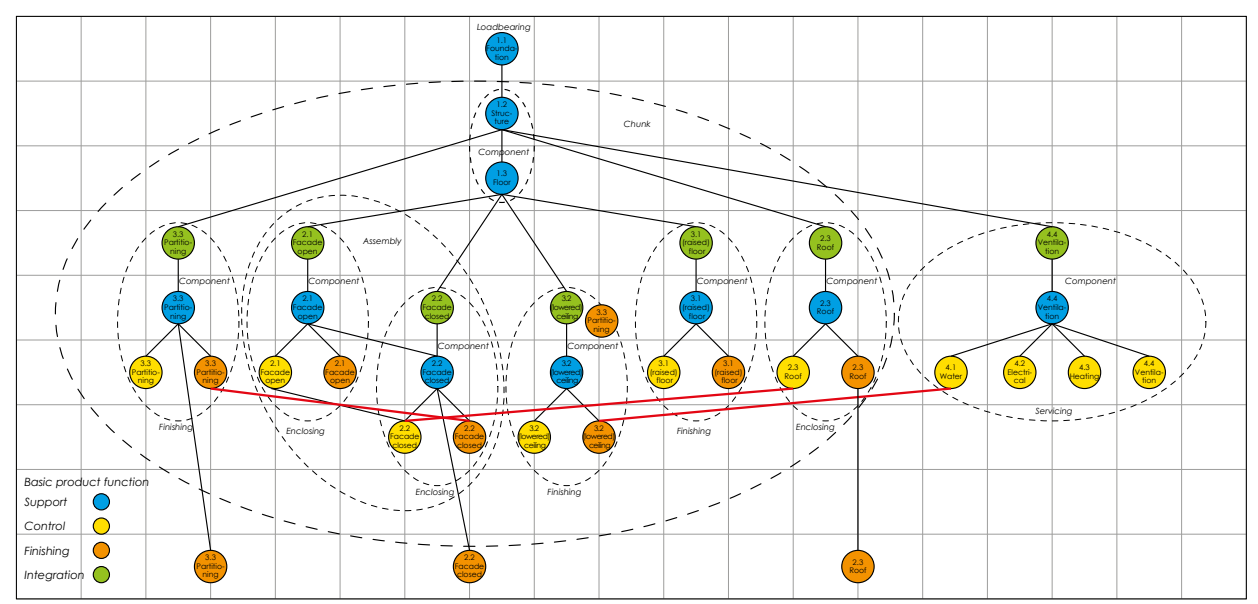

Figure 5.49: Relational pattern of a conceptual building whereby the red lines indicate the connections that are taken into account for the criteria hierarchical position of relations

Table 5.27: Assessment values of the hierarchical position of relations

\section{R2 Hierarchical position of relations}

Percentage of parts connected to another main function (excluding support function)

Rating

1. $x \leq 10$

2. $10<x \leq 20$

3. $20<x \leq 30$

4. $30<x$ 


\section{R3 Type of relational pattern}

In addition to the number of relations and the hierarchical position of relations, the type of relational pattern can be identified as an open or closed relational pattern. A closed relational pattern is identified based on a high number of relations that are relations between non-base elements or non-intermediary parts and increases the number of sequences to access parts. While in an open relational pattern the number of relations that are relations between non-base elements or non-intermediary parts is low, which decreases the dependencies and increases the accessibility of its parts, making it easier to disassemble and reuse parts. In Figure 5.50 the relational pattern of a conceptual building is shown to depict the relations that result in a closed relational pattern with red lines. The percentage of total relations is being calculated to assess ratio closed versus openness of the relational pattern. The DSM is used to identify the relations that form a closed relational pattern, which are assessed according to the assessment values shown in Table 5.28.

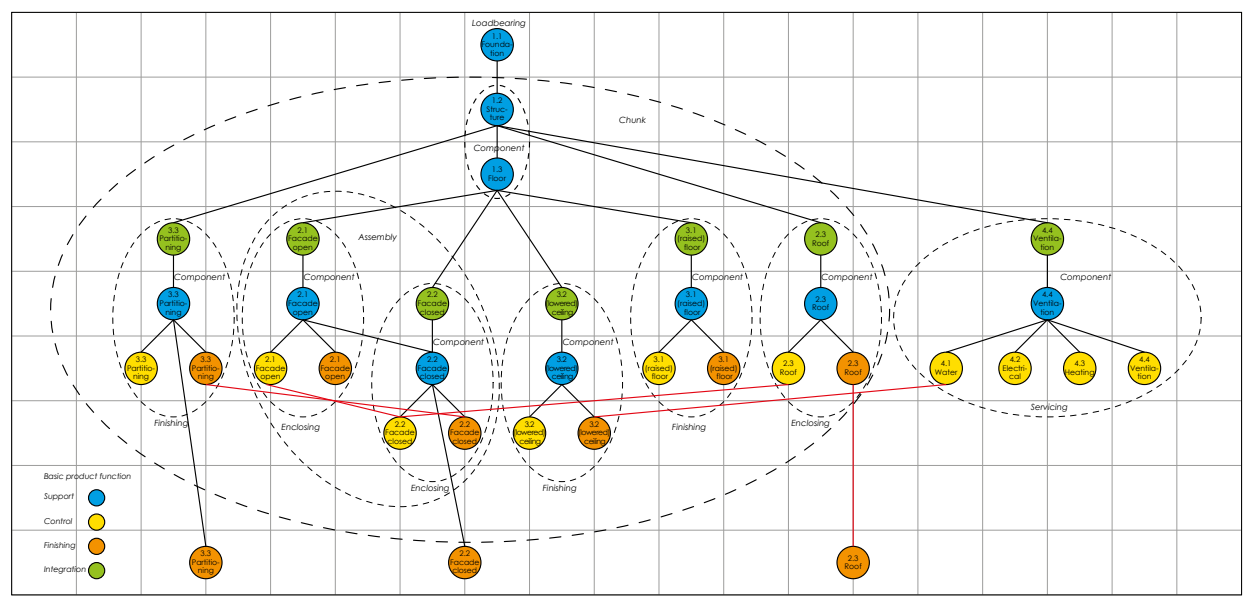

Figure 5.50: Relational pattern of a conceptual building whereby the red lines indicate the connections that are taken into account for the criteria type of relational pattern

Table 5.28: Assessment values of the type of relational pattern

\section{R3 Type of relational pattern}

Percentage of parts being relations between non-base elements or non-intermediary parts

Rating

1. $x \leq 10$

2. $10<x \leq 30$

3. $30<x \leq 50$

4. $50<x$ 


\section{A1 Assembly \& disassembly sequences}

The number of sequential steps that are required to assemble and disassemble a part and the number of parallel steps determines the the amount of effort to re-claim and assemble the part. Both parameters are essential in assessing the difficulty to disassemble or assemble the product, since a building can have few sequential steps, but many parallel assemblies that should be disassembled to e.g. replace a part. On one hand a low number of sequential steps is good, since it allows fast access to most parts, while the many parallel assemblies might still make it a very labour-intensive process to disassemble the entire building for e.g. relocation and reuse. To enable a fair assessment, different assessment values are defined depending on the disassembly level and the building system, as shown in Table 5.29 .

Table 5.29: Assessment values of the assembly and disassembly sequences - building-, system-and product level

\section{A1 Assembly \& Disassembly sequences}

\section{Building level}

Number of sequential steps to (dis)assemble the building

Rating

1. $x \leq 5$ sequences

2. $5<x \leq 8$ sequences

3. $8<x \leq 12$ sequences

4. $12<x$ sequences

Average number of parallel assemblies per (dis)assembly sequence

1. $x \leq 3$ parallel assemblies

2. $3<x \leq 5$ parallel assemblies

3. $5<x \leq 7$ parallel assemblies

4. $7<x$ parallel assemblies

\section{System and product level}

Number of disassembly sequences to (dis)assemble the load-bearing system

Rating

1. $x \leq 5$ sequences

2. $5<x \leq 8$ sequences

3. $8<x \leq 12$ sequences

4. $12<x$ sequences

Number of disassembly sequences to (dis)assemble the enclosing, finishing and servicing systems_Rating

1. $x \leq 2$ sequences

2. $2<x \leq 4$ sequences

3. $4<x \leq 6$ sequences

4. $6<x$ sequences

Average number of parallel assemblies per (dis)assembly sequence for the load-bearing system

Rating

1. $x \leq 3$ parallel assemblies

2. $3<x \leq 5$ parallel assemblies

3. $5<x \leq 7$ parallel assemblies

4. $7<x$ parallel assemblies

Average number of parallel assemblies per (dis)assembly sequence for the enclosing, finishing and

1. $x \leq 2$ parallel assemblies

2. $2<x \leq 4$ parallel assemblies

3. $4<x \leq 6$ parallel assemblies

4. $6<x$ parallel assemblies 


\section{B1 Base element specification}

A base element is a part that can be identified as the carrier of specific building's functions, which can be identified on different levels. In the reuse potential evaluation method four principles of base elements are defined, based on Durmisevic (2006), namely (Figure 5.51):

1. Base element/ intermediary between systems and/ or components, e.g. the load-bearing system which should function as a base element and intermediary between the other systems;

2. Base element on one level, which should ideally be identifiable in each main building system and possibly each sub-function, whereby the base element should form a cluster with other functions basic part functions to create independent clusters;

3. Base element on two levels, which is a base element of one building function, to which e.g. finishing parts of another system are also connected, resulting in a more complex configuration and should be avoided, and;

4. No base element, which is the lack of a base element in a sub-function or building system, which is often found in combination with another base element being a base element on two levels.

In Figure 5.50, the blue elements can be identified as base elements, in which the load-bearing parts are base elements/ intermediary between systems (1) and the other elements are base elements on one level. The type of base elements are evaluated at building level, system level and product level according to the assessment criteria as shown in Table 5.30.

principle 1
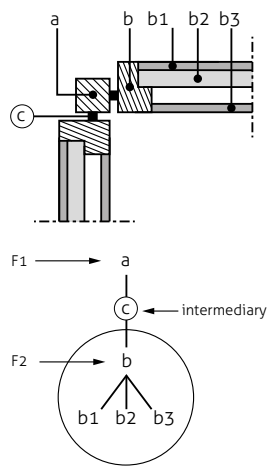

principle 2
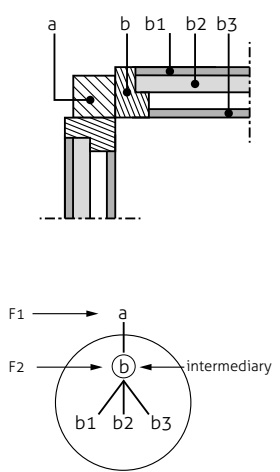

principle 3
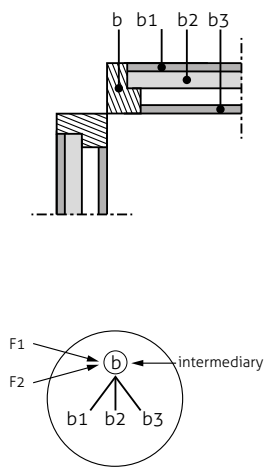

principle 4
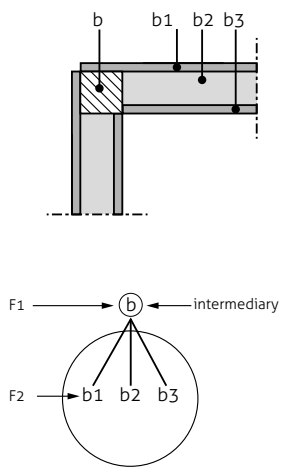

Figure 5.51: Four principles of base element specification (Durmisevic, 2006, p. 176)

Table 5.30: Assessment values of the base element specification

1. Base element / intermediary between systems and/or components

2. Base element on one level

3. Base element on two levels

4. No base element 


\section{L1 Technical life cycle coordination}

The technical life cycle coordination is a criteria that addresses the relation between the sequence in which products are accessible and the technical life span. To avoid unnecessary disassembly and potentially damaging of products due to replacement and product upgrades. The products with a shorter technical life cycle should be assembled last and thus allow disassembly first. If a part with a shorter technical life cycle is located behind a part with a longer life cycle, this means that the part with longer life cycle needs to be disassembled to replace the part with a shorter life cycle, which can potentially lead to premature replacement or damage to the part located before the part with shorter life cycle. Therefore, the life cycle coordination is essential to fulfil the entire technical life cycle of parts. To enable this assessment, the technical lifespan of all products in the DSM should be determined to allow the model to assess the technical life cycle coordination of parts. The assessment is based on the percentage of parts that have a shorter technical lifespan than the later assembled parts is calculated and assessed according to the assessment values as shown in Table 5.31 .

Table 5.31: Assessment values of the technical life cycle coordination

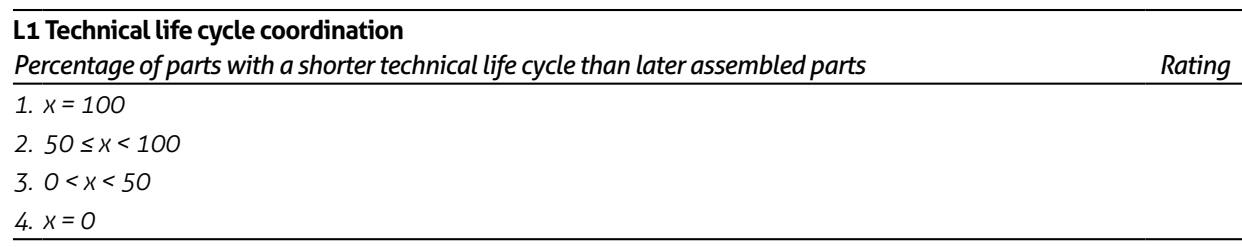

\subsubsection{Physical domain}

Physical domain deals with interfaces that define physical integrity and dependencies in the structure. This includes the following design aspects: type of connections, accessibility to fixing and geometry of the product, which is subdivided in standardisation of product edge and geometry of product edge.

\section{C1 Type of connections}

The effort it takes to re-claim the dedicated part can be determined by: 1) the connections the dedicated part is fixed with to keep it in place, 2) the connections of parts that are connected to the dedicated part and need to be disassembled to enable disassembly, and 3) the parts that need to disassembled before the dedicated part can be accessed. Since the effort it takes to remove the parts that need to be removed before the dedicated part can be re-claimed can be performed in multiple ways, this effort is not taken incorporated in the assessment method. The main reason for this is that the parts that need to be removed to access the dedicated part, may also be disassembled for reuse, thus not increasing the effort for the dedicated part. It could be removed in a destructive manner, to enable fast access to the dedicated part, or it could be removed according to the disassembly steps identified in the DSM model. The uncertainty about the fate of the parts that need to be disassembled before the dedicated part can be accessed are therefore limited by not taking this into account the associated connections to disassemble those parts. 
Table 5.32: Assessment values of the type of connections

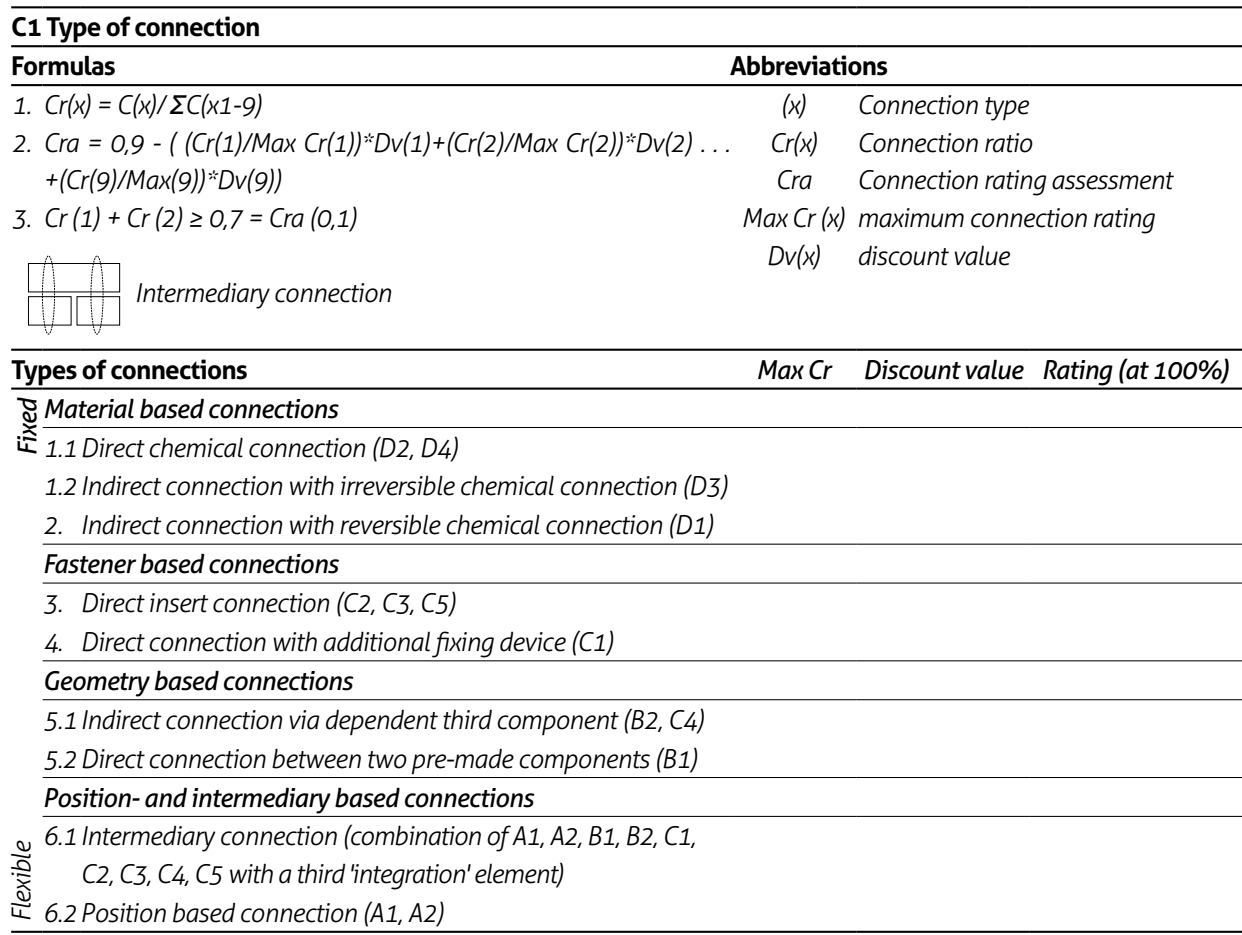

In section 5.5 four main connection categories have been defined to classify all types of connections in the DSM. While in order to identify the effort and impact the connection has on the parts, it is important to incorporate the parts that are connected via an integration element, so-called intermediaries, that allow elements to be disassembled without affecting the indirectly connected parts. According to Durmisevic (2006) these type of connections are the most flexible. In order to incorporate the intermediary connections in the assessment method, in Table 5.32 the assessment values and formulas used to define the type of connection effort are defined, whereby an intermediary connection can be a combination of two of the following connection types $A 1, A 2, B 1, B 2, C 1, C 2, C 3, C 4, C 5$, and cannot be created with material based connections. For each disassembly level, the assessment is based on the formulas shown in Table 5.32 .

\section{AC1 accessibility to fixing}

The accessibility to fixing is determined to indicate the ability to replace or repair parts to prolong the longevity of the building products. This criteria requires additional input data, since it is sometimes possible to access the dedicated element without following all disassembly steps as identified by the DSM model. Therefore, an additional parameter is defined to identify the accessibility from either outside the building or inside the building, as shown in Figure 5.52. If no is selected, the number of disassembly steps generated by the DSM model are used to identify the number of disassembly steps and its difficulty, which is rated according to the assessment values as determined in Table 5.33. 


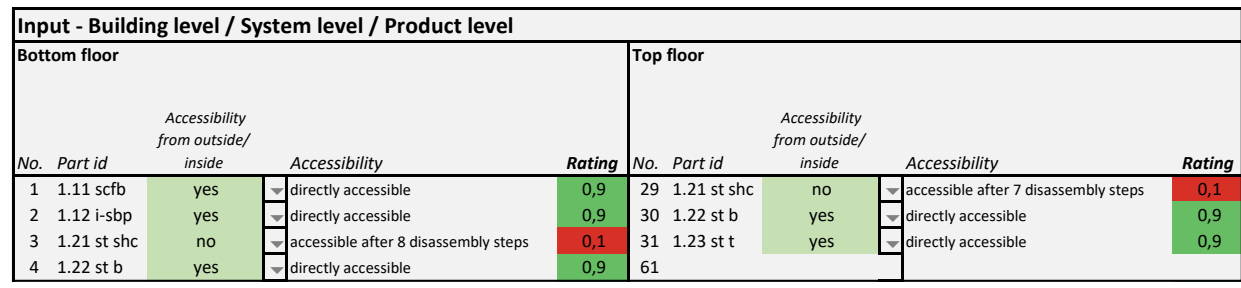

Figure 5.52: Accessibility to fixing input table example from the Reuse Potential evaluation method.

Table 5.33: Assessment values of the accessibility to fixing

\begin{tabular}{l}
\hline AC1 Accessibility to fixing \\
Types of accessibility to parts
\end{tabular}

\section{Geometry}

The geometry criteria is determined to identify the standardisation of product edge and the geometry of the product edge, which determine the dependencies between the products and the commonality of the product, which supports its reuse potential.

\section{G1 Standardisation of product edge}

The standardisation of products can be defined by the types of building products that are applied in a building. A distinction can be made between pre-made products, half standardised products and products made on-site. A pre-made geometry can be described as a building product that is manufactured off-site that can be assembled directly in the building without any modifications to the product. Pre-made products are the most desirable, because pre-made products are considered as building products that are designed in such a way that it can be easily assembled and has a high change it can also be disassembled more easily than half-standardised products or even raw materials processed on the construction site. A half-standardised product could for example be a material of commerce that requires modifications in order to adapt it to the specific building configuration and dimensions. An example of material of commerce could be the wooden planks used for external cladding of a facade, which has to be cut in the specific dimensions for its application. This method is often more labour intensive in assembly operations and presumably also in the disassembly operations, than pre-made building products. Furthermore, the on-site processes can be negatively influenced by ambient factors. Finally, products that are made on-site are in general the materials that are applied in a liquid state, which have to dry to become in their final solid state, such as in-situ concrete, cement and plaster finish, which are often difficult to disassemble and reuse and thus should be avoided. In Figure 5.53 an example input table of the standardisation of product edge is shown. The standardisation of product edge is assessed according to the following values, as shown in Table 5.34 . 


\begin{tabular}{|c|c|c|c|c|c|c|c|c|}
\hline \multicolumn{9}{|c|}{ Input - Building level / System level / Product level } \\
\hline \multicolumn{5}{|c|}{ Bottom floor } & \multicolumn{4}{|l|}{ Top floor } \\
\hline No. & Part id & Type of product & & Rating & No. Part id & Type of product & & Rating \\
\hline 1 & $1.11 \mathrm{scfb}$ & pre-made & $\nabla$ & 0,9 & $291.21 \mathrm{st}$ shc & pre-made & $\nabla$ & 0,9 \\
\hline 3 & $1.21 \mathrm{st} \mathrm{shc}$ & pre-made & $\nabla$ & 0,9 & $31 \quad 1.23 \mathrm{st} \mathrm{t}$ & pre-made & $\nabla$ & 0,9 \\
\hline 4 & $1.22 \mathrm{st} \mathrm{b}$ & pre-made & $\nabla$ & 0,9 & 61 & & . & \\
\hline 5 & $1.23 \mathrm{st} \mathrm{t}$ & pre-made & $\nabla$ & 0,9 & $32 \quad 1.31 \mathrm{co} \mathrm{fl}$ & pre-made & $\nabla$ & 0,9 \\
\hline
\end{tabular}

Figure 5.53: Standardisation of product edge input table example from the Reuse Potential evaluation method.

Table 5.34: Assessment values of the standardisation of product edge

\section{G1 Standardisation of product edge}

Types of standardisation

Rating

1. Pre-made

2. Half-standardised

3. On-site

\section{G2 Geometry of product edge}

The ease of disassembly and number of disassembly sequences can be affected by the geometry of product edge. Therefore, the assessment criteria geometry of product edge is defined to identify the geometry of product edge according to the six defined product edges by Durmisevic (2006, p.178). This criteria requires additional user input, which has to be done for all elements, components, assemblies and chunks identified in the building, as shown in Figure 5.54, which are assessed based on the assessment values defined in Table 5.35.

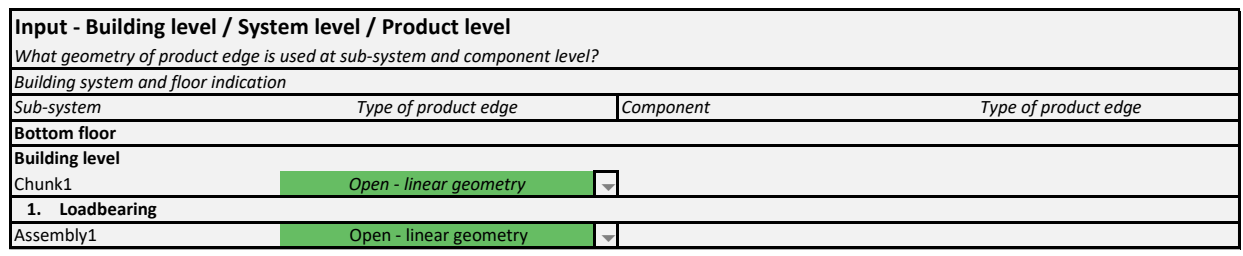

\begin{tabular}{|c|c|c|c|c|}
\hline \multicolumn{5}{|c|}{ Input - Building level / System level / Product level } \\
\hline \multirow{2}{*}{\multicolumn{5}{|c|}{$\begin{array}{l}\text { Bottom floor } \\
\text { No } \quad \text { Part id }\end{array}$}} \\
\hline & & & & \\
\hline 1 & $1.11 \mathrm{scfb}$ & Foundation & Open - linear geometry & \\
\hline 2 & $1.12 \mathrm{i}-\mathrm{sbp}$ & Foundation & Closed - integral on one side & $\theta$ \\
\hline 3 & $1.21 \mathrm{st}$ shc & Structure & Open - linear geometry & \\
\hline 4 & 1.22 st b & Structure & Open - linear geometry & $\nabla$ \\
\hline & $1.23 \mathrm{st} \mathrm{t}$ & Structure & Open - linear geometry & \\
\hline
\end{tabular}

Figure 5.54: Geometry of product edge input table example from the Reuse Potential evaluation method.

Table 5.35: Assessment values of geometry of product edge (based on Durmisevic, 2006, p.178)

\section{G2 Geometry of product edge}

Types of geometry of product edge

1. Open-linear geometry

2. Symmetric overlapping

3. Overlapping on one side

4. Unsymmetric overlapping

5. Closed-integral on one side

6. Closed-integral on two sides
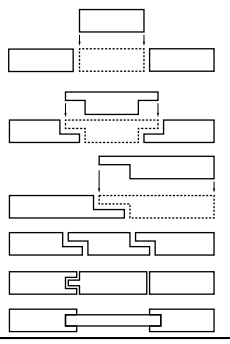


\subsubsection{Re-condition effort}

The re-conditioning effort is the effort that is required to bring the re-claimed product into the demanded state to allow it to be reused in a deliberate manner. The re-conditioning effort is on one hand determined by the impact the design has on the product and on the other hand determined by its use history, the state of the product. The re-claim damage can be determined by: 1) disassembly damages based on the used connections, and; 2) the robustness of the product, which determines the how fragile the product is and how susceptible it is to damages during disassembly, transportation and re-assembly. Furthermore, the maturity of the product is also determined by its design and function, which is in the reuse potential evaluation method mainly focused on the technological obsolescence, which refers to the advances that technology makes, which renders the existing building product obsolete, because it is no longer technologically superior to its alternatives (e.g. window frames or solar panels are replaced with an improved model because of its expected lower operating costs or greater efficiency). Finally, the state of the product is determined by the use history, which can be based on the remaining technical lifespan.

\section{Re-claim damage}

To determine the re-claim damage, for each part, the used connection types and connection direction are important, but also the robustness of the element since the connection damage might be low, but due to the nature of the product it might still be highly susceptible to damage and prevent the element from being reused.

\section{D1 Disassembly damage}

The disassembly damage is based on two types of connections, namely: 1) the connections that are connected to the part to fixate other parts, 'connection to part', and; 2) the connections through which the part itself is fixed in place, 'connections from the part'. Depending on the direction of the connection, the damage to the dedicated part can vary. In Table 5.36, both types of connection damages are defined. The DSM model can be used to identify the types of connections that are connected to the part and connected from the part. Finally, based on the types of connections the damage to each part can be classified in one of the five damage categories, as defined in Table 5.36 and rated accordingly.

\section{Ro1 Robustness}

The reuse of products is only feasible if the products allow repetitive reuse. To allow repeated reuse the product should be robust enough to withstand the disassembly, transportation and re-assembly processes. Therefore, the robustness of the product can have a large impact on the reuse potential of the product. To assess the robustness of products, three categories have been defined, namely: 1) robust; 2) semi robust, and; 3) weak and fragile. The robustness should be identified for all elements in the DSM. It should be noted that the assessment of the robustness of elements is subjective and based on experiences. To give an example, metal stud parts are difficult to reuse due to 
Table 5.36: Assessment values of the connection damage

\begin{tabular}{|c|c|c|c|}
\hline \multicolumn{4}{|c|}{ D1 Connection damage } \\
\hline \multicolumn{2}{|l|}{ Types of connections } & Connection to part & Connection from the part \\
\hline \multicolumn{4}{|c|}{ ¿্ঠ Material based connections } \\
\hline \multicolumn{2}{|c|}{1.1 Direct chemical connection (D2, D4) } & Large damage & Total destruction \\
\hline \multicolumn{2}{|c|}{1.2 Indirect connection with irreversible chemical connection (D3) } & Large damage & Total destruction \\
\hline \multicolumn{2}{|c|}{ 2. Indirect connection with reversible chemical connection (D1) } & Large damage & Large damage \\
\hline \multicolumn{4}{|c|}{ Fastener based connections } \\
\hline \multicolumn{2}{|c|}{ 3. Direct insert connection $(C 2, C 3, C 5)$} & Medium damage & Medium damage \\
\hline \multicolumn{2}{|c|}{ 4. Direct connection with additional fixing device (C1) } & Little damage & Little damage \\
\hline \multicolumn{4}{|c|}{ Geometry based connections } \\
\hline \multicolumn{2}{|c|}{5.1 Indirect connection via dependent third component $(B 2, C 4)$} & No damage & No damage \\
\hline \multicolumn{2}{|c|}{ 5.2 Direct connection between two pre-made components (B1) } & No damage & No damage \\
\hline \multicolumn{2}{|c|}{ Position- and intermediary based connections } & No damage & No damage \\
\hline \multirow{2}{*}{\multicolumn{2}{|c|}{$\begin{array}{l}6.1 \text { Intermediary connection (combination of } A 1, A 2, B 1, B 2, C 1, C 2 \text {, } \\
C 3, C 4, C 5 \text { with a third 'integration' element) } \\
6.2 \text { Position based connection }(A 1, A 2)\end{array}$}} & No damage & No damage \\
\hline & & No damage & No damage \\
\hline \multicolumn{3}{|c|}{$\begin{array}{ll}\text { Damage categories } & \text { Reconditioning effort } \\
\end{array}$} & Rating \\
\hline 1. No damage & \multicolumn{3}{|c|}{ Direct product reuse without additional reconditioning } \\
\hline 2. Little damage & \multicolumn{3}{|l|}{ Product reuse after light reconditioning } \\
\hline 3. Medium damage & \multicolumn{3}{|l|}{ Product reuse after moderate reconditioning } \\
\hline 4. Large damage & \multicolumn{3}{|l|}{ Product reuse after intensive reconditioning } \\
\hline \multirow[t]{2}{*}{ 5. Total destruction } & \multicolumn{3}{|c|}{ Product is destroyed, its particles can be reused as raw } \\
\hline & \multicolumn{3}{|l|}{ resources, when separated carefully } \\
\hline
\end{tabular}

their lack of robustness and should be rated as weak and fragile, similar as roof sealing layer and vapour barriers, whereby the combination of the connection and its fragility limits its reuse potential. While, timber finishing elements, insulation and glass panes can often be considered semi robust and steel beams, concrete floors and beams and timber frames can often be considered robust elements. Depending on the disassembly level, the robustness of the product can vary, e.g. if a fragile element is incorporated in a timber frame, the robustness depends on the robustness on the timber frame. This allows products to be valued low at product disassembly level, but high at system- or building disassembly level. The robustness is assessed according to the values as shown in Table 5.37 .

Table 5.37: Assessment values of the robustness

\section{Ro1 Robustness}

Types of robustness

1. Robust element

2. Semi robust element

3. Weak and fragile

\section{Product state - Re2 Remaining technical lifespan}

The product state determines the amount of re-conditioning effort that is required to reuse the product. This state could be identified by reviewing each part of the building. Although, this would be a very labour intensive way to assess the state of each product. 
Therefore, a method was identified that allows a fast indication of the product state. For each product a technical life span can be identified based on the SBR (2011), which allows the calculation of the remaining lifespan of the product, namely the technical life span minus the used life span. Based on the assessment values specified in Table 5.38, the remaining technical lifespan of the product is rated. The rating is based on the type of function that could be fulfilled by the remaining technical lifespan of the product. It should be noted that the product with a low remaining technical lifespan can be re-conditioned to increase this value. Thereby, the assessment values provide an indication of the effort that is required to enable the product to be reused.

Table 5.38: Assessment values of the remaining technical lifespan

\begin{tabular}{ll}
\hline Re2 Remaining technical lifespan & Rating \\
Remaining technical lifespan in years & Long remaining technical lifespan (permanent function) \\
\hline $\begin{array}{ll}\text { 1. } 20<x & \text { Medium remaining technical lifespan (semi-permanent function) } \\
\text { 2. } 10<x \leq 20 & \text { Short remaining technical lifespan (medium temporary function) } \\
\text { 3. } 5<x \leq 10 & \text { Nort remaining technical lifespan (temporary function) } \\
\text { 4. } 0<x \leq 5 & \text { Nomaining technical lifespan } \\
\text { 5. } x=0 & \end{array}$
\end{tabular}

\section{Product maturity - M1 Impact on operational energy}

The product maturity refers to the expectancy of the product to become obsolete or require upgrades to support reuse. Since, new product technologies can render older products technologies obsolete, the potential to reuse these products reduces. Furthermore, improving product standards and building codes may render the use of certain products obsolete or require them to be upgraded to allow its reuse. For example, steel beams have reached a mature level and do not change much anymore and are expected to also not change in the near future, while the energy performance of buildings is continuously improving, which means that the products that determine the energy performance of the building are immature and require them to be easily upgradable to the improving standards. To identify the potential of a product to be reused, it is important to incorporate technical lifespan, functional lifespan and used lifespan.

The product maturity indicator is mainly focussed at the impact of products on the operational energy of the building, since these products are considered to have a lower functional and technical life and are highly susceptible to technological obsolescence. In construction, three types of products can be identified: 1) products that do not impact the operational energy of the building, which are referred to as 'no impact' products, e.g. steel beams, intermediate floors and finishing; 2 ) products that passively impact the operational energy of the building, which are referred to as 'passive impact' products, e.g. insulating properties of windows, walls, bottom floors and roofs, and; 3) products that actively impact the operational impact of the building and require an energy input, which is referred to as 'active impact' products, e.g. lighting, heating and cooling installations. The 'no impact' products are identified as mature products that can often be deliberately reused without the need of upgrades or modifications, while 'passive impact' products 
are likely to require performance upgrades to bring the product back to contemporary performance standards, whereby the amount of re-conditioning and upgrading can increase depending on the used lifespan, and 'active impact' products should be reused cautiously, since these might not be able to be upgraded to contemporary performance standards and become obsolete the fastest. In Table 5.39 assessment values are defined, to evaluate the product maturity.

Table 5.39: Assessment values of the remaining technical lifespan

\begin{tabular}{ll}
\hline M1 Impact on operational energy & Type of impact \\
Used lifespan & No impact \\
\hline 1. $0<x \leq 5$ & \\
2. $5<x \leq 10$ & \\
3. $10<x \leq 20$ & \\
4. $20<x$ & \\
\hline
\end{tabular}

\subsubsection{Reuse potential model automation}

One of the requirements of the reuse potential assessment method is to develop a method that is automated based on the building's compositional information to allow for an objective and consistent evaluation. In addition, the input data should be communicated in an accessible and transparent manner, to be able to verify the used input data and allow the user to identify specific criteria that could be improved upon. In addition to the requirements the assessment method should allow envisioned users, building engineers and architects to be able to use the assessment method.

Therefore, the reuse potential model is embedded in Excel (Microsoft, 2016), which is an electronic spreadsheet program that is used for storing, organizing, and manipulating data. This model includes all assessment criteria introduced previously and its application will be described in the next chapter in combination with case studies (permission to the excel model can be requested by mail to the author). The reuse potential model is developed in such a manner that it can use the DSM input data as basis for an automated assessment of most criteria and reduce manual input to a minimum. In Table 5.40 an overview is shown identifying the criteria that are automated based on the input DSM and the assessment criteria that require additional input information. The criteria that are not automated will require additional information. This information can be added using pull-down menus and allows for easy manual input. Furthermore, Table 5.40 provides insight in the criteria that are subdivided in different scores based on the product levels and which are not, which is important to understand the differences in final output scores.

In section 6.6 \& 6.7 two case studies are shown and includes the required steps to perform a reuse potential assessment. To support full transparency with regards to the input data after the assessment is performed in the reuse potential assessment model it is possible to generate a reuse potential report in PDF format that incorporates all input data and reuse potential assessment scores. This report can be used to verify the correctness of the input data, but above all to identify the parts of the building design that can be improved 
upon to increase the reuse potential of the building parts, which is the main goal of the reuse potential evaluation method. To provide design knowledge, to support the design of buildings and building products with a high reuse potential.

Another reuse potential assessment requirement is to allow the user to customize the assessment method to increase the emphasis of the reuse potential assessment method on certain criteria that are most valued by the user. To accommodate this wish weighting factors are incorporated in the assessment method. Based on the author's knowledge each criteria is given an weighting factor that is based on the importance of the criteria for evaluating the reuse potential, which is defined in Figure 5.41. By changing the weighting factors the user can modify the emphasis of certain criteria in the reuse potential evaluation method.

Table 5.40: Assessment values and their level of automation and differentiation in product levels.

('adopted from Durmisevic (2006), ${ }^{2}$ adapted from Durmisevic (2006), ${ }^{3}$ defined by author)

\begin{tabular}{|c|c|c|c|c|c|}
\hline 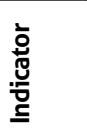 & : & Criteria & Sub-criteria & Automated & $\begin{array}{c}\text { Differentiation } \\
\text { between product } \\
\text { levels }\end{array}$ \\
\hline \multirow{4}{*}{ 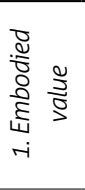 } & & \multirow[t]{4}{*}{ Highest embodied value } & E1 Embodied economic value ${ }^{3}$ & & \\
\hline & & & E1 Embodied cultural value 3 & & \\
\hline & & & E1 Embodied material value ${ }^{3}$ & & \\
\hline & & & E1 Embodied energy value 3 & & \\
\hline \multirow{14}{*}{ 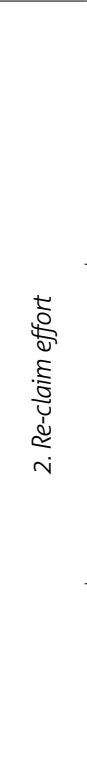 } & \multirow{4}{*}{ 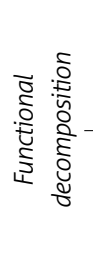 } & Functional decomposition & F1 Functional separation ${ }^{1}$ & & \\
\hline & & Servicing integration & $\begin{array}{l}\text { T1 Type of installation system } \\
\text { integration }^{1}\end{array}$ & & \\
\hline & & $\begin{array}{l}\text { Systematisation of } \\
\text { material levels }\end{array}$ & S1 Number of product levels ${ }^{1}$ & $x$ & $x$ \\
\hline & & & S2 Type of clustering ${ }^{2}$ & $x$ & $x$ \\
\hline & \multirow{6}{*}{ 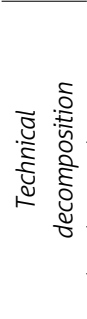 } & Relational pattern & R1 Number of relations ${ }^{3}$ & $x$ & $x$ \\
\hline & & & R2 Hierarchical position of relations ${ }^{1}$ & $x$ & $x$ \\
\hline & & & R3 Type of relational pattern ${ }^{1}$ & $x$ & $x$ \\
\hline & & Assembly & $\begin{array}{l}\text { A1 Assembly \& disassembly } \\
\text { sequences }^{2}\end{array}$ & $x$ & $x$ \\
\hline & & Base Element & B1 Base element specification ${ }^{1}$ & $x$ & \\
\hline & & Life cycle coordination & L1 Technical life cycle coordination ${ }^{1}$ & $x$ & \\
\hline & \multirow{4}{*}{ 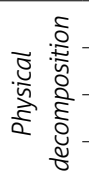 } & Connections & C1 Type of connecctions ${ }^{2}$ & $x$ & $x$ \\
\hline & & Accessibility & AC1 Accessibility of fixing ${ }^{1}$ & & \\
\hline & & Geometry & G1 Standardisation of product edge $e^{1}$ & & \\
\hline & & & G2 Geometry of product edge ${ }^{1}$ & & \\
\hline \multirow{4}{*}{ 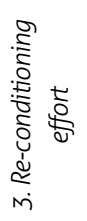 } & & Re-claim damage & D1 Disassembly damage ${ }^{3}$ & $x$ & $x$ \\
\hline & & & Ro1 Robustness 3 & $x$ & $x$ \\
\hline & & Product state & Re2 Remaining lifespan ${ }^{3}$ & $x$ & \\
\hline & & Product maturity & M1 Impact on operational energy ${ }^{3}$ & & \\
\hline
\end{tabular}




\subsection{Conclusion}

This chapter has presented the development of the reuse potential evaluation method to support circular building design, and answer RO 8: How does an evaluation method that enables the assessment of the reuse potential of buildings and building products and provides design support to designers and engineers look like?. It does so by firstly defining the aim, scope and requirements of the reuse potential evaluation method, as shown in Figure 5.26 and Table 5.16. One of the main goals of the reuse potential evaluation method is to: develop design knowledge, to support the design of buildings and building products with a high reuse potential and thereby reduce construction and demolition waste and increase resource productivity.

The conceptual reuse potential framework defines the main indicators of the reuse potential evaluation method. To identify assessment criteria that are based on technological rules and allow for an objective assessment, criteria from the knowledge model of Durmisevic (2006) have been adopted (answer to RQ 7). Furthermore, based on a review-based understanding of the reuse potential in previous chapters, the following assessment criteria have been defined:

- Highest embodied value, defined by: embodied economic-, cultural-, material- and energy value;

- Re-claim damage, defined by: D1 disassembly damage, Ro1. robustness; product state:

- Product state, defined by: Re2. Remaining technical lifespan, and;

- Product maturity, defined by: M1. Impact on operational energy.

Building upon existing theories and methods to represent structures of products and buildings, the relational pattern and Design Structure Matrix has been incorporated as essential part in the reuse potential evaluation method to incorporate the building's composition. Furthermore, the reuse potential evaluation method enables an assessment based on three reuse scenarios that are aimed at slowing resource flows, as defined in section 3.4.1, namely: building reuse, system reuse, and product reuse.

The main contribution of the reuse potential evaluation method are:

1. The identification of three essential steps to determine the reuse potential, namely: embodied value, re-claim effort and re-conditioning effort, where by re-application effort is excluded because this is dependent on the reuse application;

2. The utilisation of the building's composition to enable an automated assessment;

3. An uniform assessment method for all types of buildings, and;

4. The ability to identify the reuse potential at three product levels: building level, building system level and building product level.

In the next chapter two case studies are analysed to construct validity of the reuse potential assessment method. Furthermore, a step-by-step approach of the reuse potential evaluation method is included to describe the functioning of the reuse potential evaluation method. 


\section{Part IV - Descriptive study II}

In this section descriptive study II is presented. The aim of this section is to evaluate the design support that has been developed in the previous stage based on its usability, applicability and its usefullness. In chapter 6 , the reuse potential evaluation method will be evaluated using a case study method. Finally, the thesis ends with a general discussion and conclusion in chapter 7.

\section{Chapter 6 Testing the reuse potential evaluation method}




\section{6| Testing the reuse potential evaluation method}

\subsection{Introduction}

As explained in sections 1.3.1 and 1.3.4, the fourth stage in a design research study comprises a descriptive study II. The objective of descriptive study II is to evaluate if the proposed design support can be used for the task for which it is intended and to identify if the support has the expected impact (Blessing and Chakrabarti, 2009, p.38). In their Design Research Methodology, Blessing and Chakrabarti (2009, p.167) distinguish two types of evaluation that should be performed in descriptive study II, namely:

1. Application evaluation: the evaluation of the usability and applicability i.e. the ability of the system to address the key factors as intended, and;

2. Success evaluation: the evaluation of the usefulness of the support, i.e., its ability to realise the expected and fulfil the measurable success criteria

The goal of this chapter is to answer RO9: How usable, applicable and useful is the evaluation method that is presented in this study if applied to case studies?

In chapter 5 the reuse potential evaluation method has been developed to such an extent that its application and success can be evaluated. To achieve the goal of this chapter, a retrospective case study approach is proposed.

\subsection{Method}

To evaluate the usability, applicability and usefulness of the reuse potential evaluation method, the method should be evaluated against the aim of the evaluation method, as defined in section 5.2.1, and its requirements, as defined in section 5.2.4.

For the selection of cases it is important that the cases are expected to represent the phenomenon under study quite clearly. Therefore, two cases have been selected that are expected to have a high reuse potential, since the aim of the reuse potential evaluation method is to allow an objective assessment of the potential to reuse buildings and building products and support the designer in the design of buildings and building products with a high reuse potential.

To enable the comparison of the reuse potential evaluation method with reality, critical cases were selected using a retrospective case study approach. According to Swanborn (2010) the selection of critical cases is especially useful when testing a theory, or like in this instance the evaluation of the reuse potential evaluation method. Furthermore, 
in a retrospective design approach, the impact on the dependent variables, the end of the building's first functional life and potentially its reuse, has already taken place, which allows for a verification of the reuse potential evaluation method by comparing the reuse potential results with the actual situation.

The critical retrospective cases will be selected conform the so-called 'case/ control' approach, whereby one case study object represents the 'case', which is expected to have a high reuse potential, but in reality did not result in the reuse of the building, and the second case study object represents the 'control', which is a building that is expected to be reused and is in reality also reused.

When utilising the 'case/control' case study method, Swanborn (2010) states that special attention should be paid to the comparability of the selected 'cases' and 'controls', to warrant generalisability. To support comparability of the selected cases, case-variance should be minimised. Therefore, two critical retrospective cases have been selected that utilise a similar construction method. The first critical retrospective case study object is the 'Villa Zebra - Red House' building, representing the 'control', which is a successful reuse example and the second critical retrospective case study object is the ' $4{ }^{\text {th }}$ Gymnasium' building, representing the 'case', which is a non-successful reuse example. Both case study objects were intentionally designed to be easily reused and relocated. Despite its design effort the 4th Gymnasium building was mainly demolished with merely the reuse of a few easily accessible parts at the end of its functional life.

To construct validity, multiple sources of evidence will be utilised (Yin, 2014). In addition to the assessment of the dependent variables with the application of the reuse potential evaluation method, both cases will firstly be analysed in an exploratory manner, utilising qualitative research methods. In this exploratory research both cases will be studied in-depth to their dependent and independent variables, to increase the understanding of contextual influences that might have influenced the decisions about the fate of the buildings, which could not have been clarified by the reuse potential evaluation method.

Therefore, the case study method starts with step 1: a qualitative analysis to identify the factors that influenced the decision making about the reuse process. In this step available documentation is retrieved and interviews with the main actors involved in the reuse process are performed to increase the understanding of the dependent and independent variables that influenced the decision making about its reuse. To construct validity, the interview data will be transcribed and validated. Furthermore, the lessons learned that supported or restricted the reuse will be defined. In section 6.3 the successful reuse case, 'Villa Zebra - Red House' will be analysed and in section 6.4 the unsuccessful reuse case, ' 4 th $G y m n a s i u m$ ' case will be analysed. To conclude the qualitative analysis, in section 6.5, a comparison of both cases will be performed, which is structured according to the four mechanisms that have been identified in the conceptual reuse potential framework, in section 3.4 . 
After having built up an understanding of the different factors that influenced the decision making, the case study method can proceed to step 2: the application of the reuse potential evaluation method and the evaluation of the results. In this step, both case study buildings will be studied and the reuse potential results will be reflected upon, with regards to the actual fate of the building. The performance of step 2 is described respectively in section 6.5. for the 'Villa Zebra - Red House' and in section 6.7 for the '4th Gymnasium' case.

Next, the case study method can proceed to the goal of this chapter, step 3: evaluate the usability, applicability and usefulness of the reuse potential evaluation method. This will be done by evaluation if the developed method fulfils the aim as defined in section 5.2.1, this evaluation will be discussed in section 6.8 .

\subsection{Qualitative analysis Red House}

The first case study 'Red House' is a successful reuse example, which started its third generation of use and functionality in 2013. The name 'Red House' refers to the name of its $3^{\text {rd }}$ generation building. In order to analyse and understand the design decisions and methods that were used to enable the successful reuse of the building for multiple times, the architect and involved contractor were interviewed and available documentation about the building have been collected and analysed, including a site visit see the building in its current form and use. In Figure 6.55 an overview of all three configurations and uses of Red House is depicted, revealing the different configurations during its life cycle. It can also be seen that one part of the building's 3rd generation use is unknown. Firstly, the building's life cycle will be described, including a description of the: $1^{\text {st }}$ generation - Villa Zebra; $2^{\text {nd }}$ generation - Villa Notenkraker, and; $3^{\text {rd }}$ generation - Red House. Finally, based on the interviews and the available documentation, the main lessons learned from this case are summarised.

\section{$1^{\text {st }}$ Generation - Villa Zebra}

The design of the original building, which was named 'Villa Zebra' and was the winning design of a design competition held in 1999. The design brief was to design a semi-temporary exhibition space for children of $1900 \mathrm{~m}^{2}$, that can be used for a minimum of one year and maximum of five years. Furthermore, the building should must be designed utilising of a pre-defined volumetric modular construction system to enable a quick construction within the limited budget. The specified volumetric modular construction system consists of units that are $6 \times 3 \times 3 \mathrm{~m}$ in size and consists of a steel skeletal frame (Hoogstede \& Tummers, 2001). Architect Jouke Post in collaboration with students from the Rotterdam Academy of Architecture, Jaap van Dijk, Ramon Knoesteren and Remco Tolvink designed the final building design, which follows the principles of Industrial Flexible \& Demountable (IFD)building design (Crone, 2007).

One of the aims of the project was to demonstrate that by utilising a volumetric modular construction method with standardised dimensions it is possible to design an architectural building that does not reveal its temporary and modular character. This was achieved by 


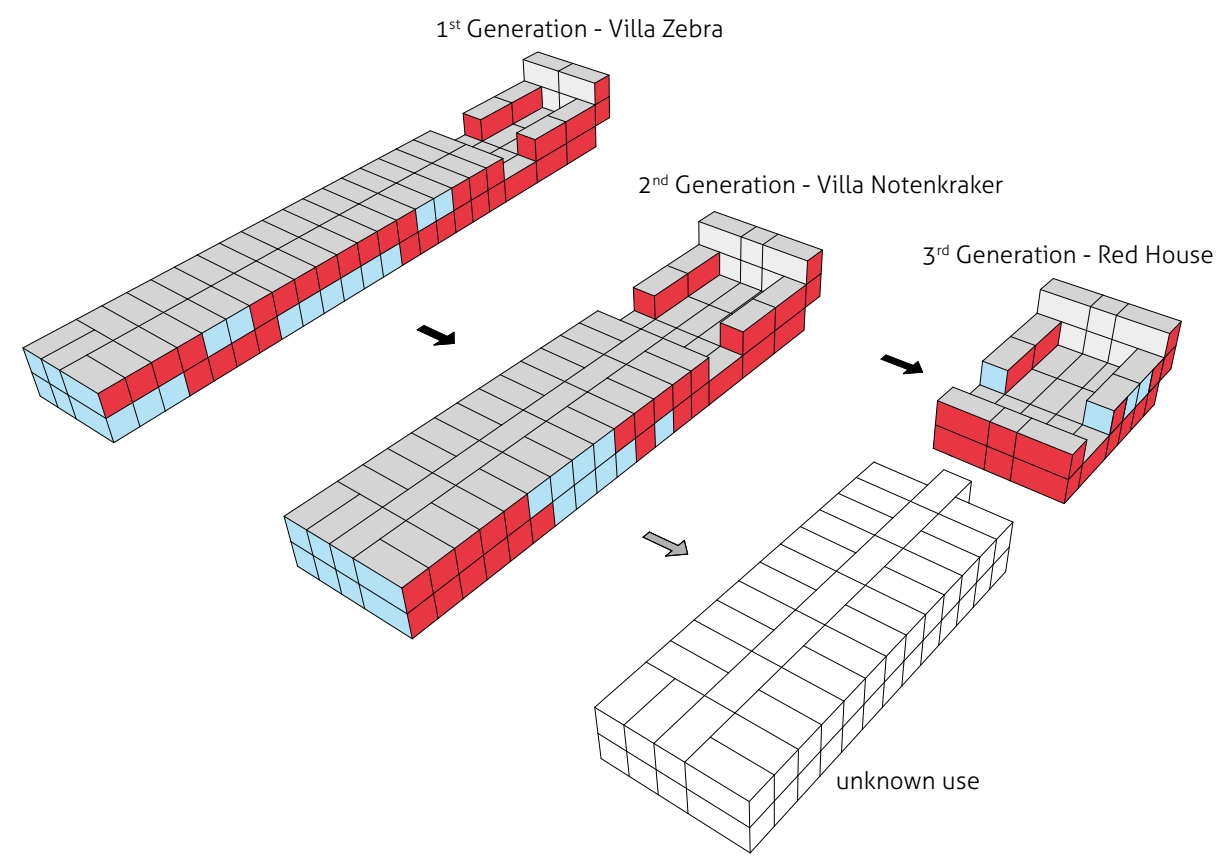

Figure 6.55: Schematic representation of the three configurations of Red House

conceiving the units as steel cages, which can be filled in with open or closed panels instead of closed units that could have a window (Hoogstede \& Tummers, 2001).

The short use period with a maximum of five years required a different design approach. Therefore, the building was designed with its end-of-life in mind by designing the building in such a way to allow as much parts as possible to be demounted and reused. To support the demountability and reuse of the building, the final design was composed of approximately 100 volumetric modular units, with two exceptions to the standard units. The first exception was made to create a ramp to display art, but also connect the ground floor with the first floor and allow wheelchair users to enter the first floor. The second exception was made to create a theatre area, whereby units are positioned to form a stair, which forms inside and outside on the roof a theatre area. In both exceptions adjacent units are used to support the additional steel parts to create these spaces.

Additionally, the following measures where taken to support its disassembly and reuse, for the foundation concrete foundation blocks were positioned on top of the asphalt on-site, allowing the foundation to be easily removed at the end-of-life without leaving any marks of the building. Furthermore, the prefabricated steel units were filled in with prefabricated facade panels, interior walls were reduced to a minimum and the few internal walls were made of metal-stud walls with OSB plates and the ceilings were unfinished leaving the installations visible. Each unit could be assembled and disassembled including its facade frames and interior walls. To conceil the temporary character of the building, the facade was finished with a red polytex sheet, which is covered with a transparent corrugated polycarbonate sheet, which resulted in its unique and coherent character. Furthermore, 

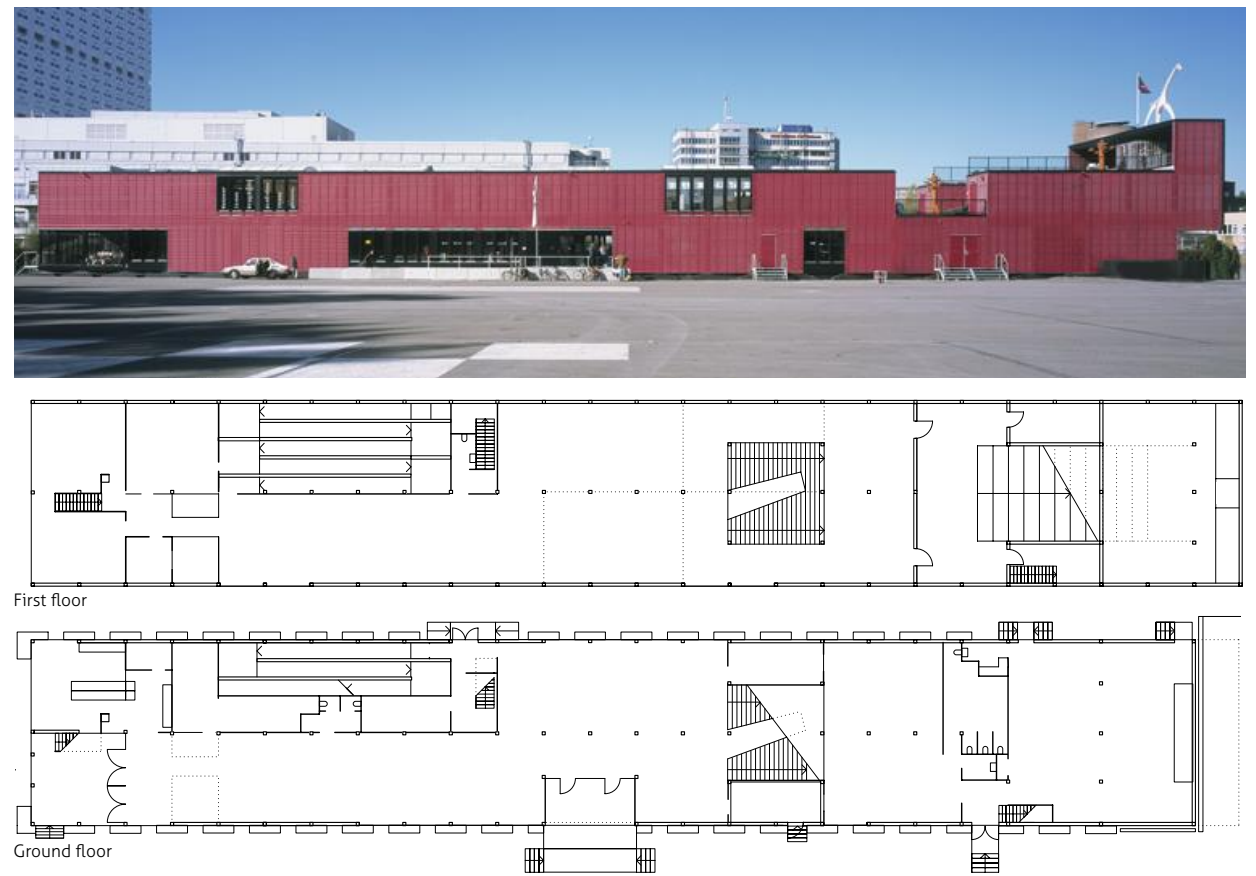

Figure 6.56: Photo of the facade (Post, 2017) and the floor plans of Villa Zebra in Rotterdam (Detail, 2002), the Netherlands, the $1^{\text {st }}$ generation.

these materials were specifically selected for the facade to match its technical life span with its pre-defined functional life span and allowing its facade materials to be written off in five years time. The allowed the architect to select materials specifically to be suitable for this specific location, since it was unknown if they would also suit future uses and allowing future uses to adapt its appearance. At the end-of-life most of its parts can be reused and relocated in either the same configurations or a different configuration.

From a financial perspective a take-back guarantee contract was made, stating that the contractor would take back the units for a set price at the end of its five year use period. Due to bankruptcy of the construction company and later continuation of the construction company, the take-back guarantee was expired. This resulted in the investor/ project developer to become the owner of the building.

After five years of use, the owner (investor/ project developer) hired the initial contractor to relocate the building to a storage place until the owner finds a new use for the building. Because they knew the building would need to be stored for a longer time, the building was stored at an outside location where the building was assembled as two halves of the original configuration next to each other and its roof was sealed of with a temporary sealing layer and the open ends were closed from weather influence. After two years of storage, the owner, being a investor and project developer, identified a potential use for the building, which marks the beginning of the $2^{\text {nd }}$ generation of use of the building. 


\section{$2^{\text {nd }}$ Generation - Villa Notenkraker}

After the new location and function, a temporary primary school building in Hoogvliet the Netherlands, was identified, the original architect was hired by the owner to support during the design stage to match the new client's needs with the existing building parts. To enable the building to be reused as a primary school building, the width of the building was increased from $12 \mathrm{~m}$ to $15 \mathrm{~m}$ to create a hallway in the middle of the building by the insertion of a row of units. Furthermore, toilets were added, (movable) partitioning walls to create classrooms and the required installations. The original contractor was hired to transform and construct the temporary building. Most of the modifications to the units were done in the factory, after which they were assembled on-site. For the facade only the finishing was replaced, the red polytex sheet and corrugated polycarbonate sheet, with a new moisture barrier and a more durable corrugated steel sheet painted in red. Within three months the design was finished and five months later, the building was realised.
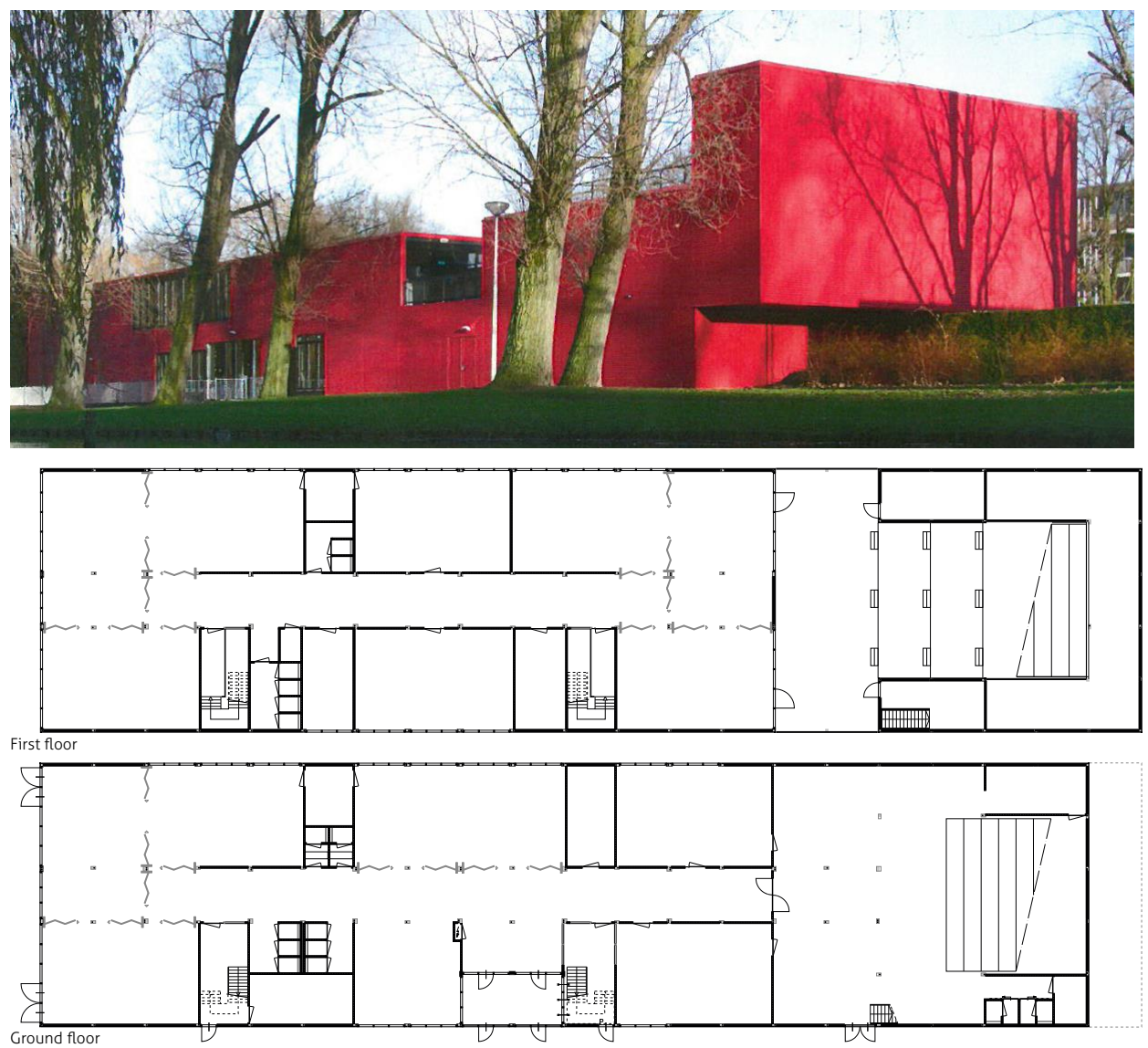

Figure 6.57: Photo of the facade (Post, 2017) and the floor plans of Villa Notenkraker in Hoogvliet, the Netherlands, the $2^{\text {nd }}$ generation. 
The building contains a part that deviates from the standard units, which was used to create a theatre area with a higher ceiling height. This deviation from the standard units, which is often considered as being more difficult to reuse, did not disrupt the reuse of these parts of the building. For the new users these special features would probably not have been asked for in the design brief, but since the building included it, it provided an additional quality to its new users. Furthermore, the contractor stated that it is unique for this project, what he called a 'custom' project, to enable such a transformation. He stated that the transformation was mainly possible because the initial building did almost have no infill elements, which made it easy to perform changes and add the required parts for its new use. Furthermore, from a financial perspective this was a very attractive option for the new client, because the depreciation costs are relatively high after the first use, which made it financially attractive to use, used parts for their temporary building. Finally, from a liability and warranty perspective, the building's ownership was transferred from the investor to the client during its use period for a symbolic price of 1 Euro to overcome liability and warranty issues and at the end of the use period, approximately 3,5 years, the building was sold back for 1 Euro, whereby the new user paid a montly rent to use the temporary building.

\section{$3^{\text {rd }}$ Generation - Red House}

At the end of its functional life of the $2^{\text {nd }}$ generation, the owner of the building managed to identify a consecutive use for one part of the building. In the new function the building would be used partly as a warehouse to store cameras and partly as an office. It is unknown where and what the other part of the building is used for, it is believed to be used in the east of the Netherlands. The consecutive use meant that the building could directly be relocated to its new location, avoiding addition transportation and storage costs.
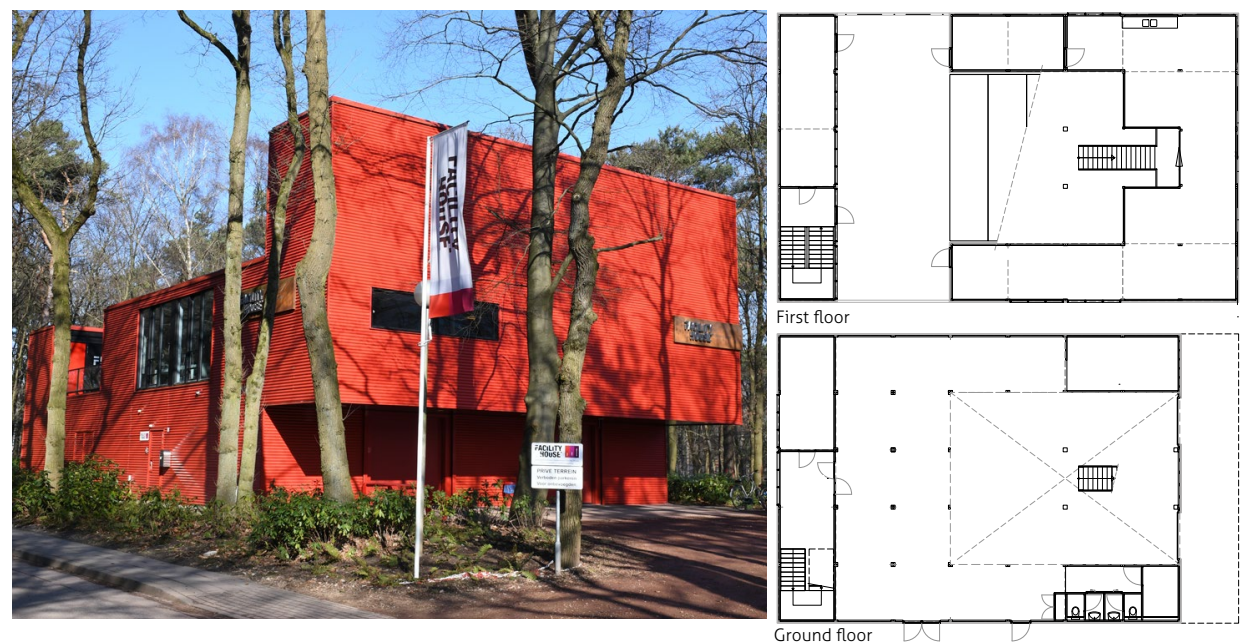

Figure 6.58: Photo of the facade (own photo) and the floor plans of Red House in Hilversum, the Netherlands, the $3^{\text {rd }}$ generation. 
Furthermore, it is interesting to note that the latest disassembly and relocation of the building is performed by a different contractor. According to the initial contractor they made an offer to the owner to execute the job but were more expansive than the other contractor. This reveals that the relocation of the building is not bound to only one contractor. Furthermore, the modifications made to the last generation building were performed by the new client in collaboration with the contractor and owner, without the involvement of the original architect. The architect was only asked to become involved when the Red house building was nominated for an architectural prize, to prepare a presentation about the building and its reuse.

In Figure 6.59 an overview of the entire time-line of the Red house building is shown, which also depicts the involvement of the architect, contractor and ownership of the building during its use. Whereby the involvement and significance of the role of the architect decreased after each reuse generation.

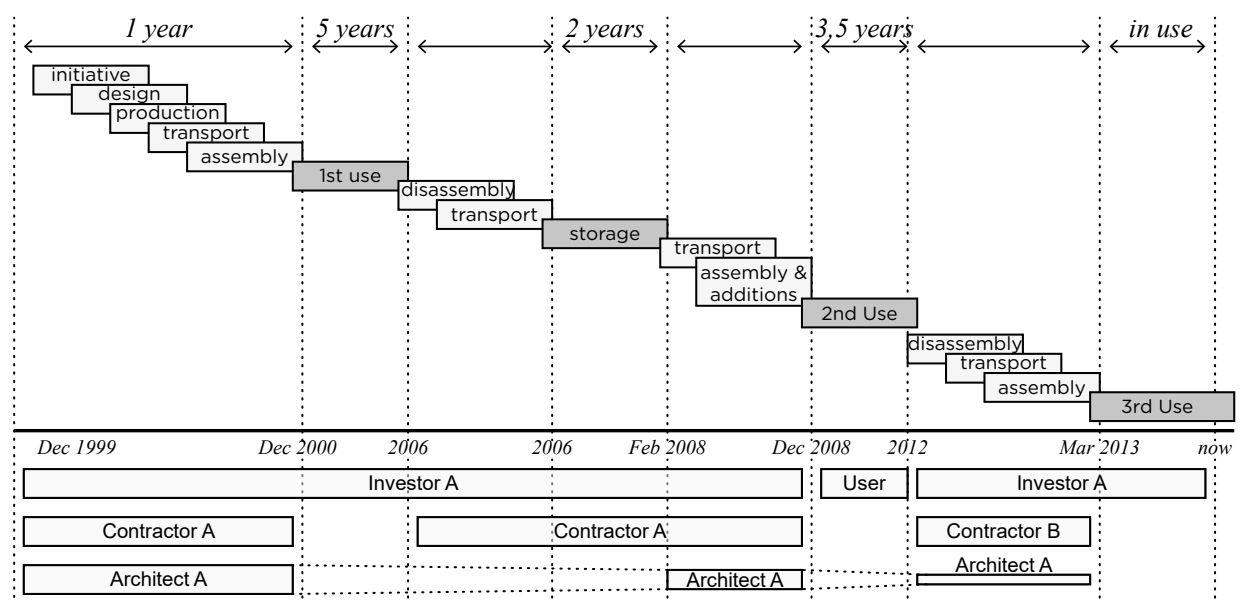

Figure 6.59: Time-line of the Red House building during its life cycle, including the ownership, involved contractors and role of the architect. 


\section{Lessons learned}

Based on the interviews and documentation about Red House, the following can be learned from the Red House case:

- Standardised volumetric modular construction method. The volumetric modular construction method facilitated in easy disassembly, reconfiguration and relocation of the building and successfully fulfilled the needs and demands of different users. The transformation from first to second generation required a different configuration of the units to comply with the user requirements of a primary school. This transformation was considered easy, because in its first use the building did almost not contain any interior walls or lowered ceilings, which made it easy to add the required installations, partitioning walls and lowered ceilings. Furthermore, the building blocks of $6 \times 3 \times 3 \mathrm{~m}$ proved to be a dimension that allows many configurations and can be used to fulfil the needs of multiple building functions;

- Standardisation of dimensions. The used volumetric modular construction system contains standard dimensions ( $3 \mathrm{~m}$ width $\times 6 \mathrm{~m}$ length $\times 3 \mathrm{~m}$ height), which comprises of a concrete floor with a steel structure and façade frames. The used volumetric modular construction method and dimensioning is according to the contractor commonly used in The Netherlands. This allows the contractor to purchase used units that were originally constructed by other companies, although these units may contain small feature differences, they can easily be reused within the contractor's construction system;

- Ease of disassembly and reassembly to support ease storing. Between the 1st and 2nd generation the building was stored for approximately two years. To preserve the quality of the building products the building was assembled in almost exactly the same configuration as its first use on an empty site and the roof was temporary waterproofed. The ability to easily disassemble and reassemble the building on an empty plot proved to be successful method to allow the building to be stored outside at a cheap location without the need of a large roof above the building to preserve it from weather influences.

- Strong design concept. The architect stated that the strong design concept of the building facilitated in the reuse of the building and attracted users to the building. The strong design concept can be confirmed by the minimal amount of changes that were made to the building's appearance over time. As he stated: "if something [a building or building product] is beautiful or good looking, it poses lots opportunities to reuse it, while if something [a building or building product] is not beautiful one may come up with many explenations to not reuse it". Even though, this is a subjective statement based on aesthetics, it provides insight in the social aspects of how people judge the reuse potential of a building or its parts;

- Investor/ project developer building ownership. During all stages the owner of the building remained the same and took initiative in proposing locations to reuse the 
building/ parts of the building at the end of their use, with the exception of the use period of the second generation use when an agreement was made, to overcome liability and warranty issues by temporary transferring the ownership to the second user. The ownership of the easily relocatable building by an investor/ project developer proved to be a successful combination, because the awareness of the investor about the demand for buildings on the market enabled him to identify new locations when the building became available;

- Contractor continuity. At first the contractor continuity seemed to be a factor that supported the successful reuse of the building, but since the relocation and modification of the 3rd generation was performed by a different contractor the success of its reuse is in this instance not limited to contractor continuity;

- High initial cost of reusable products. The contractor noted that the costs to incorporate plug-in-play installation components in each modular unit and a lowered ceiling that does not have to be disassembled before relocation of the modular unit is at this moment more expansive than installing the installations and lowered ceiling in a traditional manner, after the units are put in place. The costs of the expensive plug-in-play elements can only be justified if the contractor knows for sure that he will also deconstruct the building at the end of use. Since initial construction costs are often the deciding factor, the contractor is forced to incorporate a lowered ceiling an installation products that are more difficult to dissemble, to stay competitive. Taking into consideration the total life-cycle costs can in this case for the installation and lowered ceiling be identified as essential to support the incorporation of alternative products with higher reuse potential.

- Architect's role. The architect noted that the role and involvement of the architect with the relocation and reuse of the building decreases, depending on the amount of changes that are required to suit its new use. In this case during the first generation building the architect was fully involved with all decisions, similar to regular building designs. For the 2 nd generation the building had to be changed and reconfigured to enable the building to be used as a school building. Since the technical detailing and units were known, the main task was to bring the user requirements in line with the building and the internal floor plan arrangement. While for the 3rd generation the architect was only involved when the building was nominated for a prize;

- Availability of additional building features in reused buildings. The reuse of a building that included a theatre area, the primary school benefited from the presence of this area, which would probably not have been asked for if a design brief would have been specified for a temporary building of new materials. Since the building included this feature, the client could benefit from this feature. They liked this parts so much that it was later included in the design brief for the permanent school building. 


\subsection{Qualitative analysis $4^{\text {th }}$ Gymnasium}

The second case study, called '4th Gymnasium', is a building that was designed as a temporary school building using a modular construction system, with the intention to enable easy disassembly, relocation and reuse at the end of its use (Figure 6.60). Although, after a use period of eight years the disassembly and relocation did not materialise and the majority of the building was demolished using traditional demolition methods with reuse of minor parts. Considering the building was designed to support an easy disassembly and reuse, the analysis of the reasons why the building was demolished rather than disassembled and reused provides a great opportunity to improve the understanding of the different factors that influence the actual reuse of building products and to determine to what extend the reuse potential evaluation method can be used to identify complications.

To understand the different design decisions and methods that were used to support reuse, which ultimately were not utilised and understand the decision to mainly demolish rather than disassembly and reuse, the municipality, the owner of the building, has been interviewed and available documentation has been analysed. An attempt was made to interview the architect and the contractor, but the architect did not respond and the initial contractor went bankrupt. Although it was not possible to interview the architect and contractor, the municipality of Amsterdam was open for interview. Furthermore, since the building is a public building, their expenses need to be well studied and documented. Therefore, the municipality studied multiple end-of-life scenarios to make a sensible decision about the fate of the building. All documentation is publicly accessible, which provided detailed information to enable this research.

First, the context, location, design and its methods that were used to support disassembly and reuse will be described, after which the different end-of-first use scenarios will be described including the context in which the final decision to demolish rather than reuse was made, after which the lessons learned will be summarised.

\section{Development of $4^{\text {th }}$ Gymnasium}

At the time of the redevelopment of the Houthaven area in Amsterdam, The Netherlands, the area was an open, undefined space with separate industrial buildings. The area was planned to become a new residential area, but due to delays with the permanent zoning plan, it was decided to allow a part of this area to be used to fulfil pressing needs with temporary buildings, such as student residences, restaurants and artists' studios. Furthermore, to fulfil the increasing demand for Gymnasia in Amsterdam, the municipality of Amsterdam decided that the 4th Gymnasium will have a place in the new residential area. However, it would take several years before the final zoning plan would be finished and the permanent school building would be built. Therefore, it was decided to build a temporary school, planned to be used for five years.

At the same time, the development of a temporary school in a relatively unknown and almost uninhabited area was considered a potential risk for the success of the school, as a temporary building in a deserted area might refrain the attraction of new students. The 

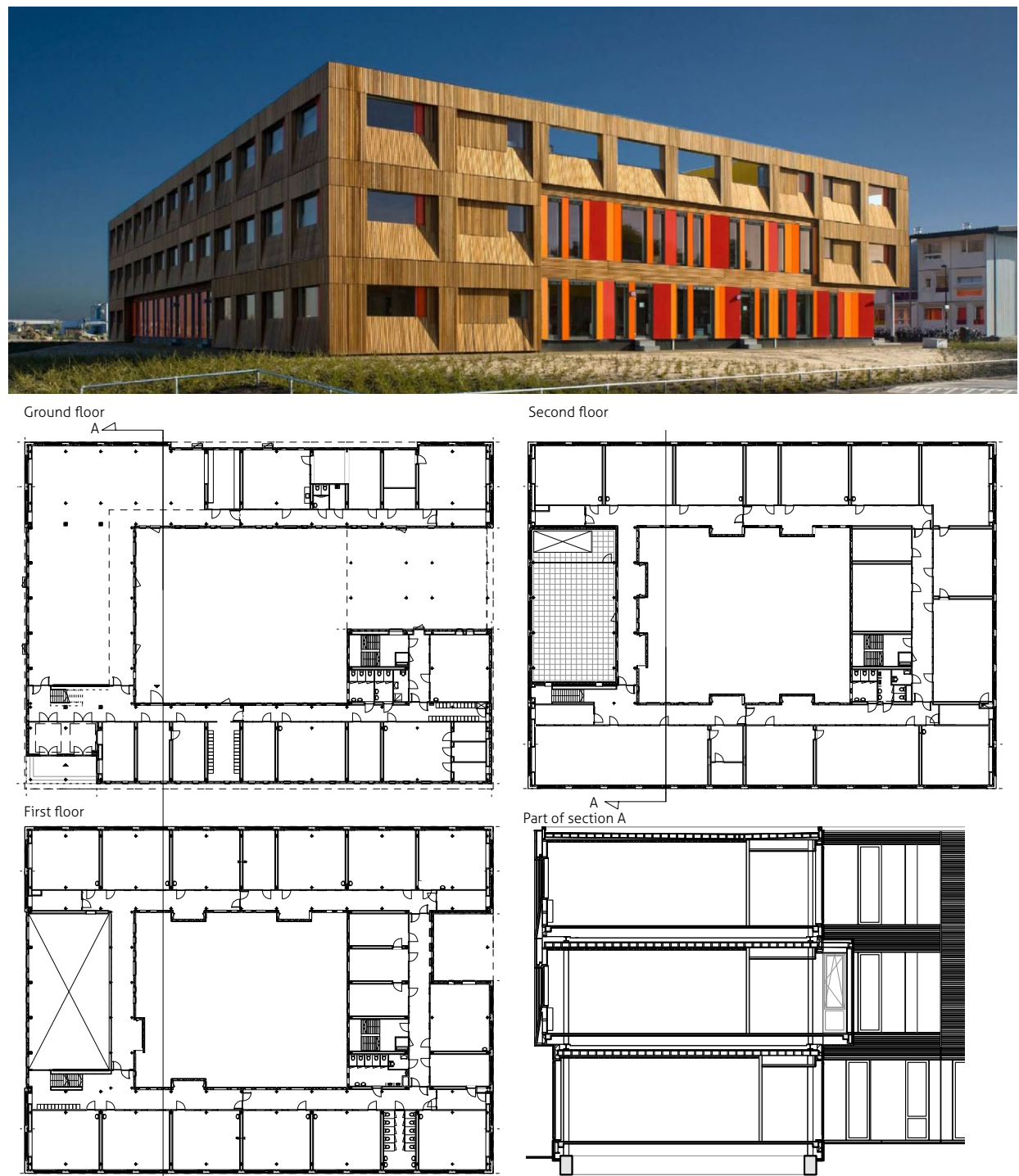

Second floor

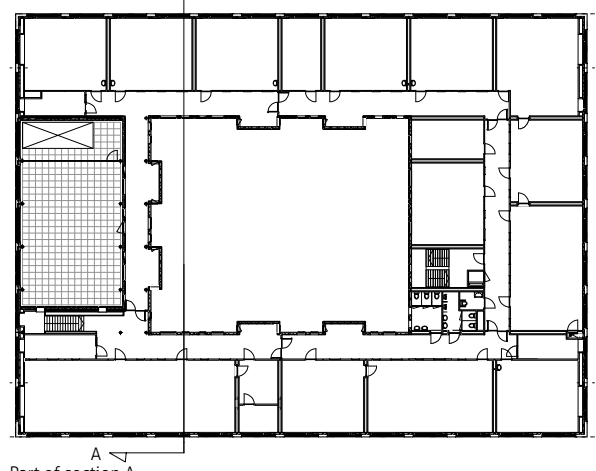

Part of section A

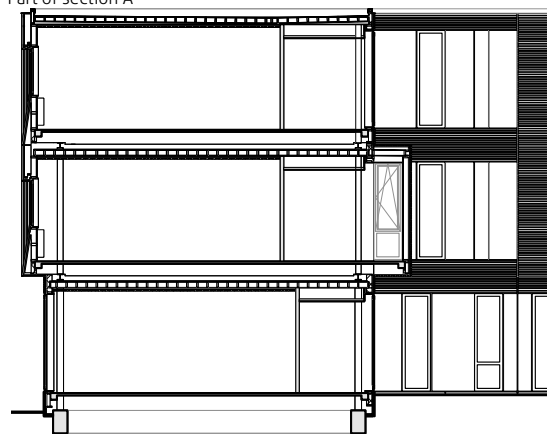

Figure 6.60: Photo of the facade (John Lewis Marshall) and the floor plans and one section of the $4^{\text {th }}$ Gymnasium building in Amsterdam, the Netherlands (HVDN Architecten, now Studioninedots; Lebesque, 2018).

new temporary school building would therefore be important for the attractiveness of the area and had to be of good quality to become a fully-fledged school. Therefore, it was decided to realize a sustainable and high-quality temporary facility for the $4^{\text {th }}$ Gymnasium (Timman \& Bogers, 2016).

The Amsterdam based office hvdn architects (now Studioninedots), in collaboration with contractor Ursem Bouwgroep, who had previously already collaborated on the realization of movable IFD school buildings, signed the contract to design and construct the $4^{\text {th }}$ Gymnasium within one year, with a total construction cost of 4,5 million (De vries, 2008). 

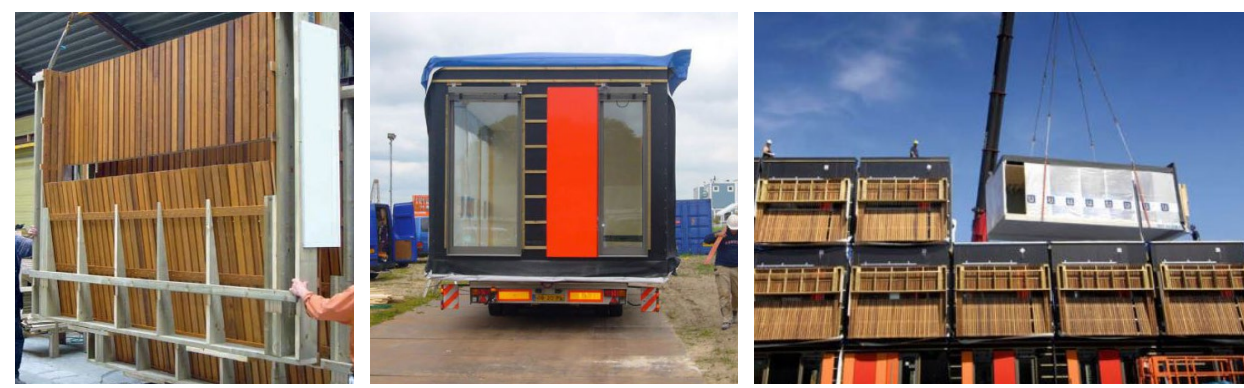

Figure 6.61: Photos of the prefabrication of the facade, transportation of the units to the construction site and the assembly of the units (photos by John Lewis Marshall)

To be able to realise a $4.000 \mathrm{~m}^{2}$ building within the available time and comply with the wish to enable the relocation of the building after its first use, it was decided to utilise a volumetric modular construction system, which they had already used in previous collaborations. As the architect wrote on their website:

"The 4th Gymnasium is developed with a IFD-building system (Industrial, Flexible and Demountable). It is completely transferable to a new location and can easily be adjusted to specific requirements from the stakeholders or program" (hvdn architecten, 2018).

The number of unique prefabricated elements was limited to six, which could be used to built multiple configurations and allowed for swift manufacturing of the prefabricated elements. To demonstrate the different possible configurations, four types of configurations were developed from which the O-model was chosen to optimise the circulation and routing in the building.

To suppress the modular character of the building, the facade is finished with vertical timber slats to conceal the dilatation between the units, which are occasionally alternated with coloured aluminium panels, creating a dynamic appearance. Furthermore, to support the assembly and disassembly speed, a prefabricated rotating facade part was developed, as shown in Figure 6.61. Furthermore, the building contains a steel structure onto which the volumetric modular units are placed, which made it possible easily create large open spaces with a double ceiling height for the canteen area and close the facade and roof with prefabricated frames (De vries, 2008). Furthermore, the architect stated that:

"The school has a quality and finish level that is comparable to permanent, traditional construction, both technically and aesthetically. At the same time, the building is very flexible in several respects. It is movable and can therefore be used in the coming years where needed. And due to the modular structure, it can easily change with changing user requirements, which extends the life of the building" (hvdn architecten, n.d. p.4).

Although the building was originally planned to be used for five of its planned twenty year exploitation period in Houthaven, due to the economic crises the development of the Houthaven area was delayed. This includes the construction of the permanent school building, which was finished three years later than planned. In August 2016, the new permanent school building was taken into use, which left the temporary building into disuse after 8 years. 


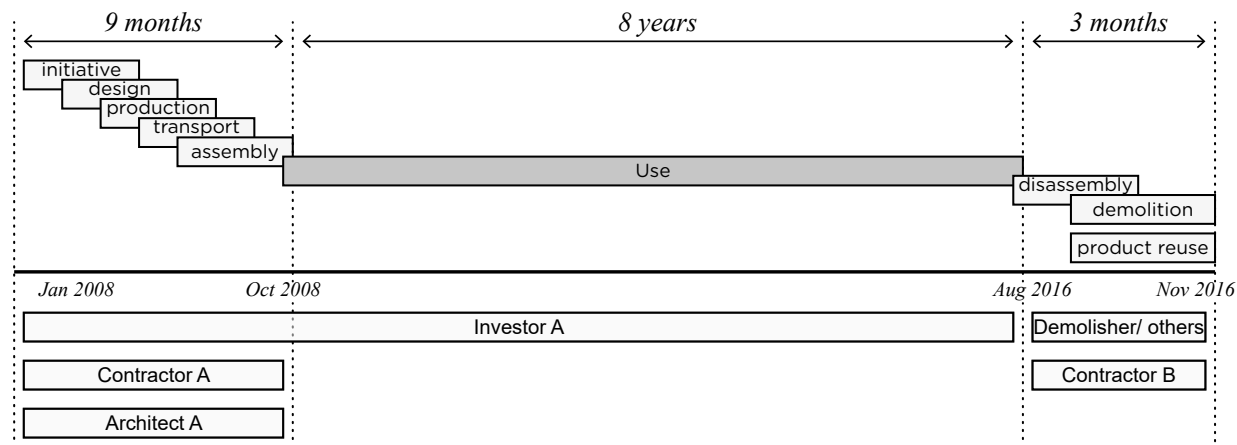

Figure 6.62: Time-line of the 4th Gymnasium building during its life cycle, including the ownership, involved contractors and role of the architect.

At the end of its use period, the Amsterdam municipality wrote in their report, "Now, 8 years later, it has been established that the semi-permanent building of the 4th gymnasium has met expectations. The school has grown according to plan and has been able to create a good educational climate in the building, and the multicoloured building has been a landmark in the area for many years and has contributed to the urbanization of the area" (Timman \& Bogers, 2016, p.3). Additionally, the municipality of Amsterdam stated that the children really enjoyed the colourful building, which formed the wish for their permanent building to be as colourful as their temporary school building. This marked the end of its first use period. Prior to the end of its first use, the municipality started to investigate three potential end-of-first-use scenarios.

\section{End-of-first-use scenarios $4^{\text {th }}$ Gymnasium}

The following three end-of-first-use scenarios have been analysed by the Amsterdam municipality (Timman \& Bogers, 2016):

- Scenario A: relocation of the building;

- Scenario B: sell the building, and;

- Scenario C: demolish and make as much parts as possible available for reuse.

It should be mentioned that the available time to perform any of the scenarios was limited to three months, because the temporary building became available from August the $1^{\text {st }}$, 2016, and the plot on which the temporary building was located had to be delivered empty to a real estate developer on November the $1^{\text {st }}, 2016$. The delivery date of the empty plot was a very strict deadline and a delayed delivery date of the empty plot could result in claims from the developer that could easily reach multiple millions (Timman $\&$ Bogers, 2016). Additionally, the original contractor went bankrupt, resulting in the loss of knowledge about the composition of the construction system and its disassembly. This forced the municipality to identify a new contractor that is foreign to the construction system, but willing to disassemble the building for relocation. In Figure 6.62 an overview of the time-line including the ownership, involved contractor and architect has been depicted. Hereafter, all three analysed scenarios and conclusions are described: 


\section{Scenario A - Relocation of the building}

After the preparation of the tendering process, it became clear that the expected flexibility and ease of disassembly to relocate this building was more difficult than it was alleged to be (Timman \& Bogers, 2016). In consultation with experts, it was stated that the disassembly will decrease the quality of the building products significantly and will require major reconditioning works prior to reuse. Furthermore, the limited availability of technical drawings and lack of comprehensive information made contractors hesitant in their estimation to succeed disassembly of the entire building within three months. In the interview with the municipality of Amsterdam the lack of time to enable proper disassembly was considered to be mainly a result of the unusual type of volumetric modular units and stated that three months to disassemble a 'conventional' temporary structure of this size would have been more than sufficient. While for this 'unique' building system with lack of documentation resulted in potential contractors to only take on the project with a so-called 'open-end' in their contract, which means that unforeseeable costs because of deteriorated quality resulting from the deconstruction could be directed to the municipality of Amsterdam, resulting in uncontrollable costs and high risks for the municipality. In a conservative estimation the relocation was estimated to cost 6 million and another 0,5 million to perform re-conditioning tasks. The contractors indicated that the relocation will take more time than the available three months, which means that the municipality can look forward to financial claims from the project developer, which makes the costs of this scenario uncontrollable for the municipality of Amsterdam. The municipality of Amsterdam also mentioned that the used construction system has only been applied in 4 to 5 buildings in the country and none of them have been relocated.

In December 2015 the municipality started with the investigation to identify a new location and user for the building, but did not manage to identify a suitable user and location in time (Timman \& Bogers, 2016). Thus a direct relocation would not be possible and require a storage period, which increases the costs of scenario $A$ even further and might also deteriorate the quality of its parts due to external weather influences. Besides, even finding a nearby storage location and permit for temporary storage, was identified as an obstacle, not to mention its costs. In a follow-up report it was stated that an earlier start with the investigation to a new location and user would not have increased the chance for a successful relocation of the building, because the main issue was the available execution time of its disassembly (Van Gils \& Van der Laan, 2016).

\section{Scenario B - Sell the building}

After a market research, the municipality of Amsterdam concluded that there was no demand for the building (Timman $\&$ Bogers, 2016). In the interview and their report (Timman \& Bogers, 2016), it was mentioned that the demand was limited due to: 1) the strict time frame in which the building was required to be relocated; 2 ) the 'unique' nature of the building, and; 3 ) the inability to guarantee the quality of the elements after disassembly. 

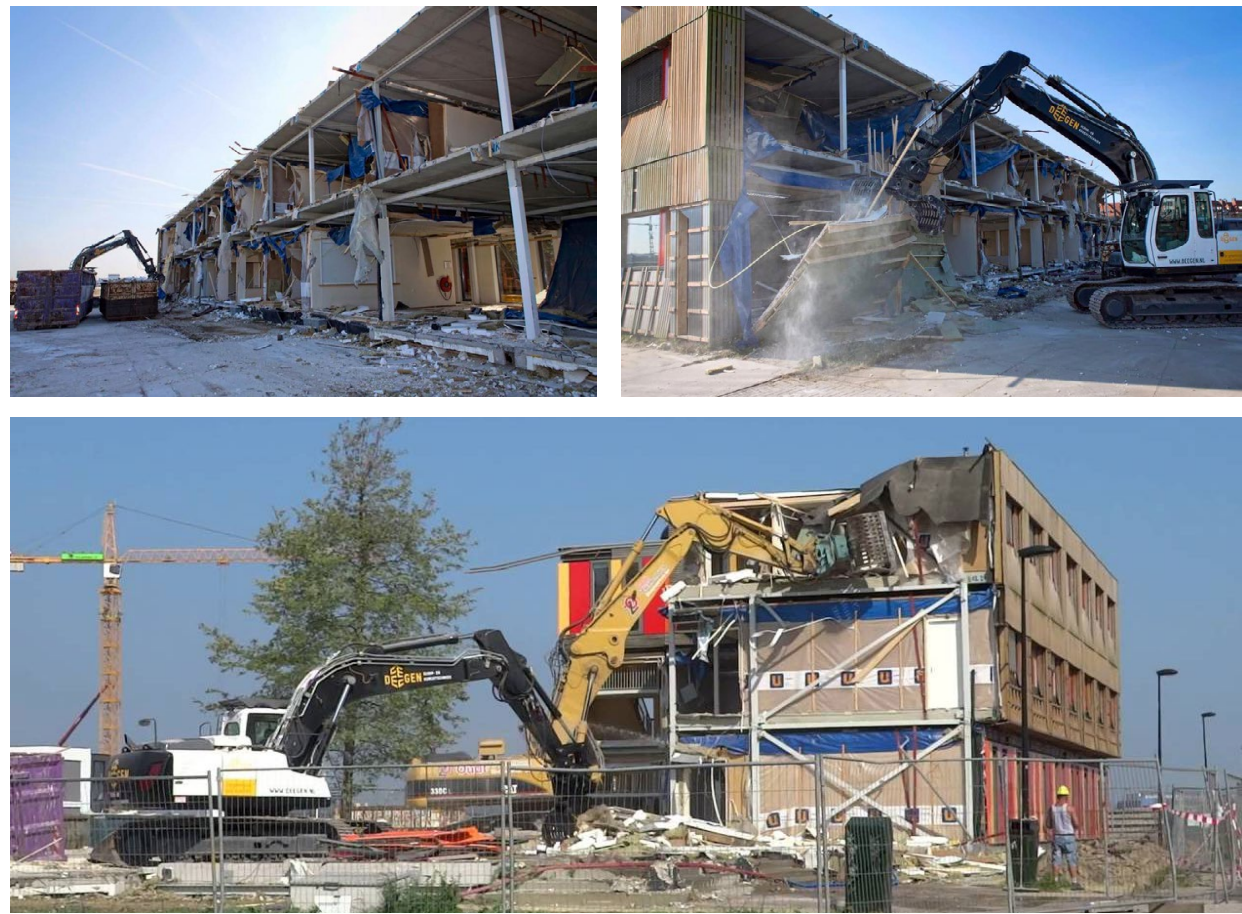

Figure 6.63: Photos of the demolition of 4th gymnasium (photos by I. Deegen \& zoon BV).

\section{Scenario C - Demolish and make as much parts as possible available for reuse}

After consultation with experts it was estimated that the deconstruction and demolition of the building would cost 0,6 million and materials with a total value of 0,4 million could be reclaimed for reuse, and could all be executed within three months time. To preserve as much value, the municipality would first examine the possibility to reuse the materials in their own projects before offering it to the market. Additionally, the selection of this scenario would mean that the remaining book value of the building, 6,4 million, would need to be written off at once. Despite the high remaining book value, this scenario seemed the most realistic scenario, especially considering the feasibility to execute the project within the strict time-frame and the ability to cover the remaining book value from available eduction housing reserves.

\section{Execution of Scenario C}

Finally, the municipality of Amsterdam decided to execute scenario $C$, demolition of the building and making as much parts as possible available for reuse. In an online article (Muis, 2016), the municipality mentioned that the following parts have been reused in their own buildings: internal door-frames, internal doors, entrance doors, door closers, escape route signs, lighting, interior furnishings and outside elements, such as: bicycle racks, outdoor benches. In the interview with the Municipality the reuse of the prefab concrete stairs have been added to this list. Furthermore, the following parts have been sold for reuse to third parties: timber battens, HPL facade panels, TL-lamps, acoustic 
ceiling panels, and the steel structure is sold for recycling, to make new steel parts (Muis, 2016). Other materials and debris have also been made available for recycling.

Despite the good intentions, to demolish and make as much parts as possible available for reuse, it can be concluded that the reused parts has been reduced to a limited number of easily accessible parts and the majority of the building has been demolished using traditional demolition methods (Figure 6.63).

\section{Technical characteristics that limited reuse}

In order to understand why the flexibility and easy of dissassembly to relocate the building was much more difficult than it was alleged to be, based on the interview and available documentation, the following technical characteristics have been identified as limiting factors for the relocation of the building and caused the need for major reconditioning works and replacement of parts:

- The decision to strive for a high quality building led to the incorporation of many 'additional' features, which would normally not be considered for application in a temporary building. These 'additional' features increased disassembly complexity. For example, the building was fitted out with traditional installation systems similar to applications in permanent buildings. In the interview it was stated that $80 \%$ of the installation could not be reused and would require replacement after disassembly. Furthermore, the used finishings often involved irreversible and hidden connections, e.g. the walls that needed to be placed after the units were placed, were metal-stud walls, which have been finished with plaster and a layer of paint, which makes it impossible to disassemble and reuse these parts.

- The lack of exact drawings of the building increased uncertainty about the disassembly procedure and could potentially increase disassembly time and require additional reconditioning tasks and replacements than originally estimated, thus increasing risks.

- The unique nature of the volumetric modular construction units in dimension and composition, made them incompatible to be applied within other existing volumetric modular construction methods. This limited the interest from contractors that utilise other volumetric modular systems. The applied units were composed of a concrete floor and timber-frame walls and ceiling elements that are used to form a rigid unit, which are assembled and finished with a third in-situ built wall, in contrast to the more commonly applied units that are made up of a concrete floor, steel structure and timber-frame elements as infill and facade elements, such as was used in the Red House case study.

- The deviation from the units and the in-situ built wall to finish the units, results in an increased complexity and difficulty of disassemble the building. As stated in the report (Timman \& Bogers, 2016), 70\% of the building was composed of units, which are finished with an in-situ built wall, and $30 \%$ of the building was composed of a steel structure to which prefabricated facade frames are connected. 
- Differentiation between the used unit dimensions within one building. After an analysis of the drawings, four types of units dimensions have been identified, which might have also increased disassembly complexity.

- The temporary school building was a tailor-made building, specifically designed for a specified function, location and scale. This limited the ability of the building to be reused directly for other purposes or functions (Van Gils \& Van der Laan, 2016).

\section{Lessons learned}

Based on the interviews and documentation about $4^{\text {th }}$ Gymnasium, the following can be learned from the $4^{\text {th }}$ Gymnasium case:

- Incorporate design strategies to ensure cost-effective disassembly and reuse. During the design stage it is stated that not enough emphasis was put on the condition that the building has to be relocated and no measures were taken to ensure a cost-effective disassembly and reuse. The lack of measures taken to ensure a cost-effective disassembly and reuse, resulted in this case in the late discovery that the building was not as easy to disassemble and reuse as it was alleged to be. To overcome this issue, it is recommended to take measures to ensure a cost-effective disassembly and reuse. The following examples describe different types of measures that can be taken, namely: 1) the design team could be required to provide evidence that the building can be disassembled and reused in a cost-effective manner, e.g. by listing the parts that can directly be reused after disassembly and the parts that would require re-conditioning due to disassembly damages; 2) A minimum score in an assessment method that assesses the ease of disassembly and reuse potential could be specified to ensure a cost-effective disassembly and reuse, e.g. the reuse potential evaluation method; 3) Include the disassembly and reuse in the initial contract. 4) Avoid ownership of the building, instead make use of performance based contracts. Performance based contracts provide additional incentives for contractors and/or suppliers to guarantee cost-effective disassembly and reuse and support take-back after its use period. In the interview with the municipality of Amsterdam they stated that from now on they include dismantling in the contract of temporary buildings, when they take ownership of the building. Although, after the $4^{\text {th }}$ Gymnasium case, the municipality of Amsterdam aims at reducing unforeseen expenses to a minimum by avoiding ownership of temporary buildings and avoiding 'experimental' projects. Therefore, the municipality of Amsterdam employs a strategy that focusses on renting the main structure and purchase the facade to meet quality requirements in terms of appearance and aesthetics. Although this is from a sustainability perspective a sub-optimal solution, it reduces risks of unforeseen expenses and can support the reuse of the main building structure.

- Avoid unique construction methods and ensure proper documentation about the building. The unique and experimental nature of the used volumetric modular construction method in the $4^{\text {th }}$ Gymnasium building and the lack of proper documentation about the building, made the municipality of Amsterdam highly 
dependent on the knowledge and existence of the original contractor. In this case the contractor went bankrupt and thereby the knowledge of the building was lost. Furthermore, the unique construction method resulted in a lack of demand due to incompatibility with more common volumetric construction methods available and the lack of proper documentation increased uncertainty about the composition of the building, and leads to uncertainty about the disassembly procedure.

- Ensure the ability to be reconfigured to changing demands. The $4^{\text {th }}$ Gymnasium building was specifically designed for its specified function, location and scale, which limited the building to be adapted to changing needs and functionalities of future users, despite the arguments from the architect that it would be possible to reconfigure the building in multiple configurations.

- Use modular, clustered and demountable installation systems. The used installation system in the $4^{\text {th }}$ Gymnasium building was similar to an installation in permanent buildings, which increased the complexity to deconstruct the building significantly and was estimated to result in a loss of approximately $80 \%$ of its parts. The use of modular, clustered and demountable installation systems will not only increase the number of parts of the installation system that can be reused, but also improve the cost-effectiveness of the disassembly and reuse of the entire building.

- Ensure there is enough time available for proper disassembly and reuse, including the identification of a future location and user of the building. In the interview with municipality of Amsterdam, they identified that the long procedure to get a building permit for a new location can require long waiting periods, which can potentially impede direct relocation of the building and cause additional storage and transportation costs. In the Netherlands, the approval of a building permit can range from 8 weeks up to 26 weeks, depending on the complexity of the inquiry. Furthermore, the limited available time of three months made it impossible to enable proper disassembly and reuse.

- Awareness of potential demand and supply. This case demonstrated the need for property owner, such as the municipality of Amsterdam who have a large portfolio of educational buildings, to be able to identify future demands for e.g. educational buildings, in order to match the supply of buildings that become available (e.g. $4^{\text {th }}$ Gymnasium buildings) with future demands. In the interview with the municipality of Amsterdam it was mentioned that during the searching for a new user and location for the 4th Gymnasium building, no potential user could be identified. While, 3-6 months later they were in need for a temporary educational building and commissioned a competition to fulfil this need. The lack of planning is a barrier for the reuse of such buildings within their own operational area. Furthermore, the availability of a platform where the supply and demand of reusable buildings is stored could support the reuse of entire buildings. Timing of supply and demand is in this instance essential, to avoid additional storage and transport costs and facilitate direct reuse. 


\subsection{Qualitative comparison of Red House and $4^{\text {th }}$ Gymnasium}

In section 6.3 and 6.4 both cases, Red House and 4th Gymnasium, have been described, analysed and concluded with lessons learned, based on the interviews and available documentation. In this section the main differences between both cases are analysed to seek for a qualitative clarification why Red House can be described as a successful reuse case and 4th Gymnasium as an unsuccessful reuse case. To enable a structured qualitative comparison between both case studies, the comparison will be described according to the four mechanisms that have been identified in the reuse potential framework (Figure 3.25): 1) impact of design; 2) impact of "additional processes"; 3) impact of "avoided processes", and 4) impact of external influences. For each mechanism the main features that contributed to the success or failure to reuse and relocate will be described.

\section{Impact of design}

Structural system and module composition

The main differences between the volumetric modular construction methods of Red House and 4th Gymnasium is the structural system and module composition, as depicted in Figure 6.64. Red House contains an integrated steel structure that creates a rigid module and allows independent assembly and disassembly, without affecting the integrity of the structure of the module. While the volumetric modular construction method of $4^{\text {th }}$ Gymnasium utilises a separate superstructure that support the modules, whereby the concrete floor, partitioning, facade frame and ceiling are combined to form a rigid module, which creates a dependency between these parts. This dependency limits the applicability of the modules of $4^{\text {th }}$ Gymnasium, because a modification to one of these parts can affect the integrity of the entire module. In contrast to the modules used for the Red House that allowed for easy modification an application in different configurations for different functionalities, the modules of $4^{\text {th }}$ Gymnasium are specifically designed for their first use and functionality, whereby the imposed dependency within the module complicates the ability to apply them in different configurations for different functionalities.
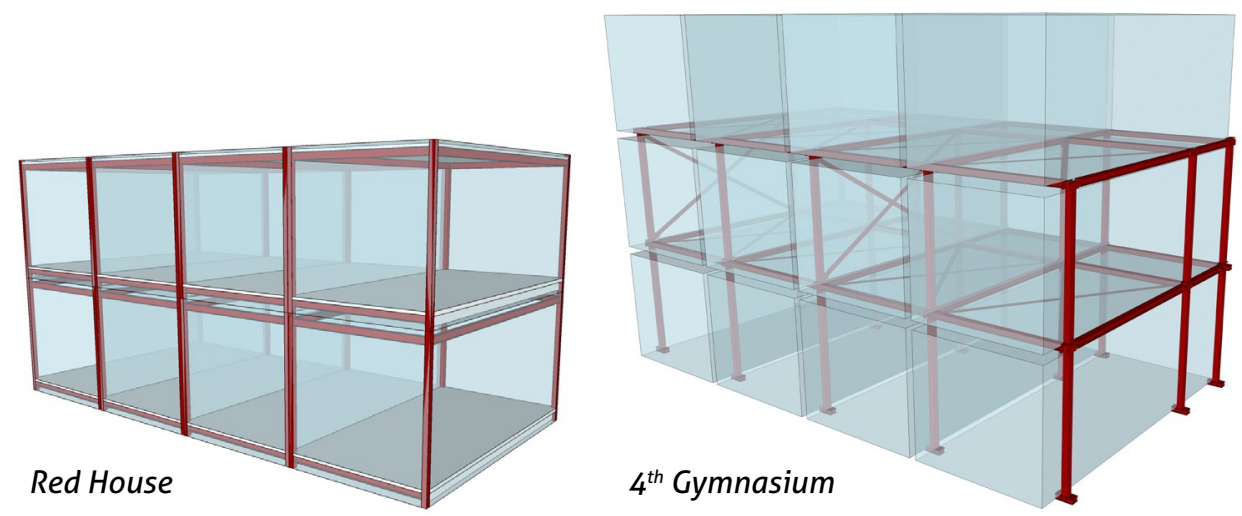

Figure 6.64: Schematic representation of the main structural systems, Red house (left), 4th Gymnasium (right). 


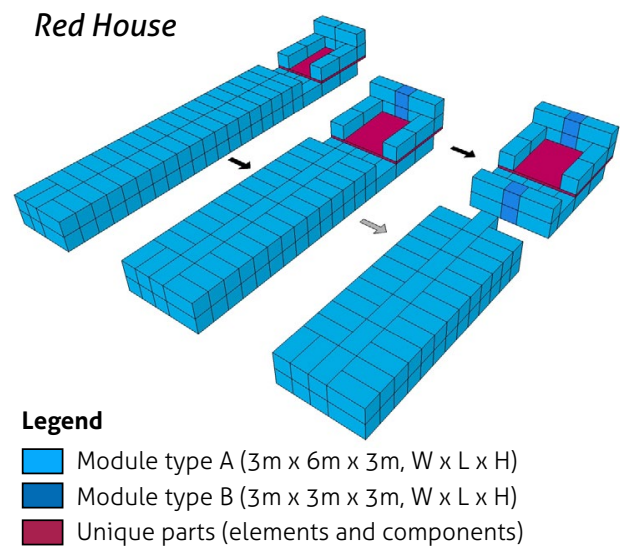

$4^{\text {th }}$ Gymnasium

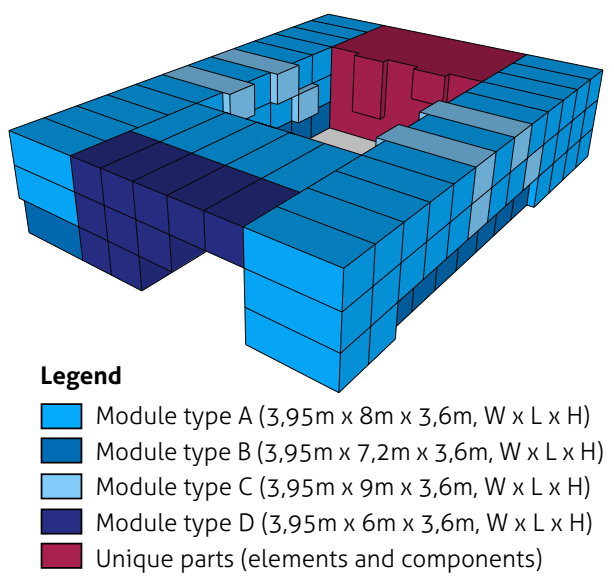

Figure 6.65: Schematic representation of Red House and 4th Gymnasium and the unit deviation within the design Generality of the volumetric modular construction system

The Red House building was designed with a common volumetric modular construction system as departure point, which resulted in a design that maximises the use of the volumetric modular construction system and reduces the deviation from the volumetric modular construction system, with only a few exceptions, as shown in Figure 6.65. The generic module of $3 \times 6 \times 3 \mathrm{~m}$ enabled multiple configurations and functionalities. While $4^{\text {th }}$ Gymnasium was designed as an iconic tailor-made temporary educational facility to attract students to an open undefined area, which utilises an unconventional volumetric modular construction system. The unconventional volumetric modular construction system is based on a standard dimension of $3,95 \times 8 \times 3,6 \mathrm{~m}$, which has three exceptions to the standard module dimension, and one larger open area that is constructed without the use of modules, all to support the iconic design. The multitude of exceptions result in a complex and project specific structure, which limits its range of configurations and future uses.

Type of interior finishing

The Red House building's interior walls were limited and the interior finishing was reduced to a raw space, leaving the roof structure and installation pipes and cable gutters visible. Furthermore, the used finishings were connected using reversible connections. This resulted in an easily legible building structure that supports disassembly and allows for easy modification to new configurations and functionalities. Furthermore, after the second generation, when additional installations and infill elements were added, the building was disassembled and relocated for reuse. In the $4^{\text {th }}$ Gymnasium it was chosen to strive for a high quality building to support attractiveness to new students. This translated itself in the application of a traditional installation systems, metal-stud partitioning walls, which are finished with plaster and paint, all without taking into consideration disassembly at end of first use, which makes it impossible to disassemble the building without damaging many of the interior finishing parts. This limited the good intentions and les to the decision to demolish the building and make as much parts as possible 
available for element reuse. Only few easily accessible parts have been reused, such as: internal door-frames and doors, entrance doors, door closers, escape route signs, lighting, bicycle racks, outdoor benches, interior furnishing, acoustic ceiling panels, TL-lamps, facade panels and the recycling of most other parts.

Strong design concept

The strong design concept of Red House was identified as a facilitator that together with the ease of disassembly supported the reuse of the building. While, the iconic design of the 4th Gymnasium did not support the identification of new users and its difficulty to disassemble the building resulted in the eventual demolition of the building after a use period of eight years.

\section{Impact of "additional processes"}

Documentation of building's composition

The composition of the Red House building was easily legible and utilises a conventional volumetric modular construction, which supported disassembly and reuse. Furthermore, ability to the relocate the Red House building was not limited to the knowledge of the original contractor, since the relocation to the $3^{\text {rd }}$ generation use was performed by a different contractor. While due to the lack of proper documentation, bankruptcy of the original contractor and the unconventional volumetric modular construction method, the relocation of $4^{\text {th }}$ Gymnasium was dependent on contractors foreign to the construction system, which resulted in uncertainty about the disassembly procedure and conservative estimations about the costs and time required to relocate the building, rendering relocation infeasible.

Unique tools and provisions required for disassembly

The 4th Gymnasium utilises an unconventional volumetric modular construction with unique dimensioning and composition. For the modules to be relocated, provisions would have been required to increase rigidity and enable safe transportation and movement by crane. As was stated in the interview, these additional provisions would increase costs and the unique dimensions and composition would require the development of tools specifically for this project, because tools used for conventional volumetric modular construction systems would not be suitable. While the dimensioning and composition of the modules used in Red House are easy to disassemble with the tools available and do not require additional provisions to maintain rigidity during disassembly.

Quick relocation in original configuration to enable outside storage

The ability to easily store a building outside on an empty plot in more or less its original configuration, or a compact configuration, without the need of a conditioned environment to preserve the quality of the reclaimed products, was a major benefit for the Red House case and reduced storage costs significantly.

Ownership

In the Red House case, the ownership of the easily relocatable building by an investor/ project developer proved to be a successful combination, because the awareness of the 
investor about the demand for buildings on the market enabled him to identify new locations when the building became available. While, in the $4^{\text {th }}$ Gymnasium case, the ownership of the building by municipality of Amsterdam, who seemed to be in a similar position as the property developer, did not result in the identification of a new user and location for the $4^{\text {th }}$ Gymnasium. The combination of ownership of an easily relocatable building and a project developer or municipality that has insight in the demand for buildings on the market, can support successful reuse, but does not guarantee success.

\section{Impact of "avoided processes"}

Cost reduction due to reuse

In the interview with the architect of Red House, it was stated that the cost reductions that could be achieved by utilising used building products in the second and third generation made it financially feasible, otherwise it might have never been possible for those clients. Furthermore, it was stated that the concept to design a building that could easily be disassembled and relocated convinced investors to finance this project and enabled the realisation of the first generation. Thus for the second and third generation building the avoided processes and costs made their use feasible. The same concept, a building that could be relocated after its first use, convinced the municipality of Amsterdam to invest in the $4^{\text {th }}$ Gymnasium building. Although at the end of its use period of eight years, the actual relocation was in practice much more difficult than it was alleged to be and resulted in no avoided costs, but became an expensive experience.

\section{Impact of external influences}

Available time to enable proper disassembly

For the Red House case there was enough time available to support proper disassembly and reuse. While, for the $4^{\text {th }}$ Gymnasium building, there was a strictly defined date at which the site on which the building was located had to be delivered empty to a developer. This resulted in a short timespan of three months, which was considered not enough to perform all disassembly tasks. The time pressure can be identified as an external factor that constrains reuse and supported in the decision to demolish and make as much parts as possible available for reuse.

\section{Changing regulations}

The initial construction of Red House was finished in December 2000 and in conforming to the regulations of that time. While the regulation regarding thermal insulation was increased over the use period, this did not limit the reuse of Red House, because it is a temporary building it has to be built according to the regulations of temporary buildings, which less strict compared to permanent buildings. If the building would have been reused for permanent use, the thermal values of the envelope would have been required to be updated to contemporary regulations and would thus increase the impact of "additional processes" required to enable reuse. Although, during the interview with the contractor it was mentioned that in order to support reuse of reclaimed volumetric modules: parts are often replaced or upgraded to suit new user demands or changing regulations. 


\subsection{Reuse potential evaluation - Red House}

In this section the Red House case will be used as an example to demonstrate the reuse potential evaluation method. This section starts with the Reuse Potential Evaluation method in section 6.6.1, which is structured following the steps of the reuse potential evaluation method. Followed by a thorough analysis of the results of the reuse potential evaluation method in section 6.6.2.

\subsubsection{Reuse potential evaluation method - Red House case}

In this section the general steps of the reuse potential evaluation method are described and demonstrated with the Red House case.

\section{Step 1: Preparation input data}

In this step all information that is required for the Reuse Potential evaluation method to perform a reuse potential analysis will be acquired.

\section{Step 1a - Identification of representative building section(s)}

For the Red House case, the first generation building is used to demonstrate the reuse potential evaluation method. The first generation building was selected, because this was the first design represents the building in its purest form, which was specifically designed to enable easy disassembly and reuse and should reflect the realised ambitions the best. The corner unit is selected as representative section of the building. This part does not only contain the commonly used volumetric modular construction, but also allows both types of facade system to be included in the reuse potential analysis. The representative section is indicated in Figure 6.66 with the red area.

\section{Step $1 \mathbf{b}$ - Identification of all building parts and functions}

In this step all building parts and functions are identified and given a unique identification number, using the code numbers that specify the main building function and building sub-function, to enable each part to be identified when used as input in the reuse potential evaluation method, as shown in Figure 6.67 and Figure 6.68. To gain a thorough
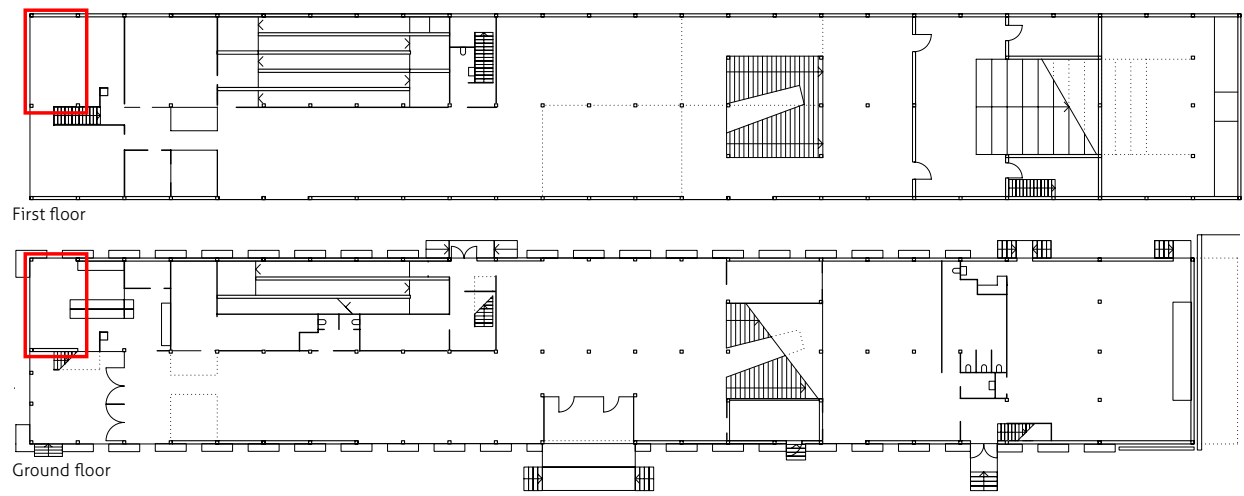

Figure 6.66: Floor plans of Villa Zebra - Red House case (Detail, 2002), representative section is indicated in red. 


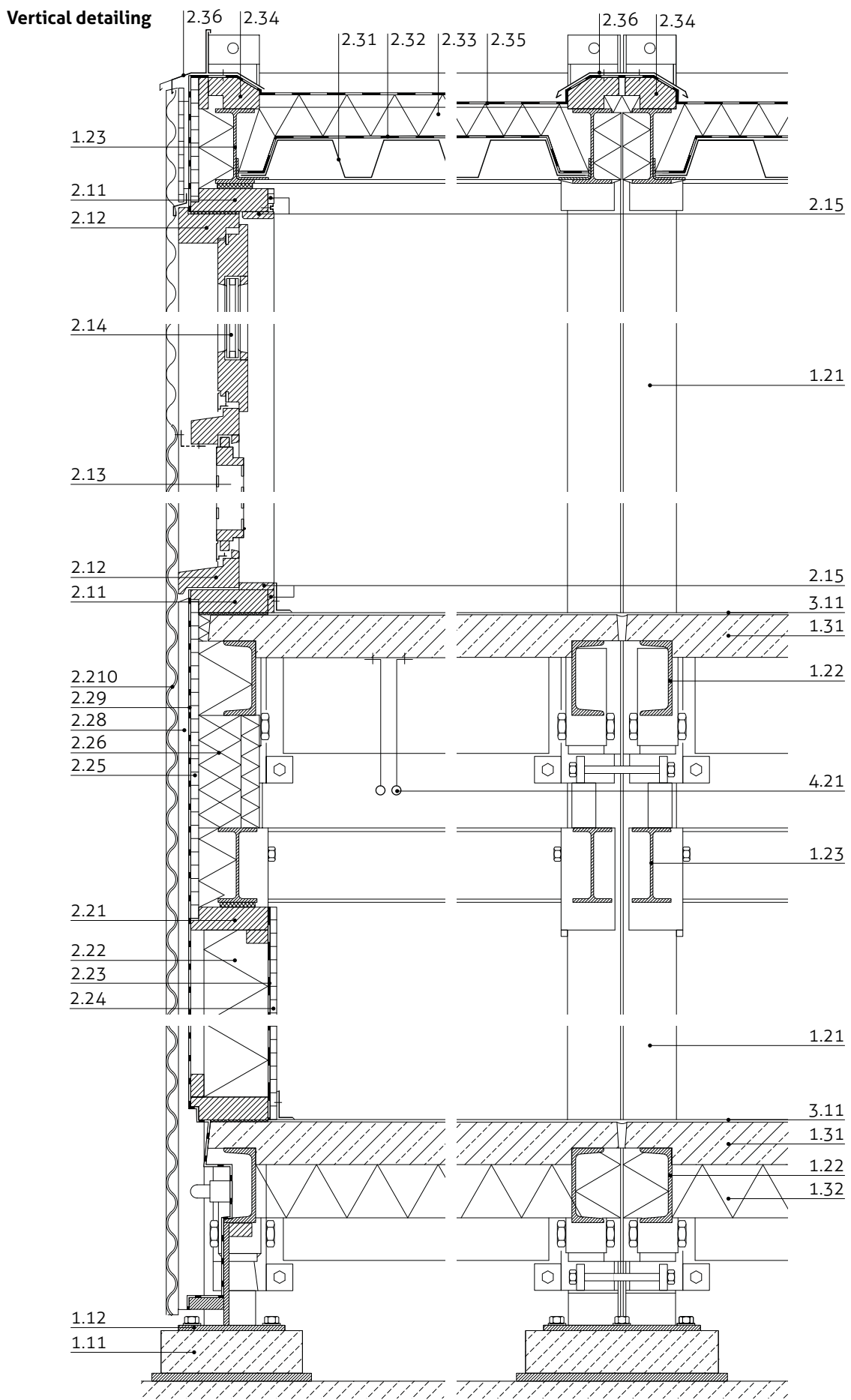

Figure 6.67: Horizontal detailing of Villa Zebra-Red House case (Detail, 2002), including part number identification. 


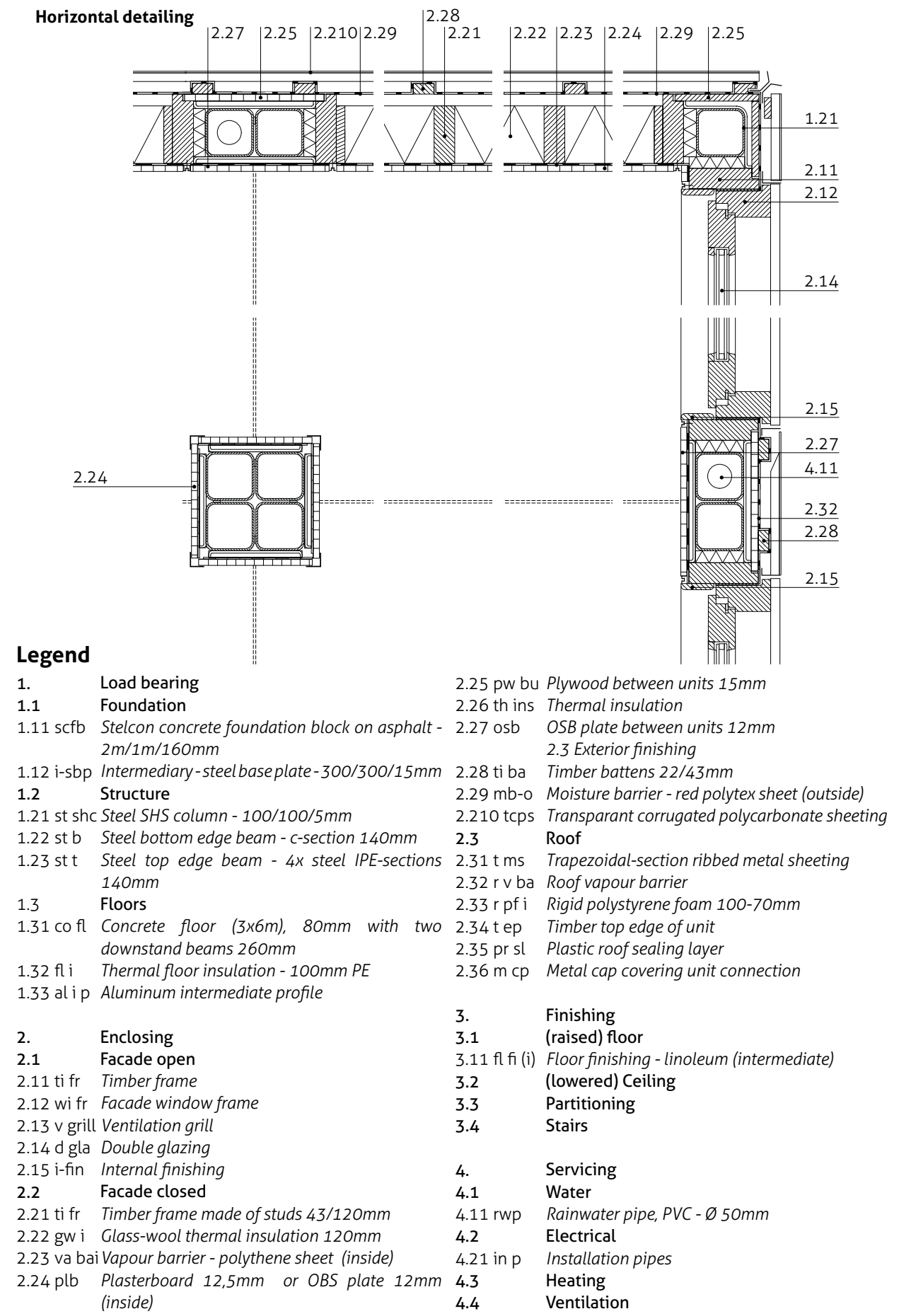

Figure 6.68: Vertical detailing of Villa Zebra - Red House case (Detail, 2002), including part number identification and a legend of all identified parts and functions of its parts 


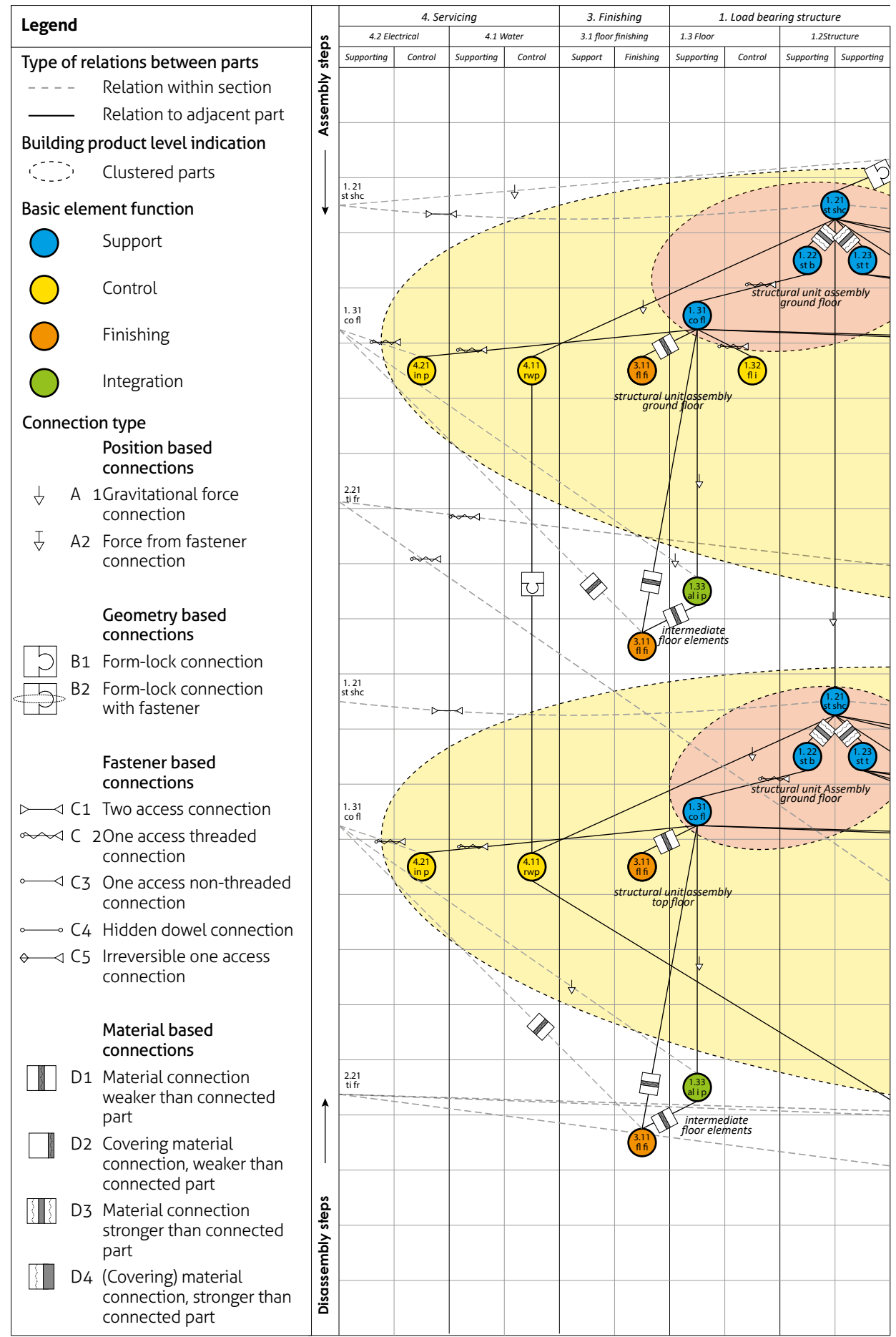

Figure 6.69: Relational pattern Villa Zebra-Red House case, part a. 


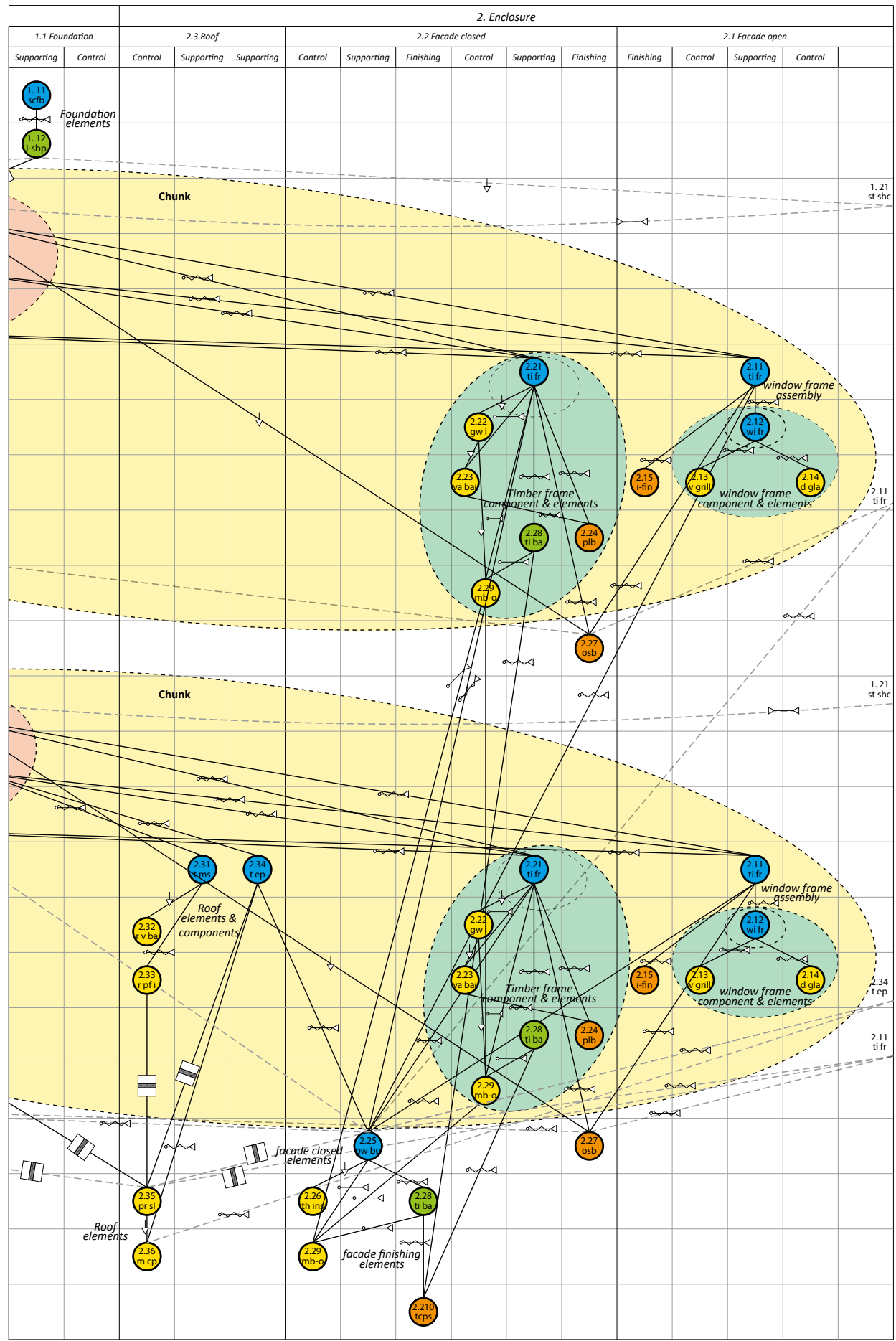

Figure 6.70: Relational pattern Villa Zebra - Red House case, part b. 


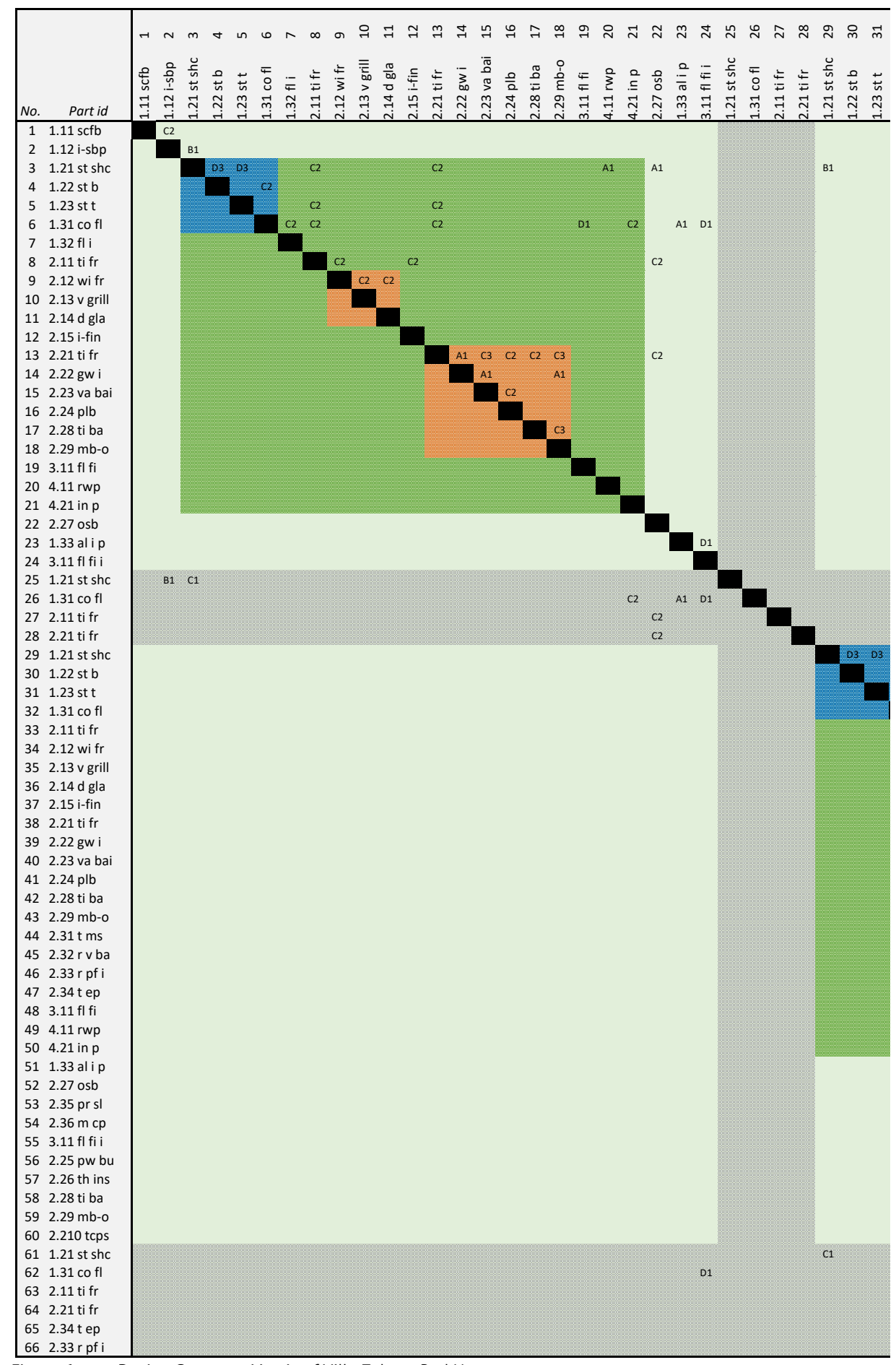

Figure 6.71: Design Structure Matrix of Villa Zebra - Red House case, part a 


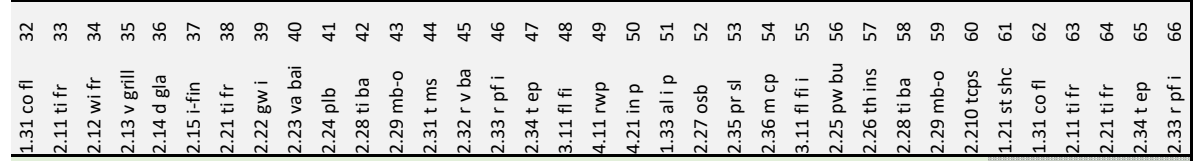

$\mathrm{C} 2$

$\mathrm{C} 2$

C3

C3

B1

$\mathrm{C} 2$
$\mathrm{C} 2$

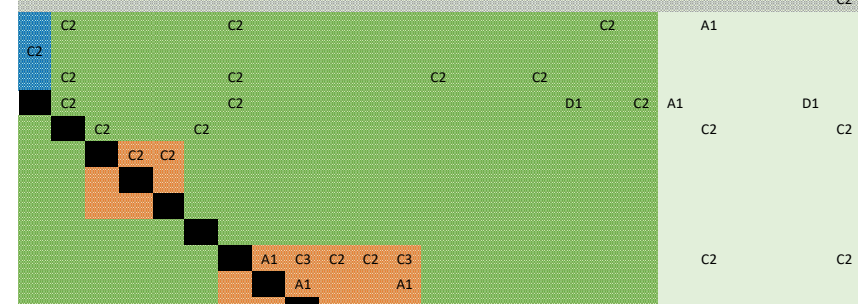

Figure 6.72: Design Structure Matrix of Villa Zebra - Red House case, part b 

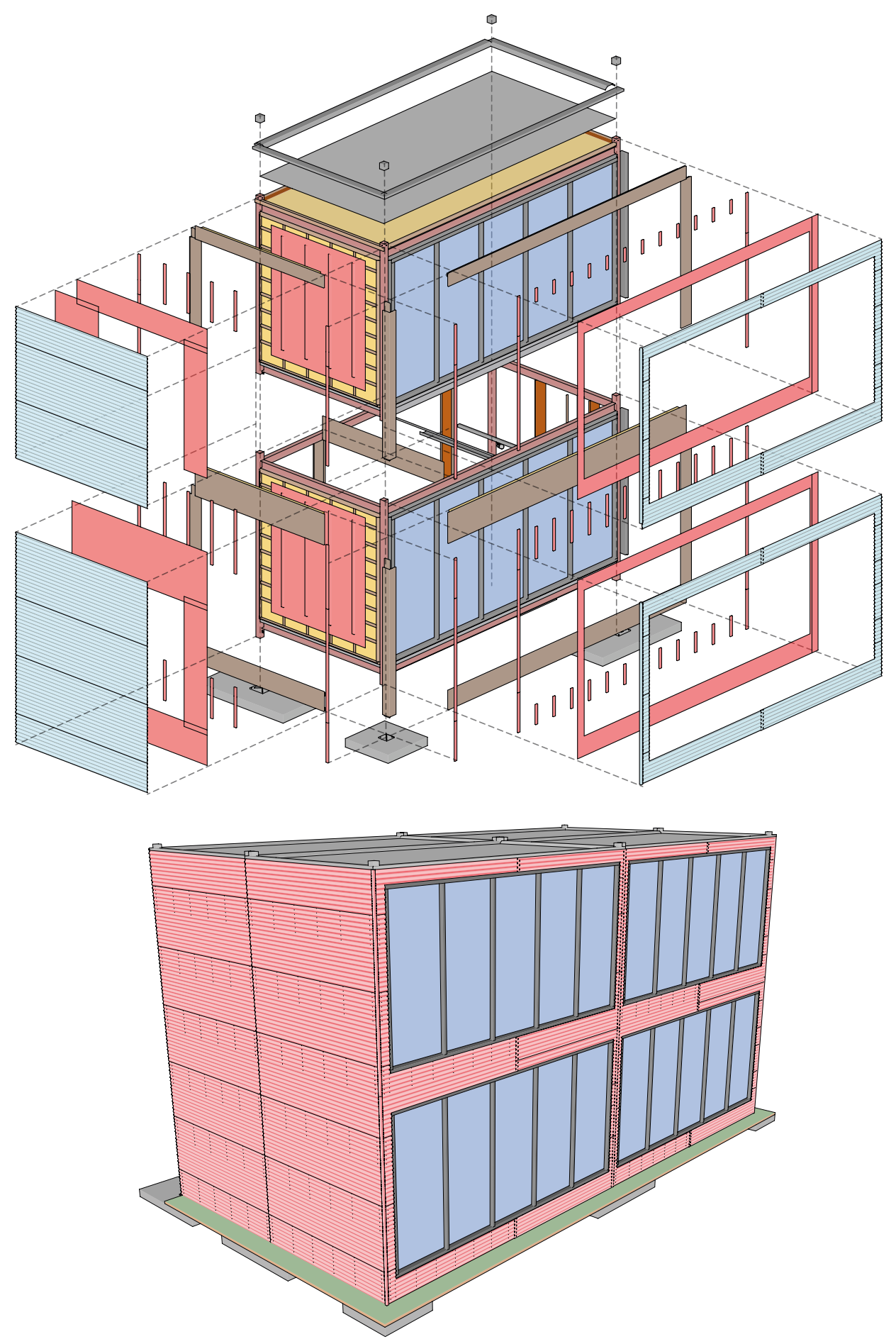

Figure 6.73: Exploded and non-exploded view of Villa Zebra - Red House case 
understanding, of the Red House case, an exploded and non-exploded view of all parts is shown in Figure 6.73.

\section{Step 1c - Development of relational pattern}

In this step the relational pattern of the Red House case is developed, based on the technical detailing, whereby all unique identified part numbers are used to create a conceptual representation of the technical composition of the building. The relational pattern will provide understanding of: the technical composition, the interconnectedness of all parts, the type of relations between the parts, the assembly and disassembly sequences and the containing building product levels in the building by the clustered parts (Figure 6.69 and Figure 6.70).

\section{Step 1d - Translate relational pattern into Design Structure Matrix (DSM)}

In this step, the relational pattern of the Red House case is translated into a relational pattern, whereby the relations between the parts are identified with the connection type numbers, as shown in Figure 6.71 and Figure 6.72.

\section{Step 1e - Part specification form}

In this step, all data required to fill in the part specification form will be acquired, to allow the following indicators to be filled in: level of prefabrication, basic product function, technical lifespan, embodied economic value, embodied cultural value, embodied material value, embodied energy value, robustness, and impact on operational energy.

\section{Step 2: Input Reuse Potential evaluation method}

In this step the reuse potential evaluation method will be filled in, the prepared data in step one will be used to fill in the 'part specification' and the 'Design Structure Matrix', which allows sixteen of the total twenty-one sub-criteria to be filled in automatically and five sub-criteria require additional manual input to perform the reuse potential evaluation.

\section{Step 2a - General information}

To be able to create a full report with all information, in one document, this step requires the input of generic building information, such as name, function, location, construction date, age of the building, owner, original contractor and design and engineering team. Furthermore, the floor plans with indication of the representative section, horizontal and vertical detailing with unique part identification and relational pattern are requested to be filled in and if available or required to understand to composition of the building, it is possible to add additional information.

\section{Step 2b - Part specification}

For the reuse potential evaluation method to be able to recognise all building parts that are present in the building, this step requires the input of all unique building parts including the following information: floor level indication, part identification code, level of prefabrication of the parts, adjacent or not adjacent parts, basic function, technical 
lifespan, embodied economic value, embodied cultural value, embodied material value, embodied energy value, robustness, and impact on operational energy.

\section{Step 2c - Design Structure Matrix input}

In this step, the Design Structure Matrix (DSM) will be filled in, which allows the reuse potential assessment to generate three types of DSM models, namely building level reuse, system level reuse and product level reuse DSM models. These models are required to identify the disassembly sequences and the connections that should be incorporated at each reuse level. In Figure 6.74 all three DSM models of the red house case are shown, whereby the chunks (green area), assemblies (orange area) and components (blue area) are shown in colored areas and adjacent elements and connections to adjacent elements in the grey area. The connections within the green, orange and blue area are not taken into account in the specified reuse level, since these parts can be reclaimed as one entity.

\section{Step 2d - Input of additional criteria data}

In this step, the criteria that require additional input data will be filled in, to enable a full reuse potential evaluation. The sub-criteria that require additional input data are: functional separation, type of installation system integration, accessibility to fixing, standardisation of product edge and geometry of product edge.

\section{Step 3: Reuse Potential evaluation method results}

In this step the reuse potential report can be generated and the results can be analysed. Depending of the aim of the reuse potential evaluation, the results can be used to identify reuse potential of the building and building products or to identify parts of the building that could be improved to increase the reuse potential of the building to the desired level.

\section{Step 3a - Check completeness}

In this step, the Reuse Potential evaluation method is entirely filled in and can be verified at the 'input specification table' that is automated to fill in a 'check' mark after each criteria that is filled in entirely and a 'cross' mark if not all required fields are filled in. When all boxes are filled with a 'check' mark, the Reuse Potential evaluation is finished and can be published to generate a report.

\section{Step 3b - Reuse Potential results}

In this step the Reuse Potential report is generated and the results can be analysed. To start in Figure 6.76 the reuse potential rating system is defined, according to which the client or designer can specify the reuse ambition of their building design or identify the building products that show potential to be reused.

In Figure 6.75, the system scores and building scores of the Red House case are summarised, depicting the sub-criteria scores, main indicator scores and the resulting reuse potential score at all three reuse levels: product reuse, system reuse and building reuse. These scores allows the designer or client to gain a full understanding of the reuse 
Building level reuse

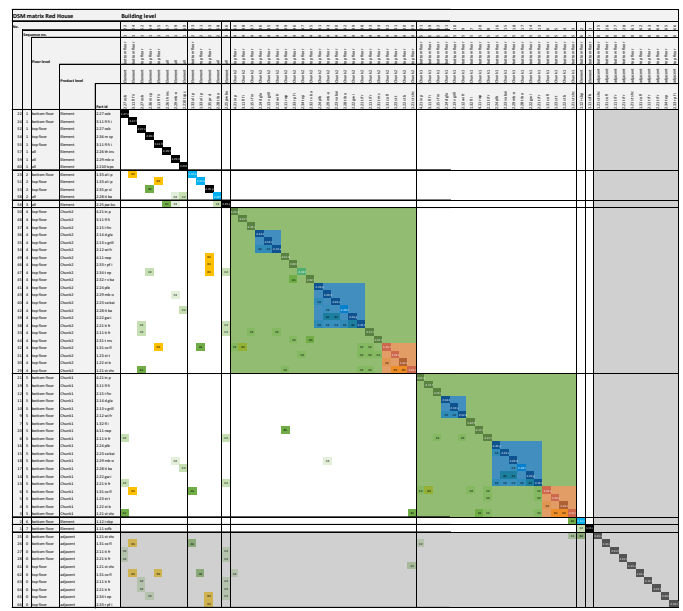

System level reuse

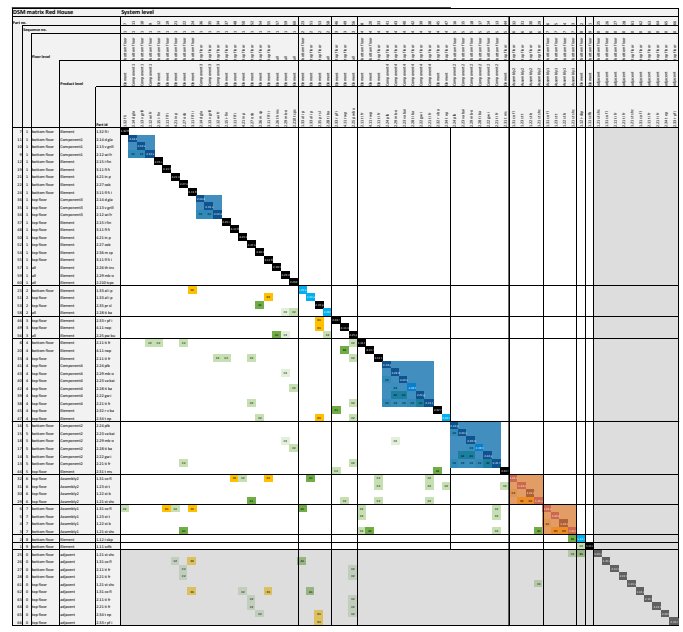

Product level reuse

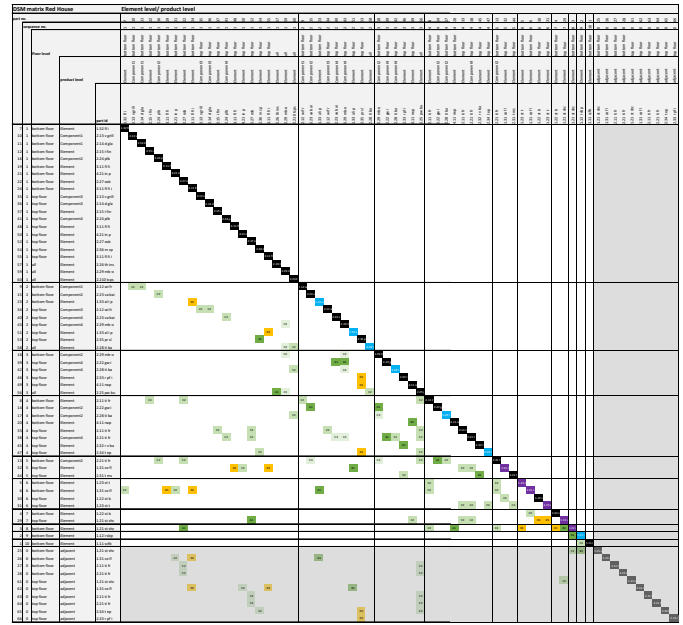

Figure 6.74: Generated Design structure Matrix of Villa Zebra-Red House case on all three reuse levels. 

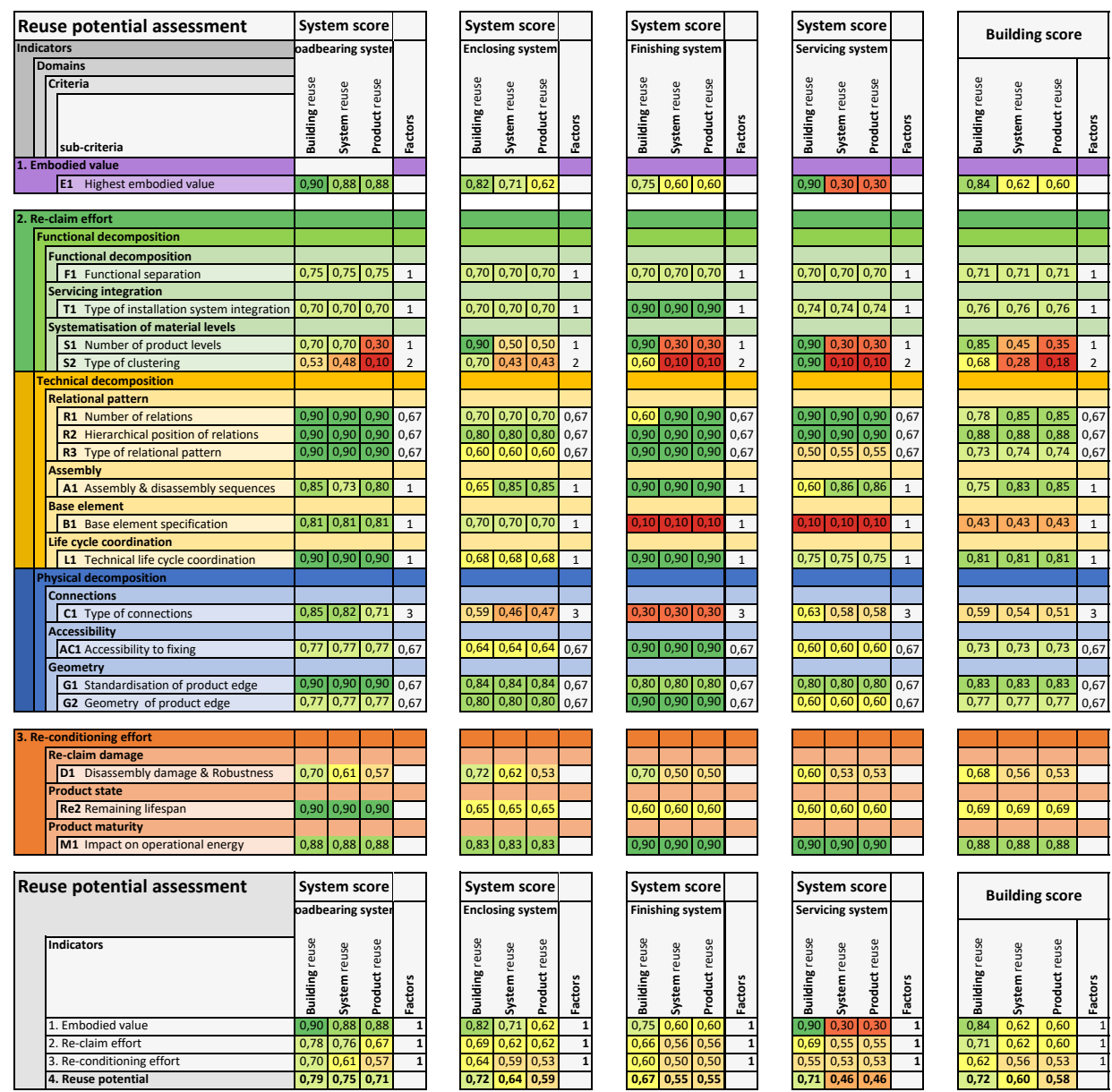

Figure 6.75: Overview of main building system and building Reuse Potential scores of Villa Zebra-Red House case

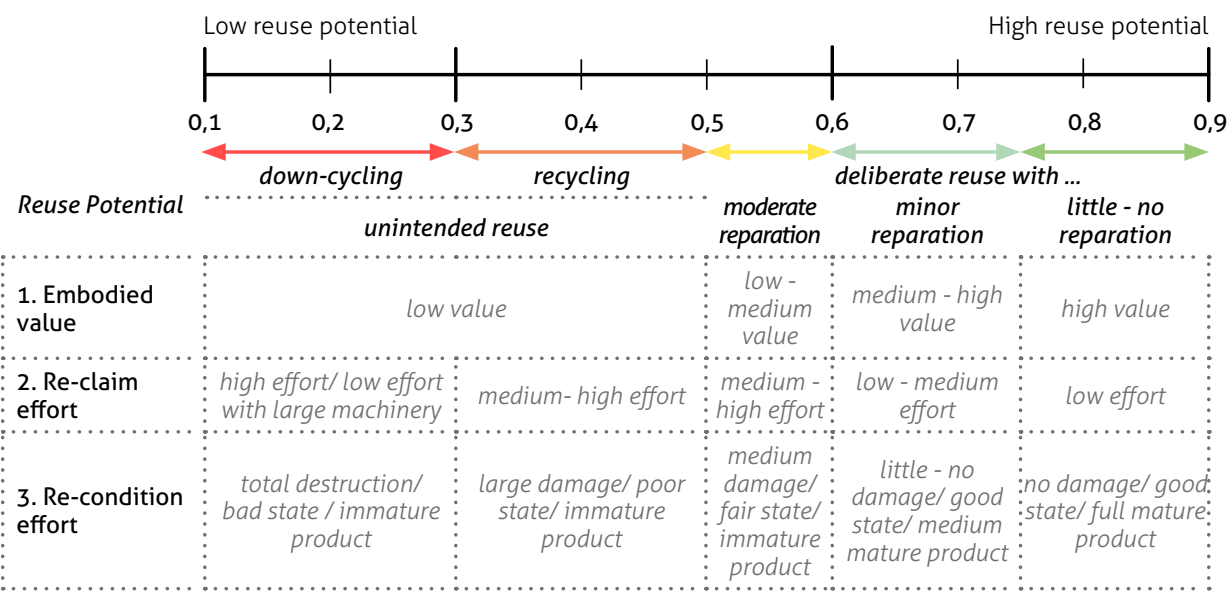

Figure 6.76: Reuse potential assessment rating system 


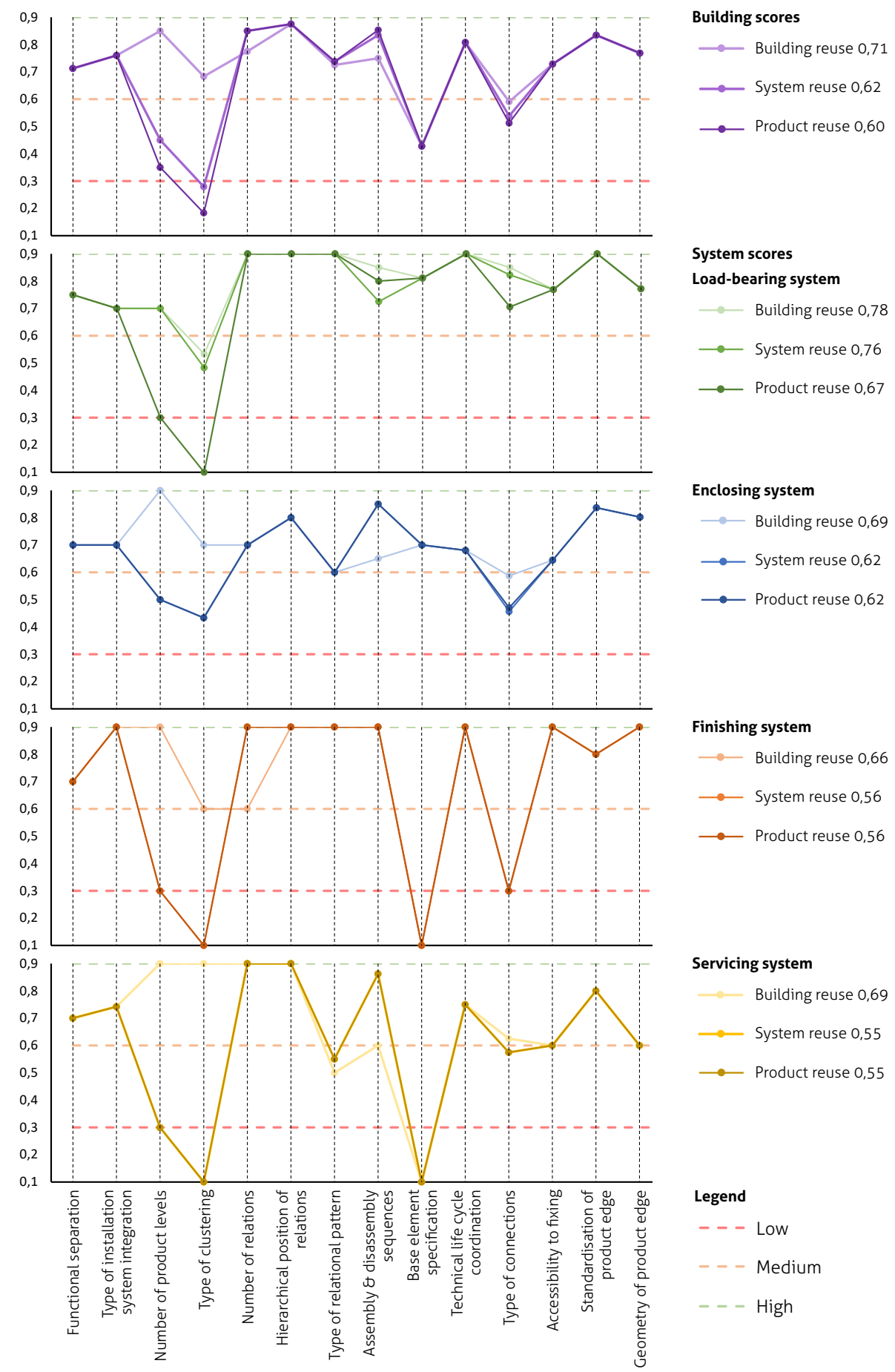

Figure 6.77: Line chart depicting the sub-criteria rating of the re-claim effort and re-conditioning effort of Villa Zebra - Red House case, for each main building system and the entire building, at three reuse levels. 

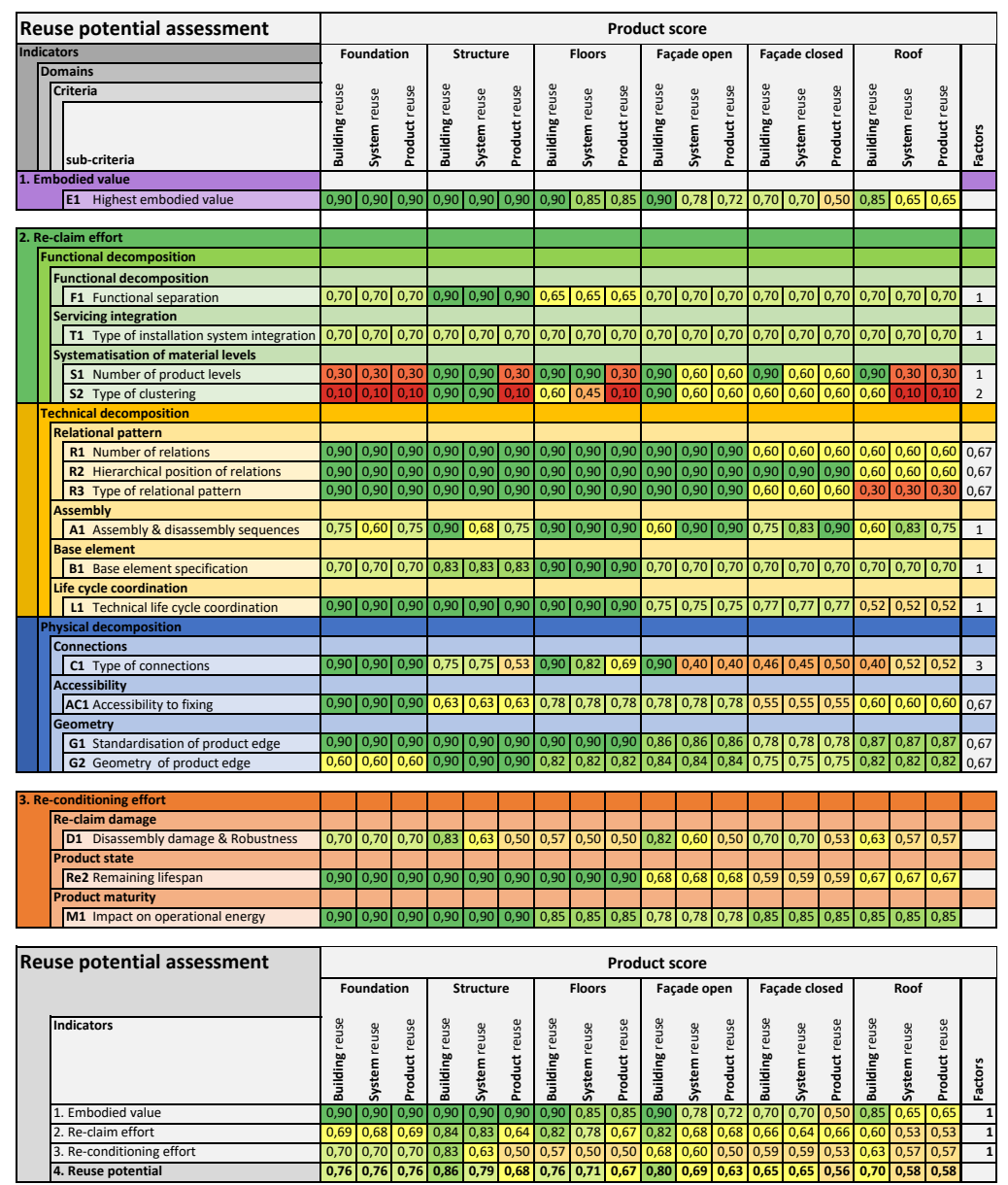

Figure 6.78: Overview of building sub-function Reuse Potential scores of Villa Zebra - Red House case, part a potential of the building and the main building functions. Furthermore, the scores can be used to identify the parts for reuse, but also identify if the reuse potential of the design complies with the reuse ambitions. If the design does not comply with the reuse ambitions, the overview can be used to identify the sub-criteria on which the building scores low and could be improved upon in the next design iteration. To improve clarity of the sub-criteria in Figure 6.77 line charts are shown, depicting the re-claim effort for each main building system and the entire building at all three levels. These charts allow the designer to identify the criteria that could be improved upon in the design stage to increase the reuse potential. It should be noted that the line charts only represent the sub-criteria can directly be influenced based on its design. Furthermore, in Figure 6.78 and Figure 6.79 scores are shown for each building sub-function, which increases the understanding of the specific parts that can be improved upon and the parts that already score high. 

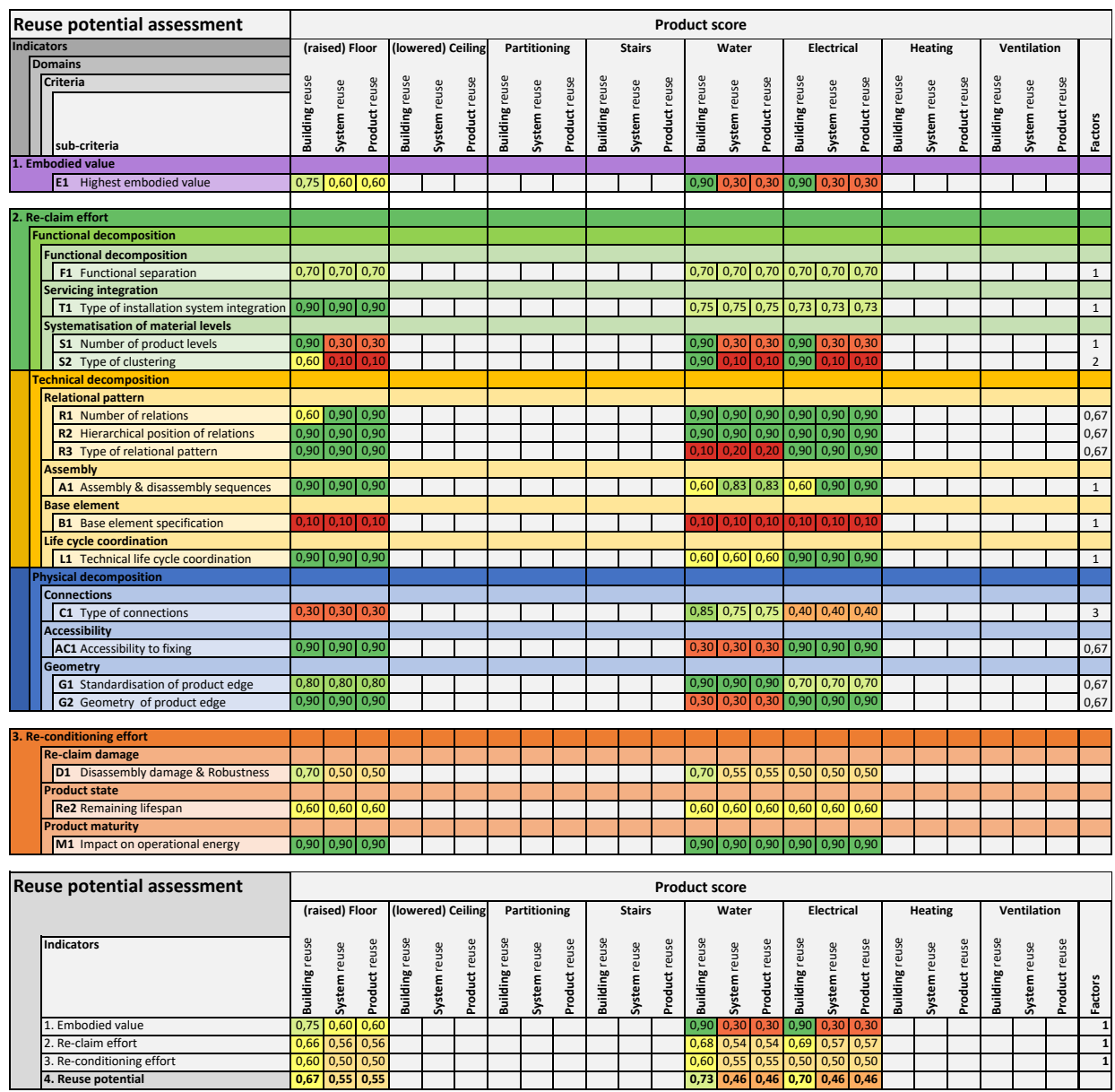

Figure 6.79: Overview of building sub-function Reuse Potential scores of Villa Zebra - Red House case, part $b$

Finally, to support full transparency regarding the results of the reuse potential evaluation method, the Reuse Potential report includes lists of the scores of each part for each sub-criteria at all three reuse levels.

\subsubsection{Reuse potential results - Red House case}

In this section, the reuse potential results of the Villa Zebra - Red House case will be analysed and discussed.

To start, it is important to understand the type of reuse that supported the successful reuse and relocation of the Red House case for three times. The reuse potential evaluation method assesses three types of reuse levels, building reuse, system reuse and product reuse. Building reuse, which is the reuse of the entire building by keeping the embodied values as high as possible, through the disassembly of the least amount of parts to allow relocation and reuse, is the type of reuse that supported the relocation and reuse of the Red House case. Therefore, the building level reuse scores are of main concern for this analysis. 
Although, it should be noted that when reviewing all three reuse scores, the building reuse scores are in multiple instances the highest scores. This is not a surprising result, since the building was specifically designed with the use of a volumetric modular unit construction system to support easy disassembly, relocation and reuse.

To analyse the different building level reuse scores, sequentially the following parts will be analysed and discussed: 1 . embodied value, 2. re-claim effort, 3. re-condition effort and 4. reuse potential.

\section{Embodied value}

The volumetric modular construction system is a construction method that results in the clustering of multiple elements, components and assemblies into chunks that can be assembled and disassembled as one entity. In this way low-, medium- and high value parts form a larger entity, which allows building sub-functions that would at product reuse level have a low embodied value, become part of an entity representing a high embodied value. This phenomenon can be seen in the servicing system, which has at product reuse and system reuse a value of 0,3 , but at building reuse a value of 0,9 , because at building level the parts become part of a larger entity of parts that have a higher value, increasing the reuse potential at building reuse level. The enclosing system and finishing did not receive the highest embodied value score, because several low to medium value enclosing- and finishing system parts need to be disassembled before the high value chunks can be reclaimed. Finally, the average building reuse value of the entire building is 0,84 . This high embodied value score would allow for a lower re-claim score effort and re-conditioning effort score, before the building will be rated as unsuitable for deliberate reuse.

\section{Re-claim effort}

The reclaim effort is composed of three domains, which will sequentially be analysed and discussed. The functional decomposition at building reuse level is relatively good, which means that most functions are properly separated and decent clustering has been applied. Although, at system- and product reuse level there exists a lack of clustering at almost all building sub-functions, this does not influence building level reuse. While at the low system- and product reuse level score would mean that modification and reuse of one main building function or building sub-functions will require most parts to be reclaimed individually as elements, which increases the re-claim effort significantly.

The technical decomposition at building reuse level is also relatively good, the main area that could be improved upon are the base elements for the finishing and servicing systems, which are currently lacking in base elements. Furthermore, the sub-building function roof can be described as being integrated in such a way that it forms a closed relational pattern. This means that the roof consists of individual elements that are not directly connected to base elements or intermediaries, which increases re-claim effort.

The physical decomposition at building reuse level are compared to the technicaland functional decomposition the lowest scores. This is mainly a result of the type of 


\begin{tabular}{|c|c|c|c|c|c|c|c|c|c|c|c|c|}
\hline \multicolumn{11}{|c|}{ (Dis)assembly sequences } & Total & \multirow{2}{*}{$\begin{array}{c}\text { Percentage } \\
70 \% \\
\end{array}$} \\
\hline Building level reuse & 1 & 2 & 3 & 4 & 5 & 6 & 7 & & & & 7 & \\
\hline System level reuse & 1 & 2 & 3 & 4 & 5 & 6 & 7 & 8 & 9 & & 9 & $90 \%$ \\
\hline Product level reuse & 1 & 2 & 3 & 4 & 5 & 6 & 7 & 8 & 9 & 10 & 10 & $100 \%$ \\
\hline \multicolumn{13}{|l|}{ Parallel assemblies } \\
\hline Building level reuse & 8 & 4 & 1 & 1 & 1 & 1 & 1 & & & & 17 & $30 \%$ \\
\hline System level reuse & 17 & 4 & 3 & 6 & 2 & 1 & 1 & 1 & 1 & & 36 & $64 \%$ \\
\hline Product level reuse & 21 & 9 & 6 & 8 & 3 & 4 & 2 & 1 & 1 & 1 & 56 & $100 \%$ \\
\hline \multicolumn{13}{|c|}{ Number of connections } \\
\hline Building level reuse & 28 & 10 & 10 & 5 & 3 & 2 & 0 & & & & 58 & $51 \%$ \\
\hline System level reuse & 39 & 10 & 14 & 13 & 4 & 2 & 2 & 2 & 0 & & 86 & $75 \%$ \\
\hline Product level reuse & 45 & 20 & 19 & 14 & 5 & 4 & 3 & 2 & 2 & 0 & 114 & $100 \%$ \\
\hline
\end{tabular}

Table 6.41: Comparison between the amount of: (dis)assembly sequence, parallel assemblies and connections for each disassembly level of the Red House case.

connections used for the (raised) floor, facade closed and roof sub-functions, which also results in an increased reclamation effort. Changing the used connection for these sub-functions to reversible connections would improve the re-claim effort significantly.

While in general, the re-claim effort is relatively good, which can mainly be attributed to the volumetric modular construction system. The selected construction system has resulted in a significant reduction in the number of disassembly sequences, parallel assemblies per sequence and number of connections between functional layers that are required to be disassembled for relocation of the building, as shown in Table 6.41, which combined with the hierarchical composition of the structure and the utilised reversible connection types, resulted in an average re-claim effort building reuse, building score of 0,71.

\section{Re-conditioning effort}

The re-conditioning effort per sub-function is determined by the lowest score of the following three sub-criteria: 1) re-claim damage, which is based upon the disassembly damage $\&$ robustness of the building products; 2 ) product state, which is based upon the remaining technical lifespan, and; 3) product maturity, which is determined by the age and type of impact on the operational energy of the building. The lowest score is indicative for the amount of effort that is required to enable reuse. While the main building system scores are determined based on the average of the sub-function scores and the building score based on the average of the four main building system scores.

Since the majority of the building parts are robust parts connected by reversible connections, the re-claim damage is limited. Furthermore, the majority of the parts have a long remaining technical lifespan, which translates into the parts being in a relatively good product state and due to the short use period of merely eight years and most parts not impacting the operational energy usage of the building, the majority of the building products can be identified as mature products. This resulted in an average re-conditioning effort for building reuse of 0,62 . 


\section{Reuse potential}

Finally, the building reuse, building reuse potential score is 0,72 , which indicates that the building is suitable for deliberate reuse with minor repair. This value seems to reflect reality, because after the first generation, several parts have been replaced and added to support the second generation use. Whereby the added parts were mainly required to support its new function and should therefore be left out of the discussion. The minor reparation effort corresponds to the items that required replacement to enable the reuse after its first use generation, which are: the roof sealing layer, floor finishing between the units, red polytex sheets and the facade finishing. The red polytex sheets and facade finishing were deliberately selected based on their technical lifespan, to match its first generation functional lifespan. This can also be identified in the reuse potential evaluation method by identifying the specific parts and their remaining technical lifespan. The roof sealing layer and floor finishing between the units require replacement due to their used connections.

If the building would have been in the design stage and the designer would aim for an even higher reuse potential score at building reuse level, the following aspects could be improved upon: 1) the functional separation of the floor is not well defined, it integrates two building sub-functions; 2) the foundation is composed of elements without any clustering, and the clustering of the floors, facade closed, roof and (raised) floor could also be improved upon; 3 ) the roof structure, facade closed and water installation sub-functions shows signs of becoming a closed relational pattern instead of an open hierarchical relational pattern, which should be avoided. 4) the types of connections used in the facade closed, roof, (raised) floor and electrical installations contain irreversible connection types and can be improved upon; 5) the accessibility and geometry of the water installation is difficult, which makes the effort to replacement and reuse those parts difficult.

Although, in order to improve the reuse potential at system- and product reuse level there are multiple sub-criteria that could be improved upon, as shown in Figure 6.75, Figure 6.78, Figure 6.79. System- and product reuse level scores are especially important if someone would like to replace or upgrade one of the main building functions or building sub-functions and identify the reuse potential of the the re-claimed parts. 


\subsection{Reuse potential evaluation - $4^{\text {th }}$ Gymnasium}

In this section the $4^{\text {th }}$ Gymnasium case will be used as an example to demonstrate the reuse potential evaluation method. This section starts with the Reuse Potential evaluation method in section 6.7.1, which is structured following the steps of the reuse potential evaluation method. Followed by a thorough analysis of the results of the reuse potential evaluation method in section 6.6.2.

\subsubsection{Reuse potential evaluation method $-4^{\text {th }}$ Gymnasium case}

In this section the general steps of the reuse potential evaluation method are described and demonstrated with the $4^{\text {th }}$ Gymnasium case.

\section{Step 1: Preparation input data}

In this step all information that is required for the Reuse Potential evaluation method to perform a reuse potential analysis will be acquired.

\section{Step 1a - Identification of representative building section(s)}

For the $4^{\text {th }}$ Gymnasium case, the second module in the corner is selected as representative building section, as shown in Figure 6.80. Since, $88 \%$ (86/98 modules) of the used modules in the building have adjacent modules and only $12 \%$ (12/98 modules) of the modules have an adjacent facade on the longest side. The adjacent facade is not part of the module but connected independently. Therefore, in this case the corner module is not selected as representative section. In contrast to the Red House case, where the corner module was selected, because the facade solution is connected using a similar method as used on the front side and allows the incorporation of open and closed facade building function.

\section{Step $1 \mathbf{b}$ - Identification of all building parts and functions}

In this step all building parts and functions are identified and given a unique identification number, using the code numbers that specify the main building function and building sub-function, to enable each part to be identified when used as input in the reuse potential evaluation method, as shown in Figure 6.81 and Figure 6.82.
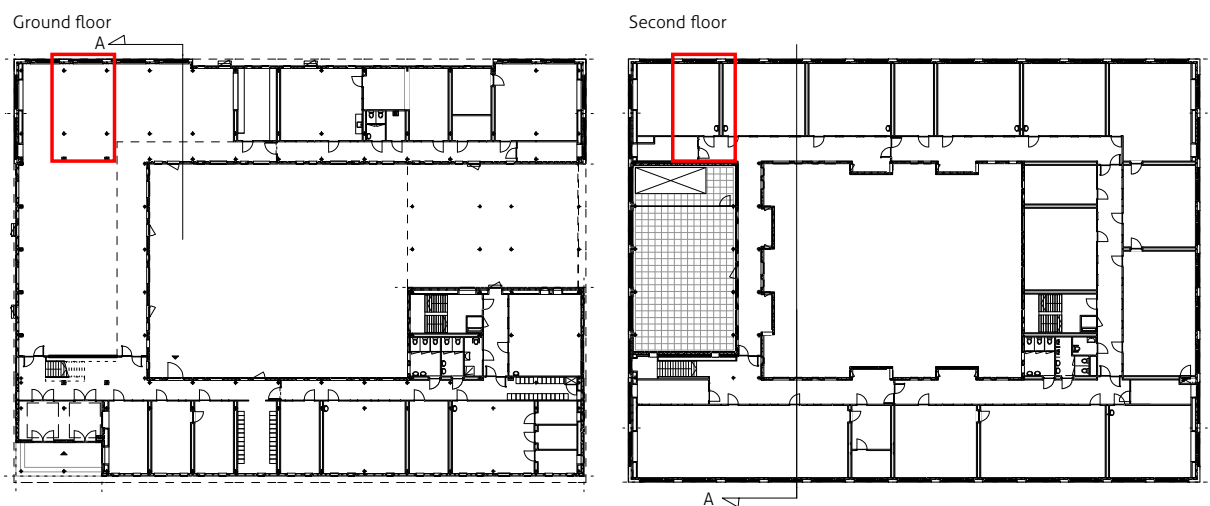

Figure 6.80: Floor plans of $4^{\text {th }}$ Gymnasium (Lebesque, 2018), representative section is indicated in red. 


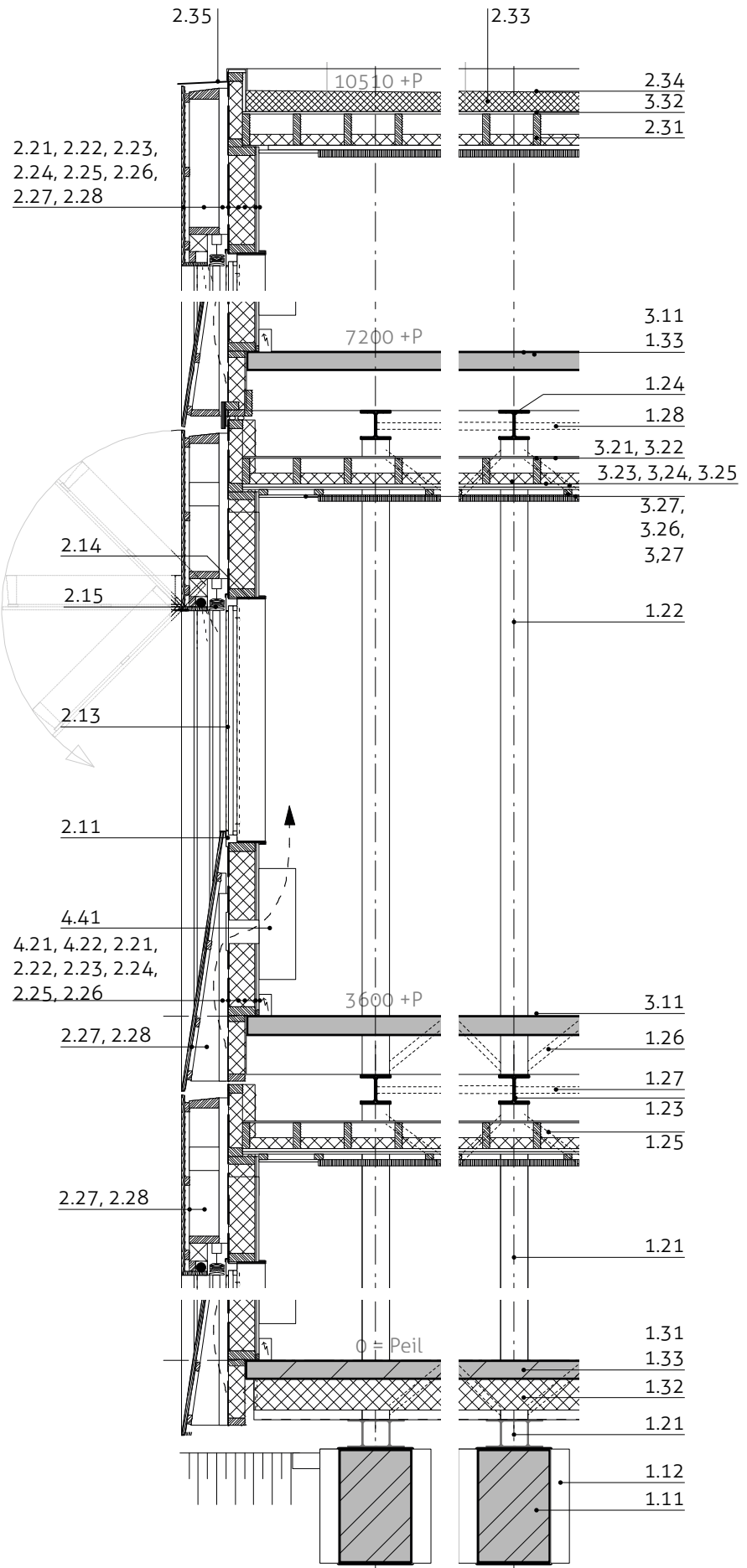

Figure 6.81: Horizontal detailing of the $4^{\text {th }}$ Gymnasium case (Lebesque, 2018), including part number identification. 


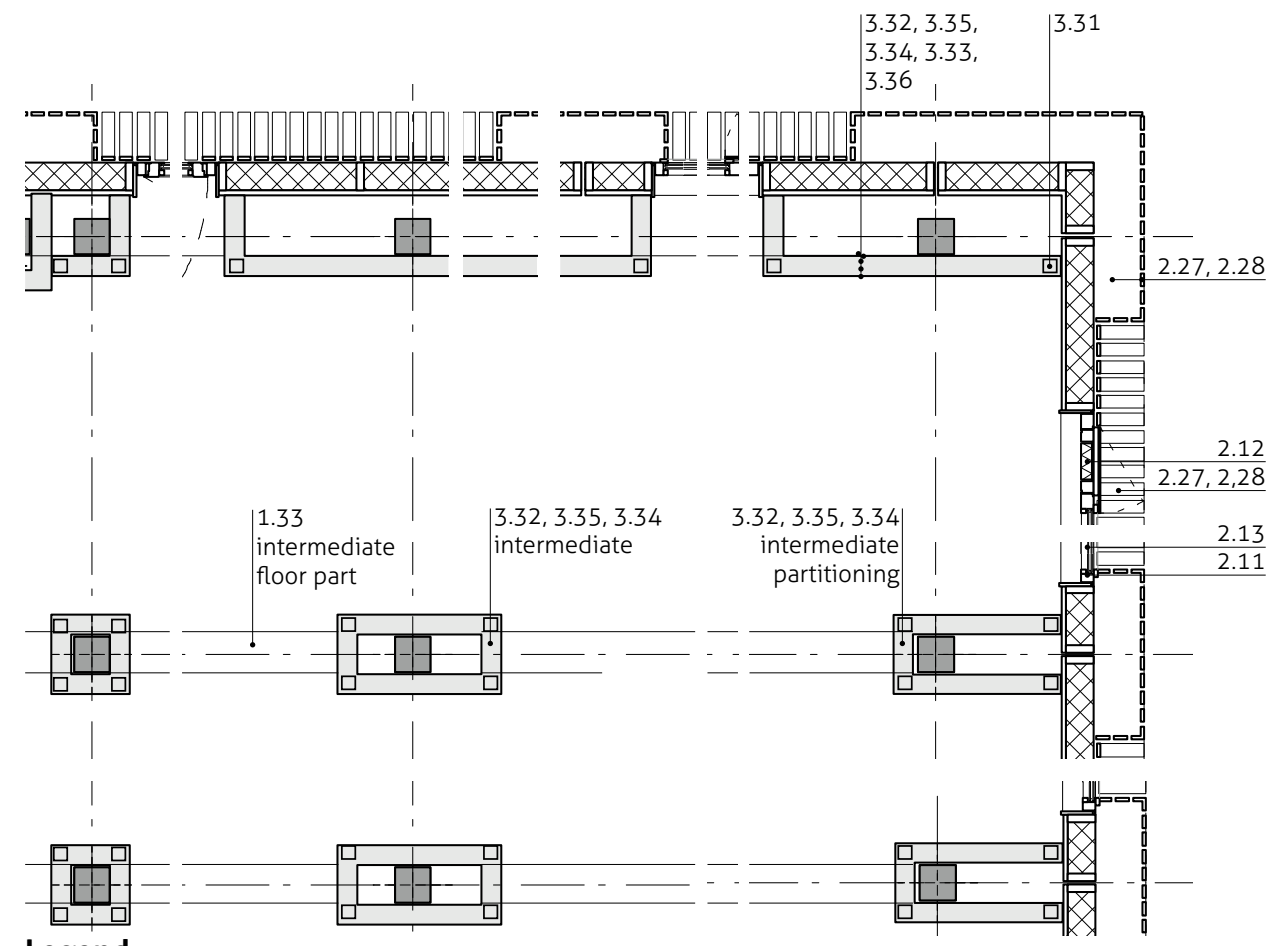

\section{Legend}

$1.1 \quad$ Foundation

2. Enclosing

2.1 Facade open

$1.11 \mathrm{cfd}$ Concrete in-situ foundation on 2.11 wi fr Aluminum window frame concrete pillars 300/600 $\mathrm{mm}$

2.12 op wp Openable window panel

2.13 fi gla Fixed glazing

2.14 i-fin Internal finishing

1.2 Structure

$2.15 \mathrm{sl}$ scr Slat screen

Facade closed

2.21 plb Plasterboard $2 \times 12,5 \mathrm{~mm}$ (inside) 3.25 gy pl Gypsum plate $15 \mathrm{~mm} 2 x$ unit, filled with concrete, ground 2.2

2.22 va bai

1.22 sc 1 Stee floor $160 / 160 / 5 \mathrm{~mm}$ concrete, first floor 160/160/5mm

$1.23 \mathrm{~s} \mathrm{b1}$ Steel beam first floor HEA160

$1.24 \mathrm{~s}$ b2 Steel beam second floor HEA160 (inside)

$2.23 \mathrm{tifr}$

Timber 43/120mm

1.25 scbvo Steel cross bracing vertical, ground $2.24 \mathrm{gw} \mathrm{i}$ floor

Glass-woomm

1.26 scbv1Steel cross bracing vertical, first $2.25 \mathrm{mb}$-oMoisture barrier-polytex sheet floor

2.26 ti ba Timber battens $22 / 43 \mathrm{~mm}$
3.27 finis Finishing

3.

(raised) floor

$3.11 \mathrm{fl}$ fi Floorfinishing-linoleum

3.2 (lowered) Ceiling

$3.21 \mathrm{tifr}$ Timber frame 43/120mm

3.22 wp Iwaterproof layer (outside)

3.23 insl Insulation $60 \mathrm{~mm}$

3.24 mo baMoisture barrier (

3.31 co st Corner stud $80 / 100 \mathrm{~mm}$

$3.32 \mathrm{tifr}$ Timber frame $45 / 70 \mathrm{~mm}$

$3.33 \mathrm{wp} \mathrm{l}$ Waterproof layer

3.34 insl Insulation $60 \mathrm{~mm}$

3.35 mo baMoisture barrier
1.27 scbh1Steel cross bracing horizontal, first 2.27 exf c Exterior facade finishing 3.36 gy pl Gypsum plate $15 \mathrm{~mm} 2 x$ floor

1.28 scbh2Steel cross bracing horizontal, component, hardwood slats 3.4 Stairs $16 / 65 \mathrm{~mm}$ on battens $46 / 59 \mathrm{~mm}$

$1.3 \quad$ Floors $2.28 \mathrm{hw}$ sl Hardwood slats (separate parts 4 between unit)

Servicing

$1.31 \mathrm{cofl}$ Concrete floor - 3,75\%9,2m - 2.3

Roof $100 \mathrm{~mm}$ with two down-stand $2.31 \mathrm{tms}$ Timber frame $43 / 200 \mathrm{~mm}$ beams $200 \mathrm{~mm}$ $2.32 \mathrm{rv}$ ba Roof vapour barrier

$1.32 \mathrm{fl} \mathrm{i}$ Thermalfloor insulation $-100 \mathrm{~mm} 2.33 \mathrm{rpfi}$ Rigid polystyrene

1.33 co ip Concrete intermediate part 100-70mm (between units)

$2.34 \mathrm{pr}$ sl Plastic roof sealing layer 2.35 al rp Aluminum roof edge plate

4.11 instl Installation pipes

4.1 Water

4.2 Electrical

4.21 elek s Electricity support - gutter foam 4.22 elek c Electricity cable
$4.3 \quad$ Heating
4.4 Ventilation
4.41 ve un Ventilation unit

Figure 6.82: Vertical detailing of the $4^{\text {th }}$ Gymnasium case (Lebesque, 2018), including part number identification and a legend of all identified parts and functions of its parts 


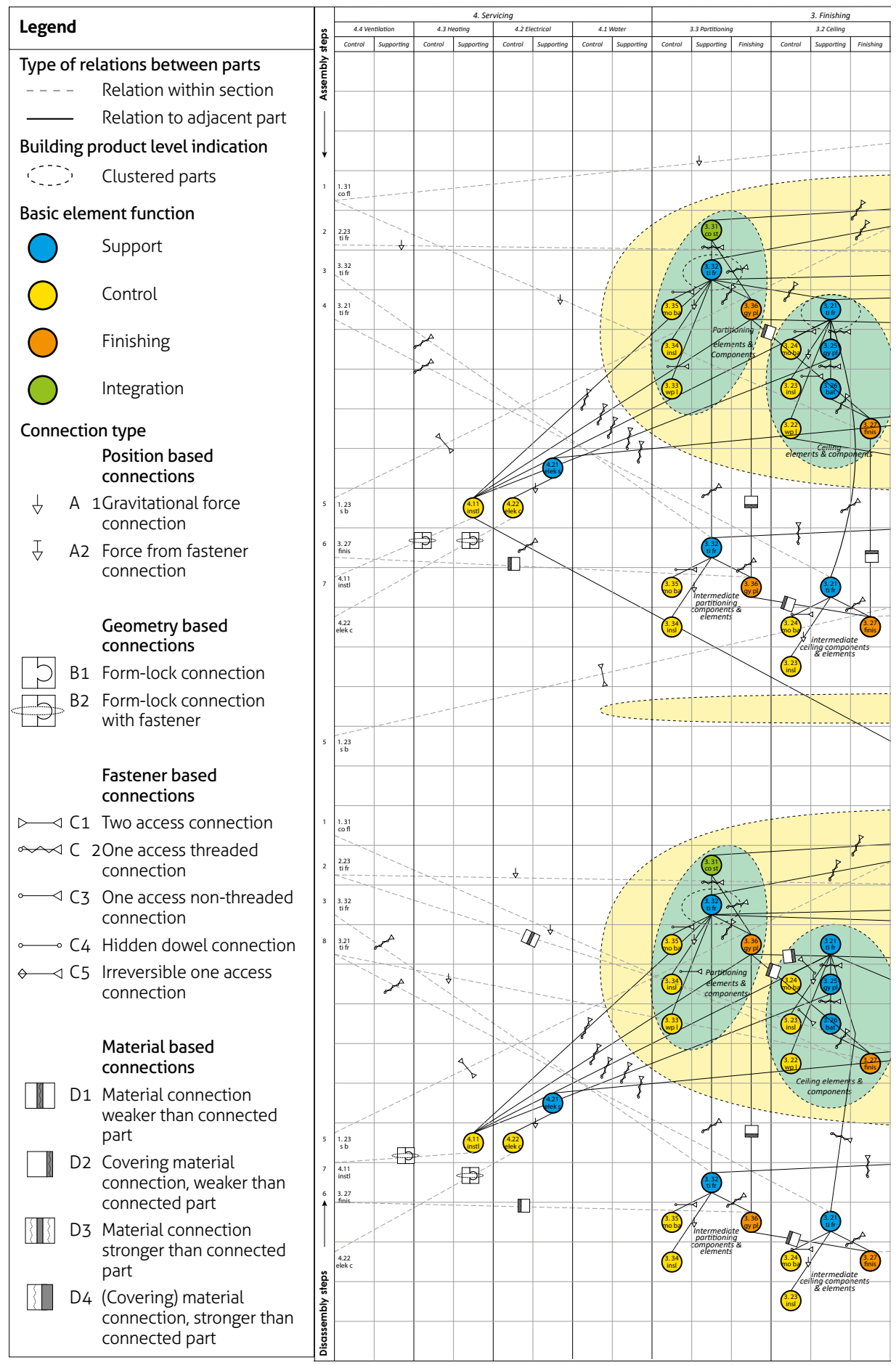

Figure 6.83: Relational pattern of the $4^{\text {th }}$ Gymnasium case, part a. 


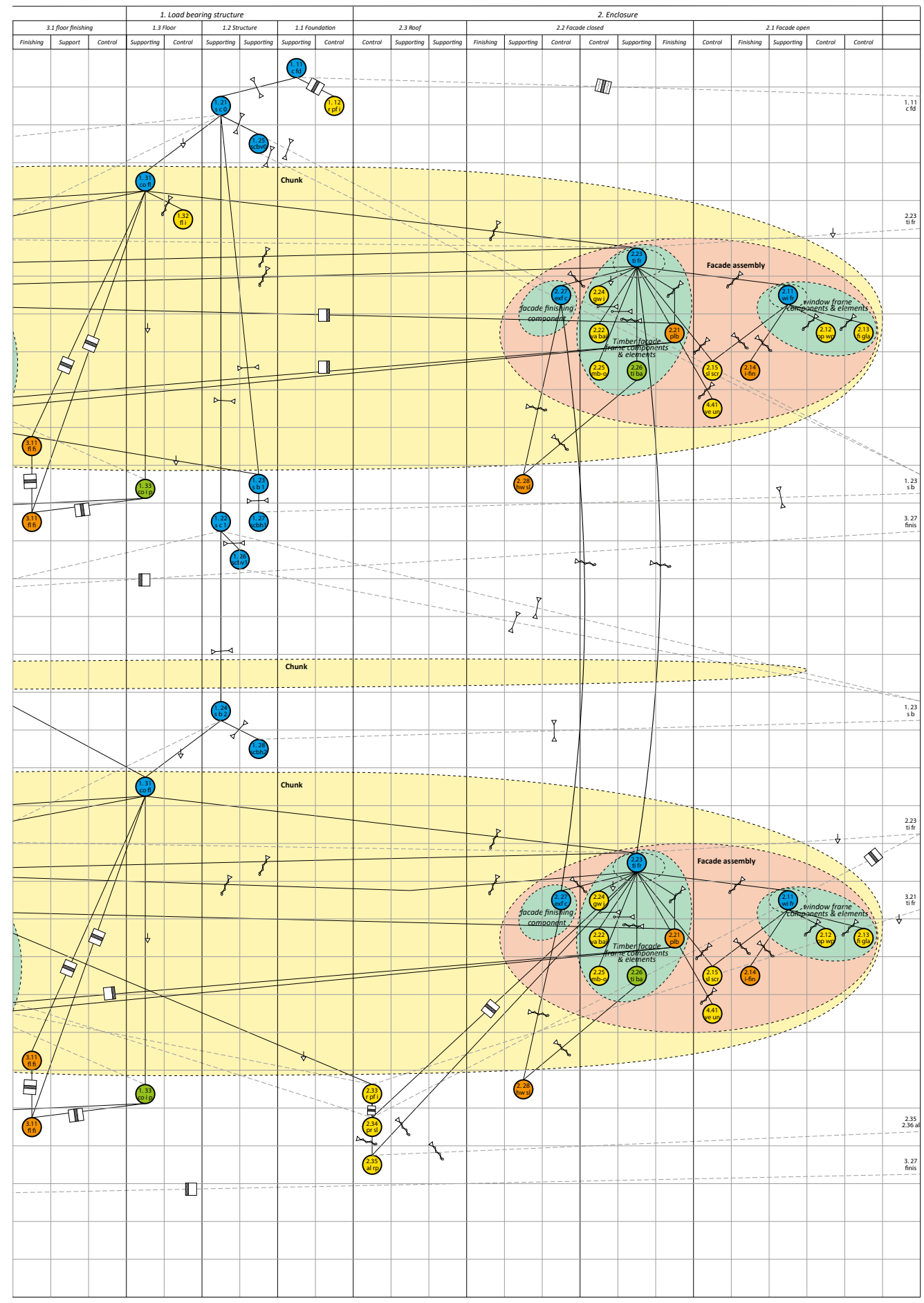

Figure 6.84: Relational pattern of the $4^{\text {th }}$ Gymnasium case, part $b$. 


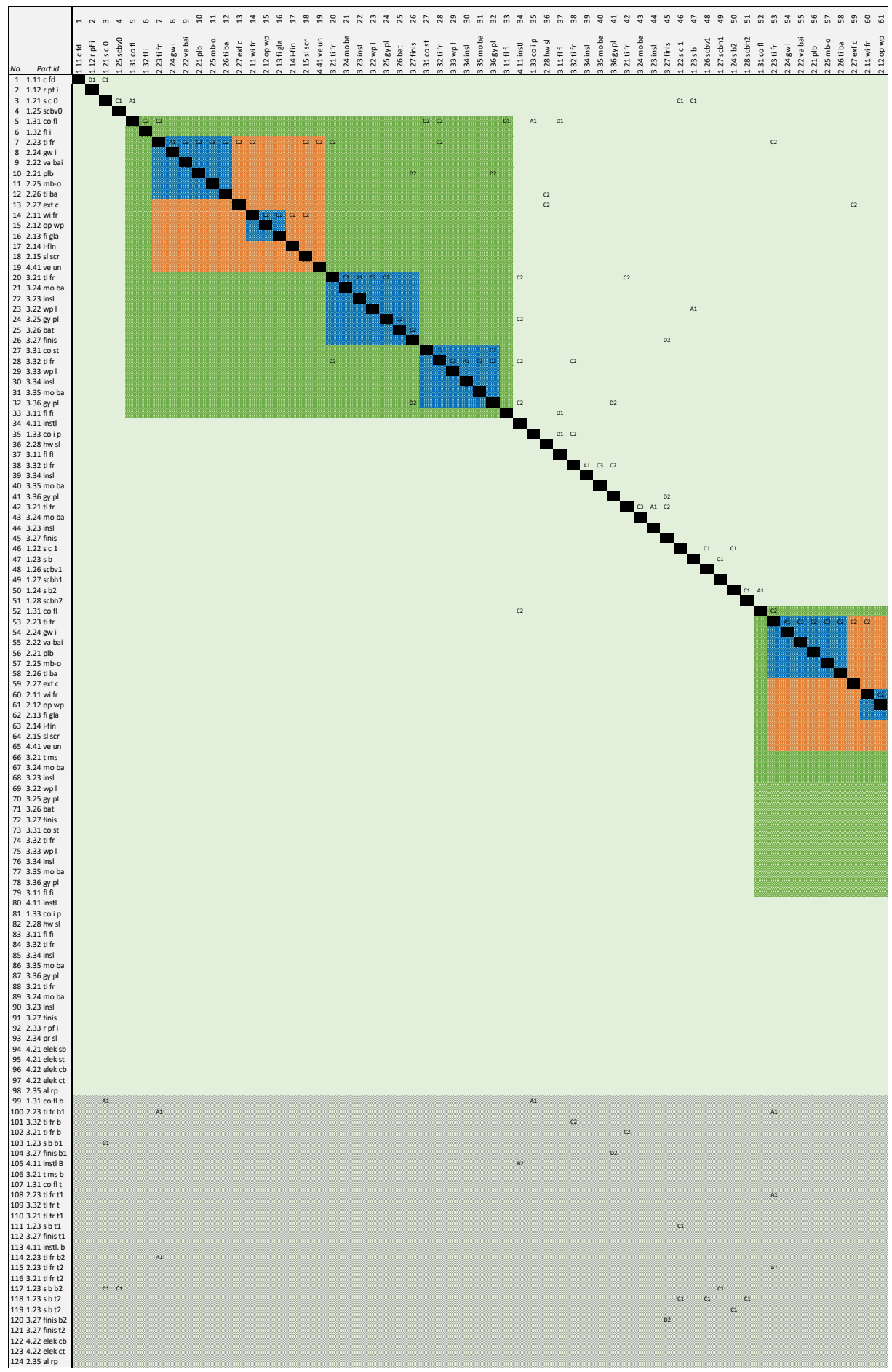

Figure 6.85: Design Structure Matrix of the $4^{\text {th }}$ Gymnasium case, part a 

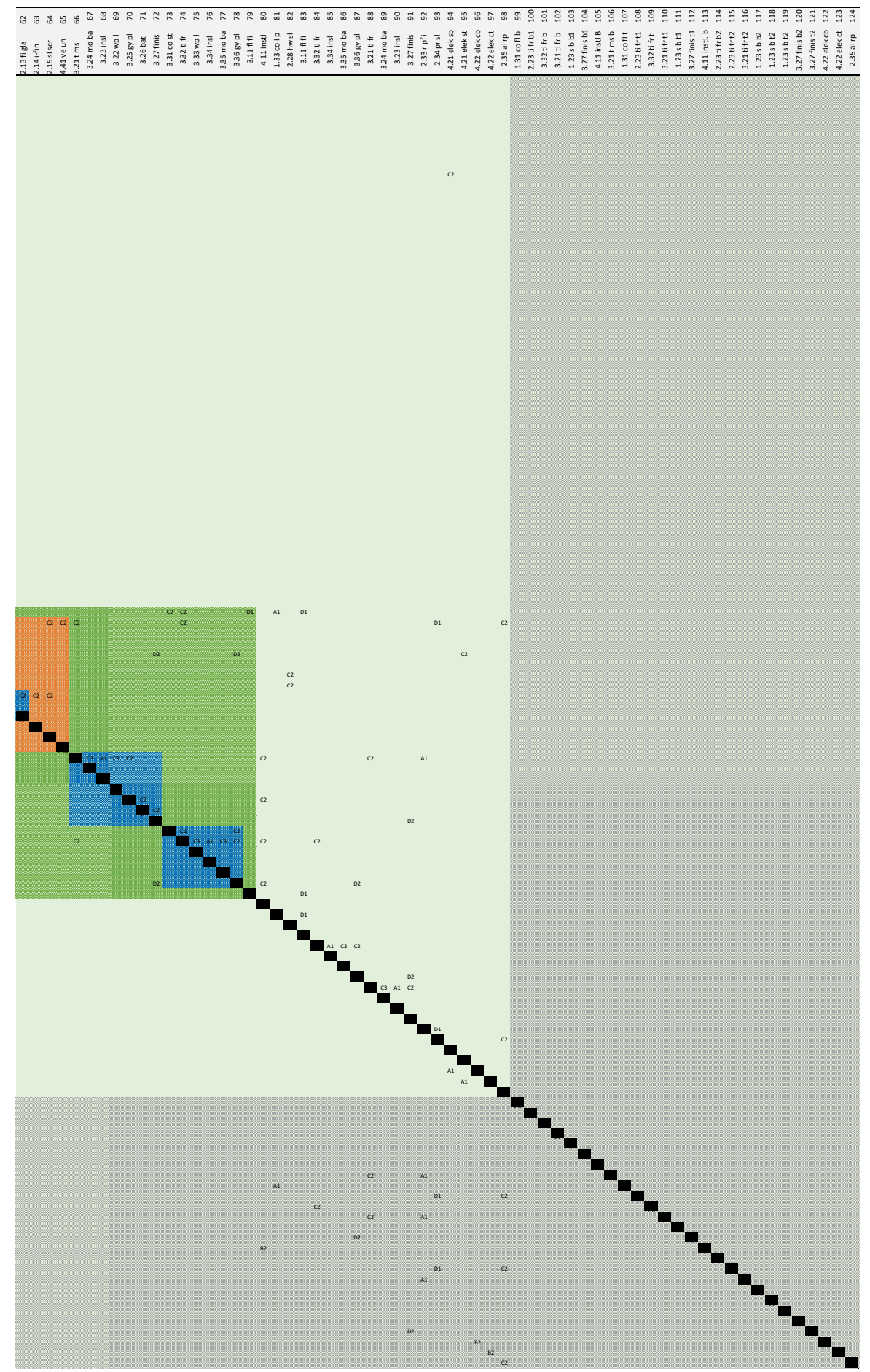

Figure 6.86: Design Structure Matrix of the $4^{\text {th }}$ Gymnasium case, part $b$ 


\section{Step 1c - Development of relational pattern}

In this step the relational pattern of the $4^{\text {th }}$ Gymnasium case is developed, based on the technical detailing, whereby all unique identified part numbers are used to create a conceptual representation of the technical composition of the building. The relational pattern will provide understanding of: the technical composition, the interconnectedness of all parts, the type of relations between the parts, the assembly and disassembly sequences and the containing building product levels in the building by the clustered parts (Figure 6.83 and Figure 6.84).

\section{Step 1d - Translate relational pattern into Design Structure Matrix (DSM)}

In this step, the relational pattern of the $4^{\text {th }}$ Gymnasium case is translated into a relational pattern, whereby the relations between the parts are identified with the connection type numbers, as shown in Figure 6.85 and Figure 6.86.

\section{Step 1e - Part specification form}

In this step, all data required to fill in the part specification form will be acquired, to allow the following indicators to be filled in: level of prefabrication, basic product function, technical lifespan, embodied economic value, embodied cultural value, embodied material value, embodied energy value, robustness, and impact on operational energy.

\section{Step 2: Input Reuse Potential evaluation method}

In this step the reuse potential evaluation method will be filled in, the prepared data in step one will be used to fill in the 'part specification' and the 'Design Structure Matrix', which allows sixteen of the total twenty-one sub-criteria to be filled in automatically and five sub-criteria require additional manual input to perform the reuse potential evaluation.

\section{Step 2a - General information}

To be able to create a full report with all information, in one document, this step requires the input of generic building information, such as name, function, location, construction date, age of the building, owner, original contractor and design and engineering team. Furthermore, the floor plans with indication of the representative section, horizontal and vertical detailing with unique part identification and relational pattern are requested to be filled in and if available or required to understand to composition of the building, it is possible to add additional information.

\section{Step 2b - Part specification}

For the reuse potential evaluation method to be able to recognise all building parts that are present in the building, this step requires the input of all unique building parts including the following information: floor level indication, part identification code, level of prefabrication of the parts, adjacent or not adjacent parts, basic function, technical lifespan, embodied economic value, embodied cultural value, embodied material value, embodied energy value, robustness, and impact on operational energy. 
Building level reuse

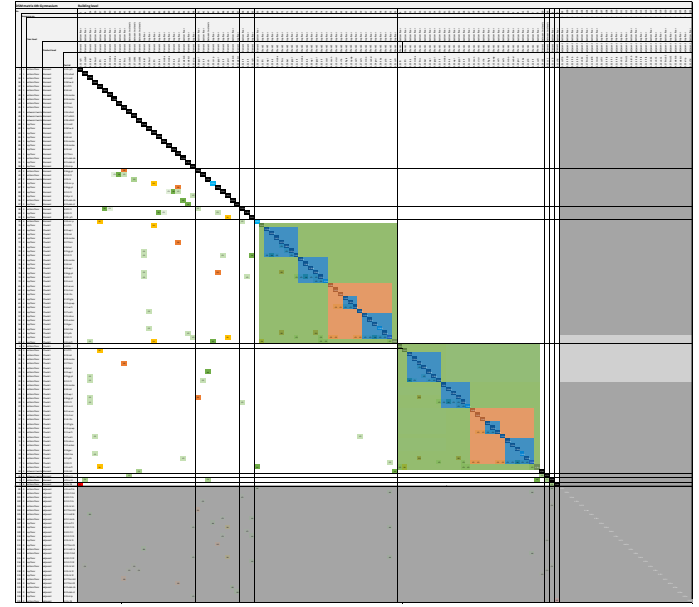

System level reuse

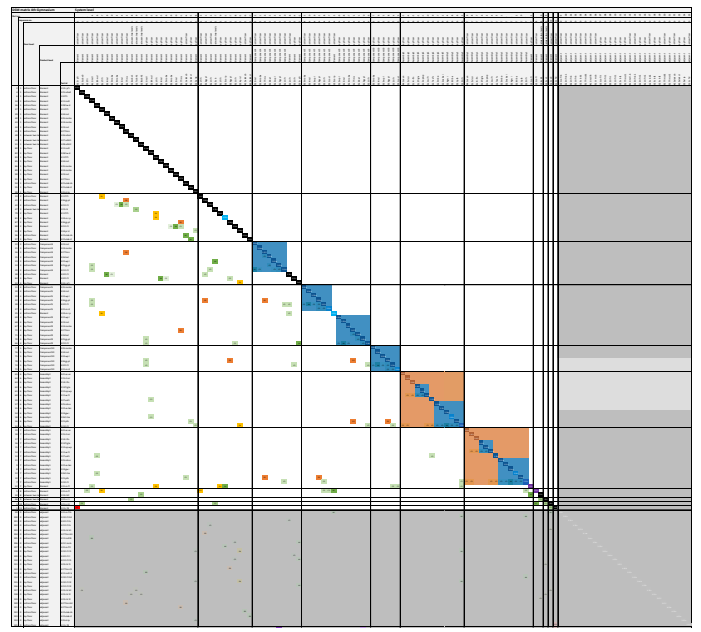

Product level reuse

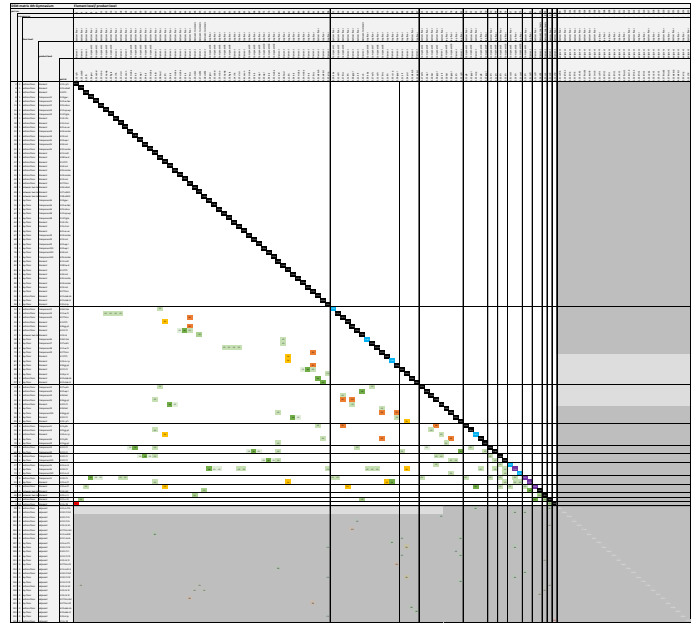

Figure 6.87: Generated Design structure Matrix of the $4^{\text {th }}$ Gymnasium case on all three reuse levels. 

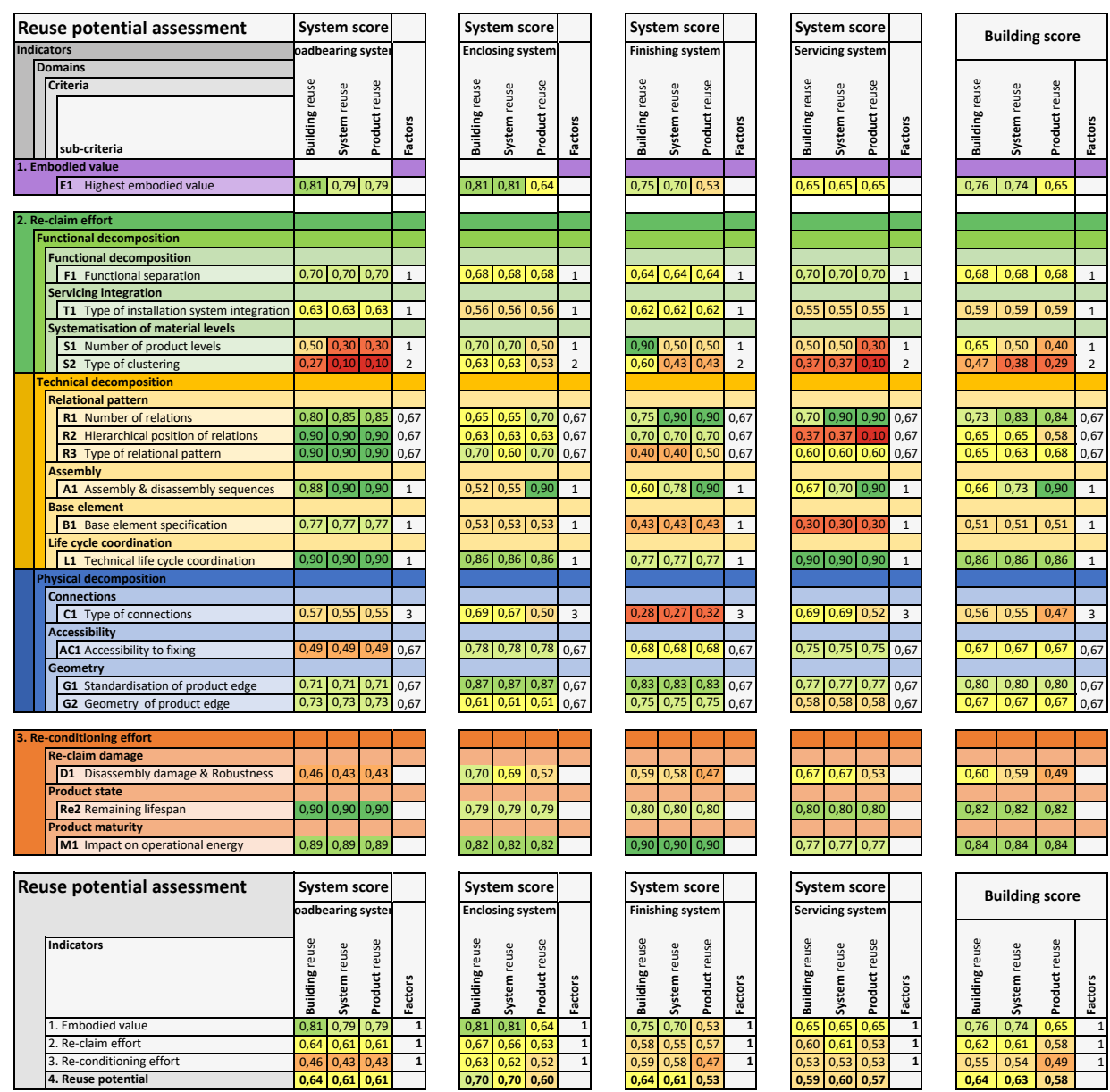

Figure 6.88: Overview of main building system and building Reuse Potential scores of the $4^{\text {th }}$ Gymnasium case

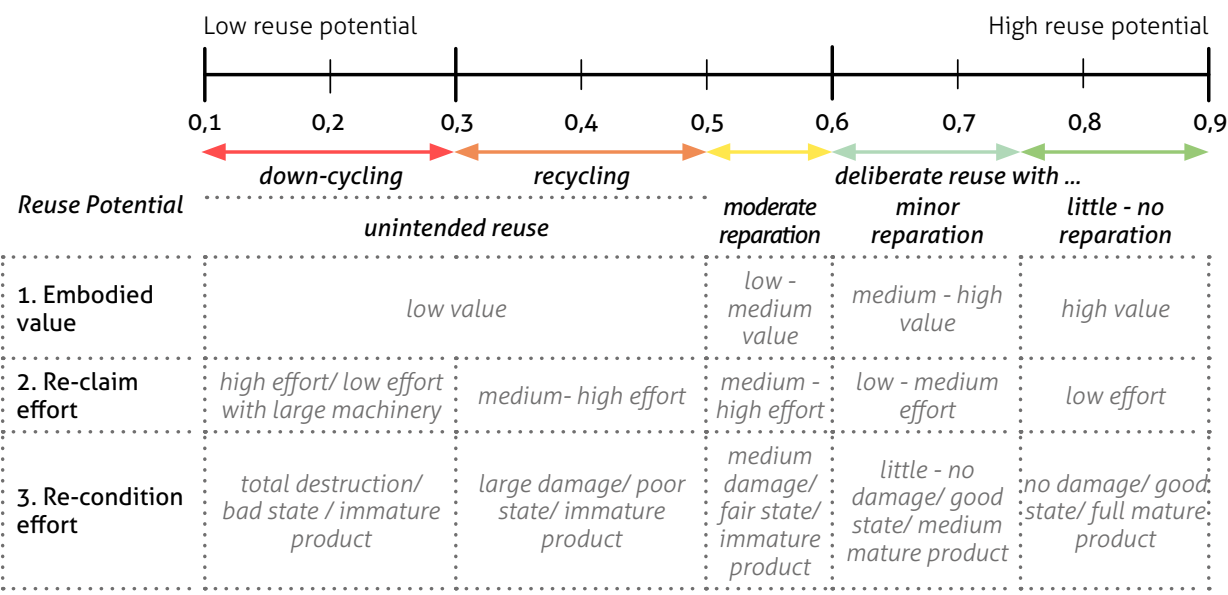

Figure 6.89: Reuse potential assessment rating system 


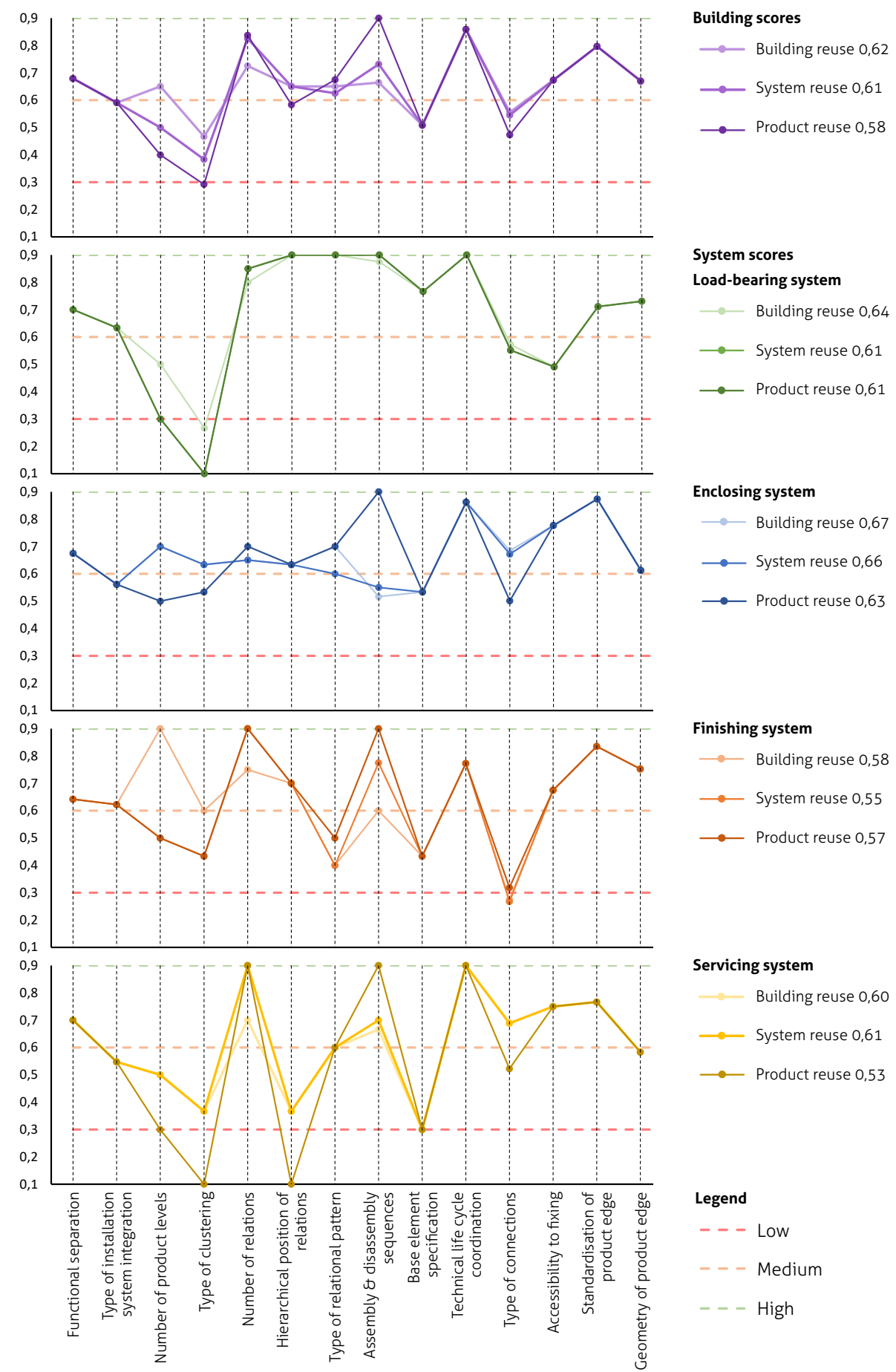

Figure 6.90: Line chart depicting the sub-criteria rating of the re-claim effort and re-conditioning effort of the $4^{\text {th }}$ Gymnasium case, for each main building system and the entire building, at three reuse levels 

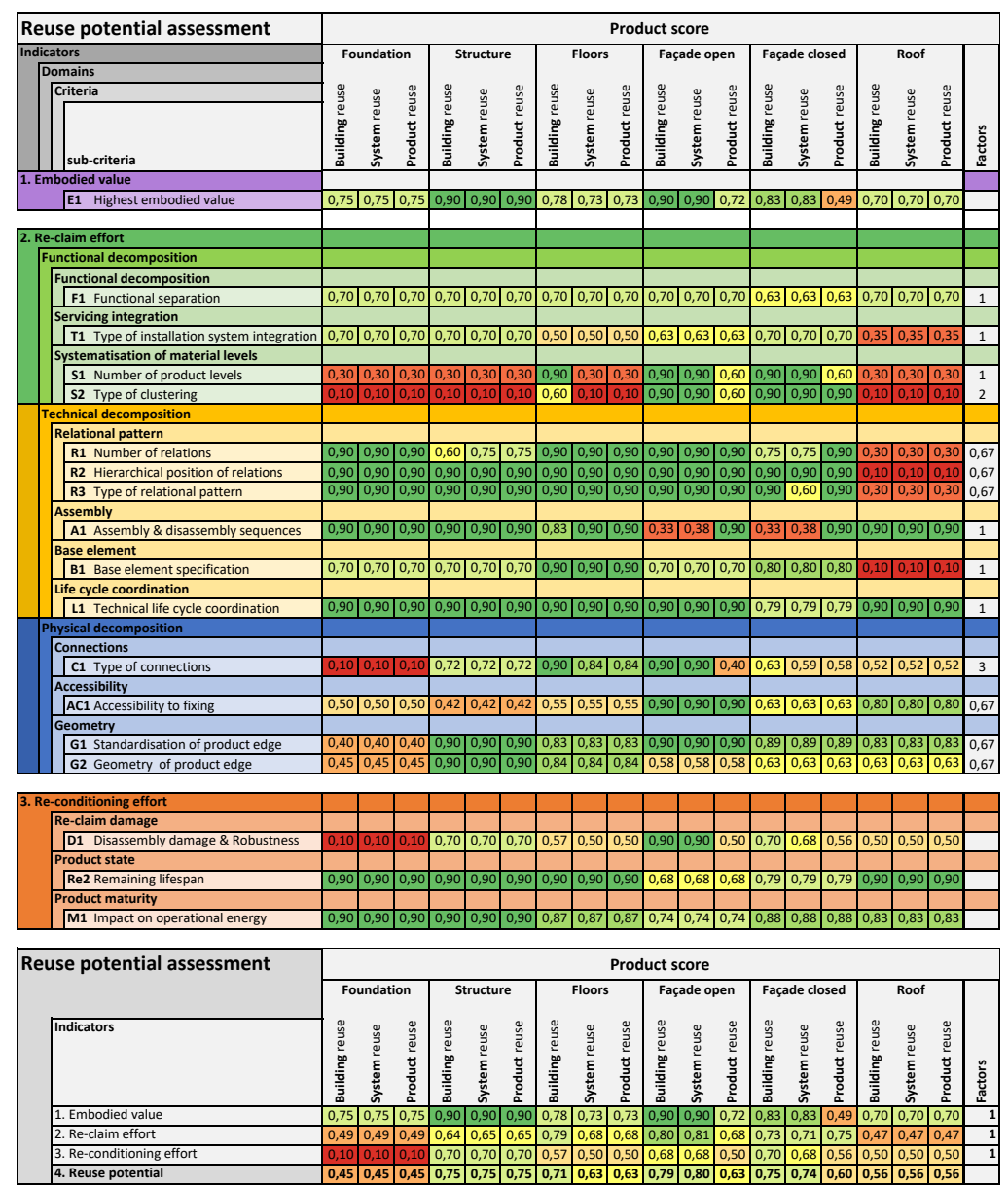

Figure 6.91: Overview of building sub-function Reuse Potential scores of the $4^{\text {th }}$ Gymnasium case, part b

\section{Step 2c - Design Structure Matrix input}

In this step, the Design Structure Matrix (DSM) will be filled in, which allows the reuse potential evaluation method to generate three types of DSM models, namely building level reuse, system level reuse and product level reuse DSM models. These models are required to identify the disassembly sequences and the connections that should be incorporated at each reuse level. In Figure 6.87 all three DSM models of the $4^{\text {th }}$ Gymnasium case are shown, whereby the chunks (green area), assemblies (orange area) and components (blue area) are shown in colored areas and adjacent elements and connections to adjacent elements in the grey area. The connections within the green, orange and blue area are not taken into account in the specified reuse level, since these parts can be reclaimed as one entity.

\section{Step 2d - Input of additional criteria data}

In this step, the criteria that require additional input data will be filled in, to enable a full reuse potential evaluation. The sub-criteria that require additional input data are: 

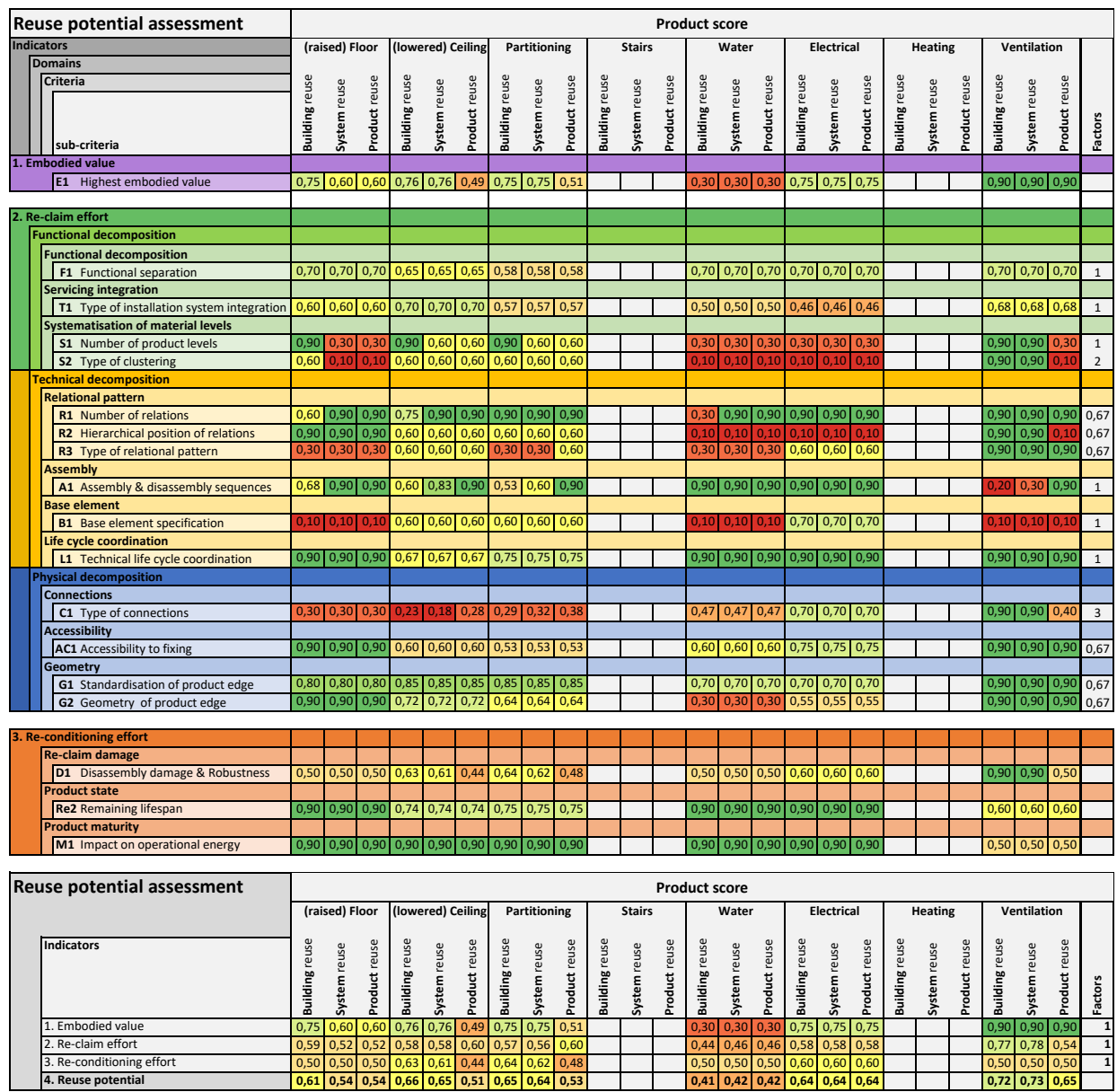

Figure 6.92: Overview of building sub-function Reuse Potential scores of the $4^{\text {th }}$ Gymnasium case, part $b$

functional separation, type of installation system integration, accessibility to fixing, standardisation of product edge and geometry of product edge.

\section{Step 3: Reuse Potential evaluation method results}

In this step the reuse potential report can be generated and the results can be analysed. Depending of the aim of the reuse potential evaluation, the results can be used to identify reuse potential of the building and building products or to identify parts of the building that could be improved to increase the reuse potential of the building to the desired level.

\section{Step 3a - Check completeness}

In this step, the Reuse Potential evaluation method is entirely filled in and can be verified at the 'input specification table' that is automated to fill in a 'check' mark after each criteria that is filled in entirely and a 'cross' mark if not all required fields are filled in. When all boxes are filled with a 'check' mark, the Reuse Potential evaluation method is finished and can be published to generate a report. 


\section{Step 3b - Reuse Potential results}

In this step the Reuse Potential report is generated and the results can be analysed. To start in Figure 6.89 the reuse potential rating system is defined, according to which the client or designer can specify the reuse ambition of their building design or identify the building products that show potential to be reused.

In Figure 6.88, the system scores and building scores of the $4^{\text {th }}$ Gymnasium case are summarised, depicting the sub-criteria scores, main indicator scores and the resulting reuse potential score at all three reuse levels: product reuse, system reuse and building reuse. These scores allows the designer or client to gain a full understanding of the reuse potential of the building and the main building functions. Furthermore, the scores can be used to identify the parts for reuse, but also identify if the reuse potential of the design complies with the reuse ambitions. If the design does not comply with the reuse ambitions, the overview can be used to identify the sub-criteria on which the building scores low and could be improved upon in the next design iteration. To improve clarity of the sub-criteria in Figure 6.90 line charts are shown, depicting the re-claim effort for each main building system and the entire building at all three levels. These charts allow the designer to identify the criteria that could be improved upon in the design stage to increase the reuse potential. It should be noted that the line charts only represent the sub-criteria can directly be influenced based on its design. Furthermore, in Figure 6.91 and Figure 6.92 scores are shown for each building sub-function, which increases the understanding of the specific parts that can be improved upon and the parts that already score high.

Finally, to support full transparency regarding the results of the reuse potential evaluation method, the Reuse Potential report includes lists of the scores of each part for each sub-criteria at all three reuse levels

\subsubsection{Reuse Potential results $-4^{\text {th }}$ Gymnasium}

After a use period of eight years, the $4^{\text {th }}$ Gymnasium building was demolished with only few parts being reused, while the building was designed with the intention to support easy disassembly, relocation and reuse. Therefore, in this section, the reuse potential results of the $4^{\text {th }}$ Gymnasium case will be analysed and discussed, in order to identify if the reasons why the building was demolished with only minor parts being reused, can be clarified based on the reuse potential results, besides the independent variables as described in section 6.4 . Since the aim was to relocate the entire building, the reuse level that best described the aim is building reuse level. Therefore, the building level reuse scores are of main concern for this analysis. While, if the building level reuse score is low, the system- and product reuse level scores can be used to identify main building functions or sub-building function parts that have a high reuse potential. Therefore, sequentially, the system- and product reuse level scores will be analysed to identify if the parts of specific building functions could have been identified for reuse. 
To enable a structured analyse of the different reuse scores, the following parts will be analysed and discussed: 1 . embodied value, 2. re-claim effort, 3. re-condition effort and 4. reuse potential. Whereby each section starts with building reuse level and sequentially system- and product reuse level are being discussed.

\section{Embodied value}

Similar to the Red House case, the $4^{\text {th }}$ Gymnasium was constructed using a volumetric modular construction system, which results in the clustering of multiple elements, components and assemblies into chunks that can be assembled and disassembled as one entity. Although, the main building structure in the $4^{\text {th }}$ Gymnasium building is not part of the chunks, this did not limit the embodied value of the structure parts, because they are by themselves parts with a high embodied value. In general the embodied value of the product is high at building reuse level, resulting in an average building score of 0,76 . The only sub-function that has a low embodied value are the water installation parts, which are not part of a chunk and need to be removed before the chunk can be disassembled. At system level, the embodied value score is only 0,02 lower, 0,74. While at product level, the embodied value scores the lowest, with 0,65 , which is mainly a result of the finishing system and the enclosing system sub-functions, which are by themselves of low embodied value.

\section{Re-claim effort}

The reclaim effort is composed of three domains, which will sequentially be analysed and discussed. The functional decomposition at building reuse level scores, compared to the technical- and physical decomposition scores, the lowest, which is mainly a result of the type of installation system integration, number of product levels and type of clustering. Especially, for the foundation, structure, roof, water installation, and electrical installation sub-function parts a lack of systematisation and clustering of products exists, which increases the re-claim effort from a functional decomposition perspective. At product level reuse, the floor, (raised) floor, ventilation sub-function parts also lack systematisation and clustering, which results in a further decrease of the building scores for the systematisation of material levels sub-criteria.

The technical composition at building reuse level scores, compared to the functionaland physical decomposition scores, the highest. Especially, the load-bearing system components are well structured, while the roof, (raised) floor, partitioning, water-, electrical- and ventilation installation parts can be improved upon from a relational pattern perspective, assembly and disassembly sequences perspective and base element perspective. To give an example, the chunk consists of floor, partitioning, facade and ceiling parts that together form an entity, but neither the partitioning or facade parts can be removed individually from the chunk, because there is no base element that can be identified as the intermediary between these parts, forming a closed chunk structure. This results in the chunk losing its integrity when one of the sub-function parts is removed. The same difficulty occurs at system- and product reuse level. 
The physical decomposition at building reuse level is mainly compromised by the connections that are used for the foundation, roof, (raised) floor, (lowered) ceiling, partitioning and water installation parts, which makes the parts difficult to re-claim and simultaneously results in the need for re-conditioning of these elements due to the re-claim damage that is being incurred by the types of connections that have been applied.

Overall, the re-claim effort at building reuse level at building score is rated with 0,62, which is acceptable. Although, the re-claim effort rating could be significantly improved if: 1) the foundation, roof, finishing system, water installation would make use of reversible connection types; 2) base elements for the roof, (raised) floor, water- and ventilation installation parts would be introduced, and; 3) the systematisation of material levels would improved by the introduction of new clusters. To be more specific, based on the product scores it can be stated that the re-claim effort of the foundation, roof, (raised) floor, (lowered) ceiling, partitioning, water- and electrical installation sub-function parts require medium to high re-claim effort at building- system- product reuse level. This means that the embodied value of the products should be relatively high and the re-conditioning effort score should also be relatively high to compensate the low re-claim effort score and allow for deliberate reuse.

\section{Re-conditioning effort}

The re-conditioning effort per sub-function is determined by the lowest score of the following three sub-criteria: 1) re-claim damage, which is based upon the disassembly damage $\&$ robustness of the building products; 2 ) product state, which is based upon the remaining technical lifespan, and; 3) product maturity, which is determined by the age and type of impact on the operational energy of the building. The lowest score is indicative for the amount of effort that is required to enable reuse. While the main building system scores are determined based on the average of the sub-function scores and the building score based on the average of the four main building system scores.

The building reuse level re-conditioning building score is 0,55 , which is relatively low, meaning that some level of re-conditioning is required to allow deliberate reuse. The product scores of the sub-building functions reveal that the reclamation of the foundation sub-function parts result in total destruction of the foundation parts. Furthermore, the floor, roof, (raised) floor, water and ventilation installation sub-function parts require medium re-conditioning effort to enable deliberate reuse. This means that the embodied value and re-claim effort should be relatively high, to allow for deliberate reuse.

\section{Reuse potential}

Finally, the building reuse level, building reuse potential score is 0,64 , which indicates that on average the building is suitable for deliberate reuse with moderate reparation. This score differs from the actual fate of the building, in the sense that the building was not deliberately reused with moderate reparation, but has resulted in demolition with the 
ambition to make as much parts as possible available for reuse, and resulted in mainly the demolition of the building, with only a few easily accessible parts being reused and most parts being recycled. It should be mentioned that the reuse potential evaluation method provide an indication of the potential to reuse parts of the building or the entire building based on its dependent variables, the embodied values and the building's composition. The fate of the $4^{\text {th }}$ Gymnasium building was influenced by a combination of strict independent variables, the short time-frame in which the building had to be removed from its location, and dependent variables. This makes the direct comparison between the reuse potential results with the actual fate of the building difficult.

The reuse potential results indicate that the building reuse, building re-conditioning effort score is 0,55 , which indicates that on average the building parts are medium damaged/ in a fair state/ an immature product, and thus requires medium re-conditioning effort to allow for deliberate reuse. This score is in line with the re-conditioning effort that was also identified by the Municipality of Amsterdam during consultation meetings with industry experts.

While, at building reuse level, the product reuse potential scores of the following building sub-function parts: structure $(0,75)$, floors $(0,72)$ open facade $(0,79)$, closed facade $(0,75)$ and ventilation $(0,72)$, indicate that they would be suitable for deliberate reuse, with minor reparation. While in the interview with the municipality of Amsterdam and an online article (Muis, 2016) it was mentioned that from the building sub-functions mentioned above, only the timber facade battens and HPL facade panels have been reused and that the structural steel parts have been sold for recycling. The difference between reality and the reuse potential evaluation method can be explained by the influence of independent variables, whereby the parts that have been reused were limited to the most accessible parts due to time restrictions.

In addition to the limited time-frame for proper disassembly, the Municipality of Amsterdam, mentioned that at the time they analysed potential end-of-first-use scenarios, the number of construction companies operating in the deconstruction and reuse industry was in July 2015 not as established as it was at the time of the interview with the Municipality of Amsterdam (22 Februari, 2018).

If the reuse potential evaluation method was used as a design decision support model to increase the reuse potential in the design stage, Figure 6.88, Figure 6.91 and Figure 6.92 provide an overview of the sub-criteria that could be improved upon. Especially, the foundation, roof, (raised) floor, (lowered) ceiling, partitioning, water- and electrical installation sub-function parts can be improved upon. The main sub-criteria that could be improved upon are the systematisation of material levels, to create functional clusters and the type of connections, to reduce the re-claim effort and reduce re-claim damage. 


\subsection{Discussion \& conclusion}

The aim of this chapter is to evaluate the usability, applicability and usefulness of the reuse potential evaluation method, to answer RQ9: How usable, applicable and useful is the evaluation method that is presented in this study if applied to case studies?

To evaluate the reuse potential evaluation method, it is important to verify if the evaluation method fulfils the aim of the reuse potential evaluation method, as defined in section 5.2.1. The main objectives of the reuse potential evaluation method are defined as:

1. Enable the assessment of the reuse potential of buildings, systems and building products in the design stage and existing buildings.

2. Provide design knowledge, to support designers and engineers in the design of new buildings and building products with a high reuse potential;

3. Allow clients to set a minimum reuse potential score to ensure a defined reuse potential level of the building, building system and its building products, to facilitate in circular building design objectives;

To evaluate the reuse potential evaluation method a critical retrospective case study approach has been applied to test the reuse potential evaluation method. Two cases have been analysed in a qualitative manner and a quantitative manner using the reuse potential evaluation method, to determine if the method is able to assess the reuse potential of buildings and building products accurately and explain the variance between the two cases. Furthermore, its application demonstrates how the reuse potential results provide design knowledge to the user, to provide design support how the reuse potential of the building product can be improved. Finally, the evaluation method results in a score that refers to the reuse potential rating system, which allows clients to set a reuse potential level as a circular building design objective.

The discussion and conclusion of this chapter is structured as follows: section 6.8.1 evaluation of case study results; section 6.8 .2 evaluation of design support, and section 6.8.3. evaluation of the method as a way to facilitate circular building design objectives.

\subsubsection{Evaluation of case study results}

To test and verify the functioning of the reuse potential evaluation method two critical retrospective case study buildings have been analysed. To enable a comparison, the critical retrospective cases are selected conform the 'case/ control' approach. The 'control' case study building is 'Villa Zebra - Red house' a building that has been successfully relocated and reused multiple times and the 'case' building is the '4th gymnasium', a building that has been unsuccessful in being relocated despite its effort and intention to be easily relocated and reused. Since both cases already passed their first functional life and their reuse or end-of-life has already taken place, it is possible 
to compare the results of the reuse potential evaluation method with the actual outcomes and verify the functioning of the reuse potential evaluation method. In order to understand if external influences were at play in the decision making of the reuse of the building, both cases have been analysed using qualitative research methods, by studying available documentation and performing interviews with stakeholders that were involved in the construction and/or end-of-life of each case study buildings.

The reuse potential evaluation method has been successfully applied at both cases. To assess the functioning of the reuse potential evaluation method, the reuse potential result of the Red House case has been compared with its actual reuse. Since the building has been successfully relocated and reconfigured to suit multiple building functions, by demounting the least number of parts to enable relocation, the building level reuse score should be taken into account. The reuse potential score of the Red House case at building level, was rated 0,72 , which indicates that the building is designed to support deliberate reuse with minor reparation. This result complies with its actual reuse.

The 4th Gymnasium case was unsuccessful in being relocated and reused, while the building was designed with the intention to be easily relocated and reused. The reuse potential score of the 4th Gymnasium at building level reuse was rated 0,64, which indicates that the building is designed to support deliberate reuse with minor reparation. This score differs from the actual fate of the building, in the sense that the building was not deliberately reused with moderate reparation, but has resulted in demolition with the ambition to make as much parts as possible available for reuse, and resulted in mainly the demolition of the building, with only a few easily accessible parts being reused and most parts being recycled. However, based on the interviews and available documentation, it should be noted that the decision of the end-of-life of the $4^{\text {th }}$ Gymnasium building was influenced by a number of factors. In this case external influences such as the available time to enable proper disassembly has been identified as a factor that strongly influenced the end-of-life decision. This complicates the direct comparison between the reuse potential results with the actual fate of the building.

Despite the independent variables that influenced the decision about the fate of the building, the reuse potential evaluation method indicated the expected re-conditioning effort that would be required when relocating the building. Furthermore, when comparing the reuse potential scores of both cases, the 4th Gymnasium case scored overall lower than the Red House case, which complies with the expectations.

Therefore, it can be stated that based on two case study buildings the reuse potential evaluation method fulfils the aim to enable the assessment of the reuse potential of the buildings, building systems and building products. Furthermore, it proves to be successful in the identification of the differences between two case study buildings and seems to reflect reality. However, to further validate the functioning and accurateness of its assessment it is recommended to extend the number of case study evaluations. 


\subsubsection{Evaluation of design support}

In addition to the goal to enable the assessment of the reuse potential of buildings, building systems and building products, the reuse potential evaluation method should provide design knowledge to support designers and engineers to increase the reuse potential of their designs. To enable design support a reuse potential report is generated in the final step. This report shows an overview of all reuse potential scores, including all input data that has been used per assessment criterion. To ease the interpretation of the reuse potential results and the identification of criteria that could be improved upon, in the overview graphs the ratings are colored from red (low score) to green (high score). To be more specific about how the score of a criteria can be improved upon, the input data can be consulted for further specification of the parts that determine the low score. In section 6.6.2 and section 6.7.2 suggestions have been described how the reuse potential of both cases could be increased.

The suggestions that have been described to improve the reuse potential of the buildings, demonstrate how the reuse potential evaluation method is able to provide design knowledge to increase its reuse potential. The design knowledge and direct feedback highlighted in the reuse potential results allow the user (designers, engineers and construction consultants) to get a better understanding of factors in their design that constrain its reuse potential and to improve the reuse potential. The feedback is realised due to the requirement that has been defined: input data should be verifiable, accessible and transparent. As demonstrated in the case study analysis, the input data and the results seem to provide useful feedback to improve the reuse potential as shown in the case study application. To ensure this type of feedback is useful for the users of the evaluation method, it is recommended to test the reuse potential with actual users in the design stage of circular buildings. Due to time constraints of this research it was not possible to perform a validation of the usefulness of the method with the actual users.

\subsubsection{Evaluation of the method as a way to facilitate circular building design objectives}

The evaluation method developed in this thesis demonstrates how the reuse potential of buildings and building products can be evaluated and provides design knowledge to support designers and engineers to increase the reuse potential. After validation with additional case studies has further demonstrated the usefulness of the developed method during the design stage of circular buildings, the method can also be used by clients and policy makers to set a minimum reuse potential score in e.g. design competitions to ensure a minimum level of reusability and contribute to a circular built environment. 


\section{Chapter 7 Discussion and conclusion}




\section{$7 \mid$ Discussion and conclusion}

This final chapter summarizes the main contributions and implications of this $\mathrm{PhD}$ research. The first section provides a brief overview of the research questions and methods that were used in chapters 2-6. Subsequently, in the second and third section, a summary is provided of respectively the main scientific contributions and managerial implications. The chapter ends with a reflection on the limitations of this study and the implications for future research.

\subsection{Research questions and methods}

This section will summarize and discuss the research questions posed in section 1.3 and finally answer the main research question as defined in section 1.2.

R01: How can circular building design be defined?

A clear definition of circular building design could not be identified in literature. Therefore, in this thesis a definition for circular building design is proposed. Based on the review of key concepts in literature in chapter two, it was determined that in a circular economy it is essential to address four distinct resource flows, namely: narrowing resource flows, slowing resource flows, closing resource flows and leaking resource flows. In this thesis, circular building design is defined as: A design approach to create buildings that have the capacity to accommodate changing demands by taking into account all life cycle stages, to minimise resource input by narrowing resource flows, retain a high embodied value through design for disassembly, reparation and refurbishment and extend product life by slowing resource flows, utilise recyclable materials to enable closing resource flows, and eliminate leaking resource flows by continuously forming an incentive for future reuse.

RO2: Which types of building reuse and building product reuse methods can generally be identified in the building practice?

The identification in literature of types of building reuse and product reuse methods has resulted in the development of a 'building product reuse design typology'. This typology (illustrated in Figure 2.09) is helpful to provide a better understanding of reuse design methods and to categorise reuse strategies from practice. The building product reuse design typology is based on two important design characteristics, with on the $x$-axis the 'design intent', which distinguishes its reuse design as: 1 . deliberate reuse or 2 . unintended reuse, and on the y-axis the 'type of configuration', which distinguishes its design as an 1. indeterminate configuration or 2 . determinate configuration. The combination of both design characteristics resulted in four reuse design methods, namely: 1) reversible design, 2) reversible redesign, 3) conventional design, 4. conventional re-design. In addition, the four design methods have been related to five reuse strategies, namely: relocated reuse, 


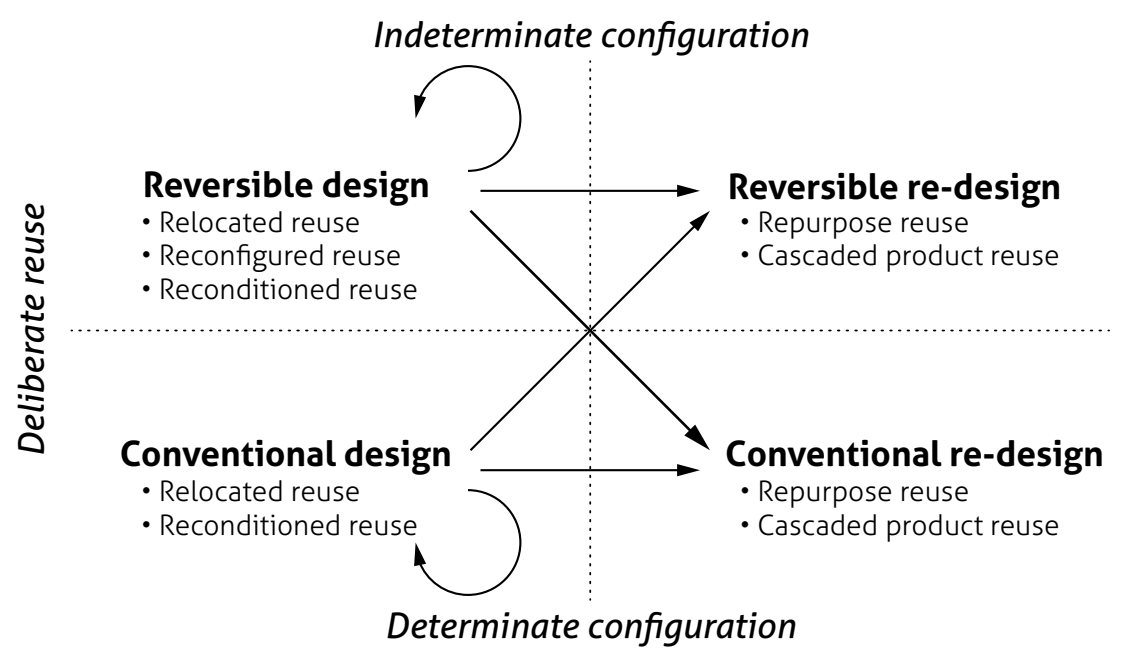

Figure 7.93: Building product reuse design framework

reconfigured reuse, reconditioned reuse, repurpose reuse and cascaded reuse. Reversible building design is classified as indeterminate configurations that enables deliberate reuse, which is typically achieved by relocated, reconfigured and/ or reconditioned reuse strategies.

Additionally, it is important to understand the different transformations a reused product can undergo and understand the effect of their design solution on the potential for future reuse. Therefore, the reuse design typology has been transformed into a reuse design framework by identifying six possible transformations that a product can undergo depending on the reuse strategies and its integration in its new context. These reuse strategies have been depicted using arrows in Figure 7.93 (and earlier also in Figure 2.10). This framework allows the categorisation of initial design and reuse design solutions to make the designers conscious about the effect of their reuse design solution on its potential for future reuse. In section 2.8, each of the six reuse transformations depicted in the reuse design framework has been clarified with the use of reuse examples from practice.

RO3: Which enablers, opportunities and barriers for deconstruction and reuse can be identified in literature?

In chapter 3, 25 scientific publications have been reviewed to identify enablers, opportunities and barriers that influence the decision making of deconstruction and reuse. The identification of these enablers, opportunities and barriers resulted in a better understanding of the factors that influence the decision making whether or not a building product will be reused. A total of 48 enablers and opportunities, and 49 barriers have been identified. To structure all enablers, opportunities and barriers, they are divided in six perspectives, namely: environmental, social, organisational, compliance and legislation, technical, and economical perspective. 
R04: What are the main causes and effects of the enablers, opportunities and barriers for deconstruction and reuse?

To improve the understanding of the mechanisms that influence the decision making of deconstruction and reuse, the enablers, opportunities and barriers are translated in cause-effect schemes. This has resulted in six cause-effect schemes: environmental perspective is shown in Figure 3.19, social perspective in Figure 3.20, organisational perspective in Figure 3.21, compliance and legislation perspective in Figure 3.22, technical perspective in Figure 3.23, and economical perspective in Figure 3.24.

R05: How can the main factors of deconstruction and reuse be structured in a conceptual framework to evaluate the reuse potential of buildings and building products?

Building upon the literature review described in chapter two and three, a conceptual reuse potential framework has been developed, as shown in Figure 7.94 (and earlier also in Figure 3.25). In the conceptual reuse potential framework five key indicators have been defined, which determine the reuse potential of buildings and building products, namely: 1. impact of 'additional processes'; 2. impact of 'avoided processes'; 3. impact of 'reuse on the embodied value'; 4. impact of 'reuse on the operational value', and; 5. impact of "external influences'. The first four variables can be influenced based on the design of the building

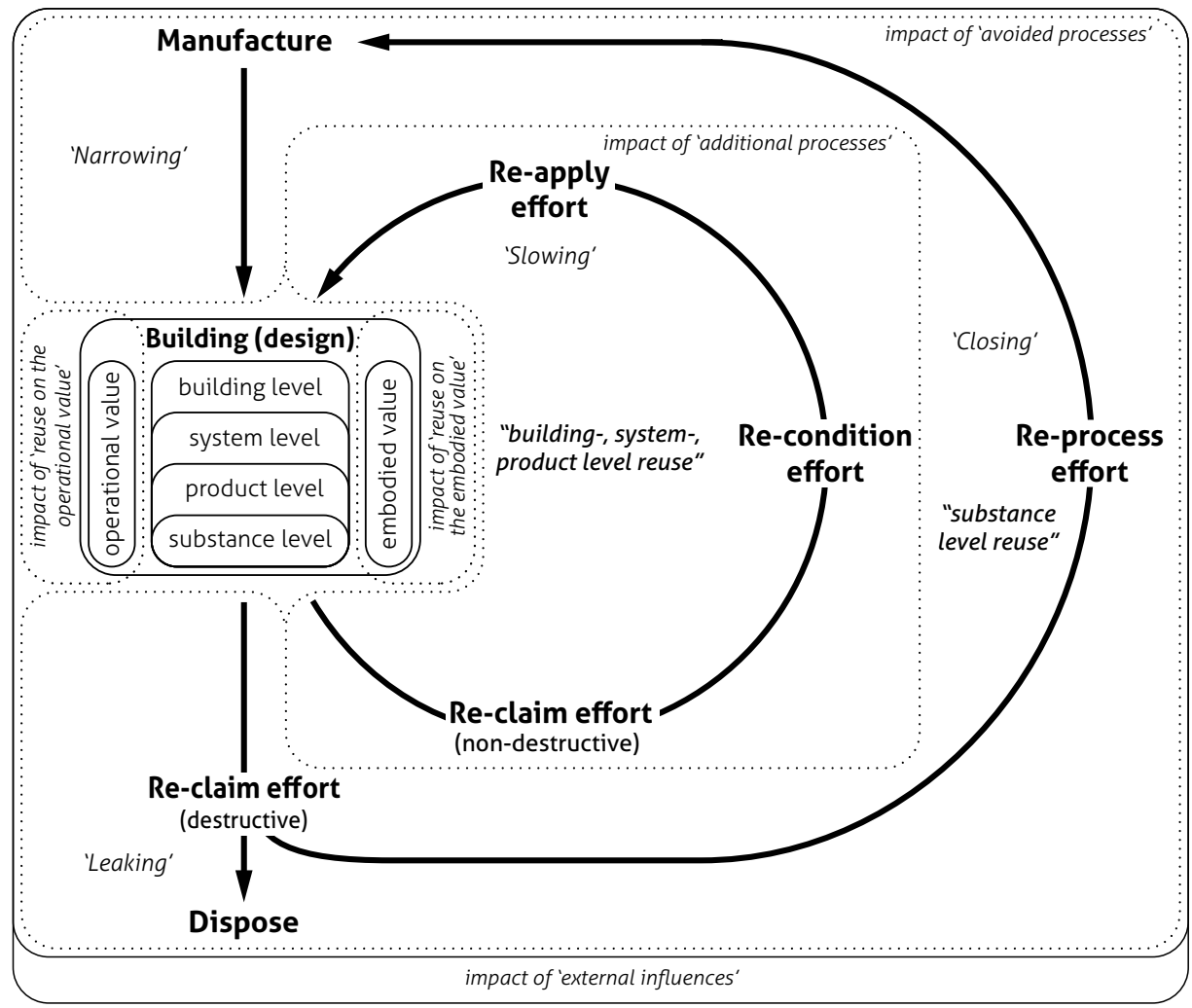

Figure 7.94: Conceptual reuse potential framework. 
or building product, these factors are termed dependent variables in this research. The fifth variable, can modify the reuse potential of a building product independent from its design, these variables are termed independent variables.

Building upon the main variables that influence the reuse potential of building products, a general strategy to increase the reuse potential of building products has been defined: "design buildings, systems and products: with high embodied value to allow for the impact of 'additional processes'; that maintain most of their embodied value during reuse processes, and; to allow the impact of 'reuse on the operational value' to be reduced to a minimum through upgrading the parts that impact the operational value". The reuse potential evaluation method should support the designer in the operationalisation of this strategy.

RO6: Which 'Design for Disassembly' guidelines can be identified in literature to support reuse of buildings and building products and what is the guideline's reasoning?

To answer this research question, a comprehensive literature review is performed in chapter 4 to identify the main Design for Disassembly guidelines and principles. Throughout the review of 22 scientific publications 106 design guidelines have been identified. To gain an overview of the guidelines and principles that have a similar scope, the design guidelines have been categorised in three levels, 1) strategy groups, 2) principles, and 3) guidelines including its reasoning. In total, four strategy groups have been identified, namely: building strategies, system \& product strategies, material strategies and documentation strategies. Each strategy group is divided in design principles, a classification of multiple design guidelines that have a similar goal, which is summarised in Table 4.14. Since, the aim of the reuse potential evaluation method is 'slowing resource flows', the strategies that are related to slowing resource flows have been identified in Table 4.15. Furthermore, the overview of Design for Disassembly and reuse guidelines and principles define a reference frame for the development of the reuse potential evaluation method.

R07: What existing methods can be identified in literature to evaluate the reuse potential of buildings and building products?

In chapter 5, multiple assessment methods have been identified to assess the potential for disassembly, reuse and recycling. Such as the methods defined by: Thormark (2001), Sassi (2002) and Nordby (2009). However, all three assessment methods are limited to the assessment of individual objects, which make it difficult to understand the effect a design change has on other parts of the building. Therefore, the incorporation of the entire building structure in the assessment method is considered of major importance. Durmisevic (2006), introduced a knowledge model for assessing the Transformation Capacity of structures, with the main focus on the disassembly potential. The knowledge model of Durmisevic (2006) is composed of seventeen assessment criteria, sub-divided into functional-, technical- and physical decomposition, that are being assessed based a relational pattern of the entire structure. The transformation capacity assessment method of Durmisevic (2006) is defined as an indicator of the disassembly potential. In terms of reuse potential, the disassembly potential can be used to identify the re-claim 
effort. Therefore, the knowledge model of Durmisevic (2006), as shown in Table 5.17 is adopted and further specified in the development of the reuse potential evaluation method. Although the existing model of Durmisevic (2006) does not comply with all reuse potential assessment requirements, it provides a theoretical basis for the development of the reuse potential evaluation method to extend upon. Barriers in the knowledge model of Durmisevic (2006) that are to be addressed by the reuse potential assessment method are: 1) a uniform method to address the building structure and type of connections conform the identified reuse potential levels; 2 ) the assessment of the embodied value and re-condition effort, and; 3 ) to support ease of use and ensure consistency in assessment, the assessment should be automated based on the composition of the building.

R08: How does an evaluation method that enables the assessment of the reuse potential of buildings and building products and provides design support to designers and engineers look like?

Chapter 5 has presented the reuse potential evaluation method, which is a set of steps that includes an algorithm to evaluate the reuse potential of buildings, building systems and building products based on technological rules that utilise the building's compositional information. The reuse potential evaluation method is structured according to the conceptual reuse potential framework, in which three essential steps have been determined to evaluate the reuse potential of buildings, building systems and building products, namely: embodied value, re-claim effort and re-conditioning effort. A fourth indicator re-application effort has been excluded from the method, because this is dependent on the reuse application and cannot be predicted. Furthermore, the reuse potential evaluation method incorporates criteria from the knowledge model of Durmisevic (2006) to assess the re-claim effort. To enable an automated assessment to ease the use of the assessment method, the relational pattern of a representative section of the building needs to be identified and translated into the Design Structure Matrix. In this way an objective and consistent assessment of the reuse potential is made possible that addresses three reuse levels: building level reuse, building system level reuse and building product level reuse. A relational pattern is a generic method to define the relations between building parts, which can be identified for all buildings or construction systems and enables a uniform assessment of all types of buildings.

The reuse potential evaluation method results in a reuse potential report, which provides insight in all input values that are used and provides design support for each criteria, how the building's reuse potential could be improved. The feedback is presented in rating from 0,1 low reuse potential (indicated with red) to 0,9 high reuse potential (indicated in green). For each criteria the input data is shown to indicate which parts contributed to a low or high reuse potential score, to provides design knowledge to support designers and engineers in the design of new buildings and building products with a high reuse potential.

The users that are envisioned to benefit from this evaluation method are architects and engineers to increase their understanding how the reuse potential of buildings can 
be improved upon. Furthermore, construction consultants can be identified as users to execute the reuse potential evaluation method and support designers in improving the reuse potential of their building design or to identify reusable building products in existing buildings. Finally, the reuse potential evaluation method could be used by clients and policy makers as a benchmark method to define a minimum reuse potential score to implement circular economy objectives and contribute to a circular built environment.

RO9: How usable, applicable and useful is the evaluation method that is presented in this study if applied to case studies?

To verify the usability and applicability of the proposed evaluation method, a critical retrospective case study approach has been applied in chapter 6. In this approach two critical retrospective cases have been selected conform the 'case/ control' method. The 'control' case study building is 'Villa Zebra - Red house' a building that has been successfully relocated and reused multiple times and the 'case' building is the '4th gymnasium', a building that has been unsuccessful in being relocated despite its effort and intention to be easily relocated and reused. Since both cases already passed their first functional life and its reuse or end-of-life has already taken place, it is possible to compare the results of the reuse potential evaluation method with the actual outcomes. In order to understand and take into account the contextual influences, the impact of external influences, both cases have also been analysed in a qualitative research methods, by studying available documentation and interviewing stakeholders that were involved in de construction and/ or end-of-life of each case study buildings.

The first objective of the reuse potential evaluation method is to enable the assessment of the reuse potential of buildings, building systems and building products in the design stage or identify reusable parts in existing buildings. The results of the critical retrospective case study approach show that the reuse potential evaluation method is successful in the evaluation of the reuse potential of the case study buildings and identify the variance between two cases.

The second objective of the reuse potential evaluation method was to provide design knowledge to support designers and engineers in the design of new building and building products with a high reuse potential. The case study application demonstrates that the reuse potential results provide valuable feedback to improve the reuse potential of the design. To ensure this type of feedback is useful for the users of the evaluation method, it is recommended to test the reuse potential with actual users during the design stage of circular buildings.

The third objective of the reuse potential evaluation method is to allow clients to set a minimum reuse potential score to ensure a defined reuse potential level of the building, building system and its building products, to facilitate in circular building design objects. The evaluation method developed in this thesis demonstrates, based on two case studies, the core concept how the reuse potential of buildings and building products can be evaluated and provide design knowledge to support designers and engineers to increase 
the reuse potential. When the evaluation method is validated with the use of additional case studies and its usefulness during the design stage of circular buildings is proven, the method can also be used by clients and policy makers to set a minimum reuse potential score in e.g. design competitions to ensure a minimum level of reusability and contribute to a circular built environment.

MO: How can the reuse potential of buildings and building products be evaluated and provide design knowledge to support circular building design?

To answer the main research question, in chapter 5 the reuse potential evaluation method has been proposed, as a method to evaluate the reuse potential of building and building products and provide design knowledge to support circular building design. Furthermore, in chapter 6 the usability, applicability and usefulness of the evaluation method has been demonstrated with the use of two case study buildings.

Finally, it can be concluded that this research identified a framework to understand the effect of a design solution their potential for future reuse, provides a holistic view on the main aspects that influence the reuse potential of buildings and building products, identified the main Design for Disassembly principles and guidelines and contributes to the body of knowledge to support circular building design, by the development of a method to evaluate the reuse potential of buildings, building systems and building products.

\subsection{Scientific contributions}

This PhD thesis, of which the main research findings are outlined in the preceding section, makes several scientific contributions related to the field of circular building design. Firstly, a definition for circular building design is proposed, which is based on the key concepts that should be addressed in a circular built environment (chapter 2). Furthermore, a building product reuse design framework has been developed to gain a better understanding of the impact a design solution has on the potential for future reuse as well as the different transformations that a reuse product can undergo.

Many researchers have identified Design for Disassembly as a key strategy to enable the reuse of building products. This resulted in researchers identifying a plethora of design strategies to support the design of decomposable and reusable building structures. A third scientific contribution of this PhD thesis is the provision of a comprehensive overview of the main Design for Disassembly and Reuse strategies, which are structured in four main strategy groups.

Although, design strategies provide generic design support, they are often limited to guidelines, principles and checklists, which are unable to quantify the resulting impact on the reuse potential of the building products. Therefore, the development of a solid framework is required that supports and measures the reuse potential of buildings, buildings systems and building components. An important scientific contribution of this $\mathrm{PhD}$ therefore has been the development and validation of a framework by which the 
reuse potential of buildings and building products can be measured and which supports the designers and engineers to design buildings characterized by a high reuse potential.

In this $\mathrm{PhD}$ thesis an analysis of the environmental, social, organisational, compliance and legislation, technical and economical factors for deconstruction and reuse resulted in the identification of key indicators that influence the reuse potential of buildings, building systems and building products and forms the basis for the reuse potential evaluation method.

The main contribution of this thesis is the reuse potential evaluation method, which is presented in chapter 5 . This method extends upon the knowledge model of Durmisevic (2006) and incorporates three essential steps to determine the reuse potential, namely embodied value, re-claim effort and re-conditioning effort. The reuse potential evaluation method is based on technological rules and allows for an automated assessment based on the building's composition. One of the key elements in the automated evaluation is the translation of a relational pattern into a Design Structure Matrix (DSM). This translation allows for a structured evaluation of the reuse potential based on the building's functional, technical and physical composition. Furthermore, the DSM input method allows for a uniform assessment of all types of buildings. The reuse potential evaluation method results in a reuse potential report, which provides insight in all values that are used and specific feedback for each criterion, to support the designers and engineers in increasing the reuse potential of their design. Furthermore, the assessment method is able to identify the reuse potential at three product levels: building level, building system level and building product level, to identify the most suitable reuse approach.

Furthermore, the reuse potential evaluation method enables an explanation between the variance between the potential to reuse one building product compared to another, based on the building's or product's composition, as shown in the case study results in chapter 6 . The variance is explained based on dependent design variables. This type of evaluation allows for an objective assessment of the reuse potential of buildings, building systems and building products and supports designers in the design of circular buildings.

\subsection{Practical contributions}

The developed and validated reuse potential evaluation method, allows practical application by supporting designers in making informed design-decisions to increase the reuse potential of buildings, building systems and building products. Furthermore, it allows policy makers and clients to use the evaluation method to set a defined reuse target to enhance the transition towards a circular construction industry and eliminate the concept of waste. Additionally, the Design for Disassembly and Reuse principles and guidelines provide a comprehensive overview of existing principles and guidelines to support circular building design. 


\subsection{Limitations}

In order to identify the limitations of the research, the reuse potential evaluation method will be evaluated based on four aspects, namely: generalisability, transferability, maintainability and efficiency in use.

Firstly, the generalisability of the reuse potential evaluation method will be discussed. The reuse potential evaluation method has been developed to be used by designers, engineers and most likely consultants, to evaluate the reuse potential of any type of building. To evaluate a building, a relational pattern of a representative section of the building needs to be identified. A relational pattern is a generic method to define the relations between building parts, which can be identified for all buildings or construction systems and enables a uniform assessment of all types of buildings. Due to limited time available, the developed evaluation method has only been applied on two case study buildings, which both made use of a volumetric modular construction system.

Furthermore, the reuse potential evaluation method is limited to the evaluation of deliberate reuse potential of buildings, building systems and building products. This scope was set, because it is impossible to predict the future, and taking into account unintended reuse alternatives. As a consequence, this means that the reuse potential to deliberately reuse an object can potentially be rated as low, while it can still be reused in the future in a creative manner or with an increased amount of effort.

Secondly, the transferability of the reuse potential evaluation method will be discussed. The reuse potential evaluation method has specifically been developed to be used in the construction industry. To support ease of use and ensure consistency in assessment, the assessment is automated, based on the composition of the building. However, to enable this automated evaluation, the user must be able to develop a relational pattern of a representative section of the building, which additionally needs a translation into a Design Structure Matrix (DSM) to enable a structured input in the evaluation method. The complexity of developing a correct relational pattern and sequential DSM can form a barrier for the ease of use and transferability of the developed reuse potential evaluation method.

Thirdly, the maintainability of the reuse potential evaluation method. The reuse potential evaluation method utilises evaluation criteria that are based on technological rules that incorporate computational values. The validation of these assessment values is limited to two critical retrospective case study buildings. Therefore, it is recommended to validate the assessment method with the use of additional case studies.

Fourthly, the efficiency in use of the reuse potential evaluation method. The reuse potential evaluation method has been developed in Microsoft Excel, which allows a large user group to access the reuse potential evaluation method. Furthermore, the reuse potential assessment method is automated based on the building's compositional information. Those criteria that are not supported by automated assessment are developed in such a way that the input can be done by using a pull-down menu. To verify the efficiency in 
use it is recommended to test the reuse potential with actual users in the design stage of circular buildings. Due to time constraints, the method has not been validated by actual users.

\subsection{Future research}

The research presented in this $\mathrm{PhD}$ thesis offers multiple possibilities for additional research, which are presented in this section:

- Perform additional validation activities. Due to the limited time available during this PhD research, two critical retrospective cases have been selected to validate the functioning of the reuse potential evaluation method. In order to gain additional insights in the value of the evaluation method, it is recommended to validate its functioning with use of additional cases. Including cases of non-volumetric construction methods, to validate the value of the evaluation method on all types of buildings.

- User experience. Another aspect that should be addressed with the implementation of evaluation methods is the user experience of the reuse potential evaluation method in practice. This can be done by incorporating user group and perform a survey to identify potential improvements of the user experience.

- Integration of the reuse potential evaluation method in BIM. The reuse potential evaluation method is currently developed in Microsoft Excel. The benefit of a common tool such as Excel is that many people know how to use the programme. However, due to the complexity data required to perform the reuse potential analysis, extensive knowledge about relational patterns and Design Structure Matrix is required. The next step of the reuse potential evaluation method would be to integrate the assessment method in BIM and provide visual feedback how the reuse potential could be improved, instead of a reuse potential report. This recommendation has been explored briefly in the BAMB project. This exploration resulted in valuable insights and lessons learned for future implementation in BIM (Durmisevic et al.,2019). Furthermore, the integration of the reuse potential evaluation method in BIM would enable the incorporation of the entire building structure in the reuse potential evaluation method, instead of limiting the evaluation to a representative section of the building. In the current form, the incorporation of the entire building structure would be too time-consuming and not in proportion to the added value it provides. 
Bibliography 


\section{Bibliography}

Addis, W. \& Schouten, J. (2004). Design for deconstruction. Principles of design to facilitate reuse and recycling. London: CIRIA.

Addis, W. (2006). The world of reclamation, reuse and recycling. Building with Reclaimed Components and Materials: A Design Handbook for Reuse and Recycling, 25-54.

Aken, J. E. V. (2004). Management research based on the paradigm of the design sciences: the quest for field-tested and grounded technological rules. Journal of management studies, 41(2), 219-246.

Akinade, O. O., Oyedele, L. O., Ajayi, S. O., Bilal, M., Alaka, H. A., Owolabi, H. A., ... \& Kadiri, K. O. (2017a). Design for Deconstruction (DfD): Critical success factors for diverting end-of-life waste from landfills. Waste management, 60, 3-13.

Akinade, O. O., Oyedele, L. O., Omoteso, K., Ajayi, S. O., Bilal, M., Owolabi, H. A., ... \& Looney, J. H. (2017b). BIM-based deconstruction tool: Towards essential functionalities. International Journal of Sustainable Built Environment, 6(1), 260-271.

Allwood, J. M., Ashby, M. F., Gutowski, T. G., \& Worrell, E. (2011). Material efficiency: A white paper. Resources, Conservation and Recycling, 55(3), 362-381.

Ashby, M. F. (2012). Materials and the environment: eco-informed material choice. Elsevier.

Bakx, M., Beurskens, P. R., Ritzen, M. J., Durmisevic, E., \& Lichtenberg, J. J. N. (2016). A morphological design and evaluation model for the development of circular facades. SB16.

Beurskens, P., \& Durmisevic, E. (2017). Increasing reuse potential by taking a whole life-cycle perspective on the dimensional coordination of building products. In Vital Cities and Reversible Buildings: Conference Proceedings.

Blessing, L. T., \& Chakrabarti, A. (2009). DRM: A design reseach methodology (pp. 13-42). Springer London.

Blomsma, F., \& Brennan, G. (2017). The emergence of circular economy: A new framing around prolonging resource productivity. Journal of Industrial Ecology, 21(3), 603-614.

Boccadoro, P. A. (2008). Reuse as a Cultural Signifier and Strategy for Design. Pennsylvania, United States: Pennsylvania State University, College of Arts and Architecture (Master thesis).

Bocken, N. M., de Pauw, I., Bakker, C., \& van der Grinten, B. (2016). Product design and business model strategies for a circular economy. Journal of Industrial and Production Engineering, 33(5), 308-320. 
Brand, S. (1994). How buildings learn: what happens after they're built. Penguin, New York.

Browning, T. R. (2015). Design structure matrix extensions and innovations: a survey and new opportunities. IEEE Transactions on Engineering Management, 63(1), 27-52.

Bruijns, (2018). Duurzamer bouwen is slopend en de kosten zijn hoog [More sustainable construction is debilitating and the costs are high]. Dutch newspaper: De Limburger. Retrieved March 3, 2018, from https://www.limburger.nl/cnt/ dmf20180122_00054553/duurzamer-bouwen-is-slopend-en-de-kosten-zijn-hoog

Bunge, M. (1967). Scientific Research II: The Search for Truth. Berlin: Springer Verlag.

Calkins, M. (2008). Materials for sustainable sites: a complete guide to the evaluation, selection, and use of sus-tainable construction materials. John Wiley $\&$ Sons.

Capelle, T., Mantell, S., Steinlage, M., Henrotay, C., Balson, K., Lowres, F., Farnetani, M., Durmisevic, E., Brancart, S., Paduart, A., Elsen, S., Lankriet, W., Poppe, J., Mul. E., Luscuere, L., Morizur C., Delatte, M., Debacker, W. and Heinrich, M. (2019). Buildings as material banks - testing bamb results through prototyping and pilot projects. Available at. https://www.bamb2020.eu/wp-content/uploads/2019/03/20190228-BAMB-D14.pdf

Chini, A. R. (2007). General issues of construction materials recycling in USA. Proceedings of Sustainable Construc-tion, 848-855.

Chini, A. R., \& Balachandran, S. (2002). Anticipating and responding to deconstruction through building design. proceedings of Design for Deconstruction and Materials Reuse, CIB Publication, 272, 175-185.

Cooper, D. R., \& Allwood, J. M. (2012). Reusing steel and aluminum components at end of product life. Environmental science $\&$ technology, 46(18), 10334-10340.

Cooper, D. R., \& Gutowski, T. G. (2017). The environmental impacts of reuse: a review. Journal of Industrial Ecology, 21(1), 38-56.

Couto, A., \& Couto, J. P. (2010). Guidelines to improve construction and demolition waste management in Portugal. In Process Management. InTech.

Couto, J., \& Couto, A. (2010). Analysis of barriers and the potential for exploration of deconstruction techniques in Portuguese construction sites. Sustainability, 2(2), 428-442.

Crone, J. (2007). Leren door demonstreren; de oogst von 7 ioar iFD bouwen (Learning by illustrating; the benefits of 7 years experimenting). Line Up Mediaservices, Boxtel.

Crowther, P. (2001). Developing an inclusive model for design for deconstruction. Deconstruction and Materials Reuse: Technology, Economic, and Policy, 1.

Crowther, P., (2002). Design for buildability and the deconstruction consequences. In: Chini, A.S., Frank (Eds.), CIB Task Group 39 - Deconstruction, Annual Meeting 2002, Karlsruhe, Germany. 
De vries, K. (2008) Ad interim met permanente kwaliteit - 4de gymnasium Amsterdam. Houtblad.

Debacker, W., Manshoven, S., Apelman L., Beurskens P., Biberkic F., Denis F., Durmisevic E., Dzubur A., Hansen K., Henrotay C., Herthogs P., Hobbs G., Hrasnica M., McCormick S., Mulhall D., Oseyran J., Paduart A, Peeters K., PetersM., Quintas A., Ribeiro A., Steinlage Cornet M., Serdarevic A., van den Berg M., van Oorschot J.A.W.H., Vandenbroucke M. and Zanatta R. (2016). D1 Synthesis of the state-of-the-art.Available at. http://www. bamb2020.eu/wp-content/uploads/2016/03/D1_Synthesis-report-on-State-of-theart_20161129_FINAL.pdf

Den Hollander, M. C., Bakker, C. A., \& Hultink, E. J. (2017). Product design in a circular economy: Development of a typology of key concepts and terms. Journal of Industrial Ecology, 21(3), 517-525.

Deniz, O. S., \& Dogan, E. (2014). Building Façade System for Deconstruction. Journal of Sustainable Architecture and Civil Engineering, 8(3), 59-74.

Detail magazine, (2002). Children's hall of art in Rotterdam. Retrieved from https:// inspiration.detail.de/childrens-hall-of-art-in-rotterdam-106390.html?lang=en

Dolan, P. J., Lampo, R. G., \& Dearborn, J. C. (1999). Concepts for reuse and recycling of construction and demolition waste (No. CERL-TR-99/58). CONSTRUCTION ENGINEERING RESEARCH LAB (ARMY) CHAMPAIGN IL.

Duffy, F. (1990). Measuring building performance. Facilities, 8(5), 17-20.

Durmisevic, E. (2006). Transformable Building Structures: Design for disassembly as a way to introduce sustaina-ble engineering to building design $\&$ construction. TU Delft, PhD Dissertation.

Durmisevic, E., Beurskens, P., Van den Boogaart, E., Balson, K. \& Hobbs, G. (2019) Deliverable D8, Reversible building design, Reuse potential tool,

Earle, J., Ergun, D., \& Gorgolewski, M. (2014). Barriers for deconstruction and reuse/ recycling of construction materials in Canada. Barriers for Deconstruction and Reuse/ Recycling of Construction Materials, 20.

Eekhout, M. (2016). Componentontwerpen en productontwikkelen. IOS Press.

Ellen MacArthur Foundation (2012). Towards the Circular Economy: Economic and Business Rationale for an Accelerated Transition, volume 1. Available at. https://www.ellenmacarthurfoundation.org/assets/downloads/publications/Ellen-MacArthur-Foundation-Towards-the-Circular-Economy-vol.1.pdf

Ellen MacArthur Foundation (2013). Towards the Circular Economy: Opportunities for the consumer goods sector, volume 2. Available at. https://www.ellenmacarthurfoundation.org/assets/downloads/publications/TCE_Report-2013.pdf 
Ellen MacArthur Foundation (2014). Towards the Circular Economy: Accelerating the Scale-up Across Global Supply Chains, volume 3. Available at. https://www.ellenmacarthurfoundation.org/assets/downloads/publications/Towards-the-circular-economy-volume-3.pdf

Eppinger, S. D., \& Browning, T. R. (2012). Design structure matrix methods and applications. MIT press.

Erens, F., \& Verhulst, K. (1997). Architectures for product families. Computers in industry, 33(2), 165-178.

EU Commission, (2011). Roadmap to a resource efficient Europe. COM, 571.

Eurostat, (2017). Waste statistics - may 2017. Retrieved September 05, 2017, from http:// ec.europa.eu

Fletcher, S. L. (2001). Developing disassembly strategies for buildings to reduce the lifetime environmental im-pacts by applying a systems approach (Doctoral dissertation, University of Sheffield).

Flores \& Prats, (2018). Home - Sala Beckett (project) Retrieved April 6, 2018, http:// floresprats.com/theatre-sala-beckett/

Gamle Mursten, (2018). The Rebrick project. Retrieved April 6, 2018, http://www. gamlemursten.eu/

Gebala, D. A., \& Eppinger, S. D. (1991). Methods for analyzing design procedures.

Geldermans, R. J. (2016). Design for change and circularity-accommodating circular material \& product flows in construction. Energy Procedia, 96, 301-311.

Geyer, R., \& Jackson, T. (2004). Supply loops and their constraints: the industrial ecology of recycling and reuse. California Management Review, 46(2), 55-73.

Geyer, R., Jackson, T., \& Clift, R. (2002). Economic and environmental comparison between recycling and reuse of structural steel sections. In Int. Iron and Steel Institute World Conf (pp. 13-18).

Ghenciulescu, (2018). ABRUPTARHITECTURA: From sheltering cars to sheltering people. E-zeppelin magazine. Retrieved April 3, 2018, from http://e-zeppelin.ro/en/abruptarhitectura-from-sheltering-cars-to-sheltering-people/

Gielen, M. (2018). Identifying new material flows in industry and construction - Rotor. Presentation at ecobuild March 7, 2018, London.

Goens, H., Capelle, T., Henrotay, C., Steinlage, M., Durmisevic, E., Beurskens, P. Mull, E., Androsevic, R., Paduart, A., Elsen, S., Lanckriet, W. and Poppe, J. (2018). D13 Prototyping + Feedback report, testing BAMB results through prototyping and pilot projects. Available at. http://www.bamb2020.eu/wp-content/uploads/2018/10/20180425BAMB-WP4-D13.pdf 
Gorgolewski, M. (2008). Designing with reused building components: some challenges. Building Research \& Information, 36(2), 175-188.

Gorgolewski, M. (2018). Resource Salvation: The Architecture of Reuse. John Wiley \& Sons.

Guy, B., \& Ciarimboli, N. (2008). DfD: Design for Disassembly in the Built Environment: A Guide to Closed-Loop Design and Building. Hamer Center.

Guy, B., Shell, S., (2002). Design for deconstruction and materials reuse. Proceedings of the CIB Task Group 39 - Deconstruction Meeting, Karlsruhe, Germany.

Habraken, N.J. (1961). De dragers en de mensen: het einde van de massawoningbouw. Amsterdam, Netherlands: Scheltema \& Holkema.

Hechler, O., Larsen, O. P., \& Nielsen, S. (2012). Design for deconstruction. COST, European Cooperation in Science and Technology, Malta.

Hechler, O., Larsen, O.P., Nielsen, S. (2012). Design for deconstruction. COST, European Cooperation in Science and Technology, Malta.

Hoogstede J. \& Tummers, S. (2001) Villa Zebra: Kunsthal voor kinderen. Chepos augustus 2001, pp. 32-35.

Hosseini, M. R., Rameezdeen, R., Chileshe, N., \& Lehmann, S. (2015). Reverse logistics in the construction industry. Waste Management $\&$ Research, 33(6), 499-514.

Hosseini, M., Chileshe, N., Rameezdeen, R., \& Lehmann, S. (2014). Reverse logistics for the construction industry: lessons from the manufacturing context (Doctoral dissertation).

Hradil, P., Talja, A., Wahlström, M., Huuhka, S., Lahdensivu, J., \& Pikkuvirta, J. (2014). Re-use of struc-tural elements. Environmentally efficient recovery of building components. VTT Technology, 200.

Hurley, J., Goodier, C., Garrod, E., Grantham, R., Lennon, T., \& Waterman, A. (2002). Design for Deconstruction-Tools and Practices. CIB, International Council for Research and Innovation in Building Construction, editor. Proceedings of the CIB Task Group, 39.

HVDN Architecten (n.d.) Het 4e gymnasium, Amsterdam - onderwijsgebouw houthavens, retrieved from http://www.hvdn.nl/2111/projecten/0789ut.htm

lacovidou, E., \& Purnell, P. (2016). Mining the physical infrastructure: Opportunities, barriers and interventions in promoting structural components reuse. Science of the Total Environment, 557, 791-807.

Kibert, C. J., Chini, A., \& Languell, J. (2000). Deconstruction as an essential component of sustainable construction. In Proceedings of the second Southern African conference on sustainable development in the built environment, Pretoria (pp. 1-5).

Kirchherr, J., Reike, D., \& Hekkert, M. (2017). Conceptualizing the circular economy: An analysis of 114 definitions. Resources, Conservation and Recycling, 127, 221-232.

Kiyoshi, S. (1977). The Art of Japanese Joinery. Boston: Weatherhill. 
Kohler, N., König, H., Kreissig, J., \& Lützkendorf, T. (2010). A life cycle approach to buildings: Principles-Calculations-Design tools. Walter de Gruyter.

Krausmann, F., Gingrich, S., Eisenmenger, N., Erb, K. H., Haberl, H., \& Fischer-Kowalski, M. (2009). Growth in global materials use, GDP and population during the 20th century. Ecological economics, 68(10), 2696-2705.

Lambert, A. F., \& Gupta, S. M. (2004). Disassembly modeling for assembly, maintenance, reuse and recycling. CRC press.

Langston, C., Wong, F. K., Hui, E. C., \& Shen, L. Y. (2008). Strategic assessment of building adaptive reuse opportunities in Hong Kong. Building and Environment, 43(10), 1709-1718.

Lazarus, N. (2003). Beddington Zero (Fossil) Energy Development Construction Materials Report Part 1 and 2. Bioregional Development Group and DTI.

Lebesque, S. (2018) Gemeente Amsterdam - Gebouwd in amsterdam - 4e Gymnasium. Retrieved from https://www.gebouwdin.amsterdam.nl

Leigh, N. G., \& Patterson, L. M. (2006). Deconstructing to redevelop: a sustainable alternative to mechanical demolition: the economics of density development finance and pro formas. Journal of the American Planning Association, 72(2), 217-225.

Lendager Group, (2018a). Upcycling - Upcycle products. Retrieved April 5, 2018, from https://lendager.com/en/upcycle-en/

Lendager Group, (2018b). Architecture - Resource rows. Retrieved April 5, 2018, https:// lendager.com/en/architecture/resource-rows/

Leupen, B. (2013). Polyvalence, a concept for the sustainable dwelling. NA, 19(3).

Maurer United Architects. (2018). Superlocal. Retrieved from http://www.maurerunited. com/projects

McDonough, W., \& Braungart, M. (2010). Cradle to cradle: Remaking the way we make things. North point press.

Meijs, M., \& Knaack, U. (2012). Components and connections: Principles of construction. Walter de Gruyter.

Meijs, M., Knaack, U., Klein, T., \& Bilow, M. (2009). Components and Connections in Architecture. Principles of Construction.

Microsoft (2016), Excel 2016.

Morgan, C., \& Stevenson, F. (2005). Design and detailing for deconstruction. Scotland Environmental Design Association, SEDA Design Guides for Scotland, (1).

Muis, R. (2016). Modulair gebouwd, toch gesloopt. Architectenweb Retrieved from https:// architectenweb.nl/nieuws/artikel.aspx?ID=39654 
Ness, D., Swift, J., Ranasinghe, D. C., Xing, K., \& Soebarto, V. (2015). Smart steel: new paradigms for the reuse of steel enabled by digital tracking and modelling. Journal of cleaner production, 98, 292-303.

Nordby, A. S. (2009). Salvageability of building materials: Reasons, criteria and consequences regarding architec-tural design that facilitate reuse and recycling (Doctoral dissertation).

Nordby, A. S., Hestnes, A. G., \& Berge, B. (2008). Lifetime and demountability of building materials. In M. Mourshed (Ed.), GBEN 2006 International Conference on Global Built Environment: Towards an Integrated Approach for Sustainability (p. 172). Lulu. com.

Paduart, A. (2012). Re-design for change: a 4 dimensional renovation approach towards a dynamic and sustainable building stock (Doctoral dissertation).. Vrije Universiteit Brussel, Brussels.

Post, J. (2017). Congres Biobased Revolution - opschalen naar brede bouwstroom (presentation). Retrieved from https://www.biobasedrevolution.nl/presentaties

Potting, J., Hekkert, M. P., Worrell, E., \& Hanemaaijer, A. (2017). Circular economy: measuring innovation in the product chain(No. 2544). PBL Publishers.

Pulaski, M., Hewitt, C., Horman, M., \& Guy, B. (2003). Design for deconstruction: Material reuse and con-structability. The Pittsburgh Papers: Best of Greenbuild 2003, 74-81.

Reike, D., Vermeulen, W. J., \& Witjes, S. (2018). The circular economy: New or Refurbished as CE 3.0?-Exploring Controversies in the Conceptualization of the Circular Economy through a Focus on History and Resource Value Retention Options. Resources, Conservation and Recycling, 135, 246-264.

Rios, F. C., Chong, W. K., \& Grau, D. (2015). Design for disassembly and deconstruction-challenges and opportunities. Procedia engineering, 118, 1296-1304.

Rios, F. C., Chong, W. K., \& Grau, D. (2015). Design for disassembly and deconstruction-challenges and oppor-tunities. Procedia Engineering, 118, 1296-1304.

RotorDC, (2018). Store - Furnishings - Laminated timber panels (gluelam). Retrieved April 3, 2018, from https://rotordc.com/product/laminated-timber-panels-2/

Rudbeck, C. C., \& Svendsen, S. (1999). Methods for designing building envelope components prepared for repair and maintenance. Technical University of DenmarkDanmarks Tekniske Universitet, Department of Civil EngineeringInstitut for Byggeri og Anlæg, Section for Building Physics and ServicesSektion for Bygningsfysik og Installationer.

Sassi, P. (2002). Study of current building methods and products that enable dismantling and their classification according to their ability to be reused, recycled or downcycled. In International Conference for Sustainable Building, Oslo.

Sassi, P. (2009). Closed loop material cycle construction: Defining and assessing closed loop material cycle con-struction as a component of a comprehensive approach to sustainable material design in the context of sustainable building. Cardiff University. 
Schmidt, R. I. (2014). Designing for Adaptability in Architecture. Loughborough, England: Loughborough University, School of Civil and Building Engineering (Doctoral dissertation).

Schulitz \& Partner, (1996). Bauten und Projekte = buildings and projects. Berlin: Ernst \& Sohn.

Schultmann, F., \& Sunke, N. (2007). Energy-oriented deconstruction and recovery planning. Building Research \& Information, 35(6), 602-615.

Shedroff, N. (2009). Design is the problem: the future of design must be sustainable. Rosenfeld Media.

Stahel, W. R. (2010). The performance economy, 2nd ed. London: Palgrave Macmillan.

Steward, D. V. (1981). The design structure system: A method for managing the design of complex systems. IEEE transactions on Engineering Management, (3), 71-74.

Storey, J. B., \& Pedersen, M. (2014). Overcoming the barriers to deconstruction and materials reuse in New Zealand. Barriers for Deconstruction and Reuse/Recycling of Construction Materials, CIB Publications, CIB General Secretariat Publisher, Rotterdam, 130-145.

Superlocal. (2018). Superlocal. Retrieved. March, 2018, from https://www.superlocal.eu

Swanborn, P. (2010). Case study research: What, why and how?. Sage.

Thormark, C. (2001). Recycling potential and design for disassembly in buildings. Lund Institute of Technology, Lund University, Lund, Sweden.

Timman, S. \& Bogers, M. (2016) Voordracht voor de collegevergadering van 21 juni 2016 - Onderwijs - Aanbesteden sloop en hergebruik van (onderdelen van) het semi-permanente gebouw 4e gymnasium, no. ZD2016-004605

Timmermans, A. W. C., \& Zwarts, M. (1985). Bevestigingsmiddelen. Delftse Universitaire Pers

Tingley, D. (2012). Design for deconstruction: An appraisal (Doctoral dissertation, University of Sheffield).

Tingley, D. D., \& Davison, B. (2011). Design for deconstruction and material reuse. Proceedings of the Institution of Civil Engineers-Energy, 164(4), 195-204.

Tingley, D. D., Cooper, S., \& Cullen, J. (2017). Understanding and overcoming the barriers to structural steel reuse, a UK perspective. Journal of cleaner production, 148, 642-652.

United Nations Environment Programme, (2011). Decoupling - Natural resource use and environmental impacts from economic growth. Retrieved from http://www.unep.org/ resourcepanel/decoupling/files/pdf/Decoupling_Report_English.pdf

Van Gils, A.H.P. \& Van der Laan, E.E. (2016). beantwoording schriftelijke vragen van de leden Vink en Bosman van 22 september, gepubliceerd op 12 oktober 2016, nr 1337 
Van Hinte, E., Peeren, C., \& Jongert, J. (2007). Superuse: constructing new architecture by shortcutting material flows. 010 Publishers.

Van Nunen, H., Hendriks, N. A., \& Erkelens, P. A. (2003). Influence of service life on Life Cycle Assessments. Proceedings ILCDES.

Vibaek, K. (2011). System structures in architecture (Doctoral dissertation, PhD thesis, School of Architecture, Design and Conservation, The Royal Danish Academy of Fine Arts).

Webster, M. D., \& Costello, D. (2005). Designing structural systems for deconstruction: How to extend a new building's useful life and prevent it from going to waste when the end finally comes. In Greenbuild Conference, Atlanta, GA.

Yin, R. K. (2014). Case study research: design and methods 5th ed. Thousand Oaks. 


\section{Part V - Supplements}

\section{Appendix A}

Enablers, opportunities and barriers 


\section{Appendix A - Enablers, opportunities and barriers}

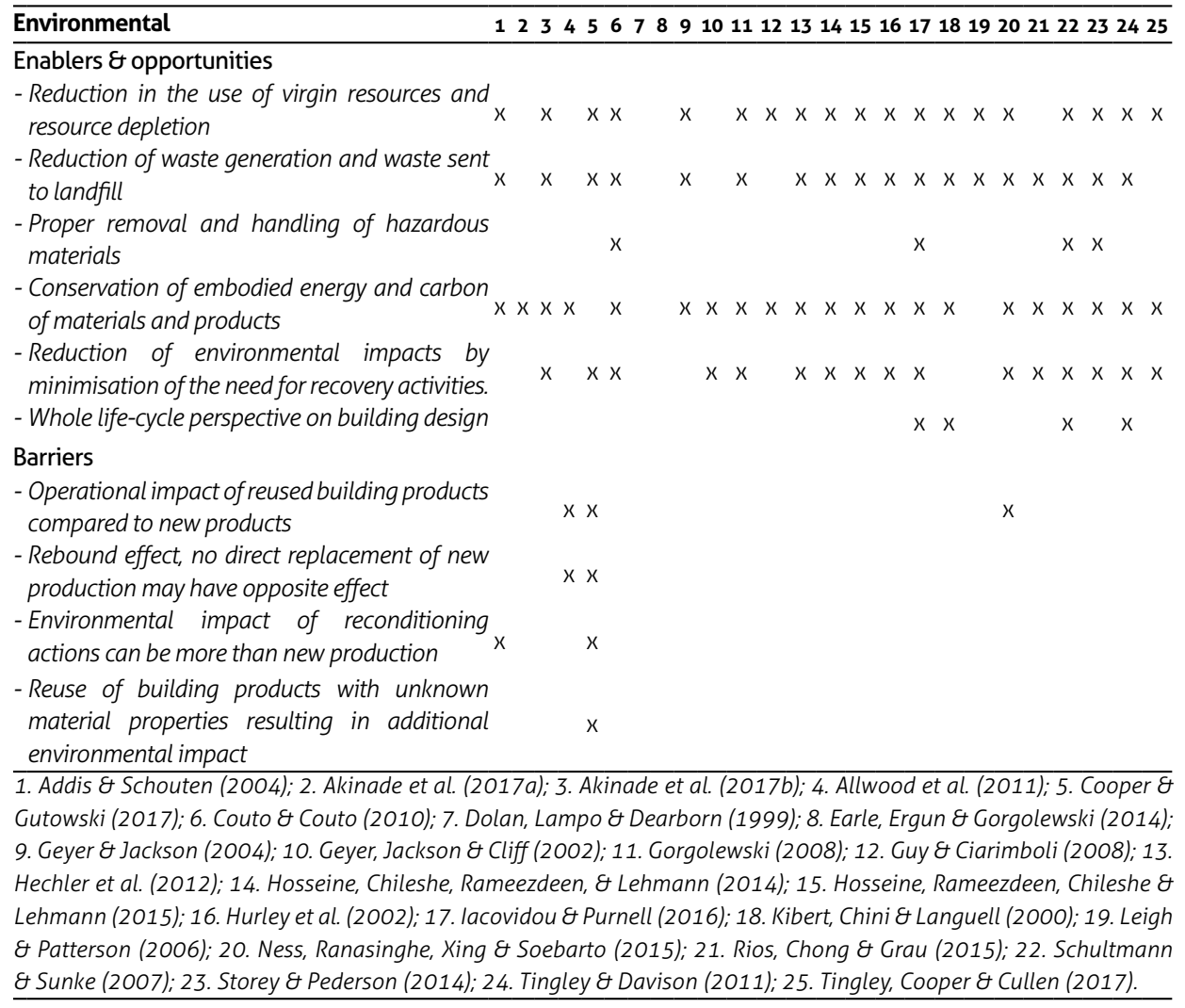




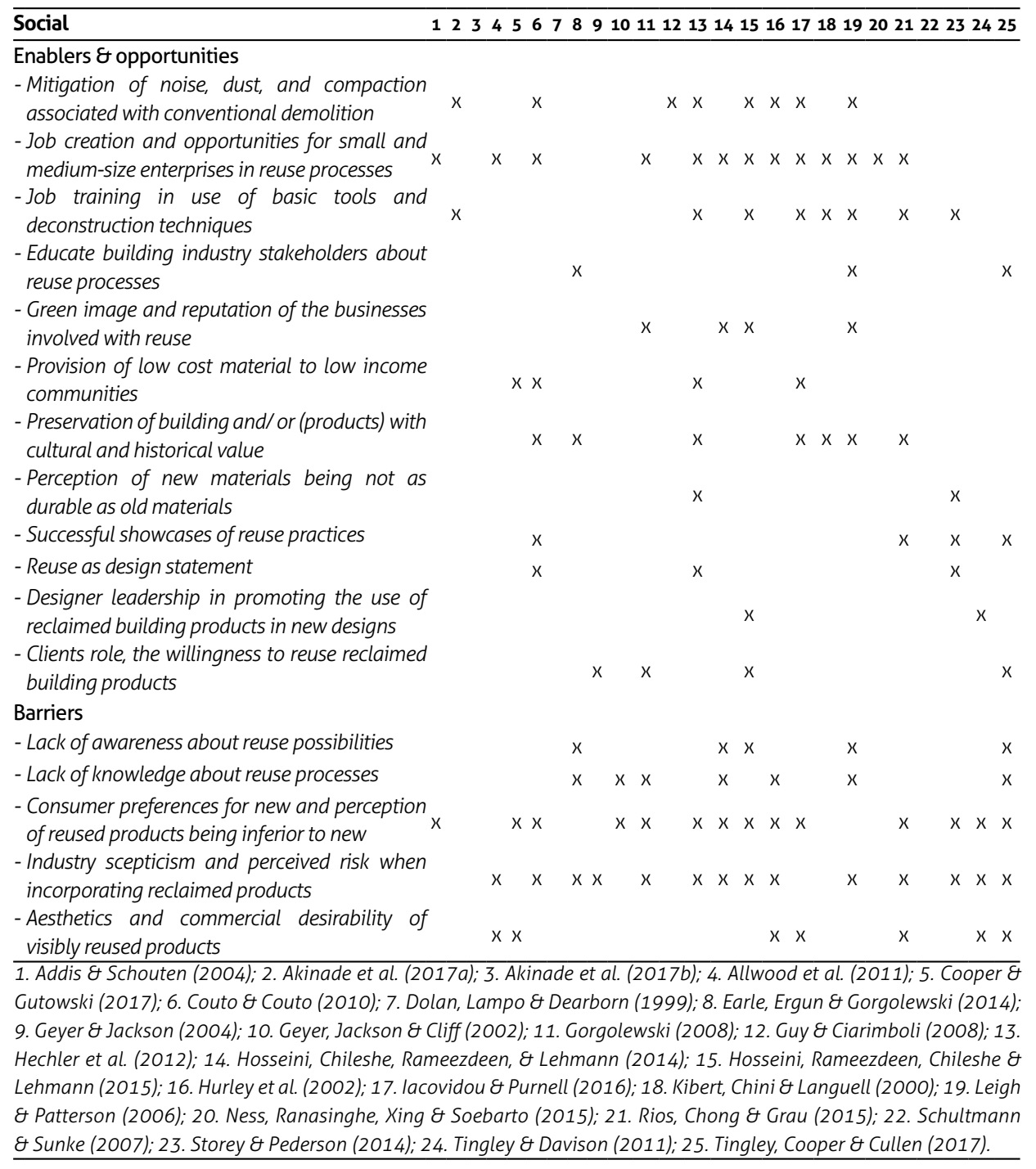




\section{Organisational}

123456678910111213141516171819202122232425

Enablers \& opportunities

- Reclaimed building product inventories/ lists of suppliers of reclaimed building products

- List buildings that are to be demolished

- Demonstrate demand for reclaimed products

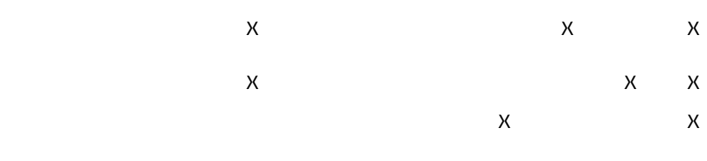

- Development of standard method to assess,

test and certify reclaimed building products $\mathrm{x} x \mathrm{x} \times \mathrm{x} \times \mathrm{x} \times \mathrm{x} \times \mathrm{x} \times \mathrm{x} \times \mathrm{x} \quad \mathrm{x} \times \mathrm{x}$ and assure performance requirements

- Building information modelling opportunities to identify, analyse and support reuse processes

- High reclamation of components for reuse and recycling, will stimulate market development

- Storage area (on-site) to overcome time gap between identification, design and actual reuse

$x \times$

Barriers

- Lack of a grading system for the reuse of reclaimed building products

- Lack of a coordinated supply chain

- Lack of collaboration among stakeholders during design, construction and deconstruction

- Lack of recovery facilities and infrastructure for reuse

- Lack of performance guarantee of reclaimed building products

- Limited supply of reclaimed building products in quantity and quality

- Lack of consistent supply of reclaimed building products and limited (guaranteed) demand for reclaimed building products

- Increased design complexity, requiring addition preparation and design time for reuse

- Wide variety of origin points when reusing building products

- Immobility of buildings and huge size of building products

- Large number of decision makers involved

- Tight scheduling of deconstruction projects

- Timing of reclaimed building products becoming available

- Timing of reclamation activities

- Time gap between identification, design and actual reuse of building products

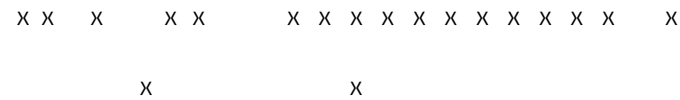

$x$

$\begin{array}{cccccccccc}x & x & & x & x & x & x & x & x & x \\ x & x & x & x & x & x & x & x & x\end{array}$

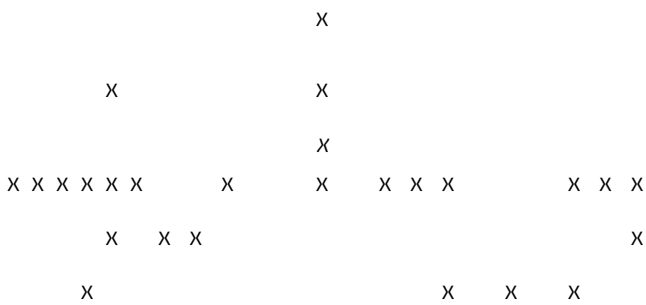

1. Addis \& Schouten (2004); 2. Akinade et al. (2017a); 3. Akinade et al. (2017b); 4. Allwood et al. (2011); 5. Cooper \& Gutowski (2017); 6. Couto \& Couto (2010); 7. Dolan, Lampo \& Dearborn (1999); 8. Earle, Ergun \& Gorgolewski (2014); 9. Geyer \& Jackson (2004); 10. Geyer, Jackson \& Cliff (2002); 11. Gorgolewski (2008); 12. Guy \& Ciarimboli (2008); 13. Hechler et al. (2012); 14. Hosseini, Chileshe, Rameezdeen, \& Lehmann (2014); 15. Hosseini, Rameezdeen, Chileshe \& Lehmann (2015); 16. Hurley et al. (2002); 17. Iacovidou \& Purnell (2016); 18. Kibert, Chini \& Languell (2000); 19. Leigh \& Patterson (2006); 20. Ness, Ranasinghe, Xing \& Soebarto (2015); 21. Rios, Chong \& Grau (2015); 22. Schultmann \& Sunke (2007); 23. Storey \& Pederson (2014); 24. Tingley \& Davison (2011); 25. Tingley, Cooper \& Cullen (2017). 


\section{Compliance and legislation}

1223455678910111213141516171819202122232425

Enablers and opportunities

- Incentive for carbon emission reduction

- Increase rewards for incorporation of DFD and reuse of building products in assessment methods

- Governmental leadership in promoting the deconstruction and reuse in their buildings

- Tax deduction on deconstruction and recovery activities

- Mandatory waiting period for demolition to increase deconstruction and reuse possibilities

- Landfill and incineration tax

- Tax virgin material use

- Legislate deconstruction and reuse plans

- Reclaimed material use quota for new buildings $x$

- Landfill bans on reusable materials

- Extended producer responsibility by product-service systems or take-back systems

${ }^{x} x^{x}$

\section{Barriers}

- Lack of standards and building codes that address reuse

- Lack of legislative and policy strategies

that provide incentives to boost design for $x \times$

deconstruction, and deconstruction and reuse

- Existing legislation forming a disincentive for reuse

1. Addis \& Schouten (2004); 2. Akinade et al. (2017a); 3. Akinade et al. (2017b); 4. Allwood et al. (2011); 5. Cooper \& Gutowski (2017); 6. Couto \& Couto (2010); 7. Dolan, Lampo \& Dearborn (1999); 8. Earle, Ergun \& Gorgolewski (2014); 9. Geyer \& Jackson (2004); 10. Geyer, Jackson \& Cliff (2002); 11. Gorgolewski (2008); 12. Guy \& Ciarimboli (2008); 13. Hechler et al. (2012); 14. Hosseini, Chileshe, Rameezdeen, \& Lehmann (2014); 15. Hosseini, Rameezdeen, Chileshe \& Lehmann (2015); 16. Hurley et al. (2002); 17. lacovidou \& Purnell (2016); 18. Kibert, Chini \& Languell (2000); 19. Leigh \& Patterson (2006); 20. Ness, Ranasinghe, Xing \& Soebarto (2015); 21. Rios, Chong \& Grau (2015); 22. Schultmann \& Sunke (2007); 23. Storey \& Pederson (2014); 24. Tingley \& Davison (2011); 25. Tingley, Cooper \& Cullen (2017). 


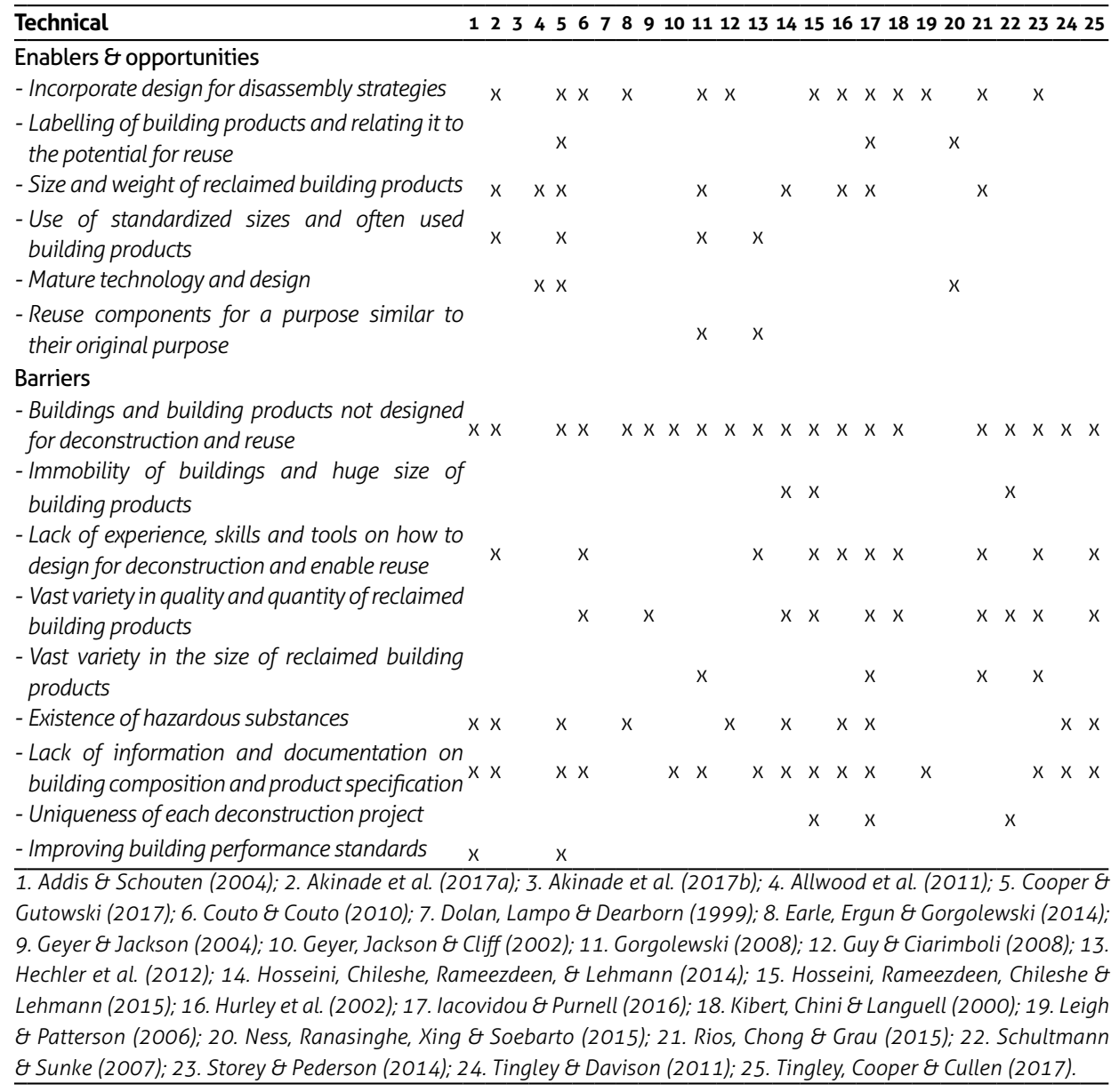




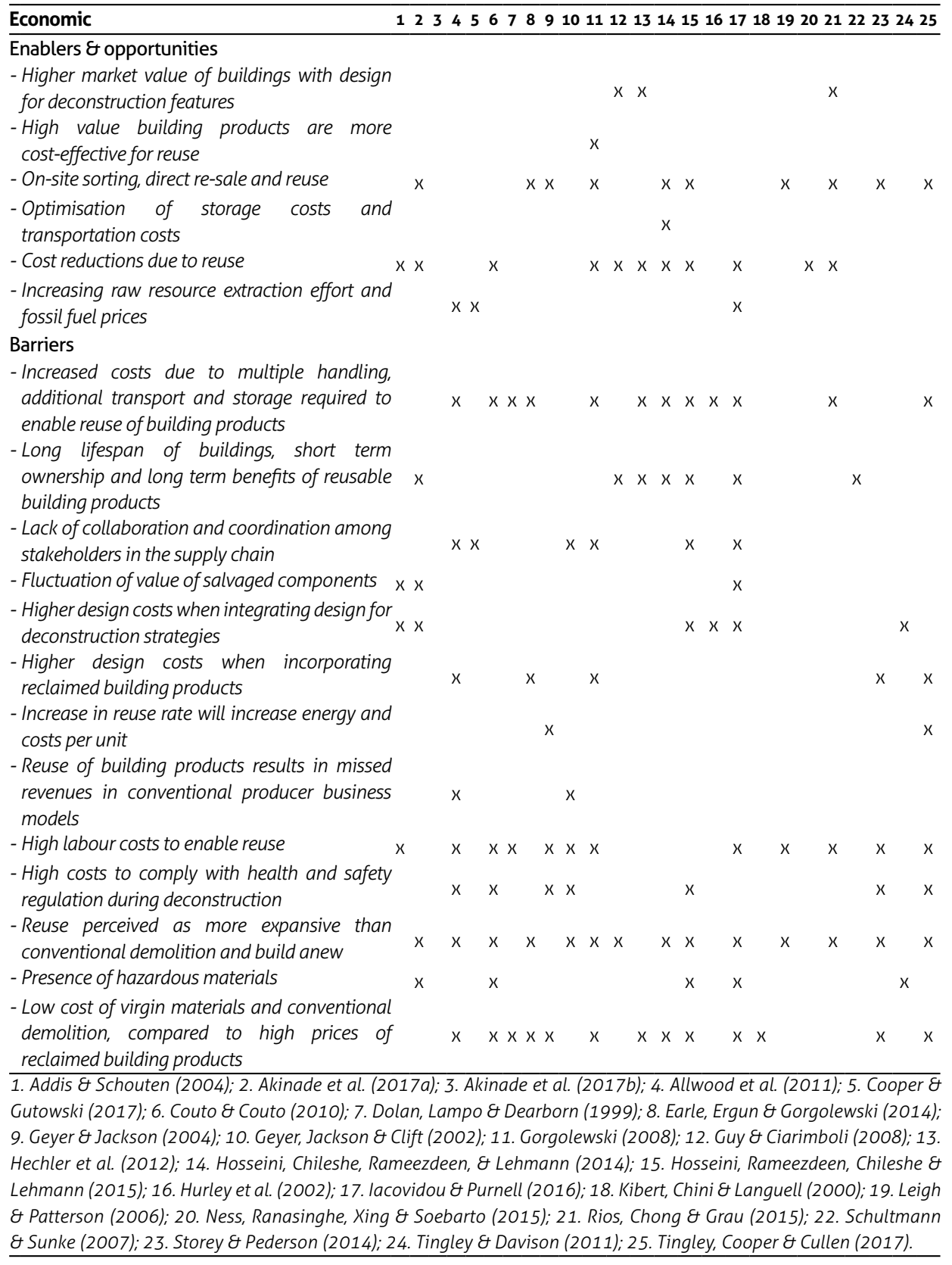


Appendix B

\section{Design for Disassembly guidelines}




\section{Appendix B - Design for Disassembly guidelines}

\section{Building strategies}

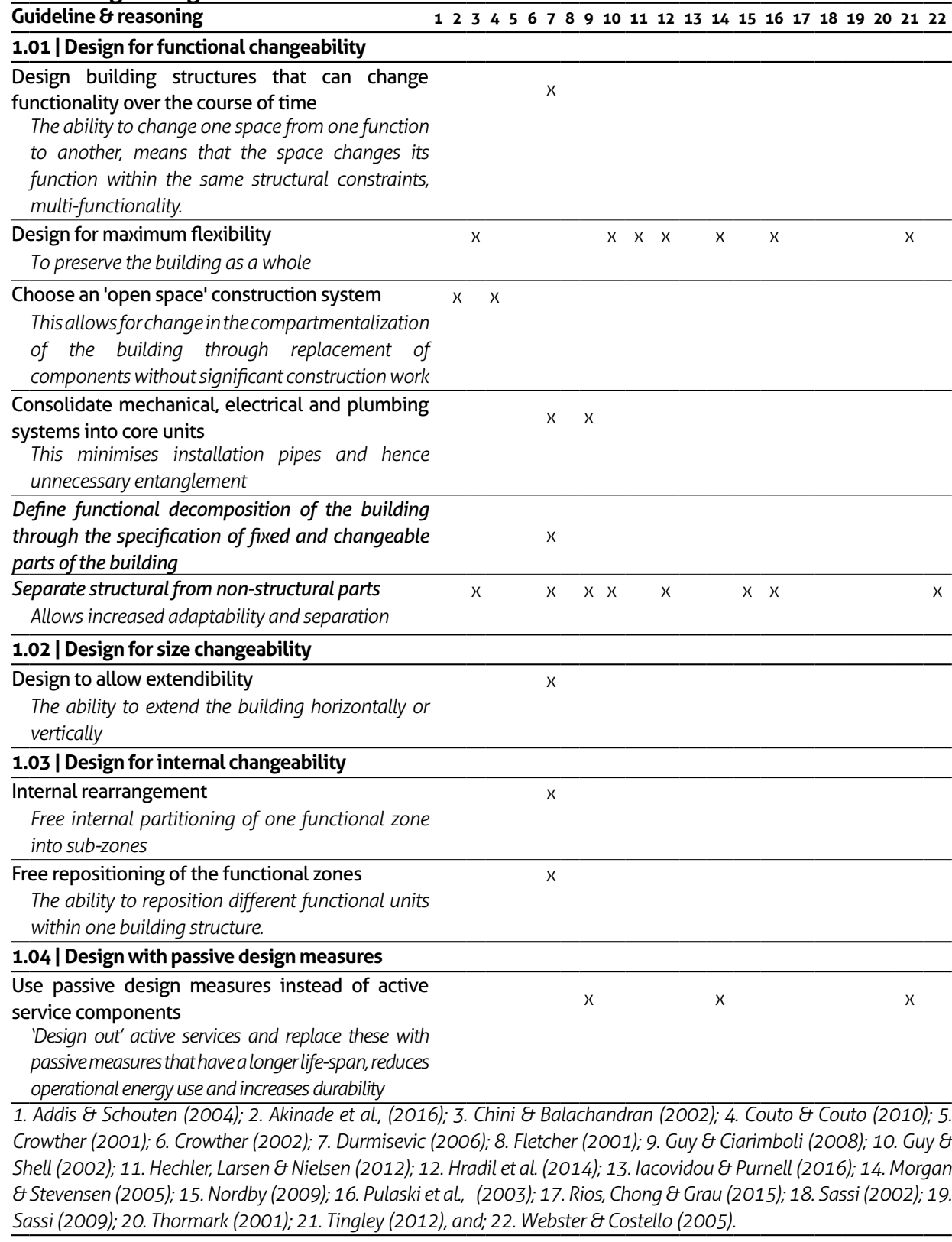




\section{System \& product strategies - Part strategies}

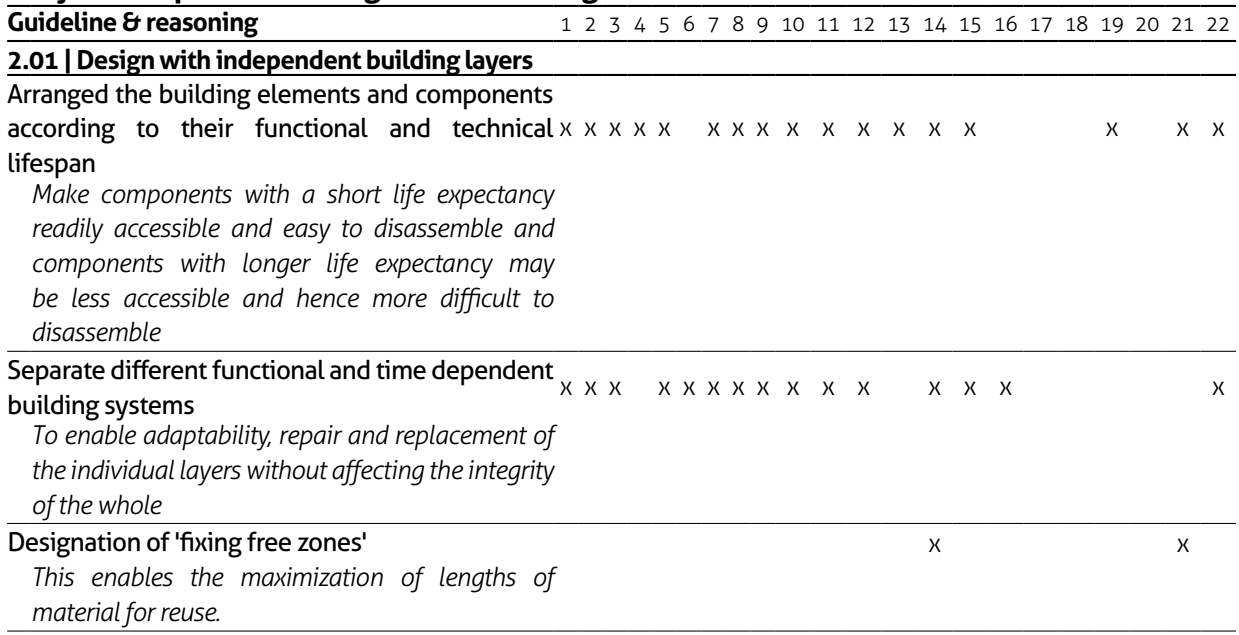

Separate building products that correspond to

independent building functions

To enable reclamation, recondition and reuse

actions of the individual layers without affecting the integrity of the building

Separate installation systems $x \times x$

Disentangling installation systems from the assemblies that host them makes it easier to separate components and materials for reclamation, recondition and reuse actions

Setting the boundary conditions for transformation and specification of long- and short-term use scenarios

Develop life cycle coordination matrix in order to

define the point of disassembly

Enable reuse of elements which are expected to

have a longer technical lifespan than the building

Provide access to all components and elements Ease of access will allow ease of disassembly

Provide accessibility to components with a shorter life cycle

This allows easy replacement of frequently

changing parts

2.02 | Modular and universal design
Use modular designs
The use of standardized components and
pre-assembled configurations that are compatible
with other systems both dimensionally and
functionally will increase its exchangeability and
reusability
1. Addis \& Schouten (2004); 2. Akinade et al., (2016); 3. Chini \& Balachandran (2002); 4. Couto \& Couto (2010); 5 .
Crowther (2001); 6. Crowther (2002); 7. Durmisevic (2006); 8. Fletcher (2001); 9. Guy \& Ciarimboli (2008); 10. Guy \&
Shell (2002); 11. Hechler, Larsen \& Nielsen (2012); 12. Hradil et al. (2014); 13. lacovidou \& Purnell (2016); 14. Morgan
\&Stevensen (2005); 15. Nordby (2009); 16. Pulaski et al., (2003); 17. Rios, Chong \& Grau (2015); 18. Sassi (2002); 19.
Sassi (2009); 20. Thormark (2001); 21. Tingley (2012), and; 22. Webster \& Costello (2005).




\section{System \& product strategies - Part strategies}

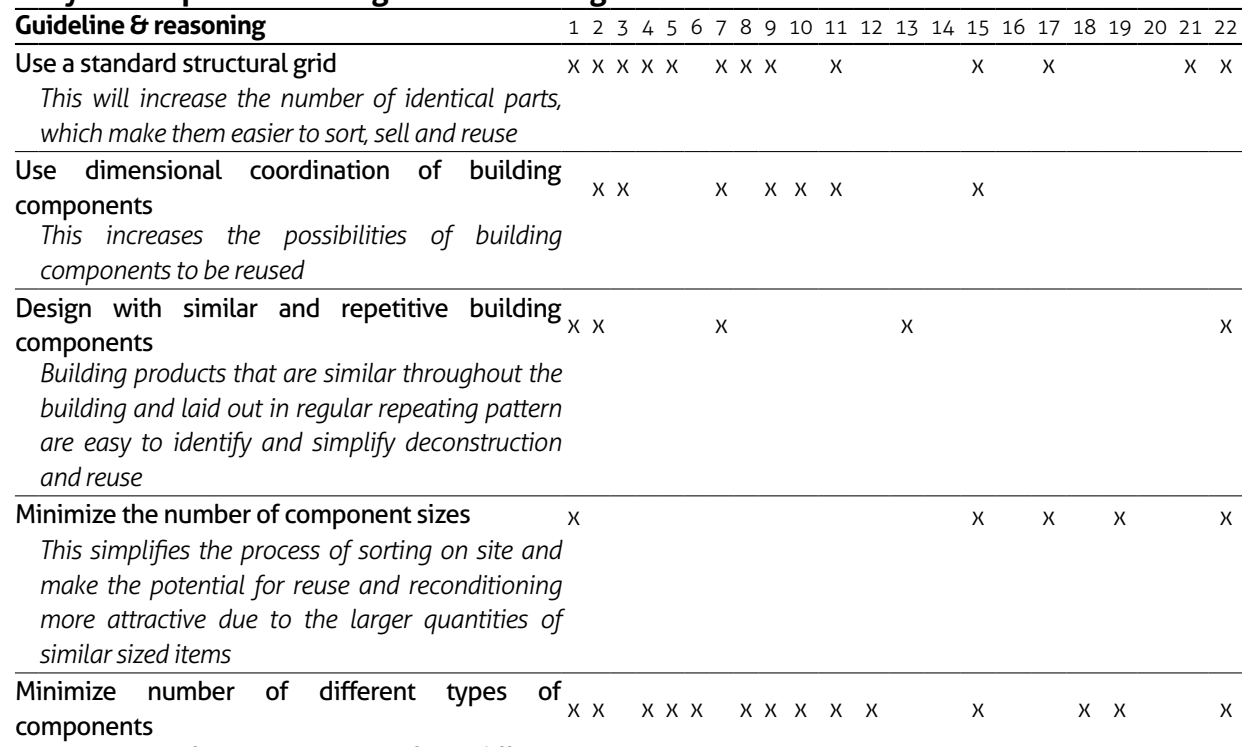

Fewer types of component means fewer different disassembly operations that need to be known, learned or remembered - it also means more standardization in the reassembly process which will ease relocation and makes the potential for reuse and reprocess more attractive due to the larger quantities of same or similar items

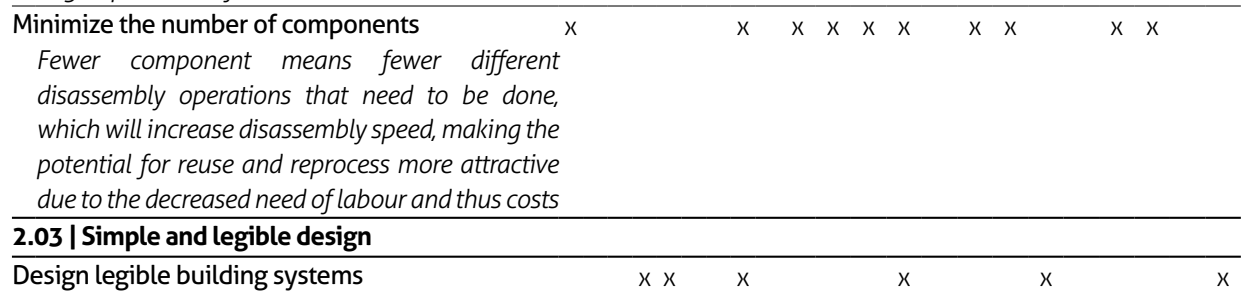

Transparency and clarity of building systems that are visible and easy to identify, simplify the deconstruction process

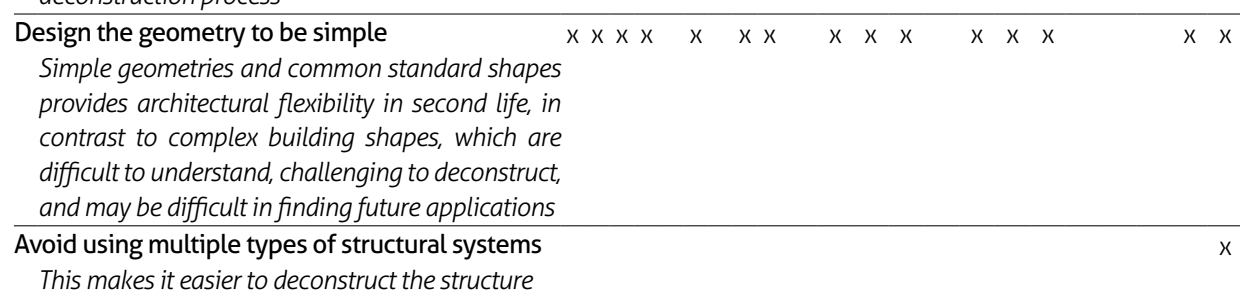

1. Addis \& Schouten (2004); 2. Akinade et al., (2016); 3. Chini \& Balachandran (2002); 4. Couto \& Couto (2010); 5. Crowther (2001); 6. Crowther (2002); 7. Durmisevic (2006); 8. Fletcher (2001); 9. Guy \& Ciarimboli (2008); 10. Guy \& Shell (2002); 11. Hechler, Larsen \& Nielsen (2012); 12. Hradil et al. (2014); 13. lacovidou \& Purnell (2016); 14. Morgan \& Stevensen (2005); 15. Nordby (2009); 16. Pulaski et al., (2003); 17. Rios, Chong \& Grau (2015); 18. Sassi (2002); 19. Sassi (2009); 20. Thormark (2001); 21. Tingley (2012), and; 22. Webster \& Costello (2005). 


\section{System \& product strategies - Part strategies}

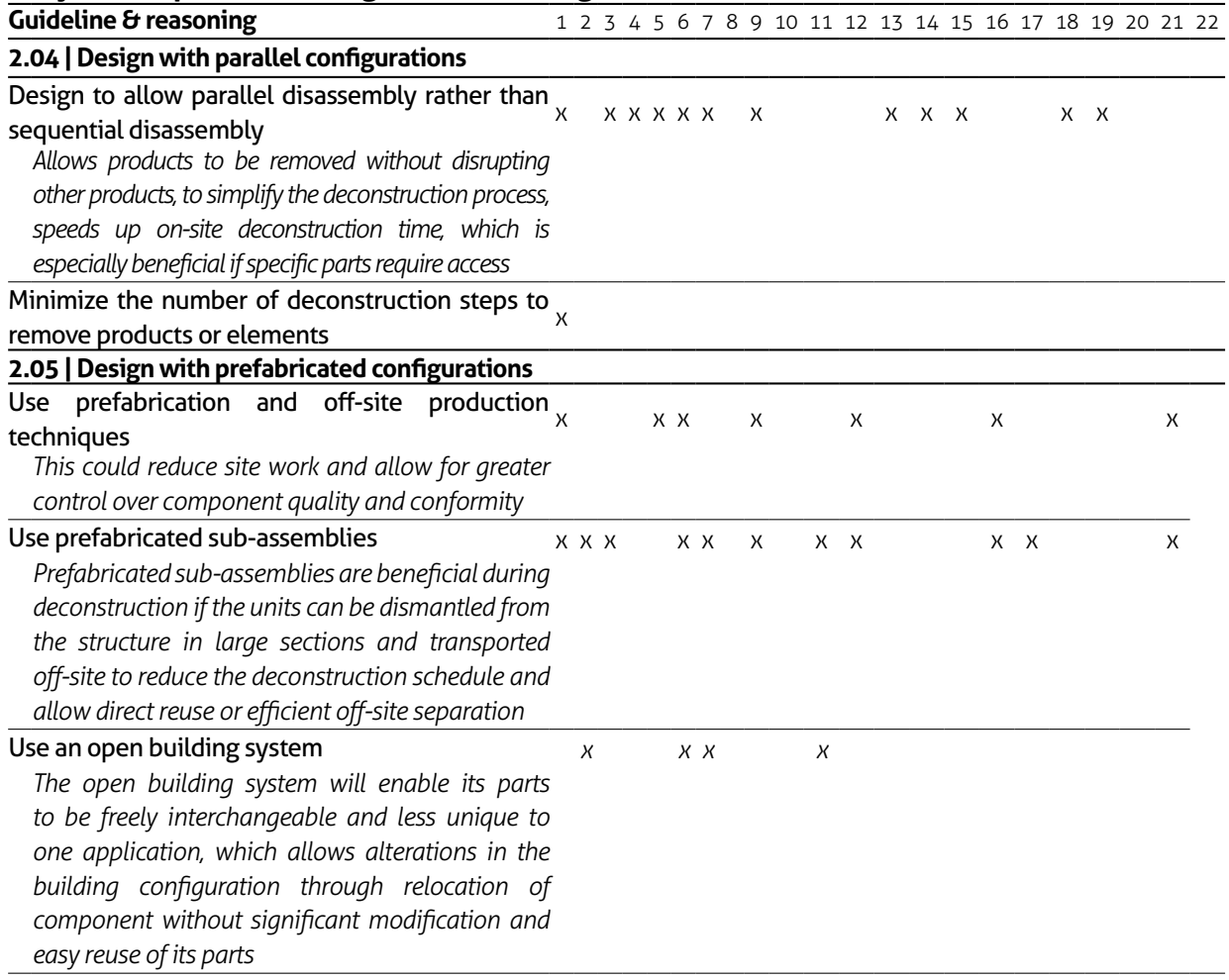

Use small size components which are part of larger assemblies in order to increase the possibility for variety

Design base element for each system and component

Design base element as an intermediary between

systems, components and elements

Create an open hierarchy of distinct configurations

2.06 | Design to suit the means of handling

Size components to suit the means of handling $x \times x \times x \times x \times x \times x \times x$

Allows for various possible handling options at all stages of assembly, disassembly, transport, reprocessing and re-assembly.

Design using fewer large parts rather than many small parts

A smaller number of larger parts can be removed more quickly from the structure. Although, they are more difficult to handle without large equipment. Furthermore, larger parts tend to resist damage more easily during the deconstruction process, increasing its reusability.

1. Addis \& Schouten (2004); 2. Akinade et al., (2016); 3. Chini \& Balachandran (2002); 4. Couto \& Couto (2010); 5. Crowther (2001); 6. Crowther (2002); 7. Durmisevic (2006); 8. Fletcher (2001); 9. Guy \& Ciarimboli (2008); 10. Guy \& Shell (2002); 11. Hechler, Larsen \& Nielsen (2012); 12. Hradil et al. (2014); 13. lacovidou \& Purnell (2016); 14. Morgan \& Stevensen (2005); 15. Nordby (2009); 16. Pulaski et al., (2003); 17. Rios, Chong \& Grau (2015); 18. Sassi (2002); 19. Sassi (2009); 20. Thormark (2001); 21. Tingley (2012), and; 22. Webster \& Costello (2005). 


\section{System \& product strategies - Part strategies}

\begin{tabular}{|c|c|c|c|c|c|c|c|c|c|c|c|c|}
\hline Guideline \& reasoning & 12 & 345 & 567 & 785 & 910 & 1112 & 13 & 141 & $\begin{array}{lll}15 & 16 & 17\end{array}$ & 18 & 1920 & 2122 \\
\hline $\begin{array}{l}\text { Use small and light weight elements and components } \\
\text { Small and light weight elements are more easily } \\
\text { handled during disassembly, transport and } \\
\text { reprocessing and has by its size a wider range of } \\
\text { applications and allows self-building and local reuse. } \\
\text { Although the required labour time can increase. }\end{array}$ & $x$ & $x \times x$ & & $x$ & $x$ & $x$ & & & $x$ & & & \\
\hline \multicolumn{13}{|l|}{2.07 | Design with durable components } \\
\hline $\begin{array}{l}\text { Design components to withstand repeated } \\
\text { assembly and disassembly } \\
\text { Enabling the assembly and disassembly process } \\
\text { with minimal damage and deformation of } \\
\text { components and elements will increase the } \\
\text { suitability for reuse }\end{array}$ & & & $x \times x$ & & $x$ & & $x$ & $x>$ & $x$ & & $x$ & $x$ \\
\hline $\begin{array}{l}\text { Provide adequate tolerances for repeated } \\
\text { disassembly and reassembly } \\
\text { Adequate tolerances minimizes the need for } \\
\text { destructive methods that can impact adjacent } \\
\text { components during repeated disassembly and } \\
\text { reassembly procedures }\end{array}$ & & $x \times x$ & $x \times x$ & & $x \times$ & $x$ & & & $x$ & $x$ & $x$ & $x$ \\
\hline $\begin{array}{l}\text { Design components to be durable } \\
\text { Durable components should enable repeated } \\
\text { assembly and disassembly without damaging } \\
\text { itself, so that they can easily be reused }\end{array}$ & $x x$ & & $x$ & & $x$ & $x$ & $x$ & $x>$ & $x$ & & $x$ & $x$ \\
\hline $\begin{array}{l}\text { Design using patchable detailing } \\
\text { This allows the lifespan of building components } \\
\text { such as doors, windows to be lengthened through } \\
\text { partial replacement rather than whole product } \\
\text { replacement }\end{array}$ & & & & & & & & $x$ & & & & \\
\hline
\end{tabular}

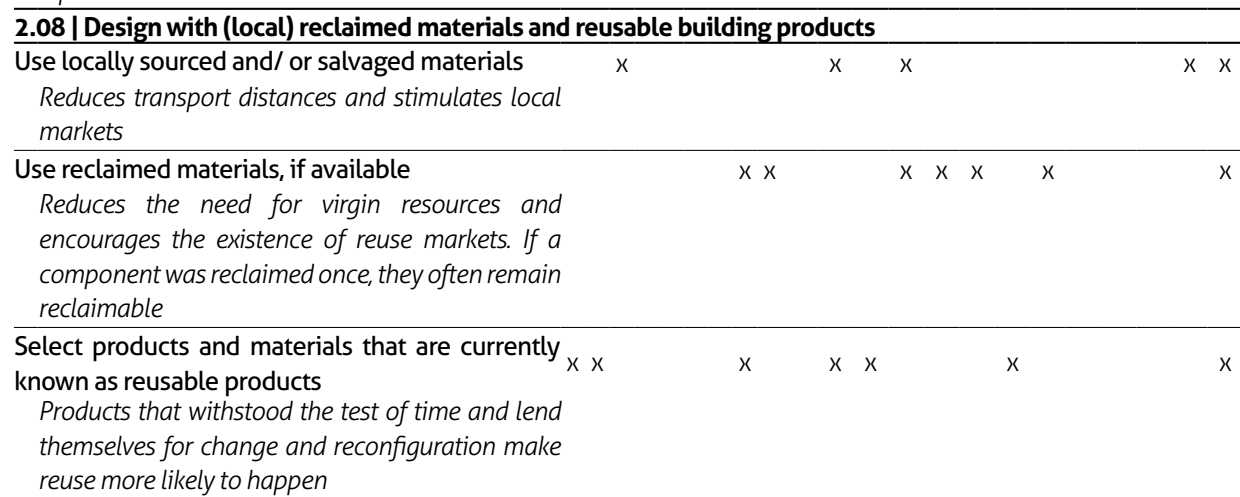

Design to minimise need to prepare the product

for composting

This will reduce labour and thus costs before

products can be composted

1. Addis \& Schouten (2004); 2. Akinade et al., (2016); 3. Chini \& Balachandran (2002); 4. Couto \& Couto (2010); 5.

Crowther (2001); 6. Crowther (2002); 7. Durmisevic (2006); 8. Fletcher (2001); 9. Guy \& Ciarimboli (2008); 10. Guy \& Shell (2002); 11. Hechler, Larsen \& Nielsen (2012); 12. Hradil et al. (2014); 13. lacovidou \& Purnell (2016); 14. Morgan \&Stevensen (2005); 15. Nordby (2009); 16. Pulaski et al., (2003); 17. Rios, Chong \& Grau (2015); 18. Sassi (2002); 19. Sassi (2009); 20. Thormark (2001); 21. Tingley (2012), and; 22. Webster \& Costello (2005). 


\section{System \& product strategies - Connection strategies}

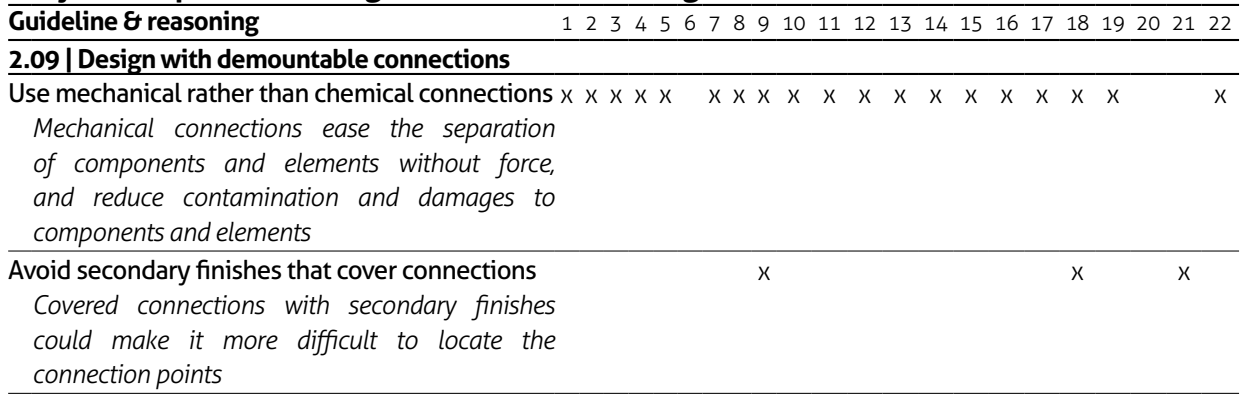

Avoid use of adhesives, resins \& coatings which compromise reuse potential, if unavoidable use compatible adhesives with both the parts joined together for recycling

Components and elements fastened by chemical connections or adhesives require special attention during deconstruction, which increase the time and cost for disassembly. When the adhesive, resin or coating is compatible with the connected parts, it eases the recycling process

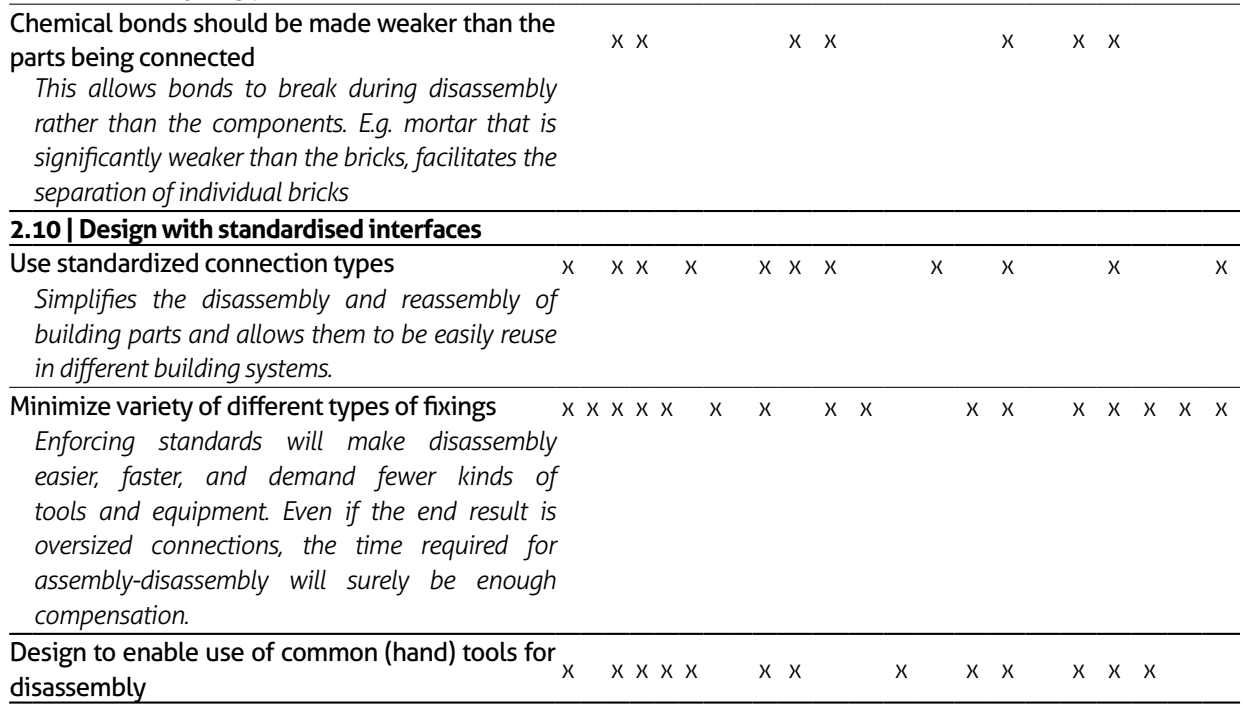
disassembly

When the design allows the use of common (hand) tools, it can: reduce preparation costs (specialist tools may not be identified or have to be purchased/rented), lower the equipment costs and no special training is required, which can stimulate self-building and local reuse

1. Addis \& Schouten (2004); 2. Akinade et al., (2016); 3. Chini \& Balachandran (2002); 4. Couto \& Couto (2010); 5. Crowther (2001); 6. Crowther (2002); 7. Durmisevic (2006); 8. Fletcher (2001); 9. Guy \& Ciarimboli (2008); 10. Guy 8 Shell (2002); 11. Hechler, Larsen \& Nielsen (2012); 12. Hradil et al. (2014); 13. lacovidou \& Purnell (2016); 14. Morgan \&Stevensen (2005); 15. Nordby (2009); 16. Pulaski et al., (2003); 17. Rios, Chong \& Grau (2015); 18. Sassi (2002); 19. Sassi (2009); 20. Thormark (2001); 21. Tingley (2012), and; 22. Webster \& Costello (2005). 


\section{System \& product strategies - Connection strategies}

\begin{tabular}{|c|c|c|c|c|c|c|c|c|c|c|c|c|c|c|c|c|c|c|}
\hline Guideline \& reasoning & 12 & 23 & 45 & 567 & 789 & 10 & 11 & 12 & 13 & 14 & 15 & 16 & 17 & 18 & 19 & 20 & 212 & 22 \\
\hline \multicolumn{19}{|l|}{ 2.11 | Design connections for fast disassembly speed } \\
\hline $\begin{array}{l}\text { Fasteners and joints should be easy to locate } \\
\text { Easily identifiable fasteners and joints ease the } \\
\text { planning of dismantling and the dismantling } \\
\text { process }\end{array}$ & $e^{x}$ & & $\times x$ & & $\times \times x$ & & $x$ & & $x$ & & $x$ & & & $x$ & $\mathrm{x}$ & $\mathrm{x}$ & & \\
\hline $\begin{array}{l}\text { Fasteners and joints should be easy to access } \\
\text { Ease of access will allow ease of disassembly } \\
\text { and facilitate planning of dismantling and the } \\
\text { dismantling process }\end{array}$ & $\begin{array}{l}x \\
y \\
e\end{array}$ & $x$ & & & $x \times x$ & $1 x$ & $x$ & $\mathrm{x}$ & $x$ & $x$ & $x$ & & $x$ & $x$ & $x$ & $x$ & $x$ & \\
\hline $\begin{array}{l}\text { Fasteners and joints should be easy to remove } \\
\text { Easily removable fasteners and joints facilitates } \\
\text { the planning of dismantling and the dismantling } \\
\text { process, in contrast to complex and unique } \\
\text { connections that increase installation time and } \\
\text { complicate the deconstruction process }\end{array}$ & $\begin{array}{l}\text { X } \\
g \\
e \\
e\end{array}$ & $x$ & $x$ & $x$ & $x \times x$ & $x$ & $x$ & $x$ & & $x$ & & $x$ & $x$ & $x$ & $x$ & $x$ & $x$ & \\
\hline $\begin{array}{l}\text { Minimize the number of fixings } \\
\text { This will decrease dismantling time }\end{array}$ & $x$ & & $x$ & $x$ & $x \times$ & $x x$ & & $x$ & $x$ & & $x$ & $x$ & & $x$ & $x$ & $x$ & & \\
\hline
\end{tabular}

\subsection{2 | Design with durable connections}

Design joints and connections to withstand repeated assembly and disassembly

$x \times x \times x \times x \times x$

Enabling the assembly and disassembly process

with minimal damage and deformation of

joints and connections will allow the parts and

connectors to be reused

\begin{tabular}{|c|c|}
\hline $\begin{array}{l}\text { Use independent interfaces as intermediary } \\
\text { between individual components }\end{array}$ & $x$ \\
\hline $\begin{array}{l}\text { Avoid interpenetration of connectors with } \\
\text { components } \\
\text { This enables disassembly of parts, while } \\
\text { maintaining the integrity of all elements. }\end{array}$ & $x$ \\
\hline $\begin{array}{l}\text { 1. Addis \& Schouten (2004); 2. Akinade et al., (2016) } \\
\text { Crowther (2001); 6. Crowther (2002); 7. Durmisevic (2 } \\
\text { Shell (2002); 11. Hechler, Larsen \& Nielsen (2012); } 12 \\
\text { \& Stevensen (2005); 15. Nordby (2009); 16. Pulaski et } \\
\text { Sassi (2009); 20. Thormark (2001); 21. Tingley (2012) }\end{array}$ & $\begin{array}{l}\text { Balachandran (2002); 4. Couto \& Couto (2010); } 5 \\
\text { etcher (2001); 9. Guy \& Ciarimboli (2008); 10. Guy \& } \\
\text { (2014); 13. lacovidou \& Purnell (2016); 14. Morgan } \\
\text { 17. Rios, Chong \& Grau (2015); 18. Sassi (2002); } 19 . \\
\text { lebster \& Costello (2005). }\end{array}$ \\
\hline
\end{tabular}




\section{Material strategies}

Guideline \& reasoning

$\begin{array}{llllllllllllllllllllll}1 & 2 & 3 & 4 & 5 & 6 & 7 & 8 & 9 & 10 & 11 & 12 & 13 & 14 & 15 & 16 & 17 & 18 & 19 & 20 & 21 & 22\end{array}$

3.01 | Design for recyclable and biodegradable materials

Select easily separable materials

Composite materials are difficult or even

impossible to separate and recycle

If two parts cannot be recycled together, make

them easy to separate

This simplifies the recycling process

\begin{tabular}{|c|c|c|c|c|c|c|c|c|c|c|c|c|}
\hline $\begin{array}{l}\text { Make inseparable sub-assemblies from the same } \times \times \times \\
\text { material } \\
\text { Reduces need for dismantling and sorting at } \\
\text { end-of-life when recycling them, and it can } \\
\text { prevent large amounts of mono-materials from } \\
\text { contamination by small amounts of foreign } \\
\text { materials that cannot be separated }\end{array}$ & $x$ & & $\times x$ & $x$ & & & & & $x$ & x & $x$ & \\
\hline $\begin{array}{l}\text { Try to use joints and fasteners of material } \\
\text { compatible with the parts connected } \\
\text { Enables disassembly operations to be avoided and } \\
\text { allows easy recycling }\end{array}$ & & $x$ & & & & & & & & & $x$ & \\
\hline $\begin{array}{l}\text { Hazardous materials should be easy to remove } \\
\text { Facilitates elimination of hazardous parts and } \\
\text { contamination to other materials }\end{array}$ & & & $x$ & $x$ & & & $x$ & & & & $x$ & \\
\hline $\begin{array}{l}\text { Material should biodegrade at a rate that meets } \\
\text { the criteria set out in BSEN } 13432 \\
\text { This sets a limit to prevent products from being } \\
\text { labelled biodegradable, while the time required } \\
\text { to biodegrade is unreasonable long, impacting } \\
\text { nature and society }\end{array}$ & & & & & & & & & & $x$ & & \\
\hline $\begin{array}{l}\text { Avoid use of adhesives, resins \& coatings which } \\
\text { compromise reuse potential, if unavoidable use } \\
\text { compatible adhesives with both the parts joined } \\
\text { together for recycling } \\
\text { Components and elements fastened by chemical } \\
\text { connections or adhesives require special attention } \\
\text { during deconstruction, which increase the time } \\
\text { and costfor disassembly. When the adhesive, resin } \\
\text { or coating is compatible with the connected parts, } \\
\text { it eases the recycling process }\end{array}$ & $x$ & $x$ & $x$ & $x$ & $x \quad x$ & $x \quad x$ & $x$ & & & & $x \quad x$ & \\
\hline
\end{tabular}

\subsection{2 | Design for pure and effective material recycling or biodegradability}

The recycling process should minimize material

loss

Most recycling processes result in some material

loss, therefore, the loss should minimised to be

within an acceptable range

Avoid chemical secondary finishes

$x \times x \times x \times x \quad x \quad x \quad x$

Chemical finishes may contaminate the base

material and make recycling more labour

intensive, more complicated

1. Addis \& Schouten (2004); 2. Akinade et al., (2016); 3. Chini \& Balachandran (2002); 4. Couto \& Couto (2010); 5.

Crowther (2001); 6. Crowther (2002); 7. Durmisevic (2006); 8. Fletcher (2001); 9. Guy \& Ciarimboli (2008); 10. Guy \&

Shell (2002); 11. Hechler, Larsen \& Nielsen (2012); 12. Hradil et al. (2014); 13. lacovidou \& Purnell (2016); 14. Morgan EStevensen (2005); 15. Nordby (2009); 16. Pulaski et al., (2003); 17. Rios, Chong \& Grau (2015); 18. Sassi (2002); 19.

Sassi (2009); 20. Thormark (2001); 21. Tingley (2012), and; 22. Webster \& Costello (2005). 
3. Material strategies

\begin{tabular}{|c|c|c|c|c|c|c|c|c|c|c|c|}
\hline uideline \& reasoning & 12 & 3456 & 578910 & 1112 & 131 & 1415 & $\begin{array}{lll}5 & 16 & 1\end{array}$ & 718 & 19 & & 22 \\
\hline $\begin{array}{l}\text { void composite materials } \\
\text { Composite elements are often very difficult or even } \\
\text { impossible to recycle }\end{array}$ & $x$ & & $x \times x$ & $x$ & & & & $x$ & $x$ & & $x$ \\
\hline $\begin{array}{l}\text { Avoid toxic and hazardous materials } \\
\text { Reduces the potential for human health risks } \\
\text { during disassembly and the potential of } \\
\text { contaminating other materials that are being } \\
\text { sorted for recycling }\end{array}$ & & $x \times x$ & $x \times x$ & $x \quad x$ & $x$ & $x$ & $x$ & $x$ & $x$ & & $x$ \\
\hline $\begin{array}{l}\text { void hazards that could contaminate the ground } \\
\text { Hazardous treatments that could leach out in } \\
\text { the ground and contaminate it, can compromise } \\
\text { the ability to compost products safely without } \\
\text { additional clean-up costs }\end{array}$ & & & & & & & & & $x$ & & \\
\hline $\begin{array}{l}\text { Ainimize toxic content, if toxic content is } \\
\text { navoidable ensure the ability to release it in a } \\
\text { ontrolled manner } \\
\text { Toxic materials found in building elements can } \\
\text { either be handled with precautions without } \\
\text { excessively elevating risk to health or are not } \\
\text { suitablefor reuse }\end{array}$ & & & & & & & & & $x$ & & \\
\hline $\begin{array}{l}\text { Minimize number of different material types } \\
\text { Use of few types of materials and homogeneous } \\
\text { products will ease sorting and reduce transport to } \\
\text { different reprocessing plants and make reuse more } \\
\text { attractive due to greater number of fewer material } \\
\text { types }\end{array}$ & $x$ & $x \times x$ & $x \times x$ & $x \quad x$ & $x$ & $x$ & $x$ & & $x$ & $x x$ & 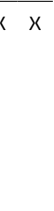 \\
\hline $\begin{array}{l}\text { Design to minimise need to prepare the product } \\
\text { for composting } \\
\text { This will reduce labour and thus costs before } \\
\text { products can be composted }\end{array}$ & & & & & & & & & $x$ & & \\
\hline \multicolumn{12}{|l|}{3.03 | Design with recycled and recyclable materials } \\
\hline $\begin{array}{l}\text { Use recycled materials } \\
\text { Increased use of recycled materials will encourage } \\
\text { the industry and government to develop new } \\
\text { technologies for recycling, which create larger } \\
\text { support networks and markets for the future }\end{array}$ & & & $x$ & $x$ & & & & & & $x$ & \\
\hline $\begin{array}{l}\text { Use recyclable materials } \\
\text { Reduces waste to landfill and increases end-of-life value }\end{array}$ & $x$ & $x$ & $x$ & $x$ & & & $x$ & $x$ & $x$ & $x$ & \\
\hline \multicolumn{12}{|c|}{$\begin{array}{l}\text { 1. Addis \& Schouten (2004); 2. Akinade et al., (2016); 3. Chini \& Balachandran (2002); 4. Couto \& Couto (2010); } 5 . \\
\text { Crowther (2001); 6. Crowther (2002); 7. Durmisevic (2006); 8. Fletcher (2001); 9. Guy \& Ciarimboli (2008); 10. Guy \& } \\
\text { Shell (2002); 11. Hechler, Larsen \& Nielsen (2012); 12. Hradil et al. (2014); 13. lacovidou \& Purnell (2016); 14. Morgan } \\
\text { \&Stevensen (2005); 15. Nordby (2009); 16. Pulaski et al., (2003); 17. Rios, Chong \& Grau (2015); 18. Sassi (2002); } 19 . \\
\text { Sassi (2009); 20. Thormark (2001); 21. Tingley (2012), and; 22. Webster \& Costello (2005). }\end{array}$} \\
\hline
\end{tabular}




\section{Documentation strategies}

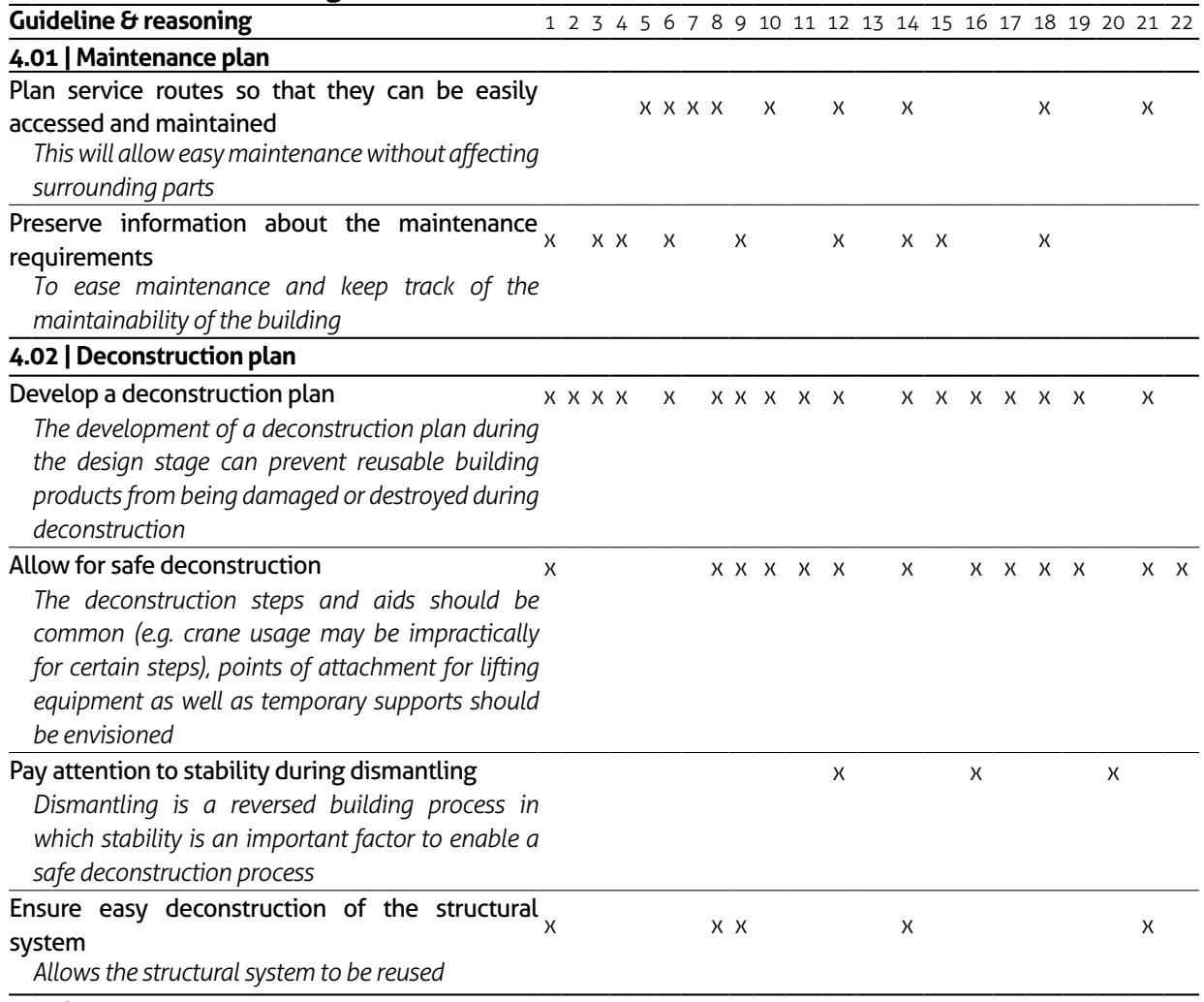

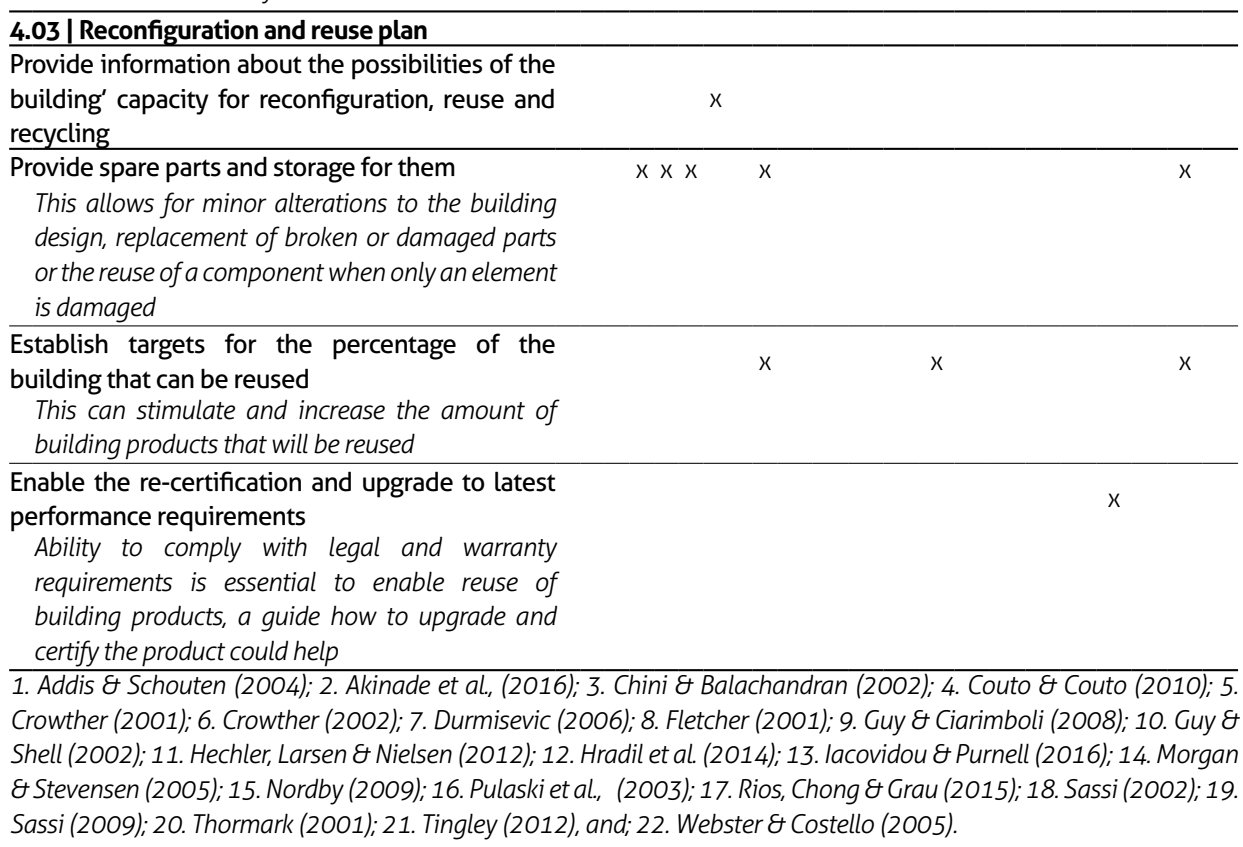




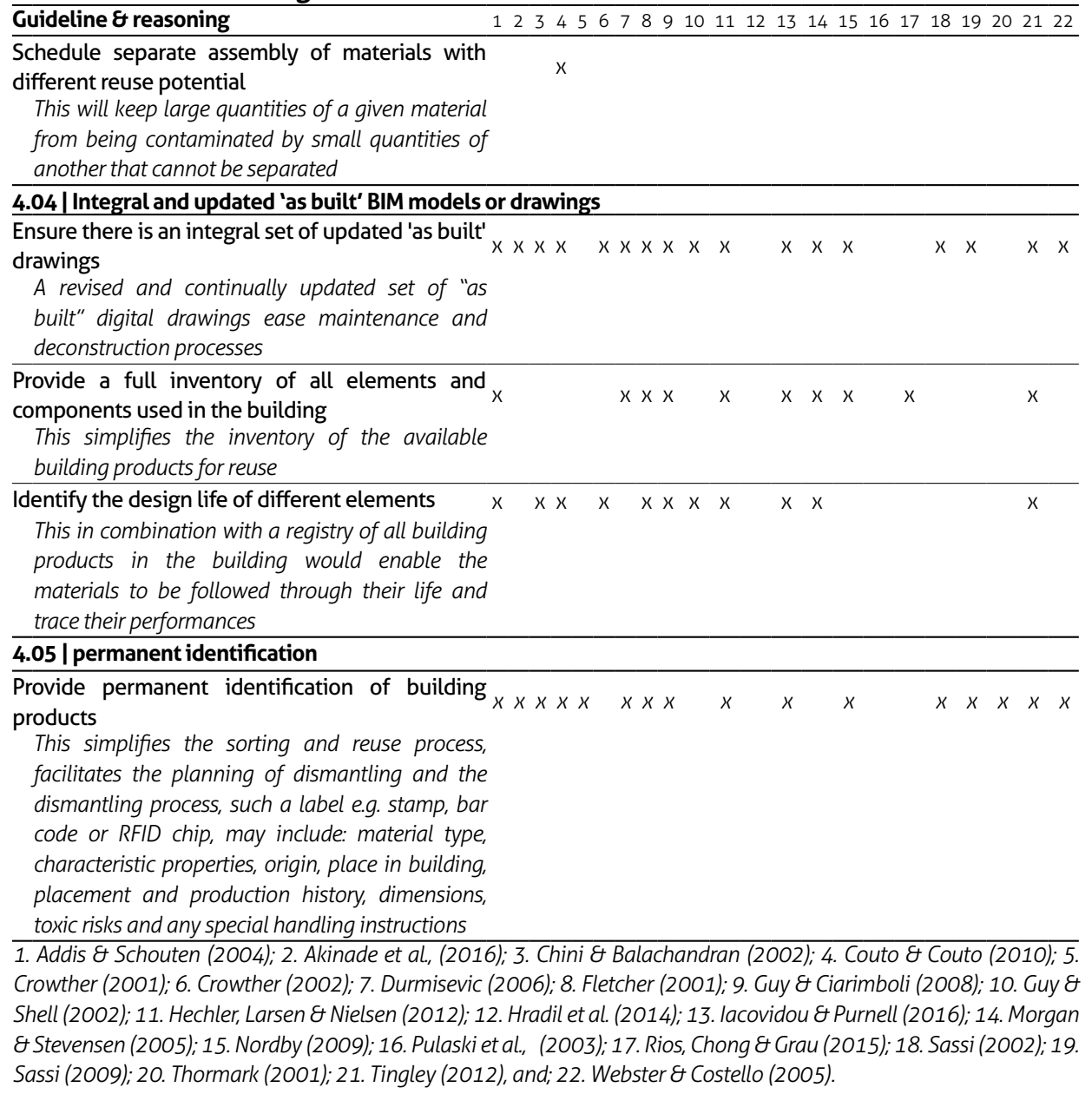




\section{Reuse process strategies}

\section{Guideline \& reasoning \\ 5.01| Reuse design process}

$\begin{array}{llllllllllllllllllllll}1 & 2 & 3 & 4 & 5 & 6 & 7 & 8 & 9 & 10 & 11 & 12 & 13 & 14 & 15 & 16 & 17 & 18 & 19 & 20 & 21 & 22\end{array}$

Whole design team, client $\&$ contractor need to aim for the same goal

$x \times \quad x$

x

x

x

Every stakeholders has different objectives during

different life-cycle stages of a building, which can

only be satisfied correctly when everyone has the

same goal

Educate professionals on Design For Disassembly

This is vital in order to achieve best results

regarding Design For Disassembly

Allow extra design time to ensure design for

disassembly is incorporated

$x$

$x$

$x$

This allows more time consuming deconstruction

technologies that could decrease damages to

reusable building products

Award more points for building deconstructability

in sustainability models

Government legislation to set target for material

recovery and reuse

Project contractual clauses that will favour

building material recovery and reuse

Make deconstruction plans compulsory at the $x$

planning permission stage

Involve demolition and deconstruction

professionals during design stage

The use of BIM to estimate end-of-life property of

materials

The use of BIM to simulate the process and

sequence of building disassembly

1. Addis \& Schouten (2004); 2. Akinade et al., (2016); 3. Chini \& Balachandran (2002); 4. Couto \& Couto (2010); 5.

Crowther (2001); 6. Crowther (2002); 7. Durmisevic (2006); 8. Fletcher (2001); 9. Guy \& Ciarimboli (2008); 10. Guy \&

Shell (2002); 11. Hechler, Larsen \& Nielsen (2012); 12. Hradil et al. (2014); 13. lacovidou \& Purnell (2016); 14. Morgan

EStevensen (2005); 15. Nordby (2009); 16. Pulaski et al., (2003); 17. Rios, Chong \& Grau (2015); 18. Sassi (2002); 19.

Sassi (2009); 20. Thormark (2001); 21. Tingley (2012), and; 22. Webster \& Costello (2005). 
Appendix C

Assessment values of the reuse
potential evaluation method 


\section{Appendix C - Assessment values of the reuse potential evaluation method}

In this appendix the assessment values of the reuse potential evaluation method are specified. The assessment values are under embargo, therefore, the specified values are kept out of the main texts in the thesis.

\section{Embodied value}

\section{E1 Highest embodied value}




\section{Re-claim efffort}

Functional decomposition

Functional decomposition

Servicing integration 
Systematisation of material levels

Technical decomposition

Relational pattern 
Assembly

Base element

Technical life cycle coordination 


\title{
Physical decomposition
}

\author{
Connections
}

Accessibility

Geometry 


\section{Re-conditioning effort}

Re-claim damage

Product state

Product maturity 


\section{Acknowledgements}

I would like to thank all those who helped me to write - and also to delete:

To dr. Elma Durmisevic, who first came up with the idea for this research, and who guided me through the long process of researching, analysing and writing this thesis.

To prof. Leo van Dongen and prof. Joop Halman for their careful reading of the thesis draft, constructive feedback, good advice and for motivating me during the final steps of the thesis.

To Patrick for the pleasant collaboration, sparring sessions and long conversations on the topics of resource depletion, circular economy, design for change and design for disassembly and reuse.

To Marc for sharing ideas and working together. And the many wonderful trips Patrick, Marc and I had during the International Design Studios and international BAMB meetings.

To the BAMB project members and companies involved in the GTB-lab development for the inspiring and interesting conversations on the topic of circular buildings.

To Jouke Post of XXarchitecten, Wim van der Ven of Wagenbouw Bouwsystemen, Adam Duivenvoorden of De Groot Vroomshoop and the Municipality of Amsterdam, who agreed to have interviews with me and sent me project documentation for the case studies, for their valuable contribution to this thesis.

To my colleagues in N211 and W258, Johannes, Robert-Jan, Monique, Patrick and Katja who made working at the UT a pleasant experience.

To the members of the futsal team OPM Ultras, Moreno, Roberto, Alberto, Willem, Robert-Jan, Monique and Jan-Jaap for all the fun during our futsal matches.

To Inge, Inge and Annemarie for orchestrating all organisatoric matters and their enthusiastic personality.

To all my family members and friends for their patience and love.

To my father, who encouraged me along the way, for sharing his experience and insights on a doctoral study.

To my partner Ana for her unconditional love and support and for her valuable comments and ideas.

And finally to my readers for their time and interest.

My gratitude also goes to the departed professor Fred van Houten for his guidance and advice. This research would not have been possible without him. 


\section{About the author}

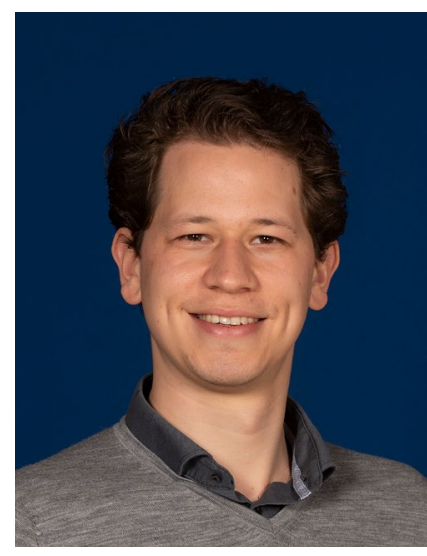

Pieter Robert Beurskens was born on July $27^{\text {th }}, 1992$ in Lelystad. He then spent the largest part of his childhood in Empel, a village near 's-Hertogenbosch. He completed HAVO secondary school focused on Nature \& Technology in 2009. After completing the study Architecture and Construction Engineering at the Avans University of Applied Sciences, he received his bachelor degree in 2013. He proceeded to Eindhoven for the Master Building Technology at the Eindhoven University of Technology. Pieter graduated in 2015 with a thesis focusing on the development of a circular building framework and a morphological design and evaluation model for circular facades. As he felt there were many gaps in the literature on the application of the circular economy concept in building design, he was eager to continue this line of research in a PhD position at the University of Twente. The $\mathrm{PhD}$ research was part of the European Union's Horizon 20|20 research and innovation programme, the Buildings As Material Banks project. After the PhD contract finished, he started working for Van Wijnen, one of the largest construction companies in The Netherlands, focusing on implementing circular design strategies in the development of a new circular housing product platform and translate theory into scalable circular solutions using off-site construction methods. 


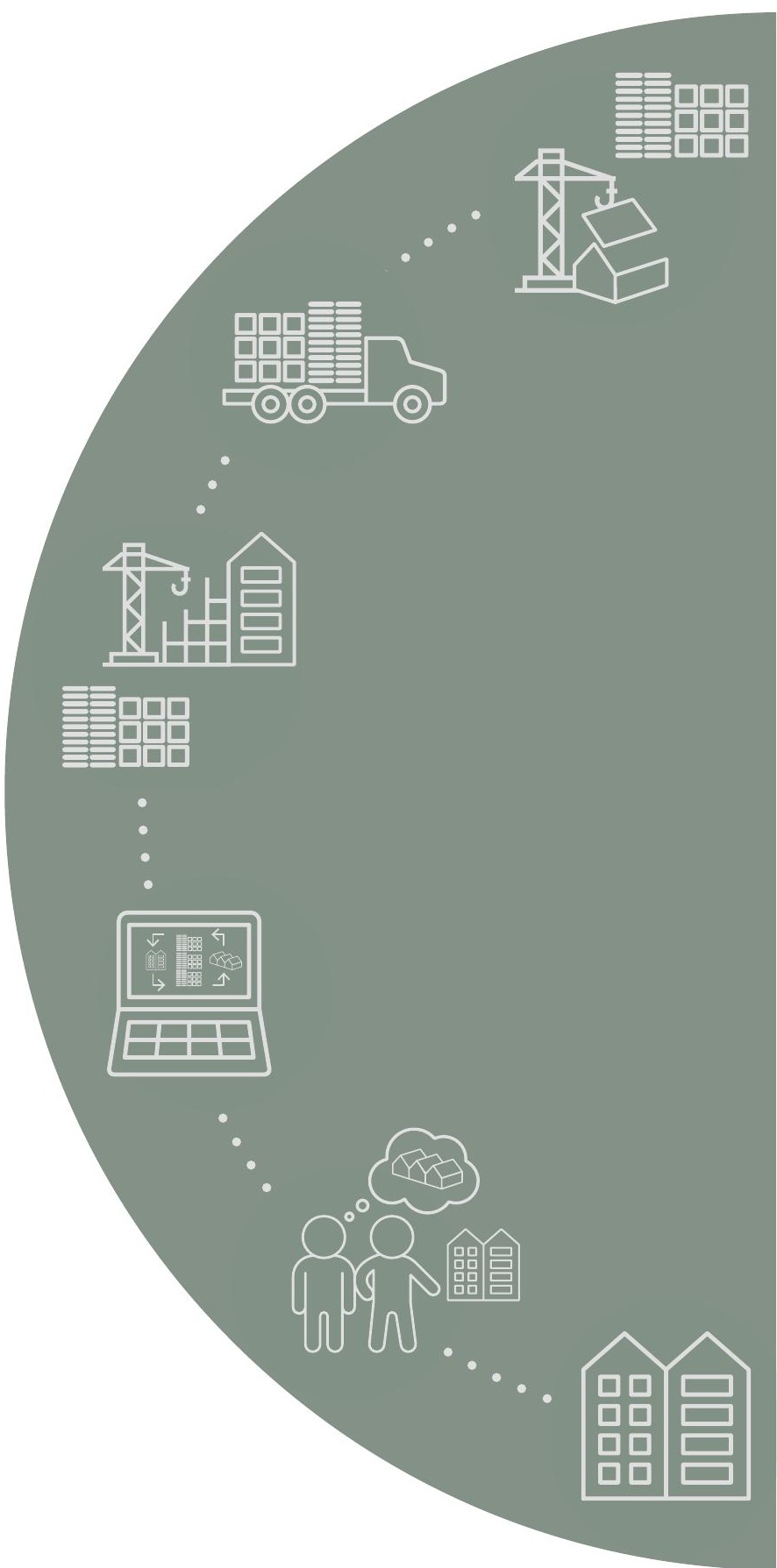

